Building it Up and Tearing it Down: A Three-Study Examination of Trust, Trust Building, and the Effects of Erroneous Messaging in the Blogosphere

by

James D. Doyle

A thesis submitted to the Faculty of Graduate and Postdoctoral Affairs in partial fulfilment of the requirements for the degree of

Doctor of Philosophy

in

Management

Carleton University

Ottawa, Ontario

(C) 2012

James D. Doyle 
Library and Archives

Canada

Published Heritage

Branch

395 Wellington Street

Ottawa ON K1A ON4

Canada
Bibliothèque et

Archives Canada

Direction du

Patrimoine de l'édition

395 , rue Wellington

Ottawa ON K1A ON4

Canada
Your file Votre référence

ISBN: 978-0-494-93658-0

Our file Notre référence

ISBN: $978-0-494-93658-0$
NOTICE:

The author has granted a nonexclusive license allowing Library and Archives Canada to reproduce, publish, archive, preserve, conserve, communicate to the public by telecommunication or on the Internet, loan, distrbute and sell theses worldwide, for commercial or noncommercial purposes, in microform, paper, electronic and/or any other formats.

The author retains copyright ownership and moral rights in this thesis. Neither the thesis nor substantial extracts from it may be printed or otherwise reproduced without the author's permission.
AVIS:

L'auteur a accordé une licence non exclusive permettant à la Bibliothèque et Archives Canada de reproduire, publier, archiver, sauvegarder, conserver, transmettre au public par télécommunication ou par l'Internet, prêter, distribuer et vendre des thèses partout dans le monde, à des fins commerciales ou autres, sur support microforme, papier, électronique et/ou autres formats.

L'auteur conserve la propriété du droit d'auteur et des droits moraux qui protege cette thèse. $\mathrm{Ni}$ la thèse ni des extraits substantiels de celle-ci ne doivent être imprimés ou autrement reproduits sans son autorisation.
In compliance with the Canadian Privacy Act some supporting forms may have been removed from this thesis.

While these forms may be included in the document page count, their removal does not represent any loss of content from the thesis.
Conformément à la loi canadienne sur la protection de la vie privée, quelques formulaires secondaires ont été enlevés de cette thèse.

Bien que ces formulaires aient inclus dans la pagination, il n'y aura aucun contenu manquant. 


\begin{abstract}
Blogs are a channel through which commercial and non-commercial communicators disseminate product- and topic-related claims. Questions regarding the ability and motivation of bloggers to make accurate claims make trust necessary for productive blogger-blog reader relationships. The three studies that comprise this dissertation examine blogger-disseminated trustworthiness signals, trust antecedents, and outcomes of inaccurate messaging in the blogosphere.

A content analysis of wine blogs reveals commercial and non-commercial wine bloggers to be active signalers of trust-building information. Wine bloggers signal ability more frequently than benevolence or integrity, but commercial and non-commercial wine bloggers differ in the content of their ability signals and the distribution of their benevolence and integrity signals. Commercial wine bloggers exploit their resourcebased authoritative knowledge advantage, whereas non-commercial wine bloggers signal non-authority based consumption experience and structural social capital. Noncommercial wine bloggers signal their honourable motives by exploiting their resourcebased integrity advantage but commercial wine bloggers have few authentic ways of compensating for their integrity disadvantage.

A survey of topic-area blog readers reinforces the importance of benevolence and integrity and casts doubt on the trust-building value of topic-area authoritative knowledge relative to topic-area engagement knowledge. Trust intentions in the blogosphere depend heavily on topic-area knowledge gains, and blog readers will reward bloggers who consistently disseminate high-quality claims and provide unique reading experiences.
\end{abstract}


A between-subjects experiment reveals the effects of authoritative knowledge versus consumption experience signals and a word-of-mouth marketing disclosure on the trust-related ratings of a movie-reviewing blogger. In a purchase decision context, authoritative knowledge drives ratings of the credibility of a blogger and the believability of its claims. Bloggers with high authoritative knowledge are most credible when their claims align with the nature of their ability. Word-of-mouth marketing disclosures help the consumption experience ratings of subject-matter experts and do not negatively affect their credibility ratings.

Implications of erroneous messaging for blog readers, bloggers, and marketers are significant. Blogger error is anger-inducing and dissatisfying and produces reduced trust intentions and potential for revenge-seeking behaviours. Blogger error is particularly threatening for bloggers and marketers engaged in word-of-mouth marketing relationships, as blog readers attribute it to deceptive blogger and marketer conduct. 


\section{Acknowledgements}

This achievement would not have been possible without the dedication, patience, helpful guidance, and instrumental support of Dr. Louise Heslop, my thesis advisor. I am thankful to Dr. Heslop for showing me the potential of a blog-based research focus, teaching me many useful methodological and analytical techniques, and tolerating my many tangents and false starts. I am also indebted to Dr. Heslop for providing me with teaching-related encouragement and advice.

Thanks are due to Dr. David Cray and Dr. Alex Ramirez for their helpful guidance as members of my thesis committee. Thanks also go to Drs. David Cray, Alex Ramirez, Diane Isabelle, Michel Rod, Haitham Tamim, Les Melamed, and Kayvan Miri Lavassani, as well as to Anahit Armenakyan and Jill Reid, as data collection would not have been possible without them. I additionally thank Anahit Armenakyan for being a good friend to me. I acknowledge the generous support of the Sprott School of Business, Carleton University, Ontario Ministry of Education, and Social Sciences and Humanities Research Council of Canada. My interest in an academic career was sparked by Dr. Narongsak (Tek) Thongpapanl and Dr. H. F. (Herb) MacKenzie of Brock University, and I thank them for encouraging me throughout my doctoral studies. I also thank Andrew Flynn, members of the Bikinas, Jelbert, Kares, and Zouzoulas families, and many others for their kind encouragement.

Heartfelt thanks go to my parents, Daniel and Joan Doyle, for their love, encouragement, and support. Thanks are also due to Joyce Weylie, for trusting and supporting me in many tangible and intangible ways. I am also grateful for the generous 
support of Raymond and Alice Sabucco. I sincerely appreciate everything you do for my family and me.

This achievement is dedicated to my beautiful wife, Kathleen (Kate) Doyle, O.C.T., and our four wonderful children. Jacob (now seven-years old) was seven-months old when I started my Master of Business Administration degree at Brock University and since that time Kate and I have been additionally blessed by the arrivals of Alicia (now four), Brianna (now two), and Colin (now eight months). You each have made countless sacrifices so that I could chase my dream, and there is no way I will be able to repay you for what you have done. With God's guidance, I promise to never stop striving to be the husband and daddy you each deserve. From the bottom of my heart, I thank you. 


\section{Preface}

James D. Doyle is the sole author of this dissertation and the lead author of two published papers from this dissertation, as noted below. With the exception of Anahit Armenakyan, all co-authors on these publications are members of the dissertation committee who provided advisory support to the dissertation work. At the time, Anahit Armenakyan was a doctoral student in the Sprott School of Business at Carleton University. Anahit Armenakyan provided data collection support for Study 1 under my direction.

\section{Study 1: Trust Building in Wine Blogs: A Content Analysis}

James D. Doyle, Louise A. Heslop, Alex Ramirez, David Cray, Anahit Armenakyan, (2012) "Trust building in wine blogs: a content analysis", International Journal of Wine Business Research, Vol. 24 Iss: 3, pp. 196-218.

http://www.emeraldinsight.com/journals.htm?issn=1751-

1062 \& volume $=24 \&$ issue $=3$ \&articleid $=17047818 \&$ show $=$ abstract

\section{Study 2: What Really Matters to Trust Intentions for Readers of Topic-Area Blogs}

James D. Doyle, Louise A. Heslop, Alex Ramirez, David Cray, (2012) "Trust intentions in readers of blogs", Management Research Review, Vol. 35 Iss: 9, pp. $837-856$.

http://www.emeraldinsight.com/journals.htm?issn $=2040$ -

$8269 \&$ volume $=35 \&$ issue $=9 \&$ articleid $=17044173 \&$ show $=$ abstract

When citing material from this dissertation research, please reference it as:

Doyle, James. (2012), "Building it up and tearing it down: A three study examination of trust, trust building, and the effects of erroneous blogger messaging in the blogosphere," Ph.D. dissertation, Sprott School of Business, Carleton University. 


\section{TABLE OF CONTENTS}

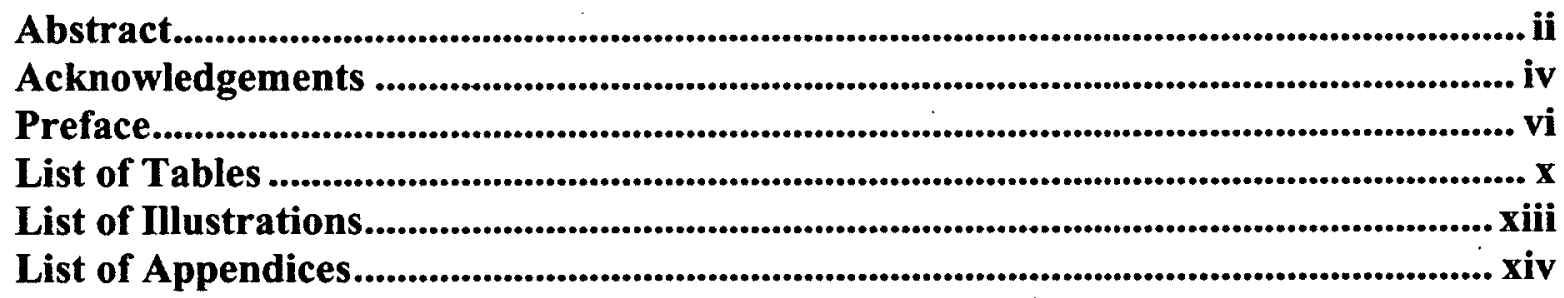

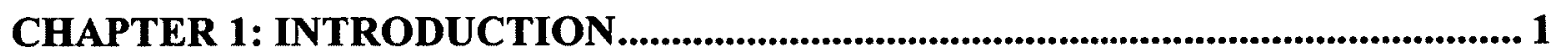

Seeking and Communicating Information in the Blogosphere .................................... 1

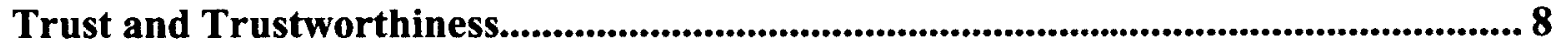

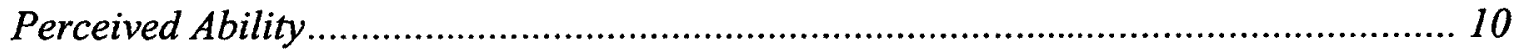

Perceived Character ........................................................................................ 12

Trustworthiness and Information-Source Types................................................ 14

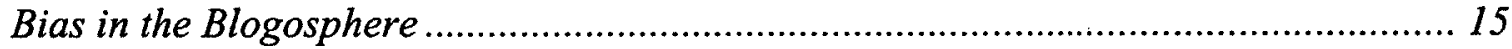

Research Needs and Directions............................................................................... 18

Purpose, Objectives, and Structure of this Three-Study Dissertation........................ 21

CHAPTER 2: OVERVIEW OF PURPOSES, OBJECTIVES, AND GENERAL METHODOLOGIES OF THREE BLOGOSPHERE TRUST STUDIES ................ 24

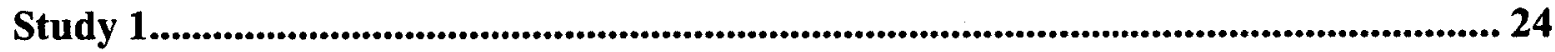

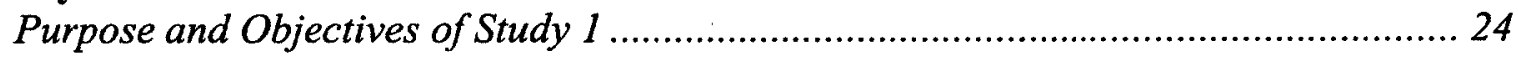

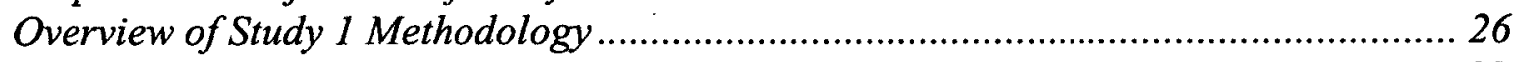

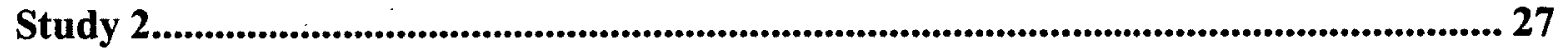

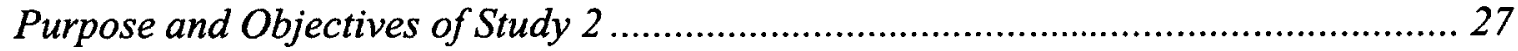

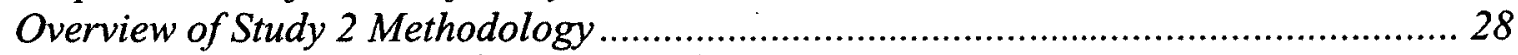

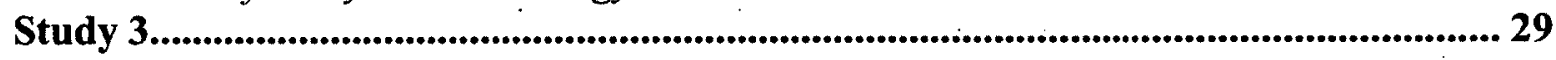

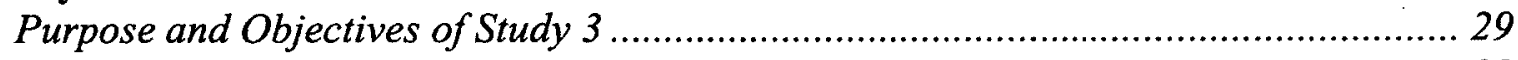

Overview of Study 3 Methodology .................................................................... 32

Three-Study Combination ............................................................................................. 33

CHAPTER 3: TRUST BUILDING IN WINE BLOGS: A CONTENT ANALYSIS 34

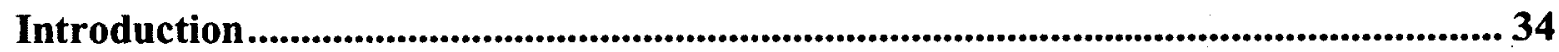

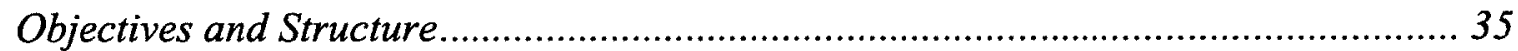

Literature Review and Hypotheses Development ......................................................... 36

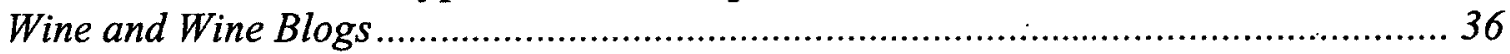

Trustworthiness Signaling in Blogs .......................................................... 37

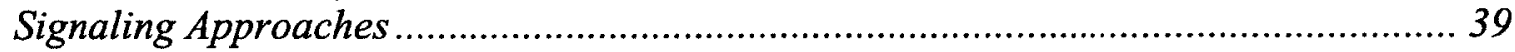

Methodology ................................................................................................................... 42

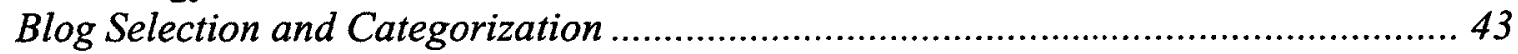

Results ........................................................................................................................... 48

Stage 1 - Pilot Study of Wine Blog Trustworthiness Signaling ............................... 48

Stage 2 - Main Study of Wine Blog Trustworthiness Signaling ............................... 50

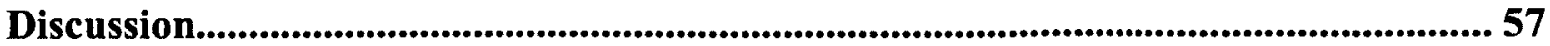

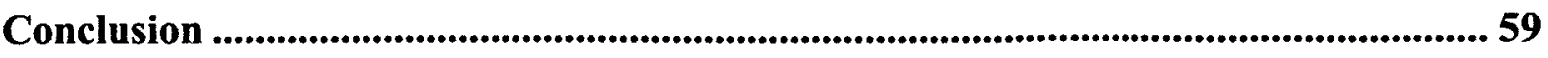

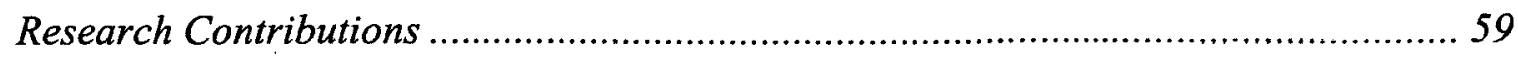




\section{CHAPTER 4: WHAT REALLY MATTERS TO TRUST INTENTIONS FOR}

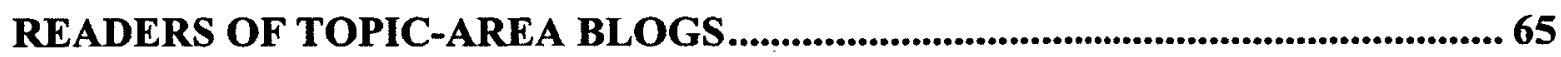

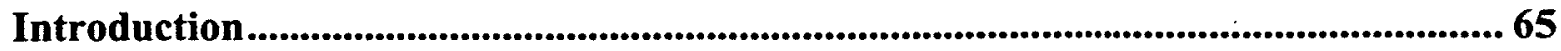

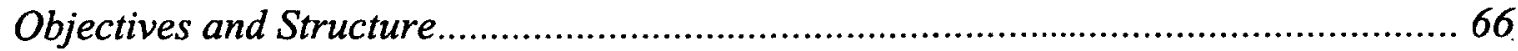

Literature Review and Hypotheses Development ........................................................67 67

Effects of Blogger Characteristics on Trust......................................................69 69

Effects of Blog Characteristics on Trust ............................................................. 73

Effects of Blog-Reading Outcomes on Trust ....................................................... 74

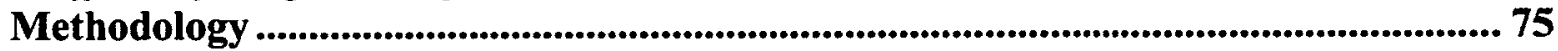

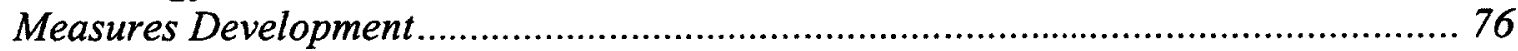

Results and Discussion......................................................................................... 81

Blog-Reading Outcomes and Blogger Characteristics....................................... 82

Blog-Reading Outcomes and Blog Characteristics ........................................ 83

Trust Intentions and Blogger Characteristics..................................................... 84

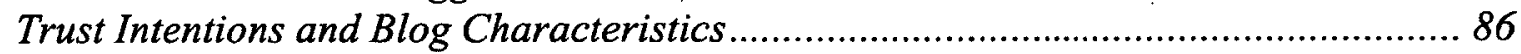

Trust Intentions and Blog-Reading Outcomes................................................ 86

Trust Intentions, Blog-Reading Outcomes, and Blogging Characteristics................. 87

The Indirect Effect of Blogger Characteristics on Trust Intentions ........................... 88

The Indirect Effect of Blog Characteristics on Trust Intentions............................... 89

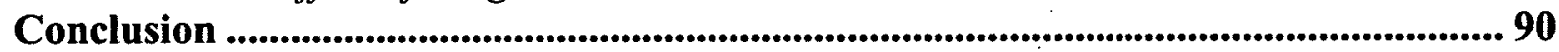

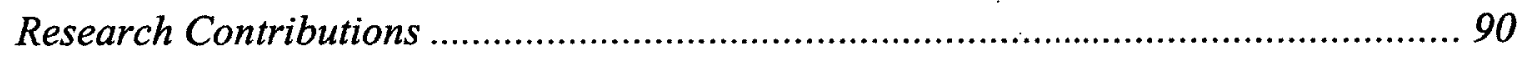

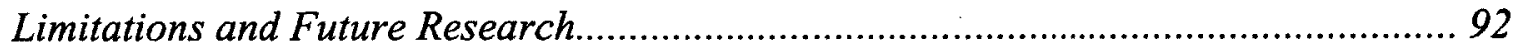

CHAPTER 5: EFFECTS OF BLOGGER-COMMUNICATED TRUST-RELATED

INFORMATION AND BLOGGER ERROR ................................................... 95

Introduction ........................................................................................................... 95

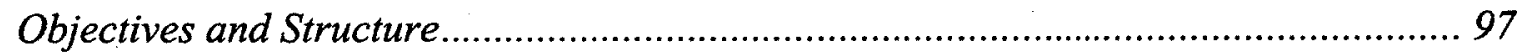

Literature Review and Hypotheses Development .............................................. 100

Blogger-Communicated Trust-Related Information and Blogger Ability Ratings .... 100

Word-of-Mouth Marketing (WOMM) and Blogger Character Ratings.................... 102

Blogger Credibility Ratings ............................................................................. 106

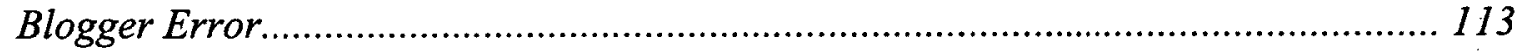

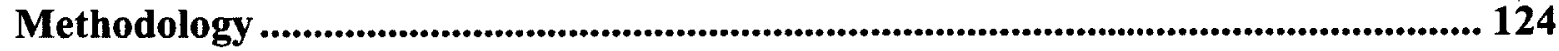

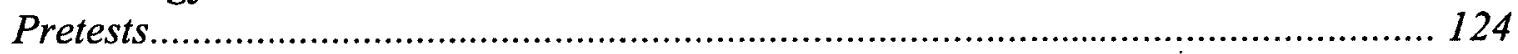

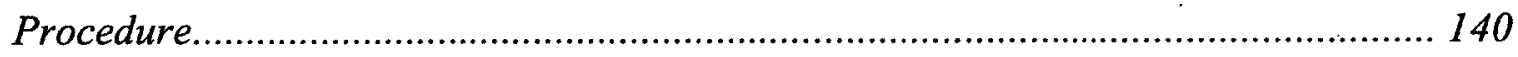

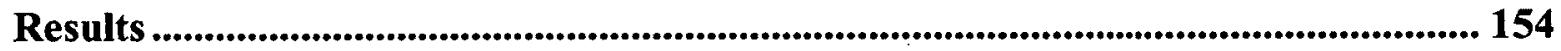

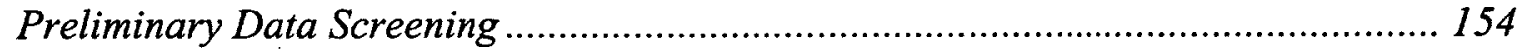

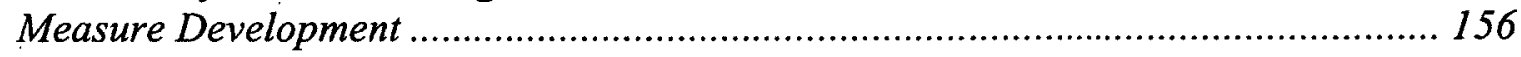

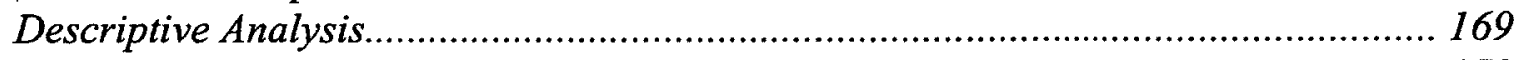

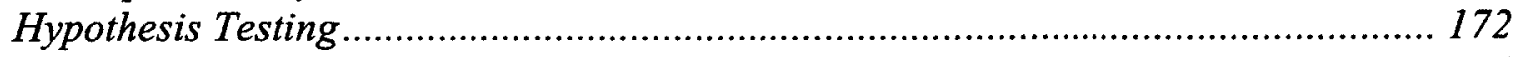

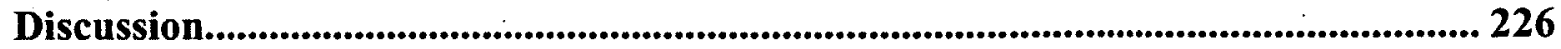

Blogger Ability Ratings and Experimental Treatments .................................... 226

Blogger Character Ratings and Experimental Treatments .................................. 227

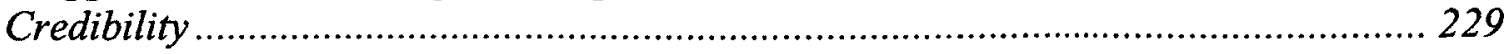




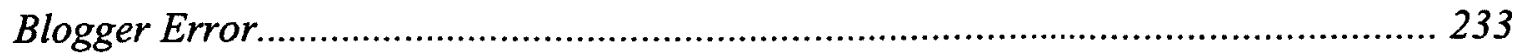

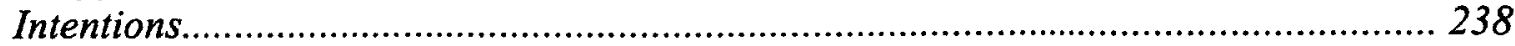

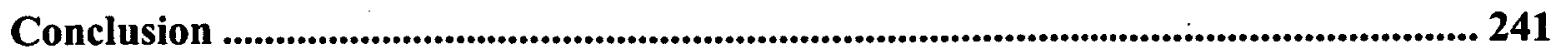

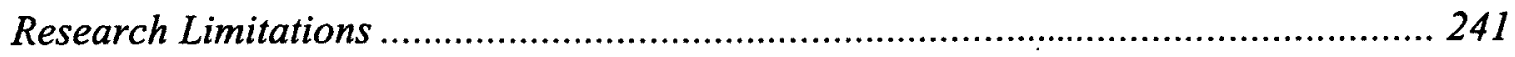

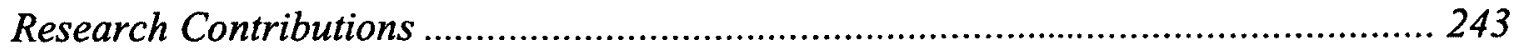

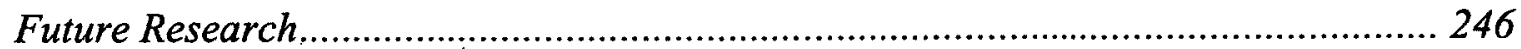

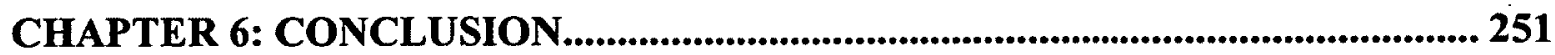

Overview of the Three Studies................................................................................... 251

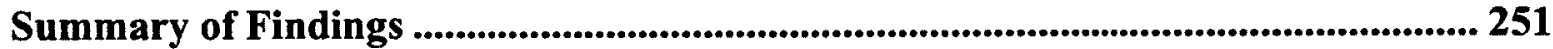

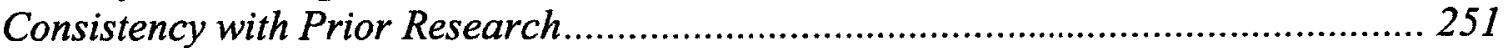

Trust and Trustworthiness ........................................................................... 252

Implications of Accurate Versus Inaccurate Blog Content................................. 255

Implications of Word-of-Mouth Marketing........................................................... 256

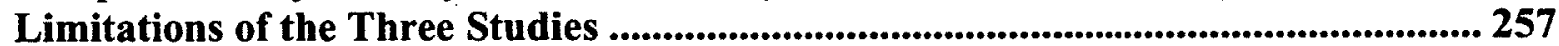

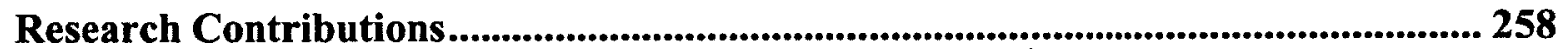

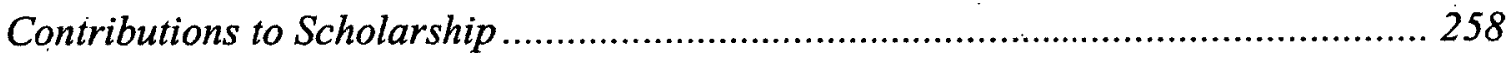

Contributions to Practice ................................................................................ 263

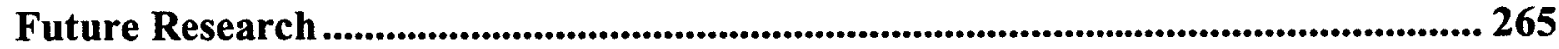

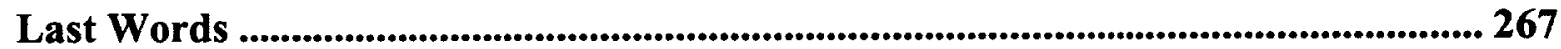

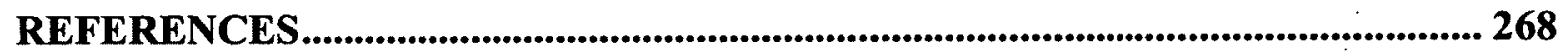

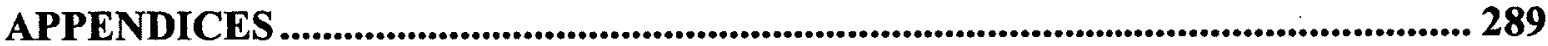




\section{List of Tables}

Table 3.1: Signals of Trustworthiness Sub-Dimensions. 47

Table 3.2: $\quad$ Stage One-Dimension-Level Trustworthiness Signals of Commercial and Non-Commercial Bloggers

Table 3.3: $\quad$ Stage Two - Dimension-Level Trustworthiness Signals of Commercial and Non-Commercial Bloggers ............................................................... 50

Table 3.4: Paired Comparison Tests of Dimension Signaling Patterns of Bloggers . 51

Table 3.5: Ability Signals by Blogger Commercial Orientation.................................. 53

Table 3.6: Authority Signals as a Proportion of Total Ability Signals ........................ 54

Table 3.7: Character Signals by Blogger Commercial Orientation ............................ 55

Table 4.1: Descriptives and Factoring Results of Blogger Characteristic Variables. 78

Table 4.2: Descriptives and Factoring Results of Blog Characteristic Variables ...... 79

Table 4.3: Descriptives and Factoring Results of Blog-Reading Outcome and Trust Variables ................................................................................................. 80

Table 4.4: Correlations and Multiple-Regression Analyses - Reading Outcomes.... 82

Table 4.5: Correlations and Main-Effect and Mediated Models - Trust Intentions .. 85

Table 5.1: Average Weekly Spending on Watching Movies................................... 126

Table 5.2: Experience with Blogs for Obtaining Movie Reviews ........................... 127

Table 5.3: Number of Movie Reviews Read in Blogs on a Weekly Basis .............. 128

Table 5.4: $\quad$ Preferred Movie Characteristics ……….................................................. 129

Table 5.5: Factoring Results of Hedonic and Utilitarian Movie Characteristics ..... 132

Table 5.6: Movie Synopses Pretest Results ……………........................................ 133

Table 5.7: Pretest Measures for the Movie Reviews and "About Me" Statements . 134

Table 5.8: Results of the Movie Review Pretest .................................................... 136

Table 5.9: $\quad$ Results of the "About Me" Pretest ............................................................. 139

Table 5.10: Descriptives and Factoring Results of Blogger Credibility Variables ... 157 
Table 5.11: Descriptives and Factoring Results of Trust Belief Variables

Table 5.12: Descriptives and Factoring Results of Typical Movie Reviews Posted on a

Personal Blog Variables.

Table 5.13: Descriptives and Factoring Results of Blogger-Disseminated Movie Review Variables

Table 5.14: ANOVA of "About Me" Statement Acceptance by Blogger and WOMM Types.

Table 5.15: Independent-Samples t-Test Results - Acceptance of the Movie Review by Movie Review Type.

Table 5.16: ANOVA of Movie Attitudes by Blogger, WOMM, and Movie Review Types

Table 5.17: Descriptives and Factoring Results of Negative Word-of-Mouth Intentions Variables. 166

Table 5.18: Descriptives and Factoring Results of Blogger and Movie Company Blameworthiness Variables

Table 5.19: Descriptives and Factoring Results of Affective Responses to Blogger Error Variables 168

Table 5.20: Tests of Sex-Based Differences on Key Variables 169

Table 5.21: Tests of Age-Based Differences on Key Variables 169

Table 5.22: ANOVA of Typical Blogger Credibility by Experience with Blogs and Similar Websites for Obtaining Movie Reviews 170

Table 5.23: ANOVA of Typical Blogger Credibility by Number of Movie Reviews Read in Blogs on a Weekly Basis

Table 5.24: MANOVA of Beliefs About the Typical Movie Review by Experience with Blogs and Similar Websites for Obtaining Movie Reviews

Table 5.25: Participant Breakdown Across Experimental Treatments . 172

Table 5.26: MANOVA of Blogger Trust Beliefs by Blogger and WOMM Types ........ 174

Table 5.27: ANOVA of Blogger Credibility Rating by Blogger, WOMM, and Movie Review Types.

Table 5.28: Bivariate Correlations with Experiment Blogger Credibility Ratings - Full Study; Across Blogger and Movie Review Types 
Table 5.29: Multiple Regression Analyses - Three Experiment Blogger Credibility Rating Models

Table 5.30: ANOVA of Blogger Blameworthiness by Blogger, WOMM, and Movie Review Types.

Table 5.31: ANOVA of Movie Company Blameworthiness by Blogger, WOMM, and Movie Review Types

Table 5.32: Correlations Between Blogger Blameworthiness and Each of Character and

Deception Intent Ratings. 196

Table 5.33: Multiple Regression Models of Character, Deception Intent, and Blogger Blameworthiness Ratings.

Table 5.34: MANOVA of Anger and Dissatisfaction by Blogger, WOMM, and Movie Review Types.

Table 5.35: Anger and Dissatisfaction Bivariate Correlations - Blameworthiness and Movie Review Incorrectness.

Table 5.36: Multiple Regression Analyses of Anger and Dissatisfaction 205

Table 5.37: ANOVAs of Pre- and Post-Error Trust Intentions by Blogger, WOMM, and Movie Review Types 207

Table 5.38: Multiple Regression Analysis of Post-Error Trust Intentions 209

Table 5.39: Descriptions of Negative Word-of-Mouth Communication Types 211

Table 5.40: MANOVA of Four Types of Negative Word-of-Mouth Communication by Blogger, WOMM, and Movie Review Types.

Table 5.41: Multiple Regression Analyses of Four Types of Negative Word-of-Mouth Communication. 215

Table 5.42: Total, Direct, and Indirect Effect Sizes of Blameworthiness and Anger/Dissatisfaction and Negative Word-of-Mouth Communication

Table 5.43: Summary of Hypotheses Testing Outcomes. 222 


\section{List of Illustrations}

Figure 1.1: Trustworthiness Dimensions and Sub-Dimensions .................................. 14

Figure 4.1: Trust Determination in Topic-Area Blogging...........................................69

Figure 4.2: Full and Partial Mediating Effects of the Knowledge Outcomes of Blog Reading .................................................................................................. 90

Figure 5.1: Individuating Trust-Related Information, Trust Beliefs, and Credibility

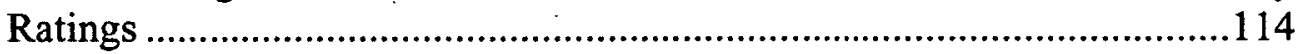

Figure 5.2: Consumption Experience Beliefs - Blogger type by WOMM type........ 176

Figure 5.3: Character Beliefs - Blogger type by WOMM type................................. 176

Figure 5.4: Blogger Credibility Rating - Blogger Type by Movie Review Type .... 179

Figure 5.5: Blogger Credibility Rating - Authoritative Knowledge Rating by Movie

Review Type ...................................................................................... 183

Figure 5.6: Blogger Credibility Rating - Experimental Treatments and Blogger Beliefs (Model 3 - Refer to Table 5.29) ............................................................ 188

Figure 5.7: Movie Company Blameworthiness - WOMM Type by Movie Review

Type

Figure 5.8: Blogger Blameworthiness Rating - Experimental Treatments and Blogger Beliefs

Figure 5.9: Pre-Error Trust Intention - WOMM Type by Movie Review Type ....... 208

Figure 5.10: Main-Effects Model of Movie-Related Interpersonal Communication.. 218

Figure 5.11: Models of Direct and Indirect Effects of Blameworthiness and Negative Affective States on Negative Word-of-Mouth Communication 


\section{List of Appendices}

Appendix 3.1: Operationalizations of Ability, Benevolence, and Integrity Signals...... 290

Appendix 4.1: Study 2 Questionnaire Items ................................................... 292

Appendix 5.1: Movie Pretest Rating Scale ......................................................296

Appendix 5.2: “About Me" Statement and Movie Review Pretest Instrument ............. 297

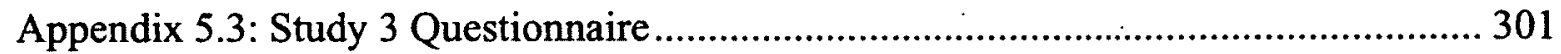

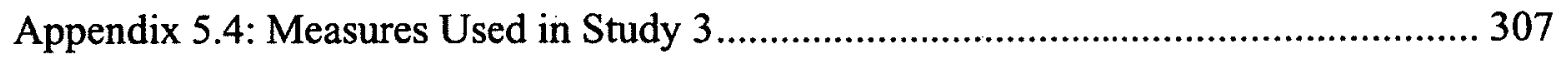

Appendix 5.5: Item-Level Descriptive Statistics ......................................... 313

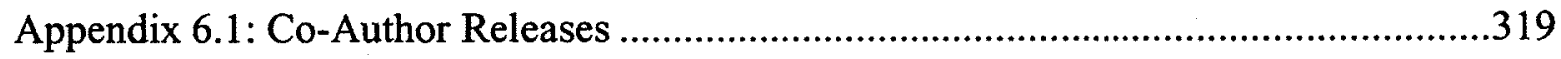




\section{CHAPTER 1: INTRODUCTION}

\section{Seeking and Communicating Information in the Blogosphere}

Motivated consumers seek accurate product- or topic-related information to inform their decisions, develop a knowledge base for potential future application, and perhaps even gain membership in the product- or topic-related community (Schlosser, White, and Lloyd 2006). In the Web 2.0 era, an increasingly diverse community of commercial and non-commercial information sources are attempting to satisfy this product- or topic-related market information need by disseminating claims through a widening array of channels (Libai et al. 2010).

Communication of product- and topic-related information is undergoing. considerable change as well-established business-to-consumer (i.e., paid personal and non-personal commercial communication) and consumer-to-consumer (e.g., word-ofmouth) practices face increasing competition from emerging ones (Ashley and Leonard 2009; Milne, Bahl, and Rohm 2008). Until recently, wide-scale information dissemination occurred on a "one-way street" on which traffic flowed unidirectionally in a controlled manner from marketers to consumers (Rosenbloom, 2004, p. 31). While the influence of word-of-mouth communication on consumer behaviour has long been appreciated (e.g., Bruner, 1986; Zeithaml, Berry, and Parasuraman, 1993), the extent to which consumers could communicate with each other has historically been limited by interpersonal-network size. Indeed, word-of-mouth communication typically occurs between familiar sources and recipients, such as friends, family members, and other personal acquaintances (Klein and Ford, 2003; Lee and Youn, 2009; Mourali, Browne, and Wetherby, 2005). Prominent Web 2.0 innovations, of which "blogging" is one, are 
changing communication in many ways, key among which is the growth in electronic word-of-mouth communication and the concomitant stripping from commercial sources of their long-held monopoly over wide-scale information dissemination (Fieseler et al., 2009; Habel, Veale, and Lu, 2010; Mangold and Faulds, 2009; Rosenbloom, 2004). Organizations have lost considerable control over the information that is communicated about them to and among their target consumers (Mangold and Faulds, 2009), as noncommercial communicators now face few obstacles to disseminating claims to an expansive audience of interested consumers (Mourali, Laroche, and Pons, 2005; Rosenbloom, 2004; Thorsten Hennig-Thurau, Gwinner, Walsh, and Gremler, 2004; Trammell and Keshelashvili, 2005).

"Blogs" are frequently updated online collections of the ideas and experiences of "bloggers" presented in reverse chronological sequence through text, imagery, and audio/video objects (Albrycht, 2004; Huang, Chou, and Lin, 2007; Trammell and Keshelashvili, 2005). Though blogging has existed since the late 1990s (Kent, 2008), it has shot to prominence in recent years, achieving status as a "global phenomenon" (Kumar et al., 2004), “American pastime” (Guadagno, Okdie, and Eno, 2007), and a key part of online culture. The "blogosphere," defined as the overall community of interconnected blogs (Fieseler et al., 2009; Kumar et al., 2004), was estimated in 2011 as being comprised of more than 178 million blogs (Blog Pulse), up from an estimate of between 50 million and 80 million blogs from approximately five years before (Lenhart and Fox, 2006).

Consumers are not the only sources of product- or topic-related information in the blogosphere. Organizations are active on blogs, too, but their activities may not always be 
apparent to information-seeking consumers. Johnson and Kaye (2004) imply that consumers may not fully recognize corporate involvement in the blogosphere because blogs did not start out as a corporate innovation. The commercial orientation of some blogs may be obvious, but the contemporary practices of word-of-mouth marketing and covert marketing mean that an information-seeking consumer could accept a claim disseminated in a blog without accurate knowledge of the true or original source of the claim.

Blogs vary widely in terms of the amount of influence they have over productrelated or topic-related discourse (Du and Wagner, 2006). The product-related or topicrelated influence of a blog can be assessed as the extent to which its readers accept the product-related or topic-related claims that are disseminated through it. A claim is an information-based assertion about an object (e.g., a product) that is designed to reinforce or change the pre-existing object-related beliefs or performance expectations of claim recipients. A belief is a subjective probability that an object either has or lacks a particular characteristic, quality, or attribute or is related or unrelated to some other object (Fishbein and Ajzen, 1975; Ostrom, 1969; Wang and Sun, 2010). Expectations are beliefs that specifically relate to the perceived probable performance of a particular product, service, or other object (Zeithaml, Berry, and Parasuraman, 1993). A product claim, for example, can focus on features of the product, how the product performs, and what consumers will experience or receive from the product. Claims can also focus on specific topic-area dynamics, addressing, for example, key new trends in entertainment, business, technology, health, and a potentially limitless array of other topics. 
Irrespective of its content, a claim is persuasive when a material difference exists between the initial and final beliefs or performance expectations of the claim recipient and when the final belief or expectation position reflects the intent of the communicator and the valence and magnitude of the claim (Cacioppo, Harkins, and Petty, 1981; Chung and Fink, 2008). Persuasion is therefore based on the voluntary acceptance of a claim by the recipient of the claim and is interpretable as a behavioural manifestation of the trust that the recipient has in the communicator (Huang, Chou, and Lin., 2008). The trust that the recipient has in the communicator could be harmed if the communicator failed to deliver on its implicitly or explicitly made domain-specific promises to the recipient. For example, "blogger error," or inaccurate messaging by a blogger, could inflict considerable harm on the trust that readers of a blog have in the blogger and the claims it makes. The general purpose of this dissertation is to develop an understanding of trust antecedents and the overall trust development process in the blogosphere, the implications of commercial activity by bloggers, the tactics by which bloggers attempt to obtain trust from blog readers, and the consequences of failure by a blogger to disseminate accurate claims.

Trustworthy information sources can be trusted to make accurate claims. Drawing from research that has examined the antecedents of satisfying information experiences (Davies, 2001; Nicolaou and McKnight, 2006) and confirmed the importance of highquality information in blog posts and online product reviews (Chen and Tseng, 2010; Hsieh et al., 2010), claim accuracy is the degree to which a claim recipient perceives the content of a claim to accord with objective, or external, reality (cf. Eagly, Wood, and Chaiken, 1978). Since research consistently shows that people only trust others who they 
perceive to be worthy of their trust (e.g., Bart et al., 2005; Doney and Cannon, 1997; Levin and Cross, 2004; Ridings, Gefen, and Arinze, 2002), it is expected that claim acceptance will only occur when the claim recipient believes the claim communicator to be sufficiently able and motivated to make and disseminate accurate domain-specific claims (Insko, 1967; Ratchford, Talukdar, and Lee, 2001). Indeed, it is well recognized that "an individual's acceptance of information and ideas is based in part on "who said it"" (Berlo, Lemert, and Mertz, 1969, p. 563) and that, "for maximum believability, the source must be perceived as not only knowing the truth but being objective enough to be motivated to tell it as he sees it" (McGuire, 1973, p. 231). It is not surprising, then, that communicator trustworthiness is "at the forefront of consumer information needs" (Grant, Clarke, and Kyriazis, 2007, p. 528). Study of blogger trustworthiness assessments by blog readers and the relationship of the assessments to trust intentions is necessary in order to improve overall understanding of blogosphere phenomena, explain differences in blogger-level topic-area persuasiveness, and allow bloggers to enhance the effectiveness of any tactical steps they take to influence the assessments. This dissertation involves examination of the assessments in order to satisfy this pressing research need.

Trust is particularly relevant for claims that are not amenable to independent verification without action being taken on the basis of them (i.e., "experiential claims;" Obermiller and Spangenberg, 1998). In a product context, it has long been recognized that consumers are particularly wary of claims that either can only be assessed through or after product consumption or that cannot ever be assessed (Houston, 1979). As with what are termed "experience goods" such as wine and movies, claim recipients can practically only determine the true accuracy of an experiential claim by acting on it and judging if it 
was substantiated by experience (Davis, 1989; Ford, Smith, and Swasy, 1988; Jover, Montes, and Fuentes, 2004; Nelson, 1970; Raban and Rafaeli, 2006; Sussman and Siegal, 2003). Acting on an experiential claim (e.g., drinking a highly rated wine, seeing a recommended movie) can involve risk of loss of financial resources, emotional wellbeing, social standing, and even physical health. To minimize risk, the initial decision to act on an object-related experiential claim is shaped by the expected accuracy of the claim, which is the degree to which a claim recipient is confident that his or her own experience-based evaluation of the object would match the content of the objectrelated claim (Bailey and Pearson, 1983). Predicting the expected accuracy of an experiential claim is the most practical basis of the initial action choice, since the costs of pre-purchase search activities generally exceed the benefits (Ford, Smith, and Swasy, 1988).

Expectation confirmation occurs when the experienced performance of an object accords with the expected performance of the object (Oliver, 1977; Zeelenberg et al., 2000). Expectation disconfirmation, then, occurs when experienced performance differs positively or negatively from expected performance. Positive disconfirmation occurs when experienced performance exceeds (i.e., is better than) expected performance and is positively associated with object-directed affect and purchase intentions (e.g., Oliver, 1977). Given the loss inherently involved, negative disconfirmation (i.e., worse-thanexpected performance) is often associated with feelings of dissatisfaction, disappointment, regret, and anger (e.g., Estelami, 2000; Finkel et al., 2002; Kalamas, Laroche, and Makdessian, 2008; Weiner, 2000; Zeelenberg et al., 2000) and a variety of 
domain-relevant revenge-seeking behaviours (Grégoire, Tripp, and Legoux, 2009; Stillwell, Baumeister, and Del Priore, 2008).

For a recipient unable to directly determine the accuracy of an experiential claim, the decision to accept or reject the claim depends heavily on the extent to which the communicator is judged to be sufficiently able and motivated to make accurate experiential claims. To enhance the probability its claims will be accepted by recipients, a communicator may employ impression management tactics aimed at influencing $a$ priori beliefs or performance expectations that claim recipients would have as to the trustworthiness of the communicator and the accuracy of its claims (Moorman, Deshpandé, and Zaltman, 1993). Impression management is a process by which a communicator directs particular behaviours (i.e., transmits signals) toward others in order to influence their beliefs about the communicator (Gardner and Martinko, 1988). Following Lee, Ang, and Dubelaar (2005, p. 610), signals are actions "taken by the better-informed party in a setting of asymmetric information to communicate its true characteristics in a credible fashion to the less-informed party." From a trust-building perspective, a communicator could transmit signals of its ability, benevolence, and integrity (i.e., trustworthiness; Mayer, Davis, and Schoorman, 1995) in order to engender trust and set the stage for acceptance of its product- or topic-related claims (Kirmani and Rao, 2000; Schlosser, White, and Lloyd, 2006).

To complement the study of trustworthiness assessments involved in this dissertation, separate study of the trustworthiness signaling behaviours of bloggers is warranted. This dissertation involves examination of the content of these behaviours. Results of these studies can be integrated in order to assess the extent to which bloggers, 
at least on a category level, are sensitive to the information needs of blog readers as they pertain to communicator trustworthiness.

\section{Trust and Trustworthiness}

Trust refers to the willingness of a trustor (i.e., trust grantor) to accept a position of relative risk under circumstances that do not allow complete monitoring and control of the actions of a trustee (Levin and Cross, 2004; Mayer, Davis, and Schoorman, 1995; Moorman, Deshpandé, and Zaltman, 1993; Yousafzai, Pallister, and Foxall, 2003). In the blogosphere, trust can be considered the extent to which blog readers voluntarily accept and rely on the assertions of a blogger to direct their own domain-specific decisions and actions and encourage others unfamiliar with the blogger to do the same (Kim and Benbasat, 2006). Risk resides in the inherent potential for loss from making a decision or taking an action that could lead to undesirable outcomes based upon inaccurate information (Mayer, Davis, and Schoorman, 1995).

Trust and trustworthiness are sometimes confused in research (e.g., Chen and Dibb, 2010), but trust is a behavioural intention in a situation involving risk and trustworthiness is the set of beliefs a trustor has regarding the ability and motivation of a trustee to fulfill domain-specific promises. Early conceptualizations of trustworthiness regarded it simply as the lack of motivation to lie (Mayer, Davis, and Schoorman, 1995) or the extent to which a communicator is perceived by information seekers to provide information that it believes is valid (Jo, 2004). Recent trustworthiness research conceptualizes it as the set of trustor beliefs of the domain-specific ability, benevolence, and integrity of a trustee (e.g., Belanger, Hiller, and Smith, 2002; Lee and Turban, 2001; 
Mayer, Davis, and Schoorman, 1995; Schlosser, White, and Lloyd, 2006; Schoorman, Mayer, and Davis, 2007; Yousafzai, Pallister, and Foxall, 2003). Specifically, trustworthiness is a multi-dimensional trustor belief encompassing the trustee's anticipated (1) ability to perform domain-specific tasks; (2) integrity in managing asymmetry in the relationship; and, (3) benevolence in facilitating positive outcomes for the trustor (Corritore, Kracher, and Wiedenbeck, 2003; Mayer, Davis, and Schoorman, 1995).

Trustor perceptions of trustee trustworthiness may be based on evaluations of outcomes of prior interactions with the trustee (i.e., experience-based beliefs; Casalo, Flavián, and Guinalíu, 2007), but trust beliefs at the outset of a relationship are made without the benefit of these evaluations (Koufaris and Hampton-Sosa, 2004; Li and Miniard, 2006; Mayer, Davis, and Schoorman, 1995). In the absence of prior personal experience, specific trustworthiness judgments can be made only on the basis of grouplevel stereotypes (Flanagin and Metzger, 2007), modified by persuasive trust-building tactics. For example, a blogger can signal its ability to make accurate topic-area claims (e.g., "I have spent my entire career working in the industry;" "I have been regularly using this product for many years") and its motivation to make accurate topic-area claims on the basis of its benevolence and integrity ("I try to help my readers make good decisions as much as I can;" "I tell the truth exactly as I see it, whether it is good or bad.") 
Perceived Ability

Perceived ability is the extent to which a trustee is believed to possess the endogenous and exogenous resources needed for performing topic-area tasks in which the trustor has a personal stake (Alba and Hutchinson, 1987; de Janasz and Forret, 2008; Doney and Cannon, 1997; Lee and Turban, 2001; Mayer, Davis, and Schoorman, 1995; Priester and Petty, 2003; Ridings, Gefen, and Arinze, 2002). Endogenous resources are the human capital assets of domain-specific knowledge, skill, and experience possessed by a trustee that enable it to perform domain-specific tasks (Alba and Hutchinson, 1987; Becker, 1975; Moorman, Deshpandé, and Zaltman, 1993). The endogenous ability of a trustee to perform a task, specifically to provide an accurate claim, can stem from general and domain-specific education, training, and work experience, resulting in authoritative knowledge, or from "the number of product-related experiences that have been accumulated by the consumer" (Alba and Hutchinson, 1987, p. 411), termed consumption experience (Brakus, Schmitt, and Zarantonello, 2009; Johnson and Russo, 1984). Applied to topic-area blogs (i.e., blogs that update readers about trends in different interest areas), consumption experience can be viewed in terms of the dedication to as well as interest and participation in the topic-area, i.e., engagement knowledge of the blogger.

The interchangeability of endogenous ability bases is limited (Zaichkowsky, 1985a), since meaningful differences exist between authoritative knowledge and consumption experience or engagement knowledge as bases for experiential claims (Holbrook, 1999). For example, research shows that professional critics and ordinary consumers employ discordant evaluative criteria to assess experience goods, such as movies (Holbrook, 1999), and that consumers tend to rely more on sources that evaluate 
products as they do (Cooper-Martin, 1992; Yaniv, Choshen-Hillel, and Milyavsky, 2011). Even though authoritative knowledge and consumption experience or engagement knowledge all convey ability to perform domain-specific tasks, these ability bases can develop independently (Jacoby et al., 1986) and differ significantly in terms of content and perspective. Topic-area authorities are presumed to fully know the topic-area external reality and to therefore possess the ability to make accurate topic-area claims. High engagement knowledge may not necessarily imply a complete grasp of the topic-area external reality, but highly engaged topic-area bloggers are likely to have well defined topic-area preferences developed through heavy topic-area dedication, interest, and participation.

External reality, or objective "truth," is a debatable concept with regard to experiential claims and claims about experience goods (e.g., wine, movies) or topic areas (e.g., entertainment, sports). For example, an enjoyable movie-watching experience to one consumer could not be to another. Although "enjoyment" from a movie-watching experience is frequently assessed in terms of amusement, pleasure, and other hedonic states, serious, poignant, and pensive movie-watching experiences can also be enjoyable to consumers (Oliver and Bartsch, 2010). The endogenous domain-specific ability of a communicator can influence its domain-specific tastes and the enjoyment it will derive from a particular consumption experience. Movie reviews and reviews of other experience goods are often provided by expert critics with highly discriminating tastes and consumers with more pedestrian preferences. Divergent ability bases can have important implications for the degree to which an information source can relate to and satisfy the needs of an individual information seeker (Moon, Bergey, and Iacobucci, 
2010; Yaniv, Choshen-Hillel, and Milyavsky, 2011). Research shows that consumers prefer personally relevant experience-based information sources (e.g., friends) for reviews of experience goods, particularly as compared to non-experience based information sources (e.g., Cooper-Martin, 1992; Yaniv, Choshen-Hillel, and Milyavsky, 2011).

Ability can also derive from social capital (Hilligoss and Rieh, 2008; Priester and Petty, 2003). Social capital is the set of value-creating exogenous trustee resources that is available through or that derives from the structural, relational, and cognitive characteristics of its interpersonal relationships (Lazarova and Taylor, 2009; Nahapiet and Ghoshal, 1998; Tsai and Ghoshal, 1998). Structural social capital is particularly relevant to the blogosphere, since the blogosphere is comprised of interconnected blogs and bloggers. Bloggers with strong structural social capital are connected to "informed

others" (e.g., subject-matter experts) who instrumentally cooperate and share resources with each other to expand their individual capacities (Chow and Chan, 2008; de Janasz and Forret, 2008; Hayami, 2009). When a blogger with strong structural social capital faces obstacles to domain-specific task performance, it can draw from the endogenous ability of connected others to satisfy its implicitly or explicitly made commitments to trustors.

\section{Perceived Character}

Trustees with strong character can be relied upon to perform domain-specific tasks to the full extent of their domain-specific ability (Hovland, Janis, and Kelley, 1953; 
Moorman, Deshpandé, and Zaltman, 1993). The character of a trustee is the totality of its integrity and general and trustor-directed benevolence.

Perceived integrity concerns the extent to which a trustee is believed to be honest, sincere, unbiased, and committed to morally and ethically acceptable conduct (Belanger, Hiller, and Smith, 2002; Lee and Turban, 2001; Mayer, Davis, and Schoorman, 1995; Ridings, Gefen, and Arinze, 2002). A trustee with high integrity has an inherent "unwillingness to sacrifice ethical standards to achieve individual or organizational objectives" (Moorman, Deshpandé, and Zaltman, 1993, p. 84). Integrity involves honesty, sincerity, reliability, and openness and is often referred to in research in terms of fairness, consistency, promise fulfillment, and value congruence (Belanger, Hiller, and Smith, 2002; Colquitt, Scott, and LePine, 2007; Lee and Turban, 2001). To develop beliefs about the integrity of a trustee, Mayer, Davis, and Schoorman (1995) claim that trustors refer to the promise-fulfilling track record of the trustee, communication about the trustee from other parties, and perception of the commitment of the trustee to justice.

Perceived benevolence is an assessment of the extent to which a trustee has goodwill intentions and, rather than wanting solely to benefit from a trustor, desires to do good things for it (Colquitt, Scott, and LePine, 2007; Mayer, Davis, and Schoorman, 1995; Pavlou and Dimoka, 2006; Szulanski, Cappetta, and Jensen, 2004). A benevolent trustee is one who would go beyond normative expectations for the benefit of the trustor and never inflict harm on it knowingly, even if harming it would convey a personal gain to the trustee (Belanger, Hiller, and Smith, 2002). Trustworthiness dimensions and subdimensions are illustrated in Figure 1.1. 
Figure 1.1: Trustworthiness Dimensions and Sub-Dimensions

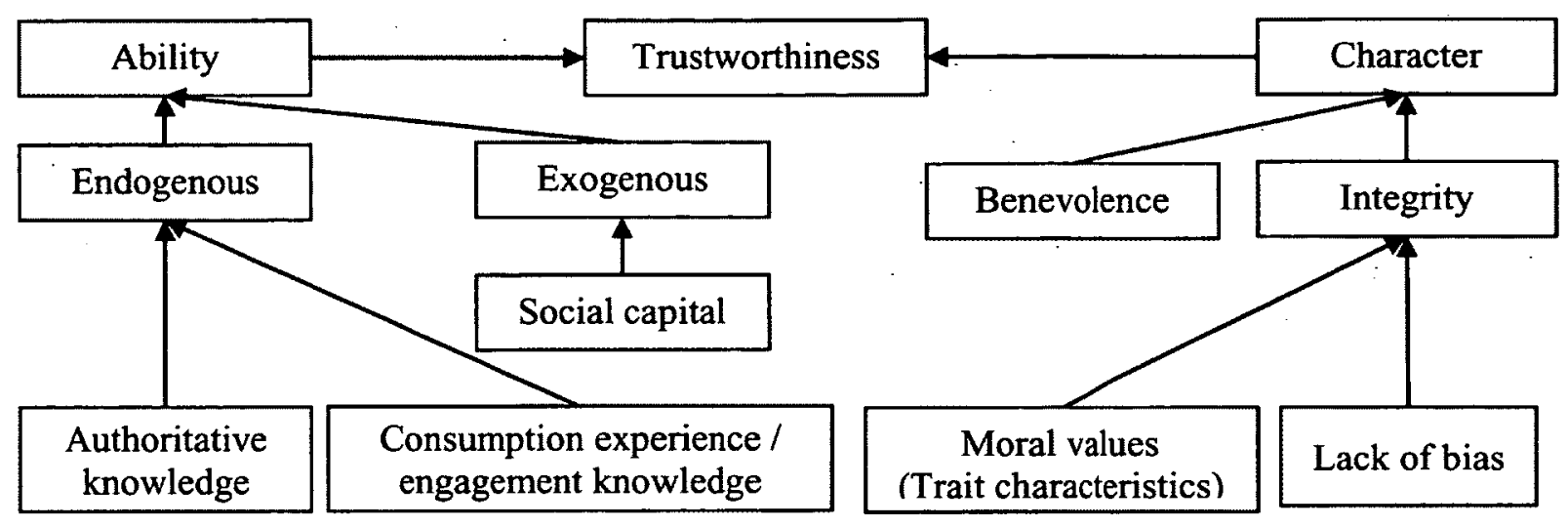

\section{Trustworthiness and Information-Source Types}

Trust beliefs make claim acceptance more likely for some blogger types than for others. The distinction between commercial and non-commercial sources of product information is well established in marketing research and in the attitudes of informationseeking consumers (e.g., advertising scepticism; see Obermiller and Spangenberg, 1998). Particularly salient to the information-seeking consumer is the pervasive belief that commercial information sources are comparatively unlikely to convey external productrelated reality in a complete, unbiased, and unscripted form (Eagly, Wood, and Chaiken, 1978). This "reporting bias" implies that embedded in any product claim communicated by a commercial source could be one or more statements that either exaggerate(s) the strengths of the focal product or service or downplay(s) its weaknesses. Misleading advertising tactics are extreme manifestations of reporting bias, but advertising regulations in most market economies permit "some latitude for exaggeration" (Obermiller and Spangenberg, 1998, p. 162). Even certain standard advertising practices (e.g., puffery) involve some degree of embellishment (Haan and Berkey, 2002). 
Promotional practices are subject to legislation (e.g., Competition Act in Canada) and practitioner groups (e.g., Advertising Standards Council, Canadian Marketing Association) espouse codes-of-conduct, but the profit imperative that motivates commercial communicators instills wariness in consumers, particularly for claims that either can only be assessed through or after consumption or that cannot ever be assessed (Houston, 1979; Lim and Chung, 2011). Information-seeking consumers can turn to non-commercial sources of product information to satisfy some of their information needs, and studies have long shown the importance of word-of-mouth communication as one of these sources (e.g., Arndt, 1968; Bruner, 1986; Zeithaml, Berry, and Parasuraman, 1993). Consumers often prefer and believe information from non-commercial sources because of their high "presumed credibility" (i.e., they are assumed to be altruistic, honest, unbiased, and free from reporting bias), particularly in comparison to sources motivated by profit (Bickart and Schindler, 2001; Day, 1971; Habel, Veale, and Lu, 2010; Lee, Rodgers, and Kim, 2009; Mourali, Laroche, and Pons, 2005; Trusov, Bucklin, and Pauwels, 2009; Tseng and Fogg, 1999; Zeithaml, Berry, and Parasuraman, 1993).

\section{Bias in the Blogosphere}

Concern has been expressed that structural characteristics of the blogosphere and characteristics of bloggers themselves make the dissemination of inaccurate claims in blog posts (i.e., erroneous messaging) a highly realistic prospect (Cox, Martinez, and Quinlan, 2008; Flanagin and Metzger, 2000; Johnson and Kaye, 2004; Lenhart and Fox, 2006; Pollach, 2008; Rosenbloom, 2004; Trammell and Keshelashvili, 2005). From a 
structural perspective, a computer, internet access, and claims to disseminate are all that are needed in order for an individual to write a blog (Johnson and Kaye, 2004; Rosenbloom, 2004; Trammell and Keshelashvili, 2005). From a blogger perspective, knowledge bias, reporting bias, and weak information management practices instill considerable variance in blog-post accuracy performance (Eagly, Wood, and Chaiken, 1978; Lenhart and Fox, 2006; Pollach, 2008; Smith, Menon, and Sivakumar, 2005). Knowledge bias is specifically defined as the belief "that a communicator's knowledge about external reality is nonveridical" (Eagly, Wood, and Chaiken, 1978, p. 424). Knowledge bias is an alleged characteristic of the blogosphere, as bloggers need not show proof of possessing nor necessarily even actually possess subject-matter expertise in order to disseminate a subject-matter claim (Smith, Menon, and Sivakumar, 2005) and perhaps even lead online discourse (Johnson and Kaye, 2004; Rosenbloom, 2004; Trammell and Keshelashvili, 2005).

Reporting bias is also a concern in the blogosphere. Given the "tremendous ability [of blogs] to bring a human voice to an organization's communications" (Albrycht, 2004, p. 14), it is not surprising that organizations are eagerly adopting blogs to complement or as an alternative to their existing communication channels (Lee et al., 2006; Rosenbloom, 2004). Contemporary marketing practice in the blogosphere can and does involve attempts by organizations to meld "nonmarketing" situations into marketing situations (Sprott, 2008), conceal their identity from blog readers (Ferguson and Ellen, 2006), and withhold details from blog readers regarding the information they disseminate to blog readers and collect from blog readers (Milne, Bahl, and Rohm, 2008). The intent of these tactics is to avoid arousing persuasion knowledge, defined as the understanding a 
consumer has of the tactics and goals of communicators (Friestad and Wright, 1994). When a communicator or a claim arouses persuasion knowledge, the recipient may become suspicious that the communicator or the claim was motivated by some sort of ulterior motive (e.g., personal gain), commence an attributional search, discount the likelihood of internal causation, derogate and question the trustworthiness of the information source, and construct arguments that counter the claims made by the communicator (Fein, 1996; Romani, 2006; Smith and Swinyard, 1988).

\section{Overcoming perceptions of bias in the blogosphere.}

Although dependent on individual-level persuasion knowledge and awareness of the potential knowledge shortcomings of non-commercial communicators, consumers commonly associate commercial and non-commercial information sources with different amounts of knowledge and reporting bias (Flanagin and Metzger, 2007; Obermiller and Spangenberg, 1998; Pollach, 2008). Commercial and non-commercial bloggers can engage in impression management activities (cf. Gardner and Martinko, 1988) to attempt to overcome perceptions of their knowledge or reporting bias, influence the trustworthiness beliefs of blog readers, and encourage blog readers to accept the domainspecific claims disseminated through their blogs. Indeed, bloggers can make claims both about a specific product or topic area and about themselves. Specifically, bloggers can make claims about, or can "signal," their ability, benevolence, and integrity, but prior research has not investigated this blogger behaviour or indicated its potential effectiveness (cf. Chung and Fink, 2008). 


\section{Research Needs and Directions}

Several research gaps and opportunities to inform blogosphere practice are evident on the basis or emerge out of this literature review. A general need exists for a better understanding of the seemingly paradoxical co-existence of increasing consumer trust in blog content and the uncertain believability of that content (Mangold and Faulds, 2009; van Heerden et al., 2009). A finely grained appreciation of the conditions under which trust is given and an information source is regarded as trustworthy would be an important contribution to the blogosphere, trust, and communication literatures (Connolly-Ahern and Broadway, 2007).

A process-based approach is appropriate for addressing this need, since trust in a relationship reflects evaluations by relationship members of the outcomes of their prior interactions (Casalo, Flavián, and Guinaliu, 2007). Although prior research has identified certain motivations and motivation-related outcomes for information-seeking consumers (e.g., Schlosser, White, and Lloyd, 2006) and blog readers (e.g., Huang, Chou, and Lin, 2008), their applicability or their role in the trust development process in the blogosphere has not been assessed. Blog-reading outcomes are the direct and indirect products of interactions between blog readers, bloggers, and blogs, as they are experienced by blog readers. It is necessary to identify the types of blog-reading outcomes that, when they are realized by blog readers, facilitate (instead of deteriorate) trust and its correlates between blog readers and bloggers. Since outcomes are based on blog reader, blogger, and blog interactions, comprehensive analysis of blogosphere trust necessarily involves identification of relevant blogger and blog characteristics and specification of their direct and indirect roles in the trust development process. 
Comprehensive analysis of blogosphere trust also involves recognition that blog readers must often extend trust to bloggers with whom they have no prior direct relationship (Kozinets et al., 2010; Lee and Youn, 2009; Thorsten Hennig-Thurau et al., 2004). The potential reach of electronic word-of-mouth communication is vast compared to that of conventional word-of-mouth communication, since electronic media allow for communication to transcend networks of family, friends, and other personal acquaintances. As a result, trust decisions in the blogosphere are not always made on the basis of prior trustee-specific personal experience. Therefore, comprehensive examination of blogosphere trust must also consider the trust-development role of preexisting beliefs of blog readers regarding the accuracy of blog content and ability, benevolence, and integrity of commercial and non-commercial bloggers. Since bloggers are expected to employ tactics (i.e., transmit trustworthiness signals) in order to obtain trust from readers and achieve influence over relevant blogosphere discourse, comprehensive examination of blogosphere trust must also involve specific identification of the content of these tactics.

The trust development process in the blogosphere must therefore be examined from the perspectives of trustees (blog readers; blog-reading consumers) and trustors (bloggers). Since communicator trustworthiness is an important information need for blog readers (Grant, Clarke, and Kyriazis, 2007) and trust is bestowed in a blogger by blog readers, the need to assess trust antecedents from the perspective of blog readers is obvious. Specific topics of inquiry basic to the application of trust-related theories in the online environment, particularly blogs, include the respective trust-building influences of authoritative knowledge, consumption experience, engagement knowledge, and character 
and how their influences could depend on the nature of the claims that bloggers disseminate to readers as well as on blog-reading context. In addition, evaluation of the importance of blogger trustworthiness characteristics as compared to blog characteristics and blog-reading outcomes is needed in order to assess the specific applicability of the blogosphere to online trust research and to identify the trust-building outcomes of blog reading.

The need to examine the trust-development process from the perspective of bloggers is perhaps less obvious. A contribution can be made to online trust theory and practice by examining the tactics of bloggers aimed at satisfying the trustworthiness information needs of blog readers, since these tactics are expected to play an important role in the trust development process in the blogosphere. Given the general beliefs of consumers as to the trustworthiness-based strengths and weaknesses of commercial versus non-commercial communicators, a particular need exists for determining what theories would best explain the approaches used by these two blogger types to build trust. Different theoretical bases could be usefully applied to guide research on whether commercial and non-commercial bloggers attempt to facilitate their topic-area influence by emphasizing their perceived inherent strengths or by attempting to remediate their perceived inherent weaknesses.

Given the potential for erroneous messaging in the blogosphere, study is also required of its cognitive, affective, and conative implications for blog readers, bloggers, and organizations. Blogger error represents an inherent violation of the implicitly or explicitly made domain-specific promises that a blogger makes to its readers. Prior research has not investigated the implications of blogger error. However, the realistic 
prospect of blogger error and research in complementary domains showing the consequences of service failure, trust violation, and betrayal (Grégoire, Tripp, and Legoux, 2009; Iglesias, 2009; Wetzer, Zeelenberg, and Pieters, 2007) make it an additional topic for study in order to expand the theoretical understanding of trust development and deterioration in the blogosphere.

\section{Purpose, Objectives, and Structure of this Three-Study Dissertation}

Beliefs, belief-change tactics, and belief change are examined extensively in this three-study dissertation of blogosphere trust. Prior research reveals that trust has a strong cognitive foundation and that tactics can be employed for changing trust-related beliefs, but belief-based trust antecedents and change tactics in the blogosphere warrant individualized attention. The general purpose of this dissertation is to develop an understanding of trust antecedents and the overall trust development process in the blogosphere, the implications of commercial activity by bloggers, the tactics by which bloggers attempt to obtain trust from blog readers, and the consequences of failure by a blogger to disseminate accurate claims.

The objectives of this three-study dissertation are:

1. to identify the signals of trustworthiness that commercial and non-commercial bloggers disseminate to blog readers in an attempt to influence the trustworthiness beliefs of blog readers and encourage blog readers to accept the domain-specific claims disseminated through their blogs; 
2. to identify the trust-building role of trustworthiness signals within an overall trustdevelopment framework involving beliefs of blogger trustworthiness, blog characteristics, and blog-reading outcomes;

3. to evaluate the effects of signals and beliefs of authoritative knowledge, engagement knowledge, consumption experience, and character on credibility ratings and trust intentions and to determine whether their effects vary according to blog-reading and claim-type contexts;

4. to assess the effects on trustworthiness beliefs and character ratings of disclosure by a blogger of its participation in a word-of-mouth marketing campaign;

5. to identify the cognitive, affective, and conative effects of blogger error for blog readers, bloggers, and organizations, and;

6. to integrate findings in order to develop understanding of the overall trust development and trust deterioration process in the blogosphere on the basis of multiple perspectives and multiple methodologies.

The three studies that comprise this research allow for triangulation of the findings from different parts of each. Triangulation is recommended as a validitybuilding method that involves the integration of findings obtained from difference sources of information (Creswell and Miller, 2000). As is outlined in the next chapter as well as in the three studies that comprise this dissertation, trust development and trust deterioration are variously assessed from the perspectives of bloggers and blog readers (i.e., multiple information sources) in different contexts using different methodologies.

The remainder of this dissertation is structured as follows. An overview of the purpose, key objectives, and major methodological choices that were made in order to 
research trust development and trust deterioration in the blogosphere is provided in Chapter 2. The three studies of this dissertation are presented in Chapters 3,4 , and 5 , respectively. In Chapter 6, summary remarks concerning the contributions and limitations of this three-study dissertation as well as opportunities for future research are presented. 
CHAPTER 2: OVERVIEW OF PURPOSES, OBJECTIVES, AND GENERAL METHODOLOGIES OF THREE BLOGOSPHERE TRUST STUDIES

The purpose, objectives, and major methodologies of the three studies that comprise this dissertation research are introduced in this chapter. To serve the research purpose and meet the research objectives outlined in Chapter 1, this dissertation involves study-level replication under different circumstances and using different tools of inquiry for the purpose of findings triangulation so that the overall set of findings is substantive and rich. Trust-related blogosphere phenomena are examined in different contexts in order to evaluate the extent to which the study findings support and reinforce each other as well as inform theory about trust communications, the development and deterioration of trust, and the practice of online communication.

\section{Study 1}

\section{Purpose and Objectives of Study 1}

With trust-building being an important concern for bloggers, an examination of the trust-building tactics employed by bloggers is warranted. The general purpose of study 1 is to learn how bloggers attempt to build trust with their readers through their ability, benevolence, and integrity signaling behaviours. Examination of these behaviours in light of a priori beliefs about the ability, benevolence, and integrity of commercial and non-commercial bloggers will reveal whether trustworthiness signaling in the blogosphere is resource based (i.e., is aimed at confirming a priori expectations; Oliver, 1977), compensative in nature (i.e., is aimed at disconfirming a priori expectations), or both. 
The objectives of study 1 are:

1. to develop and test an approach for classifying unstructured blog content within a trustworthiness framework;

2. to identify whether or not ability, benevolence, and integrity are equally emphasized in the trustworthiness signaling behaviours of commercial and noncommercial bloggers and the extent to which these behaviours reflect theories regarding trust, communication, and attitude formation;

3. to identify whether or not commercial and non-commercial bloggers differ in their trustworthiness signaling behaviours such that a priori category-level beliefs or stereotypes of the ability, benevolence, and integrity of commercial versus noncommercial bloggers are reflected in their signaling of these trustworthiness dimensions;

4. to identify whether or not commercial and non-commercial bloggers differ in their sub-dimension level ability-signaling behaviours, since commercial and noncommercial communicators are differentially associated on an a priori basis with authoritative knowledge and consumption experience, and;

5. to identify whether or not commercial and non-commercial bloggers differ in their dimension- and sub-dimension level character-signaling behaviours, since these communicator types are also differentially associated on an a priori basis with benevolence and integrity. 
Overview of Study 1 Methodology

Study 1 is a context-specific content analysis of the trustworthiness signals that commercial and non-commercial wine bloggers (i.e., bloggers who make claims about wines and wine-related topics) transmit to blog readers in an attempt to influence $a$ priori blog-reader beliefs or performance expectations as to their trustworthiness and, by extension, the accuracy of their claims. Wine was the selected product category for this study because it is information rich, complex, uncertain, and a popular topic for blogbased discussion.

A review of prior trustworthiness research offered a valuable yet incomplete foundation for examining the diversity of trustworthiness signaling behaviours in the blogosphere, so a context-grounded approach for identifying and classifying these behaviours was developed and employed. The content and placement of trustworthiness signals on blogs are highly unstructured. Therefore, the methodology developed was applied using multiple coders of all trustworthiness signals to enhance the reliability to the study results. Although organizations are active in wine blogs, marketing tactics can complicate efforts to accurately assess the commercial orientation of an individual wine blog. To ensure proper wine blog commercial-orientation classification, a criteria was developed and employed by the coders. Within-type and between-type analyses were conducted in order to test hypotheses regarding the trustworthiness signaling behaviours of commercial and non-commercial wine bloggers. 


\section{Study 2}

\section{Purpose and Objectives of Study 2}

Examination of trustworthiness signaling behaviours of bloggers, while valuable in itself, can offer only limited insight into the determinants of trustworthiness assessments and trust intentions in the blogosphere because the perspective of blog readers is not included in it. Since communicator trustworthiness is an important information need for blog readers (Grant, Clarke, and Kyriazis, 2007) and trust is bestowed in a blogger by blog readers, it is necessary to assess trust antecedents from the perspective of blog readers. Trust antecedents in the blogosphere include trust-building blog-reading outcomes and the roots of these outcomes as assessed from the blog reader perspective. The purpose of study 2 is to identify a comprehensive set of trust antecedents for the blogosphere and to map the interconnections between the antecedents in order to. achieve understanding of the overall trust development process in the blogosphere.

The objectives of study 2 are:

1. to identify trust-building blog-reading outcomes, since it has been found that consumers seek information in order to learn about products and to make satisfying decisions regarding them (Bloch, Sherrell, and Ridgway, 1986;

Schlosser, White, and Lloyd, 2006) but that blog readers also look for affective exchange, entertainment, and other outcomes from their blog-reading experiences (Huang, Chou, and Lin, 2008);

2. to identify the generalizability to the blogosphere of key findings reported in online trust research (e.g., Bart et al., 2005; Chen and Dibb, 2010; Lee and Turban, 2001; Richard et al., 2010; Schlosser, White, and Lloyd, 2006); 
3. to identify trust-building blog characteristics, although blog features are available to all bloggers through blog hosting services (e.g., blogger.com), and research shows that claim acceptance, a behavioural trust manifestation, depends heavily on claim-recipient perceptions of communicator trustworthiness, and;

4. to address the blogger-influence research gap identified by Huffaker (2010) by ascertaining the trustworthiness dimensions and sub-dimensions that influence trust intentions in the blogosphere. Specific questions concern the respective values of authoritative knowledge, engagement knowledge, and character in the blogosphere.

\section{Overview of Study 2 Methodology}

Study 2 employs a survey-based methodology to examine the belief- and experience-based determinants of trust in the blogosphere among blog readers. Whereas study 1 examines the trustworthiness signaling behaviours of bloggers, study 2 examines how blog readers perceive these behaviours and other characteristics of bloggers and blogs in terms of their contribution to blog-reading outcomes and to the trustdevelopment process. Survey respondents included people with varying levels of prior personal blog experience, but to enhance the validity and overall knowledge contribution of the study findings as well as the usefulness of the study findings to bloggers, all respondents used in this study are engaged blog readers.

The results of study 2 offer valuable evidence concerning the trust-building importance of different dimensions of trustworthiness in the blogosphere. Whereas study 
1 casts light on the types of trust beliefs that bloggers are observed to attempt to manipulate, study 2 tests the trust-building efficacy of these attempts. Given that trust unfolds as experience accumulates, multiple blog-reading outcomes were assessed not only for their relationships with trust intentions but also with both blogger and blog characteristics. Tests of mediation by blog-reading outcomes of the relationships between trust and blogger and blog characteristics show not only significant antecedents of trust in the blogosphere but also the process by which trust unfolds in the blogosphere for readers of topic-area blogs.

\section{Study 3}

\section{Purpose and Objectives of Study 3}

Prior research distinguishes between utility and hedonism in and deriving from product or service consumption (e.g., Hirschman and Holbrook, 1982; Overby and Lee, 2006; Sindhav and Adidam, 2012). Utilitarian consumption, or consumption that produces utilitarian value, is outcome based, task related, functional, and instrumental in nature. By contrast, hedonic consumption, or consumption that produces hedonic value, is experience based, non-task related, entertaining, and emotional in nature. Although some products and services are hedonic or utilitarian by their nature (Hanks and Matilla, 2012), movies have been identified as a consumer good that can possess both utilitarian and hedonic benefits from which consumers derive movie-watching experiences that are enjoyable (Oliver and Bartsch, 2010; Oliver and Raney, 2011). Study 3 involves examination of responses of blog readers to a movie review posted on blogs that vary on 
movie review content and blogger characteristics, including competence base and links to the movie marketer.

The trust-building potential of the authoritative knowledge versus the consumption experience of a blogger may depend on whether the blogger has critiqued the movie on the basis of its utilitarian merit or its hedonic merit. The believability of the movie review may also depend on whether the communicator discloses to blog readers any type of material connection to the organization that made or is marketing the movie. The believability of a movie review is effectively a judgment of the expected accuracy of the movie review on the basis of the credibility of the communicator and the claim it makes. Prior research has not fully examined or has produced inconsistent results with respect to the credibility implications of word-of-mouth marketing as well as authoritative knowledge and consumption experience vis-à-vis claim content.

The accuracy of a claim concerning a movie or another type of experience good (i.e., an experiential claim) cannot be personally known to recipients until they have experienced the good themselves. The discovered accuracy of the movie review is a judgment of how well the movie review matched external reality (i.e., the movie itself; Eagly, Wood, and Chaiken, 1978). Structural and bias conditions in the blogosphere make it feasible for the discovered accuracy of the movie review to fall short of complete or even expected accuracy. Although erroneous messaging in the blogosphere (i.e., "blogger error") is a realistic prospect, the occurrence of such error and its implications for blog readers, bloggers, and organizations have not been examined in prior research. 
The purpose of study 3 is to achieve a better understanding of the implications of different types of blogger-communicated trust-related information vis-à-vis different types of product claims and "blogger error." The objectives of study 3 are:

1. to identify the specific effects of blogger signals of authoritative knowledge and consumption experience as well as disclosed word-of-mouth marketing participation on blogger trustworthiness beliefs and the credibility of a hedonic-focused or utilitarian-focused movie review;

2. to identify the cognitive, affective, and conative responses of blog readers to blogger error and assess the extent to which they apply to blog readers, bloggers, and organizations. More specifically,

a. to assess how blog readers respond to error committed by a blogger believed to possess a high level of authoritative knowledge or consumption experience;

b. to assess how blog readers respond to error committed by a blogger who discloses its participation in a word-of-mouth marketing campaign;

c. to assess the negative affective outcomes of blogger error;

d. to assess how trust intentions change following blogger error;

e. to assess whether blogger error directly or indirectly causes blog readers to seek revenge for the error against both the blogger and, in the case of a product review, the maker of the product. 
Overview of Study 3 Methodology

Study 3 differs from study 2 in terms of research context, major methodological approach, and other important ways. Study 3 is a two-part experiment-based extension of the findings of the preceding studies in which participants imagined themselves as information-seeking consumers tasked with a particular consumption problem to solve. The first part of study 3 involves experimental manipulation of blogger-communicated trust-related blogger information in order to estimate their effects on consumer beliefs of blogger trustworthiness and expectations of the accuracy of a movie review written by the blogger with whom participants had no prior relationship. The blogger disseminated information about themselves as a reviewer and a review of the movie that focused on either its hedonic or utilitarian merit. Study participants evaluated the movie review in light of the experimentally manipulated signals of authoritative knowledge versus consumption experience and disclosed word-of-mouth marketing position of the blogger. Mediation tests show how ratings of blogger credibility, which are reflective of the extent to which blog readers believe the claims of a blogger, relate to specific trustworthiness beliefs which are themselves affected by the trust-related information communicated by bloggers.

The second part of study 3 focuses on the impact of error in the movie review in light of the trustworthiness beliefs and accuracy expectations that were created in the first part. Cognitive, affective, and conative responses to blogger error are measured, and tests of mediation show how the behavioural implications of blogger error unfold through the subsequent cognitive and affective responses. 


\section{Three-Study Combination}

Together, the three studies that comprise this dissertation examine trust building and trust deteriorating phenomena in the blogosphere from multiple perspectives in multiple contexts using multiple methodologies. Although every methodology has limitations, the overall combination of methodologies employed in this dissertation provides triangulated research findings that permit a fine-grained understanding of the complex phenomena occurring within the blogosphere. 


\section{CHAPTER 3: TRUST BUILDING IN WINE BLOGS: A CONTENT ANALYSIS} (STUDY 1)

\section{Introduction}

Consumers seek product information from sources they believe they can trust for accuracy to avoid making poor product choices with resulting negative financial, social, and psychological outcomes (Schlosser, White, and Lloyd, 2006). However, the experiential nature of information makes its assessment difficult, especially when the products to which the information refers are of a high experiential consumption nature. Source trustworthiness is an alternate basis for assessing information accuracy. Determining how consumers assess source trustworthiness and use such assessments as the basis for acceptance of marketplace assertions is important for information providers (Lee et al., 2005; Pollach, 2008).

Consumers can access product information through more channels and from more sources than ever before. While the interests and involvement of commercial communicators online is reflective of their financial gain, the increasing reach of noncommercial communicators is particularly noteworthy (Habel, Veale, and Lu, 2010). van Heerden et al. (2009, p. 124) has recently noted that "little research has thus far emerged as to the extent to which audiences believe what they read in blogs."

It has long been recognized that "an individual's acceptance of information and ideas is based in part on "who said it"” (Berlo, Lemert, and Mertz, 1969, p. 563). Both commercial and non-commercial bloggers must gain the trust of information-seeking consumers in order to secure them as readers and influence consumption decisions 
(Moorman, Deshpandé, and Zaltman, 1993). Both commercial and non-commercial bloggers face obstacles in consumer trustworthiness assessments. Consumers may be comfortable with the benevolence and integrity of non-commercial information sources but have concerns regarding their ability to make accurate claims. Consumers have concerns regarding the character-compromising motivations of commercial information sources. Indeed, consumers differentially associate commercial and non-commercial information sources with knowledge and reporting biases (Flanagin and Metzger, 2007; Obermiller and Spangenberg, 1998; Pollach, 2008). The general purpose of study 1 is to learn how bloggers attempt to build trust with their readers through their ability, benevolence, and integrity signaling behaviours. This study examines the explicit trustrelated arguments or cues that commercial and non-commercial bloggers use to attempt to overcome these bias obstacles to trust and information acceptance.

\section{Objectives and Structure}

It has been claimed that there is a dearth of research in online informational environments regarding the process through which trustworthy information sources come to be regarded as such (Connolly-Ahern and Broadway, 2007). The objectives of this study are to contribute to augmented knowledge in this area through a content analysis methodology to determine how commercial (C) and non-commercial (NC) wine bloggers signal their trustworthiness to readers; whether commercial orientation can account for differences in signaling approach; and to what extent balance or imbalance in trustworthiness dimension signaling by wine bloggers reflects theories regarding trust, communication, and attitude formation. 
In the sections that follow, the rationale for the choice of wine as the blog content area of focus is described. Then, a multi-level conceptualization of trustworthiness and trustworthiness signaling behaviors is presented along with a discussion of online trust assessments and theoretical arguments for expecting trustworthiness signaling behaviors to vary between $\mathrm{C}$ and $\mathrm{NC}$ bloggers. Hypotheses are presented within a theoretical framework that conceptualizes trustworthiness signaling in relation to consumer understandings of the strengths and weaknesses of $\mathrm{C}$ and $\mathrm{NC}$ communicators of product information. The research methodology is then outlined, including sampling from the blogosphere, distinguishing between $\mathrm{C}$ and $\mathrm{NC}$ blogs, and developing a typology of trustworthiness signals for the blogosphere. Results of hypothesis testing are then presented and discussed with implications for $\mathrm{C}$ and $\mathrm{NC}$ practitioners and ideas for future research.

\section{Literature Review and Hypotheses Development}

\section{Wine and Wine Blogs}

Trustworthiness is particularly critical in complex and ambiguous information situations and for information seekers unable to evaluate information accuracy. Mittal (2004) suggests that complex and ambiguous product information situations stem largely from the nature of the inherent physical attributes of the product that impact both expected and experienced product quality. For wine, the specific topic-based blog area for this study, grape variety, growing region, harvest year, age, "sensitivity," and "acuteness" of bouquet are just some of the inherent physical attributes that can impact the wine-drinking experience for consumers (Jover, Montes, and Fuentes, 2004; Perrouty, 
d'Hauteville, and Lockshin, 2006). Though wine is amenable to objective technical specification, the language used to describe wine performance characteristics is complex and directly interpretable only to consumers with wine expertise, which most do not have (Durrieu, 2005, Herdenstam et al., 2009). For typical information-seeking consumers, wine is a complex experience-based product category with high information needs and perceived risk of financial and social loss (Franke, Huhmann, and Mothersbaugh, 2004; Thach, 2010).

To avoid making loss-incurring wine choices, many consumers engage in considerable search efforts for trustworthy wine information and heed the advice of trustworthy sources of wine information (Barber, Almanza, and Donovan, 2006; Bentzen and Smith, 2008; Dewald, 2008). C and NC online wine information sources are available to information-seeking wine consumers. Blogging is a relatively recent phenomenon, but wine blogs are quickly gaining in numbers (Habel, Veale, and Lu, 2010; Thach, 2010). Online searches for the term "wine blog" generate over 44 million results. Wine review blogs outnumber any other type of wine blog (Thach, 2010). Since consumers in online information environments can easily compare and switch between service providers (Li, Browne, and Wetherby, 2007), wine bloggers will be interested in signaling their trustworthiness so their blogs attract committed readers who act on their advice.

\section{Trustworthiness Signaling in Blogs}

To ensure that blog readers read and take action on its recommendations, a blogger needs to overcome the source-receiver discrepancies (McGuire, 1973) that can 
lead readers to have suspicions either that the blogger is driven by opportunistic intent (i.e., has a reporting bias) or lacks product-related skills and knowledge (i.e., has a knowledge bias). Bloggers are generally expected to strategically transmit signals of their trustworthiness to blog readers in order to remediate any potential source-receiver discrepancy that could hinder their influence over readers. Since trustworthiness is a multi-dimensional construct, bloggers must decide what balance of trustworthiness dimension-level signals to incorporate in their blogs.

At the trustworthiness dimension level, bloggers can choose a balanced signaling approach, signaling ability and character (benevolence and integrity) equally. An unbalanced signaling approach emphasizes either one of ability or character more than the other and can be conceptualized vis-à-vis socialized consumer presumptions of the trustworthiness strengths and weaknesses of different communicator types. Resourcebased (RBV) and compensatory signaling approaches are the unbalanced methods considered in this research. A resource-based unbalanced signaling approach emphasizes the trustworthiness dimension that consumers view the source as having and, therefore, is employed to capitalize on positive a priori beliefs about the communicator. In contrast, a compensatory signaling approach involves using signals to remediate negative a priori trustworthiness beliefs about what the communicator lacks (i.e., source-receiver discrepancies). On an a priori basis, $\mathrm{C}$ and $\mathrm{NC}$ communicators are perceived differentially on the ability, benevolence, and integrity trustworthiness dimensions and, as a consequence, they may choose to emphasize dimensions of their own trustworthiness differentially. As a result, a resource-based signaling approach by one type of wine blogger could amount to a compensative signaling approach by the other. 


\section{Signaling Approaches}

Research and theory suggest several different signaling approaches by bloggers. Online trust research shows considerable support for perceived ability as the basis for trustee success in on-line environments. If ability signals are viewed as most determinant of information use, the following trustworthiness dimension-level hypotheses are proposed:

H1: Both (a) C and (b) NC bloggers will signal ability more than character (both benevolence and integrity).

$\mathrm{Hla}$ and $\mathrm{H} 1 \mathrm{~b}$ both presume ability signals to predominate, but differ in their assumptions regarding the signaling approaches of $\mathrm{C}$ and $\mathrm{NC}$ bloggers. Support for $\mathrm{Hla}$ would indicate reliance of $\mathrm{C}$ bloggers on emphasizing ability signals, reflective of an RBV approach. Support for $\mathrm{H} 1 \mathrm{~b}$ would indicate a compensatory signaling approach by NC bloggers designed to compensate for possible knowledge bias concerns.

Ability can be acquired and communicated in a number of different ways, as discussed earlier. Endogenous sources of ability are the product-related authoritative knowledge and product-related consumption experience possessed by wine bloggers. An exogenous source of ability is the structural social capital of wine bloggers. From a resource-based perspective, $C$ bloggers can emphasize their product-related authoritative knowledge developed through advanced training and deep involvement in the production and marketing of wines and verified by awards and testimonials. In contrast, NC bloggers 
acquire their abilities mainly from their consumption experiences (traveling to wine districts, touring wineries, and tasting wines), social network ties, and verified through external recognition of their abilities, such as receiving awards, being chosen for expertise by media or as a wine judge. Since both $\mathrm{C}$ and NC bloggers have some obvious legitimate bases for claims of abilities, it is expected that both will leverage these different bases using a resource-based approach. In accordance with this resource-based perspective:

H2: $\quad$ C and NC bloggers will differ in the bases for claims of ability with:

(a) C bloggers emphasizing authority-based cues (work experience, training and testimonials) over usage experience and social networks ties, and

(b) NC bloggers emphasizing cues regarding usage experience and social network ties over authority (work experience, training, and testimonials).

Regarding the character dimension, benevolence (dealing with concern and empathy for the other involved in the relationship) and integrity (honesty, freedom-frombias, values-based actions) are distinguished in the literature as necessary for trusting relationships with no evidence regarding preference for either type of character-based trustworthiness. Thus, there is no reason to expect either type of blogger to signal either benevolence over integrity or vice versa.

H3: $\quad$ NC and C bloggers will signal character dimensions at the same rate. 
However, benevolence and integrity have different sources and source-based cue signals. Benevolence is difficult to discern directly and is assessable less by its presence than by its absence, i.e., trustee actions not in trustors' interests. Both $\mathrm{C}$ and NC bloggers can claim general benevolence because there is little opportunity to assess benevolence in action. With regards to blog-related benevolence, readers can be expected to view NC bloggers' reasons for writing as more altruistic than exploitative. However, bloggingrelated benevolence claims of $\mathrm{C}$ bloggers would be harder to substantiate because of their commercial interests, leading to the following hypotheses:

H4: $\quad$ NC bloggers will be more likely than C bloggers to use benevolence-based cues.

H5: C and NC bloggers will differ in the bases for claims of benevolence with:

(a) NC bloggers using more blogger-related than generalized, personal benevolence cues, and

(b) C bloggers using more generalized, personal than blogger-related benevolence cues.

Some integrity claims are verifiable, e.g., claims that can be proven to be true or untrue, and some are not, e.g., claims based on non-observable personal values. However, freedom-from-bias integrity claims are dubious in conflict-of-interest situations, e.g., for $\mathrm{C}$ bloggers with potential for financial gain. Thus, $\mathrm{NC}$ bloggers have a unique resource base for integrity claims and can be expected to use it for advantage: 
H6: $\quad$ NC bloggers will use more integrity-based cues than C bloggers.

Since C bloggers are inherently disadvantaged on topic-related integrity claims, they may attempt to compensate by making more generalized claims of integrity which are not verifiable. Topic-related freedom-from-bias is inherent to $\mathrm{NC}$ bloggers and is a claim that can be invoked as a resource in integrity cues.

H7: $\quad C$ and NC bloggers will differ in the bases for claims of integrity with:

(a) C bloggers using more cues of general integrity, and

(b) NC bloggers using more cues of specific integrity claims of freedom-frombias.

\section{Methodology}

To assess trustworthiness signals in wine blogs, a content analysis of wine blogs was carried out. Content analysis is a well-established technique for objectively, systematically, and quantitatively studying communications content (Kolbe and Burnett, 1991; Neuendorf, 2002; Pavlou and Dimoka, 2006). One hundred and seventy-five wine blogs were analyzed over two stages using methodological practices for drawing inferences from unstructured data.

The first stage was designed to initially profile the communication of trustworthiness signals in a sample of fifty wine blogs in order to confirm the workability of the trust cue signaling measurement methodology and to provide an initial test of the 
dimension-level hypotheses. Stage 2 involved analysis of one hundred and twenty-five additional wine blogs to build upon Stage 1 results and test all hypotheses.

\section{Blog Selection and Categorization}

\section{Selection.}

Content analysis of websites generally and blogs specifically has many challenges, including the unavailability of exhaustive and up-to-date sampling frames ( $\mathrm{Li}$ and Walejko, 2008; McMillan, 2000; Schmidt, 2007). To construct a comprehensive sampling frame, several lists of wine blogs were obtained, integrated, and purged of duplicates, as recommended when the population of interest is not well organized and particularly for studies such as the present one (Cowan, 1991; Li and Walejko, 2008). An overall sampling frame of 687 unique wine blogs was developed.

The sampling frame was then reviewed for currency and relevancy to ensure that all blogs featured wine-related content, had been updated in the last month, and were properly functioning and available in English. A sample of 175 blogs was deemed of suitable size for the two stages of the study. A systematic probability sampling approach was used to select blogs for inspection for currency and relevancy from the sampling frame until the requisite number of 175 blogs was identified.

\section{Categorization.}

The selected blogs were classified as either commercial or non-commercial (C/NC) by two independent coders, with unclear or conflicting assignment blogs being discarded. Commercial interests are revealed in several ways in blogs, e.g., inclusion of 
commercial logos and imagery, statements of commercial affiliation, the location of the blog (e.g., embedded in a winery website), and even in the internet address. $\mathrm{C}$ wine bloggers are usually wineries and wine retailers or occasionally, representatives of a particular wine region with evidence of commercial gain. Unless they noted some specific brand affiliation, professional sommelier bloggers were coded as NC because, typically, they are not concerned with promoting specific wine brands.

Applying the definitional dichotomy, eighty-four (Stage 1: 28; Stage 2: 56; total $48 \%$ ) of the 175 wine blogs were coded as having a C orientation. Ninety-one (Stage 1: 22; Stage 2: 69 ; total $52 \%$ ) of the wine blogs, comprised mainly of wine consumers and infomediaries, were coded as having a NC orientation.

\section{Development of trustworthiness dimension typology of blog signals.}

In general, trustworthiness is primarily operationalized as a latent variable assessed from a trustor perspective. While researchers have identified several antecedents of online trust (Schlosser, White, and Lloyd, 2006), signals of the ability, benevolence, and integrity of online information sources have not been examined in published research. Communication content indicating product-related authoritative knowledge, consumption experience, or structural social capital of a wine blogger is a signal of blogger ability. Blogger benevolence refers to the extent to which a wine blogger is willing to help or has a history of helping readers and/or displays or is otherwise known for general (domain unspecific) conscientiousness. Blogger integrity is operationalized in terms of the values and principles of a wine blogger that ensure writing is open, honest, and free of bias. 
Research regarding perceived trustworthiness in online environments may benefit from a more context-grounded approach to identifying signals that online communicators use to persuade others of their trustworthiness beyond functional website features, privacy policies, and security measures. Signal categories from trust research in the online and offline domains provided the initial framework for developing measurable trustworthiness signals embedded in blogs, but amendments were made in an iterative fashion in order to accommodate the unique nature of the blogosphere. A broad selection of wine blogs was reviewed to ensure the domain relevance and content validity of the operational definitions and signal categories derived from existing trust research (Neuendorf, 2002).

Since consumers assess trustworthiness in the online domain relatively quickly and using only a small amount of information (Pavlou and Dimoka, 2006), the decision was made to assess signals observed on the main page (header and sidebar areas) and the "author profile" page (all content), as was the approach used in related research (Ha and James, 1998). These two areas are the main entry points for readers and are changed infrequently offering readers a relatively stable basis for blogger trustworthiness assessment. The richness of blogs offers bloggers several text- and graphics-based ways to evidence author trustworthiness. In addition to a blogger's own assertions, evidence of trustworthiness can be found in the forms of awards, third-party testimonials, and links to domain-related material created by the blogger and to other important individuals, institutions, or online resources.

Identified cues were discussed with other researchers in the area for face validity as a signal and were classified to a dimension or sub-dimension of trustworthiness. As a 
further validity check, 49 graduate and undergraduate business students were given a large sample of prototypical trustworthiness signals and asked to classify each into one of the trustworthiness dimensions and/or sub-dimensions. At the dimension level, average agreement between conceptual and operational definitions was $75.1 \%$ for ability, $55.6 \%$ for benevolence, and $71.2 \%$ for integrity. When benevolence and integrity signals were allowed to form a single "character" dimension of trustworthiness (Ridings, Gefen, and Arinze, 2002), very strong signal-dimension agreement (benevolence: $80.1 \%$; integrity: $79 \%$ ) and evidence of the distinctiveness of character signals was found. Any signal type that displayed weak dimension-level agreement (agreement $<70 \%$ ) or was frequently "cross-assigned" was considered for removal from the study. Based on inter-subject reliability measures commonly used in research, these results provide reasonable support for the indicator-to-construct classification system used for the first stage research. The final classification can be seen in Table 3.1, which also serves to provide a listing of subdimensions. Specific coding instructions are provided in Appendix 3.1.

With initial support for the signal classification scheme validity, two independent coders received training on its use in examining a sample of wine blogs. Identified differences in signal coding were discussed through several rounds to ensure an acceptable level of inter-coder reliability. Recent research examining inter-rater reliability has used a cut-off agreement level of 70\% (Pavlou and Dimoka, 2006), but there is an understanding that inter-rater reliability assessments based on "manifest content" are likely to be stronger than those based on "latent content" (Neuendorf, 2002), such as is the focus of this study. 
Table 3.1: Signals of Trustworthiness Sub-Dimensions

\begin{tabular}{|l|l|}
\hline \multicolumn{1}{|c|}{ Ability } & Character \\
\hline Product-related authoritative knowledge & Benevolence \\
\hline Formal wine education & Benevolence as blogger \\
\hline Informal wine education (wine training) & Benevolence as person/organization \\
\hline $\begin{array}{l}\text { Awards and references for wine making and } \\
\text { wine making knowledge }\end{array}$ & General/other benevolence signals \\
\hline Awards and references for writing about wine & Integrity \\
\hline Dedication to making/selling wine & Values of blogger \\
\hline Dedication to writing about wine & Freedom-from-bias \\
\hline Work experience as wine producer/seller & General/other integrity signals \\
\hline Work experience as wine writer & \\
\hline General knowledge, education, intelligence & \\
\hline Product-related consumption experience & \\
\hline $\begin{array}{l}\text { Non-consumption related dedication } \\
\text { (Touring wineries; travelling to wine regions) }\end{array}$ & \\
\hline Longstanding wine consumer & \\
\hline Frequent current wine consumption & \\
\hline Structural social capital & \\
\hline Access to expert information sources & \\
\hline Institutional relationships & \\
\hline
\end{tabular}

Inter-rater reliability calculations were performed using the initial two-thirds of the wine blogs examined, in line with recent content-analytic research on e-commerce trends in wine marketing which based reliability calculations on a data subset (Zhu, Basal, and Hunter, 2009). At the dimension level, inter-rater reliabilities were highly acceptable at $82 \%$ for ability, $92 \%$ for benevolence, and $89 \%$ for integrity. At the subdimension level, reliability was somewhat lower. For example, by operationalizing ability in terms of (1) product-related authoritative knowledge, (2) product-related consumption experience, and (3) structural social capital, reliability ranged from $64 \%$ to $100 \%$, which still indicates good agreement. At the item level, inter-rater reliability ranged from $50 \%$ to $100 \%$, which is not unexpected given the myriad ways in which ability can be signaled (education, work experience, training, product usage, awards and recognition). Similarly, item-level reliability for integrity ranged from $44 \%$ to $100 \%$; integrity, like ability, can be 
communicated in different ways, and judges sometimes differed in their assessments of whether a signal indicated, for example, honesty or sincerity. The lowest item-level reliability for benevolence was $81 \%$, suggesting the distinctiveness and relative unidimensionality of the benevolence dimension. Krippendorf (2009, p. 355) argues that "when some distinctions are unimportant and subsequently ignored for analytical reasons - for example, by lumping several categories into one - reliability should be tested not on the original but on the transformed data." Given the lower reliability of item-level classifications found in this study, sub-dimensional level classification is the lowest level of disaggregation used in the study.

To assess test-retest reliability, a random sample of $20 \%$ wine blogs was reexamined and reliability statistics for ability (91.7\%), benevolence (100\%), and integrity $(88.9 \%)$ were found. All are well above the $80 \%$ standard used by Peterson (2007) and others.

\section{Results}

\section{Stage 1 - Pilot Study of Wine Blog Trustworthiness Signaling}

To ensure methodology workability and to facilitate hypothesis testing, an initial group of fifty blogs was drawn randomly from the 175 wine blog sample. Each blog was classified as either $\mathrm{C}$ or NC, and signals of trustworthiness were identified and coded by two coders as described above. The twenty-eight ( $56 \%$ of the sample) wine blogs classified as $\mathrm{C}$ blogs communicated 128 ability, 35 benevolence, and 29 integrity signals; the twenty-two (44\%) NC wine blogs transmitted 98 ability, 20 benevolence, and 13 integrity signals. The $\mathrm{C}$ and $\mathrm{NC}$ wine blogs communicated an average of 6.86 and 5.95 
trustworthiness signals respectively, which is not significantly different $(|t|(48)=1.02, p$ $>$.1). Table 3.2 presents dimension-level trustworthiness signaling data for this sample. Given the relatively small number of blogs under study, only $\mathrm{H} 1$ and $\mathrm{H} 3$ involving dimension-level trustworthiness signaling were tested.

Table 3.2: Stage One - Dimension-Level Trustworthiness Signals of Commercial and Non-Commercial Bloggers

\begin{tabular}{|l|c|c|c|c|}
\hline Blogger type & Ability & Benevolence & Integrity & Total \\
\hline Commercial & 128 & 35 & 29 & 192 \\
$(\mathrm{~N}=28)$ & $(M=4.57$, & $(M=1.25$, & $(M=1.04$, & $(M=6.86$, \\
& $S . D .=1.97)$ & $S . D .=1.14)$ & $S . D .=1.1)$ & S.D. $=2.34)$ \\
\hline Non-commercial & 98 & 20 & 13 & 131 \\
$(\mathrm{~N}=22)$ & $(M=4.45$, & $(M=.91$, & $(M=.59$, & $(M=5.95$, \\
& $S . D .=2.63)$ & $S . D .=1.34)$ & $S . D .=.91)$ & $S . D .=3.89)$ \\
\hline Total & 226 & 55 & 42 & 323 \\
$(\mathrm{~N}=50)$ & $(M=4.42$, & $(M=1.1$, & $(M=.84$, & $(M=6.46$, \\
& $S . D .=2.26)$ & $S . D .=1.23)$ & $S . D .=1.04)$ & $S . D .=3.12)$ \\
\hline
\end{tabular}

Note: Information in cells indicates total number of signals of this type across all blogs. Mean $(M)$ and standard deviation (S.D.)

$\AA^{2}(2)=2.75, p>.1$.

No significant difference between $\mathrm{C}$ and $\mathrm{NC}$ wine bloggers in the distribution of dimensional level trustworthiness signaling behaviours was observed $\left(X^{2}(2)=2.75, p>\right.$ .1). Wine bloggers of both types emphasize ability over each of benevolence and integrity $(|t|(49)=9.71$ and 12.43 , respectively) and both combined $(|t|(49)=7.95, p<.001)$ providing support for $\mathrm{H1}$. C and NC wine bloggers both communicate ability more than four times more frequently than benevolence and more than five times more frequently than integrity, suggesting a shared recognition of the role of ability as the primary trustworthiness assessment dimension. However, NC bloggers used relatively more ability signals than $\mathrm{C}$ bloggers, suggesting they are aware of perceptions of their ability weaknesses and are trying to compensate for this perceived deficiency. Finally, the 
analysis indicated benevolence and integrity are communicated at similar frequencies $(|t|(49)=1.1, p>.1)$, providing initial support for $\mathrm{H} 3$.

The pilot study analysis confirmed the workability of the methodological approach in identifying and classifying wine blog signals and comparing across trustworthiness dimensions and blogger types. It also provided initial support for dimension level similarity and differences across blogger types.

\section{Stage 2 - Main Study of Wine Blog Trustworthiness Signaling}

With verification of the signal classification scheme, Stage 2 of the study could proceed to examine a larger sample of 125 blogs, testing all the hypotheses on both the dimension and sub-dimension levels. The fifty-six ( $45 \%$ of the sample) wine blogs classified as $\mathrm{C}$ blogs communicated 213 ability, 52 benevolence, and 30 integrity signals; the sixty-nine (55\%) NC wine blogs transmitted 261 ability, 53 benevolence, and 71 integrity signals. The $\mathrm{C}$ and $\mathrm{NC}$ wine blogs communicated an average of 5.27 and 5.58 trustworthiness signals respectively, which is not significantly different $(|t|(123)=.55, p$ $>$.1). Table 3.3 presents dimension-level trustworthiness signaling data for this sample.

As in Stage 1, dimension-level analysis of the sample of 125 wine blogs found ability signals greatly outnumber those of benevolence $(|t|(124)=13.13, p<.001)$ integrity $(|t|(124)=14.63, p<.001)$, and overall character $(|t|(124)=9.48, p<.001)$. No significant difference was found between $\mathrm{C}$ and NC wine bloggers in use of ability vs. character signals $\left(X^{2}(1)=1.54, p>.1\right)$, confirming $\mathrm{H} 1$.

Table 3.3: Stage Two - Dimension-Level Trustworthiness Signals of Commercial and Non-Commercial Bloggers 


\begin{tabular}{|l|c|c|c|c|}
\hline Blogger type & Ability & Benevolence & Integrity & Total \\
\hline Commercial & 213 & 52 & 30 & 295 \\
$(\mathrm{~N}=56)$ & $(M=3.80$, & $(M=0.93$, & $(M=0.54$, & $(M=5.27$, \\
& $S . D=2.45)$ & $S . D .=1.08)$ & $S . D .=0.87)$ & $S . D .=3.09)$ \\
\hline Non-commercial & 261 & 53 & 71 & 385 \\
$(\mathrm{~N}=69)$ & $(M=3.78$, & $(M=0.77$, & $(M=1.03$, & $(M=5.58$, \\
& $S . D=2.29)$ & $S . D .=0.84)$ & $S . D=1.18)$ & $S . D .=3.15)$ \\
\hline Total & 474 & 105 & 101 & 680 \\
$(\mathrm{~N}=125)$ & $(M=3.79$, & $(M=0.84$, & $(M=0.81$, & $(M=5.44$, \\
& $S . D .=2.35)$ & $S . D .=0.95)$ & $S . D .=1.08)$ & $S . D .=3.11)$ \\
\hline
\end{tabular}

Note: Information in cells indicates total number of signals of this type across all blogs. Mean $(M)$ and standard deviation (S.D.)

$X^{2}(2)=9.77, p<.01$.

Table 3.4 shows the results indicating support for H1a and $\mathrm{b}$ using paired t-tests.

$\mathrm{C}$ wine bloggers signal ability far more frequently than each of benevolence $(|t|(55)=$

$8.02, p<.001)$, integrity $(|t|(55)=10.36, p<.001)$, and overall character $(|t|(55)=6.5, p$

$<.001$ ), indicating a resource-based signaling approach is used. NC wine bloggers were

also found to signal ability far more frequently than each of benevolence $(|t|(68)=10.5, p$

$<.001)$, integrity $(|t|(68)=10.43, p<.001)$, and overall character $(|t|(68)=6.91, p<$

.001 ), suggesting a compensatory signaling approach at the overall dimension level. In

summary, at the dimension level both types of wine bloggers appear to recognize readers

are most interested in their ability levels and consequently communicate trustworthiness

in an asymmetrical, ability-dominant fashion. Nevertheless, a comparison of blogger

types across all dimensions found significant differences in signaling of trustworthiness

$\left(X^{2}(2)=9.77, p<.01\right)$. Next, the heterogeneity of ability signaling at the sub-dimensional

level is considered.

Table 3.4: Paired Comparison Tests of Dimension Signaling Patterns of Bloggers 


\begin{tabular}{|c|c|c|}
\hline . & Commercial bloggers & Non-commercial bloggers \\
\hline Benevolence & $\begin{array}{c}M_{\text {diff }}=2.88, S . D .=2.68 \\
t_{(55)}=8.02^{*}\end{array}$ & $\begin{array}{c}M=3.01, \text { S.D. }=2.39 \\
\mathrm{t}_{(68)}=10.5^{*}\end{array}$ \\
\hline Integrity. & $\begin{array}{c}M=3.38, S . D .=2.44 \\
\mathrm{t}_{(S 5)}=10.36^{*}\end{array}$ & $\begin{array}{c}M=2.75, S . D .=2.19 \\
\mathrm{t}_{(68)}=10.43^{*}\end{array}$ \\
\hline $\begin{array}{l}\text { Character } \\
\text { (Benevolence and integrity) }\end{array}$ & $\begin{array}{c}M=2.45, S . D .=2.82 \\
t_{(55)}=6.5^{*}\end{array}$ & $\begin{array}{c}M=1.99, S . D .=2.39 \\
\mathrm{t}_{(68)}=6.91^{*}\end{array}$ \\
\hline
\end{tabular}

Note: Information in cells indicates mean differences between signal types indicated in the column vs. row with paired t-test results of comparison of means reported in Table 3.3.

${ }^{*} p<.001$.

Ability Cue Signals: Sub-dimensional ability signaling data was examined to test $\mathrm{H} 2 \mathrm{a}$ and $\mathrm{b}$ regarding differences between blogger types on signaling of sources of abilities. Table 3.5 results indicate ability sub-dimension signal level differences across all levels of aggregation - individual ability signal types $\left(X^{2}(13)=190.61, p<.001\right)$, and authoritative knowledge vs. consumption experience vs. structural social capital $\left(X^{2}(2)=\right.$ $15.34, p<.001)$. The largest discrepancies in authority-based ability signaling is $\mathrm{C}$ bloggers' greater use of references to awards for winemaking and knowledge of winemaking $(|t|(123)=4.53, p<.001)$, and dedication to $(|t|(123)=6.6, p<.001)$ and work experience in making wine $(|t|(123)=6.39,<.001)$, and by NC bloggers of dedication to $(|t|(123)=4.22, p<.001)$ and work experience in writing about wine $(|t|(123)=2.32, p<.05)$.

$\mathrm{NC}$ bloggers give much greater emphasis to general knowledge and to nonauthority based signals of ability, structural social capital, and consumption experiencebased abilities. Product-related consumption experience is signaled with greater frequency by $\mathrm{NC}$ wine bloggers $(|t|(123)=2.59, p<.05)$. The odds that a NC wine blogger will signal ability through structural social capital are 1.63 times that of a commercial wine blogger. The specific driver of this difference is signaling of access to 
other expert information sources (personal relationships, use of guest writers) which NC wine bloggers evidenced to a slightly greater extent than $C$ wine bloggers $(|t|(123)=$ $1.79, p<.1)$

Table 3.5: Ability Signals by Blogger Commercial Orientation

\begin{tabular}{|c|c|c|c|c|c|c|}
\hline \multirow[t]{2}{*}{ Ability sub-dimensions } & \multicolumn{2}{|c|}{$\begin{array}{l}\text { Commercial } \\
\qquad(\mathbf{N}=56)\end{array}$} & \multicolumn{2}{|c|}{$\begin{array}{c}\text { Non- } \\
\text { commercial } \\
(N=69)\end{array}$} & \multicolumn{2}{|c|}{$\begin{array}{l}\text { All wine } \\
\text { bloggers } \\
(\mathrm{N}=125)\end{array}$} \\
\hline & $\mathbf{n}$ & $\%$ & $\mathbf{n}$ & $\%$ & n & $\%$ \\
\hline \multicolumn{7}{|l|}{ Product-related authoritative knowledge } \\
\hline Formal wine education & 24 & 13.56 & 29 & 16.48 & 53 & 15.01 \\
\hline Informal wine education (wine training) & 5 & 2.82 & 2 & 1.14 & 7 & 1.98 \\
\hline $\begin{array}{l}\text { Awards and references for wine making and } \\
\text { wine making knowledge }\end{array}$ & 19 & 10.73 & 1 & 0.57 & 20 & 5.66 \\
\hline Awards and references for writing about wine & 17 & 9.60 & 19 & 10.80 & 36 & 10.20 \\
\hline Dedication to making/selling wine & 27 & 15.25 & 2 & 1.14 & 29 & 8.21 \\
\hline Dedication to writing about wine & 4 & 2.26 & 26 & 14.78 & 30 & 8.49 \\
\hline Work experience as wine producer/seller & 34 & 19.21 & 9 & 5.11 & 43 & 12.18 \\
\hline Work experience as wine writer & 8 & 4.52 & 22 & 12.50 & 30 & 8.49 \\
\hline General knowledge, education, intelligence & 39 & 22.03 & 66 & 37.50 & 105 & 29.74 \\
\hline Total sub-dimension level signals & 177 & $100 \%$ & 176 & $100 \%$ & 353 & $100 \%$ \\
\hline \multicolumn{7}{|l|}{ Product-related consumption experience } \\
\hline $\begin{array}{l}\text { Non-consumption related dedication } \\
\text { (Touring wineries; travelling to wine regions) }\end{array}$ & 13 & 50.00 & 26 & 40.00 & 39 & 42.86 \\
\hline Longstanding wine consumer & 5 & 19.23 & 12 & 18.46 & 17 & 18.68 \\
\hline Frequent current wine consumption & 8 & 30.77 & 27 & 41.54 & 35 & 38.46 \\
\hline Total sub-dimension level signals & 26 & $100 \%$ & 65 & $100 \%$ & 91 & $100 \%$ \\
\hline \multicolumn{7}{|l|}{ Structural social capital } \\
\hline Access to expert information sources & 4 & 40 & 13 & 65 & 17 & 56.67 \\
\hline Institutional relationships & 6 & 60 & 7 & 35 & 13 & 43.33 \\
\hline Total sub-dimension level signals & 10 & $100 \%$ & 20 & $100 \%$ & 30 & $100 \%$ \\
\hline Total dimension-level signals & 213 & $100 \%$ & 261 & $100 \%$ & 474 & $100 \%$ \\
\hline
\end{tabular}

Note: Information in cells indicates total number of signals of this type for this blogger type.

$X^{2}(13)$ comparing blogger type for all sub-types of 3 categories of ability signals $=190.61, p<.001$.

$X^{2}(2)$ comparing blogger type for total levels of 3 categories of all ability signals $=15.34, p<.001$. 
Table 3.6 results clearly indicate a greater probability that $\mathrm{C}$ wine bloggers will communicate authority ability more than consumption experience ability, whereas NC bloggers use more balance in signaling authority and consumer experience. Through various approaches to analyzing ability signalling, there is considerable support for $\mathrm{H} 2 \mathrm{a}$ and $b$.

Table 3.6: Authority Signals as a Proportion of Total Ability Signals

\begin{tabular}{|c|c|c|c|c|c|}
\hline \multirow[b]{2}{*}{ Blogger types } & \multicolumn{3}{|c|}{ Counts } & \multirow{2}{*}{$\begin{array}{l}\text { Authority signals } \\
\text { as a proportion } \\
\text { of total } \\
\text { ability signals }\end{array}$} & \multirow[b]{2}{*}{$z$} \\
\hline & \begin{tabular}{|c|}
$\begin{array}{c}\text { Product-related } \\
\text { authoritative } \\
\text { knowledge }\end{array}$ \\
\end{tabular} & \begin{tabular}{|c|}
$\begin{array}{c}\text { Product-related } \\
\text { consumption } \\
\text { experience }\end{array}$ \\
\end{tabular} & $\begin{array}{c}\text { Structural } \\
\text { social capital }\end{array}$ & & \\
\hline $\begin{array}{l}\text { Commercial } \\
(\mathrm{N}=56)\end{array}$ & 177 & 26 & 10 & $177 / 213=0.831$ & $4.94^{*}$ \\
\hline $\begin{array}{l}\text { Non- } \\
\text { commercial } \\
(\mathrm{N}=69)\end{array}$ & 176 & 65 & 20 & $176 / 261=0.674$ & $2.90^{*}$ \\
\hline
\end{tabular}

Note: Information in cells indicates total number of signals of this type for this blogger type.

${ }^{*} p<.01$.

Character Cue Signals: $\mathrm{H} 3$ through $\mathrm{H} 7$ examine various aspects of signaling of the two character-based dimensions of trustworthiness, integrity and benevolence. These hypotheses are assessed by results shown in Table 3.7. Regarding overall character signalling, no significant difference was found in the frequencies at which $\mathrm{C}$ and $\mathrm{NC}$ wine bloggers communicate overall character $(|t|(123)=1.53, p>.1)$, so H3 is accepted. However, a chi-square analysis of character signals found a highly significant value $\left(X^{2}(5)=44.16, p<.001\right)$, indicating blogger type differences in how character is signalled. $\mathrm{C}$ and $\mathrm{NC}$ bloggers use benevolence signals at about the same level $(\mathrm{t}(123)=$ $.94, p>.1)$, leading to rejection of $\mathrm{H} 4$, but use integrity signals differently $(|t|(123)=$ $2.61, p<.01)$. NC bloggers communicate integrity more frequently than $\mathrm{C}$ bloggers - 
$57 \%$ of all character signaling by NC bloggers emphasized integrity, compared to only

$36 \%$ by $\mathrm{C}$ bloggers - supporting $\mathrm{H} 6$.

Table 3.7: Character Signals by Blogger Commercial Orientation

\begin{tabular}{|l|c|c|c|c|l|}
\hline Character signals & \multicolumn{2}{|c|}{$\begin{array}{c}\text { Commercial } \\
(\mathbf{N = 5 6}\end{array}$} & \multicolumn{2}{c|}{$\begin{array}{c}\text { Non-commercial } \\
(\mathbf{N = 6 9})\end{array}$} & $\begin{array}{l}\text { t-tests } \\
(\mathbf{C}-\mathbf{N C})\end{array}$ \\
\hline Benevolence & $\mathbf{n}$ & $\mathbf{\%}$ & $\mathbf{n}$ & $\mathbf{\%}$ & \\
\hline Benevolence as blogger & 25 & 48.08 & 39 & 73.58 & $\mathrm{t}(123)=-0.99, p>.1$ \\
\hline $\begin{array}{l}\text { Benevolence as } \\
\text { person/organization }\end{array}$ & 25 & 48.08 & 3 & 5.66 & $\mathrm{t}(123)=4.34, p<.001$ \\
\hline $\begin{array}{l}\text { General/other benevolence } \\
\text { signals }\end{array}$ & 2 & 3.85 & 11 & 20.75 & $\mathrm{t}(123)=1.33, p>.1$ \\
\hline Total benevolence signals & 52 & $100 \%$ & 53 & $100 \%$ & $\mathrm{t}(123)=0.94, p>.1$ \\
\hline & & & & & \\
\hline Integrity & 16 & 53.33 & 40 & 56.34 & $\mathrm{t}(123)=-1.92, p<.1$ \\
\hline Values of blogger & 3 & 10.00 & 19 & 26.76 & $\mathrm{t}(123)=-2.55, p<.05$ \\
\hline Freedom-from-bias & 11 & 36.67 & 12 & 16.90 & $\mathrm{t}(123)=.12, p>.1$ \\
\hline $\begin{array}{l}\text { General/other integrity } \\
\text { signals }\end{array}$ & 30 & $100 \%$ & 71 & $100 \%$ & $\mathrm{t}(123)=-2.61, p<.01$ \\
\hline Total integrity signals & & & & & \\
\hline & 82 & $100 \%$ & 124 & $100 \%$ & $\mathrm{t}(123)=-1.53, p>.1$ \\
\hline Total Character signals & & & & & \\
\hline
\end{tabular}

$X^{2}(5)$ comparing blogger type for all types of character signals $=44.16, p<.001$

$X^{2}(2)$ comparing blogger type for benevolence signals $=40.93, p<.001$

$X^{2}(2)$ comparing blogger type for integrity signals $=6.42, p<.05$

While the frequency of benevolence signaling by $\mathrm{C}$ and $\mathrm{NC}$ bloggers was comparable, signal content differences are apparent $\left(X^{2}(2)=40.93, p<.001\right)$. NC bloggers were much more likely to use signals of blogger benevolence and other general benevolence signals (for example, a blogger requests readers donate to charities) than personal benevolence, whereas $\mathrm{C}$ bloggers were equally likely to make claims of benevolence of themselves as bloggers and as a person/organization. This finding leads to acceptance of $\mathrm{H} 5 \mathrm{a}$ and $\mathrm{b}$.

A difference was also found for integrity sub-dimension signals $\left(X^{2}(2)=6.42, p<\right.$ .05). While both blogger types were equally likely to make general claims of integrity 
$(|t|(123)=.12, p>.1), \mathrm{NC}$ bloggers showed a marginally higher tendency to reference their values and principles as a basis of integrity $(|t|(123)=1.92, p<.1)$, leading to rejection of $\mathrm{H7a}$. NC bloggers made much more frequent reference to their freedomfrom-bias, a resource-based claim not easily made by $\mathrm{C}$ bloggers, who rarely did so $(|t|(123)=2.55, p<.05)$. This finding lends support to H7b. These results suggest an RBV signaling approach. Integrity is a character dimension on which $\mathrm{C}$ bloggers can be expected to have weaknesses, but they did not appear to try to compensate for such weaknesses and made such claims less than half as often as NC bloggers.

In summary, Stage 2 analyses confirm that ability signals predominate in trustworthiness persuasion attempts within the wine blogosphere and for both $\mathrm{C}$ and $\mathrm{NC}$ bloggers, providing support for H1. However, the overall distribution of dimension-level trustworthiness signaling behaviours differs according to commercial orientation. At the ability sub-dimension level, $\mathrm{C}$ bloggers were found to emphasize their product-related authoritative knowledge over product-related consumption experience and structural social capital in support of $\mathrm{H} 2 \mathrm{a}$, and the opposite pattern for $\mathrm{NC}$ bloggers was found supporting $\mathrm{H} 2 \mathrm{~b}$.

$\mathrm{H} 3$ predicting $\mathrm{C}$ and $\mathrm{NC}$ wine bloggers would signal overall character at a similar frequency is confirmed. However, $\mathrm{C}$ and $\mathrm{NC}$ bloggers appear to differentially complement ability signals with specific character signals. As a key element of character, benevolence at the dimension level was not differentially signaled by $\mathrm{C}$ and $\mathrm{NC}$ bloggers, leading to rejection of $\mathrm{H} 4$. However, $\mathrm{C}$ and $\mathrm{NC}$ bloggers communicate benevolence differently at the sub-dimension level, and $\mathrm{H} 5 \mathrm{a}$ and $\mathrm{H} 5 \mathrm{~b}$ were both supported. In contrast to overall benevolence signaling, $\mathrm{C}$ and $\mathrm{NC}$ bloggers were found to signal integrity at 
different frequencies, supporting H6. Mixed support was found for H7. C and NC bloggers signal general integrity at comparable levels, but NC bloggers signal their morally acceptable values and freedom-from-bias to a greater extent than do $\mathrm{C}$ bloggers. $\mathrm{C}$ bloggers appear to resort primarily to signals of their personal/organizational benevolence as support for character-based trustworthiness but put less weight on the character dimension than $\mathrm{NC}$ bloggers. The character of a $\mathrm{C}$ information source is presumed to be a key concern of consumers, but evidence of a compensatory approach was not observed here.

The non-significant difference in benevolence signaling between $\mathrm{C}$ and $\mathrm{NC}$ bloggers may suggest a belief in the relative ineffectiveness of benevolence as a basis of consumer trust. NC bloggers appear to leverage their presumed integrity, while $\mathrm{C}$ wine bloggers may recognize that their integrity claims are likely to be received with greater suspicion. Integrity claims are very hard for $\mathrm{C}$ bloggers to make because, particularly in the area of freedom-from-bias, they are generally transparent and unsupportable. C bloggers may instead use benevolence claims because these types of claims cannot be easily disproven.

\section{Discussion}

This research breaks new ground in exploring the establishment of online trustworthiness by examining efforts by trustees to generate trust in message claim target audiences and, in addition, emphasizes wine blogs as a relevant product-topic blog for online trustworthiness study. Hypotheses were tested regarding differences in the use of cues signaling different dimensions and sub-dimensions of trustworthiness by $\mathrm{C}$ and $\mathrm{NC}$ 
bloggers. Two theoretical foundations, RBV and compensatory signaling approaches, provide bases for explaining different signaling patterns of $\mathrm{C}$ and $\mathrm{NC}$ bloggers.

A key finding of this two-stage study is that both $\mathrm{C}$ and NC bloggers preferentially signal ability at the dimension level, confirming the usefulness of the distinction between blogger type and also between resource-based and compensatory signaling approaches. This finding is consistent with research that shows that ability is highly predictive in purchase decision contexts involving trustworthiness assessments and reliance on trustees (Schlosser, White, and Lloyd, 2006) and suggests that both C and NC bloggers view themselves as participants in such contexts. However, ability subdimension differences were found related to sources of presumed ability strengths of each blogger type. Effective persuasion demands more than just ability, however. C and NC wine bloggers signal the character dimension at comparable frequencies overall but, as found with ability signaling, do so in different ways, as will be discussed further below.

Commercial bloggers evidenced a consistent RBV approach across all cue signals types and forms. Their perceived area of strength can be presumed to be their authoritybased ability, which is what they signal most at the general and sub-dimension levels. Since $\mathrm{C}$ bloggers have a relatively weak basis for making character claims, RBV would suggest they would signal character traits less often. The study findings supported this expectation as $\mathrm{C}$ bloggers put less stress on character cues in the absolute and in comparison to ability claims. At the character sub-dimension level, $\mathrm{C}$ bloggers particularly stress their general honesty, sincerity, and commitment to moral conduct with less reliance on claims of freedom-from-bias, a relative area of weakness for them and a questionable basis for claims of trustworthiness. Unverifiable value-based character 
claims may hold the least weight in consumers' judgments about trustworthiness, however. Overall, the findings for $\mathrm{C}$ bloggers are best explained using RBV theory as dominating their approach to communication and image management.

For NC bloggers, the findings point to their use of a more balanced approach to signaling desirable trustworthiness cues. Like C bloggers, NC bloggers signal ability first even though this would not be expected to be their strongest basis for claims of trustworthiness. By emphasizing ability cues, NC bloggers reflect a compensatory-based approach to image management, focusing on the recipient's information needs, rather than on the communicator's strongest resources. To allay scepticism about ability claims, the NC bloggers use differential cue signaling at the ability sub-dimensional level. At this level and compared to $\mathrm{C}$ bloggers, $\mathrm{NC}$ bloggers take a RBV approach, putting more emphasis on product-related consumption experience over product-related authority as a believable ability claim. With regards to character signaling, RBV theories are supportive of the findings regarding NC bloggers' approach of stressing what consumers are likely to judge to be their best traits, their freedom-from-bias and blogger-specific benevolence. It appears that NC bloggers' behaviour can be best explained by their focus on their audience's needs and their own strengths using a combination of compensatory and RBV approaches.

\section{Conclusion}

\section{Research Contributions}

Study 1 contributes to knowledge through the development and validation of a novel trustworthiness signaling classification scheme and by applying the scheme in an emerging product information environment to shed light on the trustworthiness signaling 
behaviours of $\mathrm{C}$ and $\mathrm{NC}$ information sources. This study specifically assesses the overt ways by which wine bloggers are attempting to build trust with their readers and lay a foundation for influence over readers' wine attitudes and choices.

As consumer use of blogs for products increases, marketers need greater insight into the blogosphere than ever before. Wine marketers must recognize that their products and services may be the subject of blogosphere discourse between blog readers and both $\mathrm{NC}$ wine bloggers and competing $\mathrm{C}$ wine bloggers. As a starting point, ongoing monitoring of relevant discourse on wine blogs is essential, e.g., through blog tracking services, as well as of blog-related competitive developments. Since readership (i.e., audience size) varies widely throughout the blogosphere, with only a small number of blogs achieving very high readership (Du and Wagner, 2006), it is important to assess the influence of particular blogs, through determining frequency of appearance of specific blogs on "blog rolls," their "authority" score, and/or the number and nature of readers' comments posted on them and award-winning status. When analysis reveals an influential relevant wine blog, wine marketers should then make a special effort to monitor it using syndication feeds and news aggregators. Through the use of online reputation monitoring services, they can be alerted to potentially damaging negative online commentary and take appropriate marketing and reputation management actions when blog postings about their products or services are not positive or consistent with marketer-communicated product information.

Wine marketers should also ensure they are at the forefront among competitors in consumer-centric blogging. Blog reading is a purposeful consumer-initiated activity that likely reflects a level of consumption motivation and/or brand affinity that may not be 
common among consumers generally. An important implication of this is that a productrelated wine-blog message could garner more attention than similar content communicated across other channels by virtue of targeting and reaching a more interested audience without necessarily activating persuasion knowledge filters (cf. Friestad and Wright, 1994). Blogs with high-quality content and features can create value for consumers, enhancing customer relationships, brand loyalty and trust. Wine marketers who use their blog to provide useful non-commercial messaging and information to aid target customers to enhance their wine experience will enhance consumer perceptions of their benevolence. Blog writing tone should suit desired target markets. Consistent with best marketing practice, wine marketers should also strive for consistency in all their online "touch points" and between their overall online personality and competitive positioning strategy.

Readers and writers of wine blogs are a valuable consumer audience. Marketing research can help understand the importance of these target consumers to specific wine producers. Additionally, wine marketers can benefit from direct interaction with creators of blog-based product information in several ways. One way is to engage NC bloggers as writers and contributors to the marketer's own blog. More specific insight can come from engaging NC wine bloggers with high consumption experience to review their wines from a perspective that "average" consumers can identify with. However, they should not expect any product review to necessarily be positive or that NC wine bloggers would conceal the source of product samples. Another way is to participate in and support wine blogger events to gain a general appreciation of topical issues and to network with wine 
bloggers. In all cases, wine marketers can only benefit if they are prepared to act on the knowledge gained from blog and blogger engagement.

Although this study focused specifically on wine blogs, it may be reasonable to expect the findings and suggestions provided above to apply beyond wine blogs. Organizations such as not-for-profit and governmental communicators must address trustworthiness issues to ensure that their blog presence results in the achievement of any particular awareness or persuasion goal they specify for their blogs.

\section{Limitations and Future Research}

Although only English-language wine blogs were studied and inference as to the motivations of trustworthiness-signaling wine bloggers and the effectiveness of any trustworthiness signal or signaling approach is not possible from content analysis only, this study still yields significant actionable insight for all marketplace communicators. Future research can be directed at blog reader-based assessments of the role of different trustworthiness signals through surveys and experiments using the dimensions and subdimensions developed for the present study. The blog/blogger scepticism scale recently developed by van Heerden et al. (2009) and tested in the business-to-business environment could be used as a measure of the effectiveness of trustworthiness signaling behaviours. Researchers should be careful to control for message-related variables such as strength (Darley and Smith, 1993; DeCarlo, 2005), quality (Chen and Tseng, 2011; Homer and Batra, 1994), understandability (Hsieh et al., 2010), valence (Adjei, Noble, and Noble, 2010; Fein, 1996), hedonic appeal (Pollay and Mittal, 1993; Wang and Sun, 2010), realism (Wei, Fischer, and Main, 2008), and expectancy violation (Karmarkar and 
Tormala, 2010) if the objective of their trustworthiness signals study is to identify the appropriateness or the role of a particular signal in the overall trust-development process.

Given the risks associated with information overload (Jones, Ravid, and Rafaeli, 2004), it would also be appropriate to determine whether trustworthiness signaling by $C$ and NC bloggers is necessarily beneficial under all circumstances. RBV trustworthiness signaling approaches seem to presume that "more is better," but it remains to be seen whether limits exist to the effectiveness of such approaches, since these approaches typically focus on confirming prior beliefs. Compensatory trustworthiness signaling approaches may be more useful to consumers and effective for producing belief change. Additional opportunity is available for research into the relationship between the trustworthiness signaling behaviours of $\mathrm{C}$ and $\mathrm{NC}$ wine bloggers and the content of the wine reviews posted on their blogs. Given the prevalence of trustworthiness signals in wine blogs that was observed in this study, signaling at the level of an individual wine review would suggest that wine bloggers desire not only a readership base but also influence over consumer attitudes toward specific products. While this research provides a starting point for more in-depth studies of consumers, bloggers, and wine blogs, there is much more that needs to and can be learned to improve the functioning of this and other forms of online product information in this product area and more broadly.

Future research could also examine the tactics of bloggers that, instead of seeking to influence beliefs, are emotive or expressive in nature and designed to build rapport and affiliation between bloggers and blog readers. Rapport refers to felt similarity and likeability (Karmarkar and Tormala, 2010; Price, Feick, and Higie, 1989; Smith, Menon, and Sivakumar, 2005). A context-grounded approach similar to that which was developed 
and employed for identifying trustworthiness signals may be appropriate as a preliminary step for identifying rapport-building blogger tactics.

Finally, the content analysis methodology is amenable to ready exportation to other experience-based product categories and blog communities. Specific consideration of the contrasts between product categories on the basis of claim type (i.e., search, experience, credence) would permit further study of potential differences in overall, dimension-level, and sub-dimension-level signaling by commercial and non-commercial communicators. 


\section{CHAPTER 4: WHAT REALLY MATTERS TO TRUST INTENTIONS FOR READERS OF TOPIC-AREA BLOGS}

(STUDY 2)

\section{Introduction}

Conventional theories regarding interpersonal communication may have limited applicability to the blogosphere (Brown, Broderick, and Lee, 2007). On the one hand, knowledge and reporting bias (cf. Eagly, Wood, and Chaiken, 1978), coupled with perceived weak editorial standards (Flanagin and Metzger, 2000; Johnson and Kaye, 2004), encourage reluctance in blog readers to trust claims made and disseminated by bloggers. Indeed, prior research shows that source derogation, counter-argumentation, and discounting are common recipient responses to claims whose accuracy they doubt (Smith and Swinyard, 1988). On the other hand, the blogosphere grew by between 98 128 million blogs from 2006 to 2011 (Blog Pulse, 2011; Lenhart and Fox, 2006) and research indicates that consumers incorporate blog content into the consumption-related decisions they make (Mangold and Faulds, 2009). Given rising blog readership amid concerns about biased blog content, questions arise over the trust-development process in the blogosphere.

Online trust research emphasizes the role of "web atmospherics" for influencing consumer usage of web sites (e.g., Bart et al., 2005; Chen and Dibb, 2010; Lee and Turban, 2001; Richard et al., 2010; Schlosser, White, and Lloyd, 2006), but it is not clear how well these website characteristics apply to the trust-development process in the blogosphere. Huffaker (2010, p. 594) notes that little is known about the characteristics of 
online communicators who "have the ability to trigger feedback, spark conversations within the community, or even shape the way that other members of a group 'talk' about a topic." Although there is general recognition that opinion leaders occupy desirable social positions and are credited with competency and freedom-from-bias (e.g., Lee, Cotte, and Noseworthy, 2010), there is a need to determine the specific qualities of trustworthy bloggers. However, trust in the blogosphere may not only depend on these blogger characteristics, but also on beliefs of readers that the blogs themselves positively contribute to attainment of their topic-area goals (Mayer, Davis, and Schoorman, 1995). Thus, the roles of both blog characteristics and blogger characteristics are important to determine in readers' trust-formation perceptions. The purpose of this study is to identify a comprehensive set of trust antecedents for the blogosphere and to map the interconnections between the antecedents in order to achieve understanding of the overall trust development process in the blogosphere.

\section{Objectives and Structure}

Given that trust unfolds as experience accumulates (Casalo, Flavián, and Guinalíu, 2007), trust determinants in the blogosphere include trust-building blog-reading outcomes and the roots of these outcomes. The objectives of study 2 are to identify trustbuilding blog-reading outcomes and the blogger and blog characteristics that facilitate those trust-building blog-reading outcomes. In addition, study 2 seeks to assess the trustbuilding influences of authoritative knowledge, engagement knowledge, and character beliefs in the blogosphere. 
This study is structured as follows. First, relevant literature streams are reviewed and then hypotheses are developed. Second, the methodology that was developed and employed in order to permit hypothesis testing is presented. Third, results of hypothesis testing concerning the relationships between trust intentions and each of blogger characteristics, blog characteristics, and blog-reading outcomes are presented.

Relationships between blog-reading outcomes and each of blogger characteristics and blog characteristics are also presented. In the fourth and final section, summary remarks concerning the contribution of this study as well as suggestions for future research are provided.

\section{Literature Review and Hypotheses Development}

It has recently been suggested that conceptualizations of trust are so heterogeneous that researchers may be "over-trusting trust by using the word 'trust' without necessarily controlling for content validity, while taking the construct's face validity for granted" (Castaldo, Premazzi, and Zerbini, 2010, p. 658). Methodologically, trust is often assessed on the basis of cognitive constructs such as perceived trustee "trustworthiness" (Chen and Dibb, 2010; Pan and Chiou, 2011), but trust and trustworthiness are not the same, since trust is an act of the trustor and trustworthiness a perceived characteristic of the trustee (Corritore, Kracher, and Wiedenbeck, 2003).

Content analysis of trust conceptualizations across fifty years of research reveals that trustor behaviours are at the heart of the trust concept (Castaldo, Premazzi, and Zerbini, 2010), and trust research in the online domain supports this finding (McKnight, Choudhury, and Kacmar, 2002; Schlosser, White, and Lloyd, 2006). Accordingly, trust 
can be conceptualized as the behavioural reliance of a trustor on a trustee, where reliance implies risk due to information asymmetry and limited monitoring and control capabilities (Levin and Cross, 2004; Moorman, Deshpandé, and Zaltman, 1993). In the blogosphere, trust can be operationalized as the extent to which readers voluntarily rely on the assertions of a blog creator to direct their own topic-area decisions and actions and encourage others to do the same. Huang, Chou, and Lin, (2008, p. 352) offer an example of this behavioural trust operationalization for the blogosphere, arguing that "opinion acceptance is the judgment of trust after reading messages and thus represents an important variable for understanding the impacts of blogs." In this context, risk resides in the potential for loss inherent in making a decision or taking an action on the basis of "biased" information (cf. Eagly, Wood, and Chaiken, 1978).

Positive trust beliefs are critical to the facilitation of willingness in readers to rely on the assertions of an information source (Moorman, Deshpandé, and Zaltman, 1993). Trust development is, therefore, expected to relate to the anticipated outcomes of reliance on the blogger, as well as to the characteristics of the blog and blogger. Given that blogger and blog characteristics are the principal vehicles for achieving topic-area outcomes, the trust effects of these characteristics may operate through topic-area outcomes, and this study intends to address this empirical issue. An initial framework for the examination of relationships among blogger-trust constructs is presented in Figure 4.1. 
Figure 4.1: Trust Determination in Topic-Area Blogging

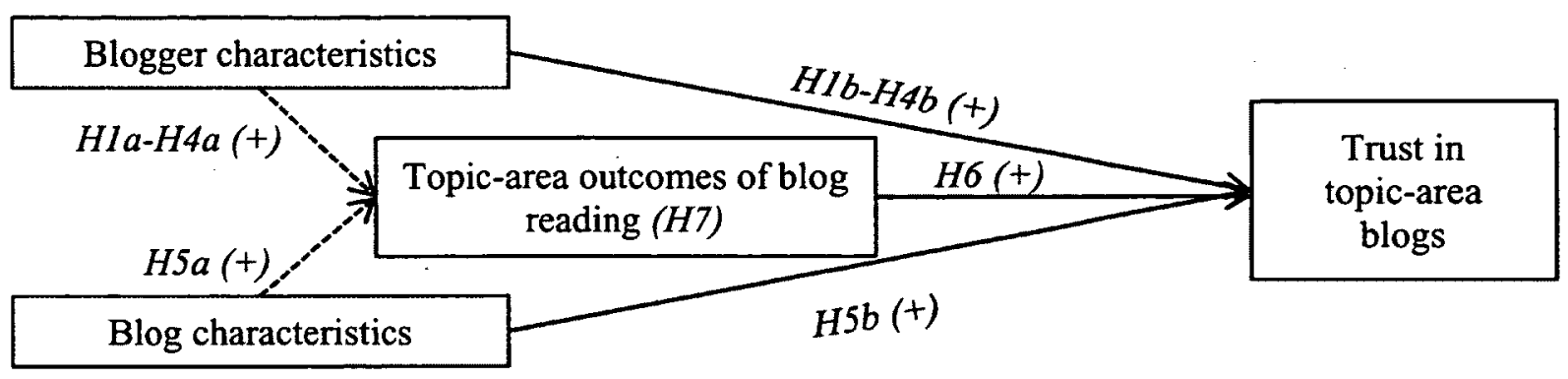

\section{Effects of Blogger Characteristics on Trust}

Blogger characteristics are the qualities and actions of a blogger perceived by blog readers that assure them that it is able and motivated to satisfy their topic-area needs. A blogger who possesses topic-area ability and integrity and who is benevolent is expected to engender willingness in readers to make decisions and take actions on the basis of its topic-area assertions.

Ability has been established in a variety of trust-related studies as a determinant trustworthiness dimension (e.g., Bruwer and Wood, 2005; Schlosser, White, and Lloyd, 2006). Perceived ability is the extent to which a trustor believes a trustee to possess human and structural-social capital sufficient for satisfying the topic-area needs of the trustor (Alba and Hutchinson, 1987; Doney and Cannon, 1997; Lee and Turban, 2001; Mayer, David, and Schoorman, 1995). An important distinction can be made between two human-capital ability sources. Authoritative knowledge is a conventional humancapital source from which a blogger could draw in order to make accurate topic-area assertions. Authoritative knowledge primarily develops over time through topic-area scholarship and can be considered a formal type of knowledge. Authorities study the topic area more from afar than from within, detachedly examining it in order to develop 
objective, fact-based topic-area knowledge (Ponterotto, 2005). Topic-area authorities can be found leading discourse in communication domains wherein formal credentials (e.g., university degrees) and signs of accomplishment (e.g., awards) are weighty informationquality cues, such as academia and the mainstream media. Authoritative knowledge can also develop through specialized topic-area education, training, and work experience.

H1: $\quad$ The more topic-area authoritative knowledge a blog reader believes a blog creator possesses, the more the blog reader:

(a) believes that reading the blog facilitates desirable topic-area outcomes, and

(b) shows trust intentions in the blog.

Given the counterintuitive co-existence of blog-readership growth and knowledge-bias concerns, it is conceivable that topic-area ability has been conceptualized too narrowly for the blogosphere. In contrast to authoritative knowledge, engagement knowledge accumulates on a longitudinal basis by way of topic-area participation, intentional social action involving time and effort within the topic-area community (Bagozzi and Dholakia, 2002). Accordingly, engagement knowledge develops primarily through involvement within the topic area and not through detached inquiry of the topic area. Acquired through the lived experiences of the knower, engagement knowledge can be distinguished from authoritative knowledge as being an informal type of knowledge. Although an interpretive reality is only imperfectly knowable (Astley, 1985), interpretive research can facilitate in-depth topic-area understanding, particularly in those who identify with the communicator. 
The sources of engagement knowledge are pluralistic, as topic-area participation is often subject to few meaningful entry barriers and because it can take on many forms. To enter most brand communities, for example, one usually need only have admiration for the brand (Mũniz and O'Guinn, 2001), although some communities are more restrictive. Whether based on affection or on something more substantive, participation in a topic-area community conveys topic-related familiarity, but familiarity does not necessarily imply objective topic-area knowledge. In fact, it has long been understood that product familiarity can even develop through exposure to product-related communications, such as advertisements (Alba and Hutchinson, 1987; Brakus, Schmitt, and Zarantonello, 2009; Johnson and Russo, 1984). High engagement knowledge, however, is enjoyed by those with topic-area passion, involvement, and wide-ranging experience. Although there may be no singular prototype of such a communicator, examples could include heavy product or service users who frequently post comments on product-review websites or topic-area bloggers who display extensive topic-area blog rolls on their own blogs, suggesting that they read as much topic-area content as possible.

H2: $\quad$ The more topic-area engagement knowledge a blog reader believes a blog creator possesses, the more the blog reader:

(a) believes that reading the blog facilitates desirable topic-area outcomes, and

(b) shows trust intentions in the blog.

Ability can also derive from social capital (Hilligoss and Rieh, 2008; Priester and Petty, 2003). Social capital is the value-creating resource that is available through the 
structural, relational, and cognitive characteristics of interpersonal relationships (Nahapiet and Ghoshal, 1998; Tsai and Ghoshal, 1998). Trustees with strong social capital are connected to informed others who willingly share resources or otherwise cooperate with each other, thus allowing a given trustee to fulfill any promise it may have made (Chiu, Hsu, and Wang, 2006; Chow and Chan, 2008; de Janasz and Forret, 2008; Hayami, 2009). A blogger with personal, professional, or institutional relationships within the topic area could, irrespective of its own ability, provide accurate and reliable topic-area information.

H3: The more topic-area social-network connection a blog reader believes a blog creator possesses, the more the blog reader:

(a) believes that reading the blog facilitates desirable topic-area outcomes, and

(b) shows trust intentions in the blog.

The character of a blogger is the totality of its personal integrity and benevolence toward readers. Perceived integrity concerns the extent to which a trustee is believed to be unbiased and committed to moral and ethical conduct (Mayer, Davis, and Schoorman, 1995; Ridings, Gefen, and Arinze, 2002). Perceived benevolence is an assessment of the extent to which a trustee has goodwill intentions and, rather than wanting solely to benefit from a trustor, desires to do good things for it (Colquitt, Scott, and LePine, 2007; Lee and Turban, 2001; Mayer, Davis, and Schoorman, 1995; Ridings, Gefen, and Arinze, 2002). Bloggers with strong character can be relied upon to perform topic-area tasks to the extent to which they are capable. 
Beliefs about the trustor's trustworthiness may also be influenced by the explicit trust-related arguments (Kim and Benbasat, 2006) or trust-building cues (Urban, Amyx, and Lorenzon, 2009) that it communicates. Recent research indicates that bloggers do reveal information about themselves in order to enhance trust between them and their readers (e.g., Lee, Im, and Taylor, 2008), but the efficacy of these attempts in the form of trust intentions in the present research context has received little attention.

H4: The more character a blog reader believes a blog creator (1) possesses and (2) claims to possess, the more the blog reader:

(a) believes that reading the blog facilitates desirable topic-area outcomes, and

(b) shows trust intentions in the blog.

\section{Effects of Blog Characteristics on Trust}

Trust is presumed in the online domain to derive from features and other "web atmospherics" that facilitate positive person-website interactions and their functional outcomes (Bart et al., 2005; Chen and Dibb, 2010; Hahn and Kim, 2009; Lee and Turban, 2001; Richard et al., 2010; Schlosser, White, and Lloyd, 2006; Urban, Amyx, and Lorenzon, 2009). This literature stream shows that website features and performance parameters such as speed, navigability, and fulfilment functions are strong consumer indicators of the ability of an online merchant to fulfill its promises (Bart et al., 2005; Lee and Turban, 2001; Schlosser, White, and Lloyd, 2006). Third-party endorsements, signs of "assistive intent," and privacy and security policies and statements have been found to

contribute to trust development directly (Bart et al., 2005; Flavian, and Guinaliu 2006) as 
well as to influence perceptions of the benevolence and integrity of online merchants (Aiken and Boush, 2006; Gupta, Yadav, and Varadarajan, 2009; Schlosser, White, and Lloyd, 2006) and members of virtual communities (Wu and Tsang, 2008).

The functional orientation of online-trust research may be of only limited appropriateness to the blogosphere; however, since the information-seeking context (i.e., purchase vs. non-purchase) has been shown to exert influence over determinants of trust (e.g., Chen and Dibb, 2010; Hennig-Thurau and Walsh, 2003; Schlosser, White, and Lloyd, 2006). Blogs do not directly facilitate buyer-seller transactions, and studies of the motivations of blog readers emphasize social and hedonic orientations in addition to functional ones (e.g., Huang, Chou, and Lin, 2008). Drawing from motivations research, in this study blog characteristics are conceptualized in terms of blog-content quality and uniqueness, the functional features that mediate interactions between blog creators and their readers, and the benefits of those interactions. An inductive approach will be taken to specify these characteristics for measurement purposes.

H5: Positive beliefs about the characteristics of a blog lead a blog reader to:

(a) believe that reading the blog facilitates desirable topic-area outcomes, and

(b) shows trust intentions in the blog.

\section{Effects of Blog-Reading Outcomes on Trust}

Assessments of outcomes that have resulted from prior interactions with topicarea bloggers could exert influence on the presence of trust intentions. The trust that exists in a particular relationship at a specific point in time is reflective of the cumulative 
desirability of the outcomes of prior occasions on which the trustor relied on the trustee. Trust in a relationship is known to strengthen over time as the number of satisfying interactions between parties increases (Casalo, Flavián, and Guinalíu, 2007). Recent research indicates that satisfaction with a product or service is a predictor of not only future consumption behaviour but also intention to encourage social-network contacts to try the product or service (Cyr, 2008). Given that blog reading is regarded as a pluralistic goal-oriented activity, satisfying prior experiences are likely to influence beliefs that future interactions with the topic-area blogger will result in similarly satisfying outcomes.

H6: $\quad$ The more a blog reader believes that blog reading facilitates desirable topic-area outcomes, the more the blog reader shows trust intentions in the blog.

The final hypothesis is proposed to test the overall relationship between blogger characteristics, blog characteristics, blog-reading outcomes, and trust intentions. These relationships may all be direct, or there may be mediation of blog and blogger characteristics by their generation of outcome beliefs that then impact on trust intentions. The final hypothesis is proposed to test this:

H7: The effects of blog readers' beliefs about the characteristics of a blog creator and a blog on the blog-directed trust intentions they show are mediated through their effects on blog-reading outcomes.

\section{Methodology}

Data were collected from undergraduate students. Prior research indicates that young adults use blogs heavily and are suitable for this research (Huang, Chou, and Lin, 
2008; Lenhart and Fox, 2006). Data were collected from respondents with varying degrees of prior personal blog experience, but only data from respondents who reported having prior personal experience reading blogs were included in this study $(n=364)$. Respondents completed a questionnaire that included questions about their age, gender, and blog-reading practices; beliefs of the characteristics of the topic-area bloggers and blogs they read; outcomes of their blog-reading behaviours and; extent to which they trust the bloggers (see Appendix 4.1). To enhance the personal relevance of the study, research respondents were directed to respond to questions on their beliefs about and trust in the specific topic-area blogs they read most. Respondents were invited to select their own topic area or to consider blogs from the business, entertainment, sports, health and fitness, or products topic areas.

\section{Measures Development}

To facilitate hypothesis testing, constructs were measured using multiple items from the survey instrument. The survey instrument was organized into sections in accordance with the research. Item-level responses were collected on continuous 1-7 scales where high values indicated strong support (i.e., agreement or importance) for the item. To identify underlying relationships among items, the principal axis factoring approach with Promax rotation was employed with eigenvalue cut-offs for factors of 1.0 and scree plot analysis indicating factors were contributing to variance explanation (Hair et al., 2006). Cronbach's alphas at or above .7 were also used as a test of reliability of measures within the factor (Hair et al., 2006). Summary measures of factors were calculated by averaging the items loading at .4 or greater on a single factor. Item- and 
factor-level descriptive statistics for blogger characteristics, blog characteristics, and blog-reading outcomes and trust are reported in Table 4.1, Table 4.2, and Table 4.3, respectively.

\section{Blogger characteristics.}

Blogger characteristics measures were derived from the trust beliefs literature adapted to suit the research context and those retained after factor analysis are shown in Table 4.1. Factor analysis of 33 trust-related blogger characteristics revealed two humancapital ability factors, termed "authoritative" and "engagement" knowledge; a social network connection factor; and two character-based factors, one of which involved claims of trustworthiness and the second included items relating to social consciousness, freedom-from-bias, and responsiveness to readers.

\section{Blog characteristics.}

Blogs can be evaluated according to the instrumental change they have effected within their relevant topic areas as well as the quality of the information they convey, the various manners by which it gets conveyed, and the participants that collaborate in conveying it. Twenty-five trust-related blog characteristics were reduced to five factors focused on the impact of the blog on the topic-area community as well as various functions and features of the blog (Table 4.2). 
Table 4.1: Descriptives and Factoring Results of Blogger Characteristic Variables

\begin{tabular}{|c|c|c|c|c|c|c|}
\hline Factors and Measures Loading on Factor & $\boldsymbol{M}$ & S.D. & Loading & Eigen. & $\begin{array}{c}\% \\
\text { var. } \\
\end{array}$ & $\begin{array}{c}\text { Cron. } \\
\alpha\end{array}$ \\
\hline Factor 1: Engagement knowledge & 5.05 & 1.09 & & 12.40 & 37.56 & .92 \\
\hline Has wide-ranging experience & 5.09 & 1.42 & .83 & & & \\
\hline Has extensive experience in the area & 5.28 & 1.48 & .65 & & & \\
\hline Has resources that that others do not & 5.02 & 1.53 & .41 & & & \\
\hline Is heavily involved in the area & 5.18 & 1.41 & .69 & & & \\
\hline Is passionate about the topic & 5.60 & 1.38 & .58 & & & \\
\hline Is very critical in discussing the topic & 4.53 & 1.61 & .44 & & & \\
\hline Is very engaged in the topic field & 5.29 & 1.39 & .87 & & & \\
\hline Is interested in topic-area improvements & 4.72 & 1.48 & .45 & & & \\
\hline Spends a lot of time studying the topic & 4.74 & 1.57 & .47 & & & \\
\hline Knows about unusual aspects of the topic & 4.89 & 1.47 & .78 & & & \\
\hline Uses correct terminology & 5.22 & 1.47 & .54 & & & \\
\hline Factor 2: Authoritative knowledge & 3.56 & 1.31 & & 3.06 & 9.28 & .89 \\
\hline Has a business on the topic area & 3.88 & 1.70 & .51 & & & \\
\hline Has one or more university degrees & 3.20 & 1.86 & .81 & & & \\
\hline Has specialized education in the topic area & 4.07 & 1.73 & .62 & & & \\
\hline Has won awards related to the area & 3.44 & 1.69 & .58 & & & \\
\hline Has written a book about the topic & 3.01 & 1.68 & .78 & & & \\
\hline Teaches courses on the topic & 3.19 & 1.72 & .74 & & & \\
\hline Works in the industry & 4.31 & 1.77 & .45 & & & \\
\hline Writes about the topic in mainstream media & 3.57 & 1.67 & .63 & & & \\
\hline Factor 3: Character of the blogger & 4.29 & 1.18 & & 2.66 & 8.06 & .86 \\
\hline Answers questions posed on their blog & 4.67 & 1.60 & .77 & & & \\
\hline Appears to get no commercial gain & 3.83 & 1.80 & .44 & & & \\
\hline Is concerned with the environment & 3.75 & 1.83 & .47 & & & $\dot{z}$ \\
\hline Has no commercial interest in the topic area & 3.86 & 1.71 & .40 & & & \\
\hline Is not critical of those who post comments & 4.13 & 1.63 & .63 & & & \\
\hline Responds to posted comments on their blog & 4.54 & 1.75 & .71 & & & \\
\hline Seems sincere and honest & 5.09 & 1.37 & .50 & & & \\
\hline Shows concern for me as a reader & 4.43 & 1.60 & .62 & & & \\
\hline Factor 4: Blogger's character claims & 4.42 & 1.44 & & 1.37 & 4.14 & .85 . \\
\hline Says their information is trustworthy & 4.42 & 1.63 & .68 & & & \\
\hline Says they are accurate, fair and unbiased & 4.55 & 1.64 & .54 & & & \\
\hline Says they are trustworthy & 4.28 & 1.67 & .69 & & & \\
\hline Factor 5: Blogger's social connections & 4.41 & 1.38 & & 1.07 & 3.23 & .78 \\
\hline Attends major events on the topic area & 4.44 & 1.66 & .66 & & & \\
\hline Has contacts with other topic experts & 4.60 & 1.61 & .62 & & & \\
\hline Promotes good social causes & 4.18 & 1.68 & .50 & & & \\
\hline
\end{tabular}


Table 4.2: Descriptives and Factoring Results of Blog Characteristic Variables

\begin{tabular}{|c|c|c|c|c|c|c|}
\hline Factors and Measures Loading on Factor & $M$ & S.D. & Loading & Eigen. & $\begin{array}{c}\% \\
\text { var. }\end{array}$ & $\begin{array}{c}\text { Cron. } \\
\boldsymbol{a}\end{array}$ \\
\hline Factor 1: Instrumental topic improvements & 4.69 & 1.11 & & 9.43 & 37.74 & .87 \\
\hline Has won awards & 3.24 & 1.72 & .40 & & & \\
\hline Improves outcomes of topic-area decisions & 4.76 & 1.47 & .82 & & & \\
\hline Improves topic-area value that people receive & 4.85 & 1.33 & .81 & & & \\
\hline Increases topic-area knowledge effectively & 5.17 & 1.38 & .70 & & & \\
\hline Is helping create a better industry & 4.35 & 1.57 & .65 & & & \\
\hline Is well written & 5.52 & 1.24 & .38 & & & \\
\hline Makes better offerings known and available & 4.76 & 1.43 & .84 & & & \\
\hline Factor 2: Involvement of topic community & 4.24 & 1.32 & & 2.72 & 10.88 & .89 \\
\hline Has created a strong sense of community & 4.18 & 1.64 & .65 & & & \\
\hline Has guest bloggers & 3.95 & 1.63 & .58 & & & \\
\hline Has many comments posted by readers & 4.34 & 1.64 & .86 & & & \\
\hline Reader comments are very informative & 4.27 & 1.64 & .76 & & & \\
\hline Reader comments express a range of opinions & 4.41 & 1.60 & .73 & & & \\
\hline Reader comments lead to lively discussions & 4.31 & 1.60 & .86 & & & \\
\hline Factor 3: Reading-experience uniqueness & 5.41 & 0.95 & & 2.05 & 8.19 & .79 \\
\hline Has information not available elsewhere & 5.08 & 1.38 & .36 & & & \\
\hline Has information which is unique & 5.57 & 1.22 & .70 & & & \\
\hline Is updated frequently & 5.75 & 1.19 & .68 & & & \\
\hline Is visually attractive & 5.27 & 1.36 & .44 & & & \\
\hline Site is well designed & 5.41 & 1.26 & .55 & & & \\
\hline Factor 4: Connected to topic-area materials & 4.56 & 1.12 & & 1.40 & 5.61 & .81 \\
\hline Has a lot of links & 4.05 & 1.57 & .64 & & & \\
\hline Has lots of visual materials & 4.95 & 1.42 & .46 & & & \\
\hline Has many resources on the site & 5.00 & 1.39 & .60 & & & \\
\hline Has very high quality links & 4.87 & 1.57 & .68 & & & \\
\hline Uses highly advanced technology & 3.94 & 1.52 & .50 & & & \\
\hline Factor 5: Information quality & 5.83 & 1.13 & & 1.01 & 4.03 & .83 \\
\hline Information is accurate & 5.88 & 1.26 & .76 & & & \\
\hline Information is easy to understand & 5.78 & 1.20 & .62 & & & \\
\hline
\end{tabular}

Given the inductive nature of this assessment of blog characteristics, H5 will be tested at the factor level. Therefore, H5 comprises five sub-hypotheses (H5.1, H5.2, and so on), with each sub-hypothesis mapping onto the corresponding factor reported in Table 4.2. 


\section{Outcomes of blog reading and trust.}

Personal and interpersonal outcomes of blog reading identified in literature were assessed using nine items. Factor analysis showed two outcomes congruent with specific motivations of blog-reading behaviours with items and loadings seen in Table 4.3. As with H5, H6 is comprised of two sub-hypotheses (H6.1 and H6.2). The extents to which blog reading has contributed positively to each of topic-area knowledge and community engagement for the blog reader are assessed as outcomes of blogger and blog characteristics, trust antecedents, and mediators of relationships between trust and blogger and blog characteristics.

Table 4.3: Descriptives and Factoring Results of Blog-Reading Outcome and Trust Variables

\begin{tabular}{|c|c|c|c|c|c|c|}
\hline Factors and Measures Loading on Factor & $M$ & S.D. & Loading & Eigen. & $\begin{array}{c}\% \\
\text { var. }\end{array}$ & $\begin{array}{c}\text { Cron. } \\
\alpha \\
\end{array}$ \\
\hline Factor 1: Topic-area knowledge & 5.06 & 0.95 & & 4.57 & 50.76 & .85 \\
\hline I am a better judge of issues on the topic & 5.00 & 1.28 & .60 & & & \\
\hline I am better at finding good topic-area offerings & 4.93 & 1.35 & .51 & & & \\
\hline I am satisfied with the topic-area blogs I read & 5.37 & 1.13 & .49 & & & \\
\hline I get better quality for my time or money & 4.83 & 1.36 & .56 & & & \\
\hline My appreciation of the topic has increased & 5.23 & 1.22 & .66 & & & \\
\hline My knowledge of the topic has increased & 5.45 & 1.17 & .91 & & & \\
\hline Factor 2: Community engagement & 4.32 & 1.48 & & 1.10 & 12.25 & .87 \\
\hline I can relate to the others in the community & 4.32 & 1.57 & .93 & & & \\
\hline I feel like I am a part of the community & 4.32 & 1.58 & .86 & & & \\
\hline Factor 3: Trust intentions ${ }^{b}$ & 5.02 & 1.04 & & 3.45 & 57.56 & 85 \\
\hline Act on the basis of information on the blogs & 4.59 & 1.39 & .65 & & & \\
\hline Continue to read these blogs & 5.60 & 1.20 & .61 & & & \\
\hline Pass along information I read about & 5.25 & 1.30 & .72 & & & \\
\hline Recommend the blogs to others & 4.83 & 1.55 & .68 & & & \\
\hline Take advice from these blogs & 5.00 & 1.34 & .77 & & & \\
\hline Try what is recommended on these blogs & 4.88 & 1.39 & .78 & & & \\
\hline
\end{tabular}




\section{Results and Discussion}

Data were collected from 436 survey respondents. Slightly more than half of survey respondents were male (55.8\%) and two-thirds of them were under 21 years-ofage. Survey respondents were active readers of topic-area blogs. They reported spending nearly three hours on an average of 6.75 occasions per week reading an average of 4.28 topic-area blogs in order to "acquire information about the topic area" and to "share their topic-area interests with others," with the "information acquisition" motivation being a more important motivation than "interest sharing" $(|t|(300)=12.95, p<.001)$. Popular topic areas were products, entertainment, and sports, which together accounted for $59 \%$ of respondents' most-read topic areas. Approximately 17 per cent of respondents reported that they wrote their own blogs in addition to reading blogs, but all respondents were asked to report on the blogs that they read (Huang, Chou, and Lin, 2008). Respondents with more than five per cent missing data were dropped from the study, leaving 301 cases for analysis. Any missing data from remaining respondents was managed using the mean substitution technique, and $60 \%$ of them featured no missing data at all.

Results in Table 4.4 present the individual and joint relationships between blog and blogger characteristics with each of the two types of outcomes. Most of the blogger and blog characteristics were found to be significantly related to the knowledge and community engagement blog-reading outcomes. First-level support for Hypotheses 1a-6a can be inferred from these correlations, although results of multiple-regression analyses reported in the table (columns three and five) indicate that beliefs of blog-reading outcomes are driven by specific blogger and blog characteristics. These analyses tease 
out the respective strengths of the blogger and blog characteristics as predictors of the two blog-reading outcomes.

Table 4.4: Correlations and Multiple-Regression Analyses - Reading Outcomes

\begin{tabular}{|c|c|c|c|c|}
\hline \multirow{3}{*}{$\begin{array}{l}\text { Independent variables } \\
\text { Blogger characteristics }\end{array}$} & \multicolumn{4}{|c|}{ Outcomes of blog reading (Hypotheses 1a-6a) } \\
\hline & \multicolumn{2}{|c|}{ Topic-area knowledge } & \multicolumn{2}{|c|}{ Community engagement } \\
\hline & $r$ & $\beta /(t$-value $)$ & $r$ & $\beta /(t-$ value $)$ \\
\hline Hla: Authoritative knowledge & .29 & $-.03 /(-0.53)$ & .29 & $.10 /(1.40)$ \\
\hline H2a: Engagement knowledge & .58 & $.53 /(8.21)^{* * *}$ & .33 & $.16 /(2.25)^{*}$ \\
\hline H3a: Social network connections & .36 & $-.06 /(-0.91)$ & .27 & $-.02 /(-0.31)$ \\
\hline H4.1a: Blogger character & .42 & $.16 /(2.45)^{*}$ & .39 & $.30 /(3.97)^{* * *}$ \\
\hline H4.2a: Character claims & .36 & $.04 /(0.64)$ & .27 & $-.04 /(-0.48)$ \\
\hline Adjusted $R^{2} /(F$ value $)$ & & $.34 /(32.29)^{\star * *}$ & & $.17 /(13.08)^{* * *}$ \\
\hline \multicolumn{5}{|l|}{ Blog characteristics } \\
\hline H5.la:Instrumental improvements to topic & .60 & $.40 /(6.80)^{* * *}$ & .47 & $.37 /(5.99)^{* * *}$ \\
\hline $\begin{array}{l}\text { H5.2a: Involvement of topic-area } \\
\text { community }\end{array}$ & .41 & $.08 /(1.46)$ & .49 & $.33 /(5.51)^{* * *}$ \\
\hline H5.3a: Reading-experience uniqueness & .49 & $.16 /(2.40)^{*}$ & .26 & $.09 /(1.29)$ \\
\hline H5.4a: Connected to topic-area materials & .44 & $.05 /(.84)$ & .34 & $-.01 /(-0.07)$ \\
\hline H5.5a: Information quality & .41 & $.10 /(1.65)$ & $.05^{a}$ & $-.26 /(-4.19)^{* * *}$ \\
\hline Adjusted $R^{2} /(F$ value $)$ & & $.40 /(41.64)^{* * *}$ & & $.34 /(31.30)^{* * *}$ \\
\hline
\end{tabular}

${ }^{a}$ This correlation is $p>.1$ (1-tailed). All other correlations, $p<.01$.

${ }^{*} p<.05{ }^{* *} p<.01{ }^{* * *} p<.001$.

\section{Blog-Reading Outcomes and Blogger Characteristics}

Although authoritative knowledge is a conventional human-capital ability source, it is apparent that it plays a minimal role for study respondents in facilitating desirable blog-reading outcomes. For both topic-area knowledge and community-engagement outcomes, authoritative knowledge is not a significant driver, thus Hla is not supported $(p>.05)$. In contrast, $\mathrm{H} 2 \mathrm{a}$ received substantial support with engagement knowledge exerting considerable influence over the knowledge $(p<.001)$ and communityengagement $(p<.05)$ blog-reading outcomes. Interestingly, engagement knowledge appears to be the prominent source of blogger ability, since social-network connections 
(H3a) were not found to facilitate blog-reading outcomes $(p>.05)$. Blogger character (H4.1a) is a relevant concern for blog readers, since it was found that benevolence and integrity do contribute to the knowledge $(p<.05)$ and community-engagement $(p<.001)$ outcomes of blog reading. Blogger character must be perceived to exert positive influence, however, since blogger claims concerning their character $(\mathrm{H} 4.2 \mathrm{a})$ appear to be of little benefit to blog readers $(p>.05)$. That engagement knowledge and character are the essential blogger characteristics is an interesting finding, even though it has long been recognized that an information source must possess both ability and motivation for it to satisfy the needs of its audience. It is most interesting that blog readers in this study seem to acknowledge only engagement knowledge as the bona fide ability source in the blogosphere.

\section{Blog-Reading Outcomes and Blog Characteristics}

Blog characteristics exert considerable influence on the knowledge and community-engagement outcomes of blog reading. The extent to which a blog is credited with improving a topic area (H5.1a) impacts both blog-reading outcomes $(p<.001)$. Involvement of the topic-area community on the blog (H5.2a) does enhance the community engagement of blog readers $(p<.001)$ but does not facilitate knowledge acquisition for them specifically $(p>.05)$. It is evident that these benefits of topic-area blogs are of greater consequence to blog readers than are the blog features that create them. Reading-experience uniqueness (H5.3a) impacts knowledge outcomes for blog readers $(p<.05)$ but has no impact on their engagement in the topic-area community ( $p$ $>$.05). Surprisingly, high-quality information (H5.5a) seems to be of questionable 
benefit, since it does not seem to relate to knowledge outcomes $(p>.05)$ and actually appears to detract from community engagement for blog readers $(p<.001)$. It is also interesting that connections to topic-area materials (H5.4a) do not facilitate desirable blog-reading outcomes for blog readers $(p>.05)$, given the strong ability of blogs to allow readers access to online materials.

\section{Trust Intentions and Blogger Characteristics}

$\mathrm{H} 1 \mathrm{~b}-\mathrm{H} 4.2 \mathrm{~b}$ were tested using multiple-regression analysis, and results are shown in Table 4.5. As the second column of the table shows, all blogger characteristics are significantly and positively associated with trust intentions $(p<.01)$. As the third and fourth columns show, however, blogger ability is the only characteristic that directly affects trust, and even then not every source of ability affects trust positively. Surprisingly, authoritative knowledge (H1b) actually detracts from trust $(p<.05)$ when assessed with engagement knowledge ( $\mathrm{H} 2 \mathrm{~b})$, which has a very significant positive impact on trust $(p<.001)$. This finding suggests that blog readers are dubious of traditional information-source ability and put more faith in topic-area experience and commitment of the blogger. It is also interesting that social network connections (H3b) do not inspire trust in topic-area blogs and that blogger character, whether perceived $(\mathrm{H} 4.1 \mathrm{~b})$ or claimed (H4.2b), similarly does nothing for trust intentions $(p>.05)$. These findings suggest that ability derived from human capital is the main characteristic of bloggers that wins the trust of readers, which has also been found to be the case in online retail environments. 


\begin{tabular}{|c|c|c|c|c|c|c|c|}
\hline \multirow{3}{*}{\begin{tabular}{|l} 
Independent variables \\
Blogger characteristics
\end{tabular}} & \multirow{2}{*}{\multicolumn{3}{|c|}{$\begin{array}{l}\text { Main effects on trust intentions } \\
\text { (H1b-H6b) }\end{array}$}} & \multicolumn{4}{|c|}{ Mediated models (H7) } \\
\hline & & & & \multirow{2}{*}{$\begin{array}{c}\begin{array}{c}\text { Direct } \text { trust } \\
\text { effects }\end{array} \\
B /(\mathrm{SE})\end{array}$} & \multirow{2}{*}{$\begin{array}{c}\begin{array}{c}\text { Indirect trust } \\
\text { effects }\end{array} \\
B /(\mathrm{SE})\end{array}$} & \multicolumn{2}{|c|}{$\begin{array}{l}\text { Bias-corrected } \\
95 \% \text { C.I. }\end{array}$} \\
\hline & $\boldsymbol{R}$ & $\beta /(t-$ value $)$ & $B /(\mathrm{SE})$ & & & Lower & Upper \\
\hline H1: Authoritative knowledge & $.22^{a}$ & $-.13 /(-1.98)$ & $-.10 /(.05)^{*}$ & $-.09 /(.04)^{*}$ & $-.02 /(.03)$ & -.08 & .04 \\
\hline H2: Engagement knowledge & .50 & $.45 /(6.63)$ & $.43 /(.07)^{* * *}$ & $.12 /(.06)^{*}$ & $.31 /(.04)$ & .24 & .41 \\
\hline H3: Social network connections & .34 & $.03 /(0.45)$ & $.02 /(.05)$ & - & - & - & - \\
\hline H4.1: Blogger character & .35 & $.13 /(1.91)$ & $.12 /(.06)$ & - & - & - & - \\
\hline H4.2: Character claims & .32 & $.05 /(0.69)$ & $.03 /(.05)$ & - & - & - & - \\
\hline H7: Knowledge outcome (med.) & - & - & - & $.68 /(.05)$ & - & - & - \\
\hline Adjusted $R^{2} /(F$ value $)$ & & \multicolumn{2}{|c|}{$.26 /(22.12 * * *)$} & \multicolumn{4}{|c|}{$.51 /\left(103.37^{* * *}\right)$} \\
\hline \multicolumn{8}{|l|}{ Blog characteristics } \\
\hline H5.1:Instrumental improvements to topic & .46 & $.21 /(3.19)$ & $.19 /(.06)^{* *}$ & $-.04 /(.05)$ & $.23 /(.05)$ & .14 & .34 \\
\hline H5.2: Involvement of topic-area community & .37 & $.10 /(1.66)$ & $.08 /(.049)$ & - & - & - & - \\
\hline H5.3: Reading-experience uniqueness & .45 & $.15 /(2.02)$ & $.16 /(.08)^{*}$ & $.05 /(.067)$ & $.11 /(.05)$ & .02 & .22 \\
\hline H5.4: Connected to topic-area materials & .43 & $.12 /(1.79)$ & $.11 /(.06)$ & - & - & - & - \\
\hline H5.5: Information quality & .39 & $.13 /(2.11)$ & $.12 /(.06)^{*}$ & $.07 /(.05)$ & $.05 /(.03)$ & -.008 & .121 \\
\hline H7: Knowledge outcome (med.) & - & - & - & $.66 /(.05)$ & - & - & - \\
\hline Adjusted $R^{2} /(F$ value $)$ & & \multicolumn{2}{|c|}{$.29 /(25.58 * * *)$} & \multicolumn{4}{|c|}{$.51 /\left(53.05^{* * *}\right)$} \\
\hline \multicolumn{8}{|l|}{ Outcomes of blog reading } \\
\hline H6.1: Knowledge outcome & .70 & $.70 /(13.65)$ & $.76 /(.06)^{* * *}$ & - & - & - & - \\
\hline H6.2: Community engagement & .42 & $.01 /(0.27)$ & $.01 /(.04)$ & - & - & - & - \\
\hline Adjusted $R^{2} /(F$ value $)$ & & \multicolumn{2}{|c|}{$.49 /(145.49 * * *)$} & & & & \\
\hline
\end{tabular}

${ }^{a}$ All correlations significant, $p<.01$ (1-tailed).

${ }^{*} p<.05 .{ }^{* *} p<.01 .{ }^{* * *} p<.001$. 
Trust Intentions and Blog Characteristics

H5.1b-H5.5b were tested using multiple-regression analysis, and results are also shown in Table 4.5. As the second column shows, all blog characteristics are significantly and positively associated with trust intentions $(p<.01)$. As the regression results (third and fourth columns) show, however, trust is only positively related to instrumental topicarea improvements $(\mathrm{H} 5.1 \mathrm{~b} ; p<.01)$, reading-experience uniqueness $(\mathrm{H} 5.3 \mathrm{~b} ; p<.05)$, and information quality $(\mathrm{H} 5.5 \mathrm{~b} ; p<.05)$. In the lack of significance of resource connections (H5.4b), it appears that blog readers emphasize the direct information role of blogs over others. The plethoric information-source options that topic-area enthusiasts have may impel them to go to experts directly rather than indirectly through a blogger. Blog readers may not want to link off a blog or feel that the experts the blogger refers them to would already agree with them and any information these third-party links would have would already have been gleaned and incorporated into the blogger's own site. The importance of the blogger as the pivotal trust focal point becomes obvious. Given that topic-area community involvement was found to drive the community-engagement outcome for blog readers (H5.2a), its non-significant impact on trust (H5.2b) similarly suggests that trust may derive primarily from knowledge acquisition and therefore, have a strong functional orientation.

\section{Trust Intentions and Blog-Reading Outcomes}

Table 4.5 also shows results of tests of $\mathrm{H6}$. Multiple-regression analysis reveals that, similar to tests of $\mathrm{H} 5$, trust intentions appear driven primarily by knowledge acquisition and not by community engagement. As predicted, knowledge outcomes do 
facilitate trust $(\mathrm{H} 6.1 ; p<.001)$, so it is clear that bloggers who wish to build an audience of trusting readers must ensure that each interaction with readers facilitates knowledge acquisition. The community-engagement outcome, in contrast, does not directly facilitate trust $(\mathrm{H6} .1 ; p>.05)$. While a lot of the buzz around blogs is about the topic-area communities they support, trust formation appears to focus on the blogger's direct experience and knowledge-filtering abilities and the communication to the reader of trustworthy information not available elsewhere leading to knowledge acquisition for the reader. The two blog-reading outcomes are complementary to each other $(r=.59, p<$ .001 ), however, so an emphasis on one could facilitate the other. Still, blog creators must ensure that blog content facilitates goal attainment for readers, with community building perhaps being a secondary goal.

\section{Trust Intentions, Blog-Reading Outcomes, and Blogging Characteristics}

The final question is whether the trust effects of significant blogger and blog characteristics are mediated by outcomes of blog reading. $\mathrm{H} 7$ was tested using the bootstrapping technique, a nonparametric resampling procedure for constructing

confidence intervals around the indirect relationship between independent and dependent variables. The bootstrapping technique makes no assumption as to the sampling distribution of the effects of the indirect relationships (Preacher and Hayes, 2004, 2008). The bootstrapping technique has been applied in recent research (e.g., Ahmed et al., 2010) and is recommended over competing techniques that interpret the magnitude of an indirect effect vis-à-vis the standard normal distribution, which Preacher and Hayes $(2004,2008)$ show is rarely appropriate for such effects. Given the risks of the omitted 
variable problem and of parameter bias (Preacher and Hayes, 2008), blogger and blog characteristics not under specific examination for their indirect effects on trust were controlled in the analyses. Given the lack of significance of the community outcomes in predicting trust, only the knowledge-based blog-reading outcome was tested as a mediating variable. To assess the extent of mediation, the main, unstandardized coefficient of each significant variable (column 4) can be compared to the unstandardized coefficient of the independent variable, controlling for knowledge outcomes (the mediating variable) (column 5). Mediation occurs when the bias-corrected confidence interval (columns 7 and 8) for the indirect effect of the independent variable on the dependent variable (column 6) does not include zero.

\section{The Indirect Effect of Blogger Characteristics on Trust Intentions}

For each of the two blogger characteristics and three blog characteristics identified above as significant antecedents of trust, the mediator variable reduces its effect on trust. For authoritative knowledge and engagement knowledge, mediation is just partial, since each of the main effects has retained some significance. Mediation is most clear for engagement knowledge; because the bias-corrected bootstrapped confidence interval does not include zero, the indirect effect of engagement knowledge on trust is non-trivial (Preacher and Hayes, 2008). The mediation effect is much less apparent for authoritative knowledge, since the bias-corrected bootstrapped confidence interval does include zero. For the most part, it can be suggested that authoritative knowledge has little to do with knowledge outcomes in the blogosphere. On the basis of this finding, blog readers appear to see little reason to trust an authoritative expert, even though 
authoritative knowledge is the prototypical foundation of fact-based, accurate information. An authoritative expert may seem out-of-touch or in possession of knowledge that applies minimally to the information needs of topic-area enthusiasts. A topic-area authority new to the blogging community may fail to achieve traction within the blogging community, unless perhaps it is able to persuade readers of the personal relevance of the knowledge it possesses. It could also be possible, however, for such a blogger to partner with other bloggers recognized for their topic-area engagement and as having positively impacted readers, as authority and engagement may represent a valuable combination for some readers. Engaged bloggers unfamiliar to readers, in contrast, may not require the same sort of partnership. Instead, establishing topic-area engagement may be enough for readers to establish positive trust intentions with them. This finding is notable because it implies that bloggers new to a topic-specific blogging community may quickly achieve influence in the community if they can establish themselves as heavily dedicated to, passionate about, and involved in the topic area.

\section{The Indirect Effect of Blog Characteristics on Trust Intentions}

The knowledge outcomes of blog reading were additionally assessed for their role in the relationships between trust and the three blog characteristics. All blog characteristics were mediated through knowledge outcomes. The strongest mediation effect is associated with the relationship between instrumental improvements and trust intentions (the main effect coefficient is now negative and the bias-corrected bootstrapped confidence interval does not include zero). The instrumental improvements that a blog is perceived to have facilitated in the topic area appear to relate to trust only to 
the extent that the improvements have directly benefitted the blog reader by way of knowledge gains. Uniqueness and information quality have not retained their significance, but the bias-corrected bootstrapped confidence interval associated with each either includes or is very close to including zero. Marketers interested in influencing readers may need to focus on developing personal relationships with readers, since readers appear individualistic in their orientation toward blogs. Figure 4.2 summarizes the analysis findings indicating the significant direct and mediated paths.

\section{Figure 4.2: Full and Partial Mediating Effects of the Knowledge Outcomes of Blog Reading}

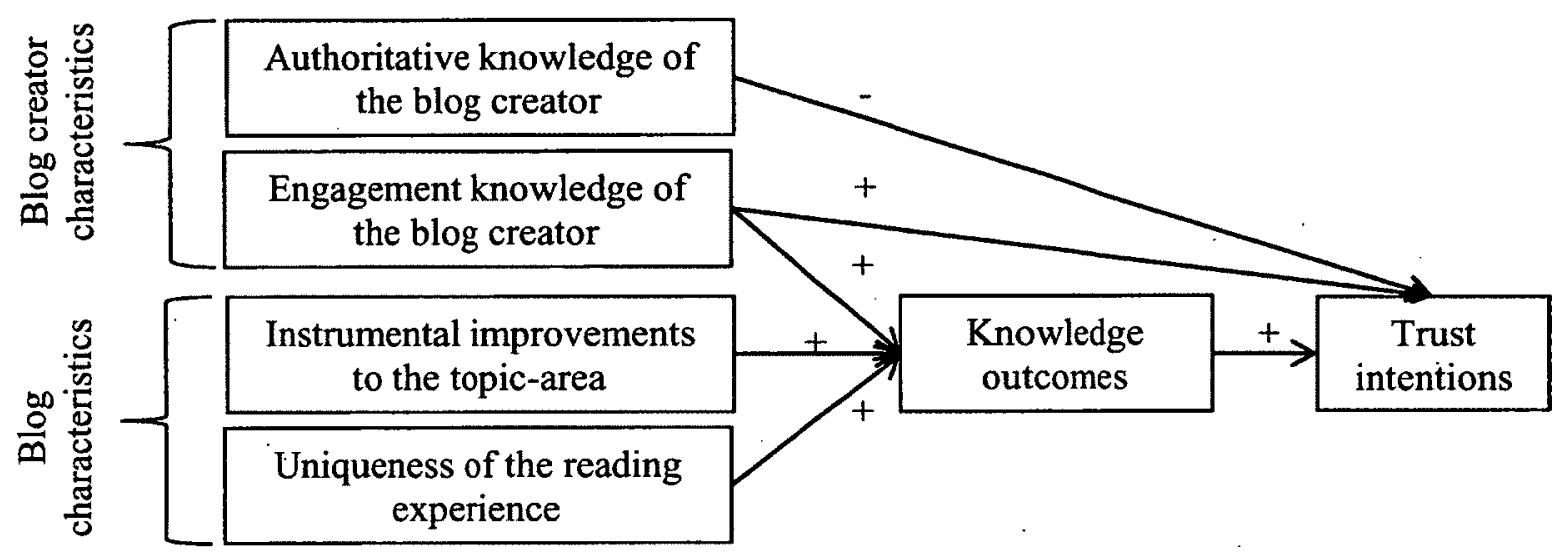

\section{Conclusion}

\section{Research Contributions}

This study casts light on the determinants of influence within blog-based topicarea communities from the perspective of blog readers. The blogosphere has a reputation as an "alternative" source of information (Johnson and Kaye, 2004) and findings reported here indicate that authoritative knowledge, one of the most conventionally recognized 
determinants of influence, has limited applicability to the topic-area blogosphere. Although knowledge is an essential characteristic of a trustworthy blogger, it is clear that the source from which the topic-area knowledge has been acquired by the blogger is a relevant issue for blog readers. Knowledge gained through personal topic-area experience appears much better suited to blog readers than that acquired through detached topic-area inquiry. If authoritative knowledge is a conventional ability base, then blog readers, or at least the blog reading context, is anything but conventional.

The assertions that any blog creator makes must appear to readers both accurate and relevant. Thus, authority may represent a liability in the blogosphere if it distances the blogger from the blog reader and their experiences, and marketers publishing blogs should recognize the limitations of it as they seek to secure readers. Marketers may be endowed with authoritative knowledge, but this particular ability base could hinder achievement of the business goals motivating their participation in the blogosphere. Consistent with advertising practice that makes heavy use of "ordinary-seeming" consumer endorsers, marketers in the blogosphere may wish to focus on establishing rapport with and satisfying the specific information needs of readers. Although consumer involvement in word-of-mouth marketing campaigns would seem designed to engender trust primarily by alleviating character-related concerns of audience members, it also evident that these campaigns could facilitate trust by influencing ability beliefs. Rather than reading technical details and advertising excerpts, blog readers may be particularly attracted to commentary based on personal experiences with which they may be more able to identify. 
Given the centrality of knowledge acquisition as a driver and benefit of blog reading, the trust that readers have in a blog and its creator is largely a function of the extent to which their prior experience with the blog is regarded as having increased their topic-area knowledge. The implications of erroneous topic-area assertions, then, could be dramatic, even when blogger and blog characteristics would other suggest high trustworthiness. Since this study reveals how much engagement knowledge is valued over authoritative knowledge in the blogosphere, blogger error may be particularly defined by blog readers. Blog readers may appreciate that engagement knowledge does not necessarily imply possession of all topic-area facts, and so define error more in terms of a misrepresented personal experience of the blogger. In general, the implications of blogger error could be serious, and research on them could help to further our understanding of how blog readers derive value from the blogosphere.

\section{Limitations and Future Research}

To extend the generalizability of these findings, future research should allow for explicit variation in the topic area involvement and pre-existing knowledge levels of blog readers. It is expected that these constructs may be salient bases for segmenting blog readers, although this study has not specifically attended to this issue.

Survey respondents were instructed in this research to consider and answer questions in terms of the blogs that reside within a topic area of personal relevance to them. These blog readers may differ from the general population both in terms of their ability to discern the quality of topic-area assertions and the importance of building topicarea knowledge over the long run. 
Involvement and pre-existing knowledge have both been shown to influence important communication phenomena but were not included as variables in this research. Of key importance is the consistent finding that message acceptance (i.e., a successful persuasion attempt) in high-involvement situations depends much more on the quality of the message than it does in low-involvement situations (e.g., Pentina and Taylor, 2010). In low-involvement situations, message recipients passively defer to the assertions of communicators they think are trustworthy. Message recipients with little prior topic-area knowledge and for whom the topic area lacks salience could, in contrast to the respondents involved in this research, rely much more on their perceptions of the ability and character of a communicator than on the objective accuracy of its topic-area assertions for determining their trust in it. However, the respondents did focus on the blogging area of most relevance to them. The character of a blog creator may assume greater significance for topic-area novices, given their presumed lack of confidence in their ability to discern between topic-area statements that could be of actual benefit to them and those that are incorrect. In a similar way, authoritative knowledge could be a valuable ability base for readers inexperienced with the topic area, since engagement knowledge is highly subjective and conditioned by the personal experiences of the knower. Marketer and non-marketer bloggers need to develop an empirically based understanding of their readers so that they can communicate trustworthiness and wellargued content to respective degrees that information-seeking consumers would find most valuable.

The lack of importance of blog creator character in predicting trust was a surprising result. Character correlates positively with trust $(p<.01)$, but blogger 
knowledge appears to override the influence of character on trust. The two forms of blogger knowledge identified in this study appear to have different character associations in terms of their individual effects on trust. Controlling for blogger character, engagement knowledge relates significantly to trust (albeit to a lesser extent; partial $r=.40, p<.001$ ), whereas authoritative knowledge loses its relationship with trust altogether (partial $r=$ $.04, p>.1)$. The bivariate correlation between engagement knowledge and character $(r=$ $.52, p<.001)$ is greater than that between authoritative knowledge and character $(r=.49$, $p<.001$ ), suggesting the potential that blog readers may attribute a certain level of inherent character to communicators with high engagement knowledge but not to those with high authoritative knowledge. As argued above, it may be beneficial for highauthority sources to communicate engagement knowledge, even if it is not their strongest ability base. If a blog reader were to communicate negative word-of-mouth in response to a blog post by a marketer blogger, for example, the effect of the communication on readers' trust in the blog could perhaps be tempered by signaling engagement knowledge (or de-emphasizing authoritative knowledge). More research is needed on these questions. 


\section{CHAPTER 5: EFFECTS OF BLOGGER-COMMUNICATED TRUST- RELATED INFORMATION AND BLOGGER ERROR}

(STUDY 3)

\section{Introduction}

The purpose of study 3 is to achieve an understanding of the implications of different types of blogger-communicated trust-related information vis-à-vis different types of product claims and "blogger error." Study 3 is a blog user-focussed investigation of trust development and trust deterioration in a highly familiar product-information context that differs markedly from the context of study 2 . Among the other questions it answered, study 2 identified the relationships of trustworthiness signals and trust beliefs (i.e., blogger characteristics) on trust in bloggers with whom respondents had prior personal experience. In contrast, study 3 evaluates the trustworthiness and credibility ratings implications of trust-related information communicated by an unfamiliar blogger who is seeking to influence consumer beliefs about a particular experience good.

One of the defining characteristics of electronic word-of-mouth communication is its vast potential reach, particularly as compared to conventional word-of-mouth communication (Rosenbloom, 2004; Thorsten Hennig-Thurau et al., 2004; Trammell and Keshelashvili, 2005): As a result, it is not uncommon for electronic word-of-mouth communication to be exchanged between a source and a recipient who, prior to the exchange, enjoyed no direct relationship (Kozinets et al., 2010; Lee and Youn, 2009). Whether within the electronic word-of-mouth communication context or not, when a claim is disseminated by an unfamiliar source, it is not possible for recipients to evaluate 
the expected accuracy of the claim on the basis of the past performance of the communicator. In the absence of prior personal experience, trustee-specific trustworthiness judgments can be made only on the basis of category-level stereotypes (Flanagin and Metzger, 2007), modified by persuasive trust-building tactics.

Researchers have observed that online communicators signal trust-building cues or disseminate trust-related arguments to influence trustworthiness beliefs and claimaccuracy performance expectations of audience members (e.g., Kim and Benbasat, 2003; Koufaris and Hampton-Sosa, 2004; Lee, Im, and Taylor 2008; Urban, Amyx, and Lorenzon, 2009). Study 1 examined this behaviour specifically, and found that wine bloggers are active communicators of trustworthiness signals. Study 2 revealed that outright claims of trustworthiness (e.g., "I am trustworthy;" "I do not lie.") are ineffective as trust antecedents as compared to established trustworthiness beliefs, but blog readers have few other unique pieces of information on which to base a trustworthiness judgment concerning an unfamiliar blogger. By eliminating perceptions of the prior performance of a specific blogger, tests of the efficacy of individual-level trust-related information can be conducted.

Study 2 revealed the importance of topic-area knowledge acquisition as an antecedent of trust for blog readers. The intuitive implication of that finding is that bloggers who consistently satisfy the needs of their readers for accurate topic-area information in turn are likely to be awarded by their readers with positive trust intentions and their correlated outcomes. Customer satisfaction research conducted by services marketing researchers may offer insight into the benefits bloggers can receive from satisfied readers: service providers who meet or exceed the expectations of their 
customers benefit from positive consumer affect as well as high re-patronage and positive word-of-mouth intentions.

Services marketing researchers recognize, however, that failure by even the most competent service provider can sometimes be unavoidable (e.g., Mattila, 2001). Concerns of knowledge and reporting bias and weak editorial standards suggest failure, or "blogger error," to be a realistic prospect in the blogosphere. Blogger error represents an inherent violation of the implicitly or explicitly made domain-specific promises that a blogger makes to its readers. Blogger error and its cognitive, affective, and conative implications for blog readers, bloggers, and organizations are assessed in this study.

\section{Objectives and Structure}

Although trust in a familiar blogger is not influenced by its trustworthiness signaling behaviours (Study 2), evidence nonetheless suggests that bloggers are active signalers of trustworthiness claims (Study 1). This study seeks to identify the effects of trust-related information communicated by a blogger who has posted a review of the hedonic or utilitarian merit of a movie on its blog on ratings of the trustworthiness and credibility of the blogger. Bloggers can develop and draw from a variety of ability bases in order to make accurate product claims, so one objective of this study is to identify whether or not the authoritative knowledge liability identified in study 2 exists outside the topic-area blog domain. This study also seeks to identify the trustworthiness and credibility implications of disclosed involvement in a word-of-mouth marketing (WOMM) campaign, as consumer responses to and other implications of WOMM have 
been cited as important research topics in the general context of "customer-to-customer interactions" (Libai et al., 2010).

Another objective of this study is to identify the cognitive, affective, and conative implications of blogger error for blog readers, bloggers, and organizations. Research in complementary domains suggests that blogger error may lead to negative affective states and behavioural intentions but that these outcomes may be shaped by the blame that offended blog readers assign for the error. In this study, responses to blogger error are evaluated in light of the trust-related information the blogger communicated about itself to readers of its blog. This inquiry involves an examination of the process through which behavioural outcomes of blogger error unfold, with particular attention to blame assignment as well as dissatisfaction and anger caused by the error.

The purpose of study 3 is therefore to achieve a better understanding of the implications of different types of blogger-communicated trust-related information vis-àvis different types of product claims and "blogger error." The objectives of study 3 are:

1. to identify the specific effects of blogger signals of authoritative knowledge and consumption experience as well as disclosed word-of-mouth marketing participation on blogger trustworthiness beliefs and the credibility of a hedonic-focused or utilitarian-focused movie review;

2. to identify the cognitive, affective, and conative responses of blog readers to blogger error and assess the extent to which they apply to blog readers, bloggers, and organizations. More specifically, 
a. to assess how blog readers respond to error committed by a blogger believed to possess a high level of authoritative knowledge or consumption experience;

b. to assess how blog readers respond to error committed by a blogger who discloses its participation in a word-of-mouth marketing campaign;

c. to assess the negative affective outcomes of blogger error;

d. to assess how trust intentions change following blogger error;

e. to assess whether blogger error directly or indirectly causes blog readers to seek revenge for the error against both the blogger and, in the case of a product review, the maker of the product.

This study is structured as follows. First, an overview of relevant literature streams is provided and then hypotheses are developed. Second, the methodology that was employed in order to permit hypothesis testing is presented. Third, results of hypothesis testing concerning the respective effects of authoritative knowledge versus consumption experience signals and word-of-mouth marketing disclosures on blogger trustworthiness and credibility ratings as well as on outcomes of blogger error are presented. In the fourth and final section, summary remarks concerning the limitations and contribution of this study as well as suggestions for future research are provided. 


\section{Literature Review and Hypotheses Development}

\section{Blogger-Communicated Trust-Related Information and Blogger Ability Ratings}

The perceived ability of a blogger is the extent to which it is perceived by a blog reader to be capable of performing topic-area tasks in which the blog reader has a personal stake, such as making and disseminating accurate claims (Alba and Hutchinson, 1987; Doney and Cannon, 1997; Lee and Turban, 2001; Mayer, Davis, and Schoorman, 1995; Ridings, Gefen, and Arinze, 2002). Accurate subject-specific claims can conceivably be made and disseminated from a variety of different ability bases (Jacoby et al., 1986). Subject-matter experts, with their formal education, relevant experience, and recognized achievements, are presumed to know the objective "truth" about the subject matter and, because of their perceived ability to make and disseminate accurate subjectspecific claims, they may be active outside the blogosphere teaching topic-area courses and writing in the mainstream media. For experience goods such as movies, accurate claims can presumably be made and disseminated by "fans," "enthusiasts," and other consumers with high levels of good-directed passion, zeal, enduring involvement, loyalty, and consumption experience (Alba and Hutchinson, 1987; Dodd, Pinkleton, and Gustafson, 1996; Redden and Steiner, 2000; Smith, Fisher, and Cole, 2007; Thorne and Bruner, 2006). As with the uniqueness of a subject-matter expert within the subjectmatter community, the typical fan is someone "who lies outside the normal range of behavior in his or her devotion to a cause, religion, a team, or even a brand" (Smith, Fisher, and Cole, 2007, p. 78).

Fanatical consumption is very relevant to entertainment products (Thorne and Bruner, 2006), as consumers can exhibit extreme enthusiasm for specific entertainment 
experiences (e.g., Star Trek, Kozinets, 2001) or general ones such as watching movies (Redden and Steiner, 2000). Movies inherently mean an extraordinary amount to highly enthusiastic movie-watching consumers and this meaning is reflected in their frequent movie-watching behaviours and complex affiliative bonds to other movie fans (Smith, Fisher, and Cole, 2007; Thorne and Bruner, 2006).

The cognitive responses of blog readers to blogger-communicated trust-related information are examined in this study. Bloggers can disseminate trust-related claims in their one-way (e.g., About Me statements, blog posts) and multi-way (e.g., responding to reader comments) interactions with blog readers. The education, experience, and achievements of subject-matter experts can all be related to blog readers through these one-way and multi-way blogger-blog reader interactions. The extreme subject-specific enthusiasm of fans can also be communicated through these blog contents. In particular, a product enthusiast blogger can communicate frequent product consumption, thoughts and feelings about the product, and affiliative bonds to other product fans to blog readers through these one-way and multi-way blogger-blog reader interactions. Given the importance of communicator trustworthiness in the blogosphere (Grant, Clarke, and Kyriazis, 2007), it is predicted that blog readers attend to the trust-related information bloggers communicate about themselves. Belief change as a result of the bloggercommunicated trust-related information will be reflected in the ability ratings of the blogger. Specifically, the blogger who disseminates the trust-related claim as to its education, experience, and achievements (i.e., the subject-matter expert blogger) is predicted to receive a higher authoritative knowledge rating from blogger readers than the blogger who disseminates the trust-related claim as to its high enthusiasm for the product 
(i.e., the product-enthusiast blogger). From a consumption experience perspective, it is

predicted that the product-enthusiast blogger will receive a higher rating than the subjectmatter expert blogger.

HIa: The authoritative knowledge rating of the subject-matter expert blogger is higher than that of the product-enthusiast blogger.

HIb: The consumption experience rating of the product-enthusiast blogger is higher than that of the subject-matter expert blogger.

\section{Word-of-Mouth Marketing (WOMM) and Blogger Character Ratings}

Word-of-mouth communication refers to positive or negative product-, brand-, or organization-related evaluative correspondence between two or more people that is typically based on the personal consumption experience of the communicator (Carl, 2008; Dichter, 1966). Even though it is well recognized that the provocation, stimulation, and production of favourable word-of-mouth communication is an advertising responsibility (e.g., Dichter, 1966), emerging marketing practices involve unprecedented "amplification" (i.e., intervention by marketers in word-of-mouth exchanges between consumers) and direct exchange (e.g., product "seeding") between marketers and participants of company-sponsored word-of-mouth marketing campaigns (Kozinets et al., 2010). Indeed, word-of-mouth marketing is a growing marketing tactic (Brown, Broderick, and Lee, 2007). Although the Word of Mouth Marketing Association asserts that WOMM is not about "creating word of mouth" (emphasis added), but rather "building active, mutually beneficial consumer-to-consumer and consumer-to-marketer communications" (2007), Kozinets et al. (2010) argue that WOMM involves intentional 
application of marketing tactics in order to influence word-of-mouth communication among consumers. The majority of consumers believe that unified guidelines for marketing practices on social media are necessary (American Marketing Association, 2011) and, in the United States, bloggers who receive compensation from companies for reviewing their products or providing product endorsements are now required to disclose that material connection to their readers (Federal Trade Commission, 2009).

Studies have reported inconsistent results with respect to the beliefs about and responses of consumers to WOMM disclosures (e.g., Carl, 2008; Ferguson and Ellen, 2006; Lee and Youn, 2009; Wei, Fischer, and Main, 2008). Consumer disapproval of WOMM could be less prevalent than might be expected, and some studies have even shown that admitted involvement in a WOMM campaign can have a beneficial effect on communicator-related trust beliefs and product evaluations (e.g., Carl, 2008; Wei, Fischer, and Main, 2008). The underlying rationale or attractiveness to marketers of WOMM is intuitive. WOMM appeals to marketers both because consumers are regarded as comparatively open to product-related assertions by non-commercial information sources and because this particular form of covert marketing is amenable to inexpensive and rapid implementation (Kozinets et al., 2010; Sprott, 2008; Trusov, Bucklin, and Pauwels, 2009; Wei, Fischer, and Main, 2008).

Attribution theory examines the social-cognitive processes that lay observers, or "attributors," use in attributing internal and external causal sources to perceived phenomena (Folkes, 1988; Kelley, 1973; Robertson and Rossiter, 1974). A claim that is believed by recipients as truly reflecting the attitudes of the communicator is attributable to an internal causal source, whereas a claim that is not believed to truly reflect them can 
be attributed to an external causal source. Claims made by salespeople and other communicators with market or financial interests are presumed to be externally caused (Campbell and Kirmani, 2000; Kelley, 1973), since "when a behavior occurs in the presence of a sufficiently strong facilitative force, an observer should not infer that the actor is predisposed to perform that behaviour" (Gilbert and Malone, 1995, p.22). In the event that a claim is attributed to an external cause, recipients suspect that the claim may not reflect the true attitudes of the communicator, as the likelihood of internal causation is inherently discounted when external causation is believed (Kelley, 1973). As a result, recipients attach more weight to a claim they perceive as having originated from an information source that is disinterested in the market and financial performance of the objective referenced in the claim than they do to a claim communicated by a source with a clear reporting bias (Bickart and Schindler, 2001; Mourali, Laroche, and Pons, 2005). Therefore, a product claim disseminated by an apparent fellow consumer enjoys an inherent credibility advantage over the same claim disseminated by a commercial communicator (Hunt, Smith, and Kernan, 1985; Kozinets et al., 2010). Indeed, Dichter $(1966$, p. 157) argues that:

"No commercial ad can help having the ultimate intention of selling for monetary profit. On the other hand, the foremost source of selling power in Word-of-Mouth lies in the belief that this very intention is missing." Through the transformation of marketing claims into claims that conform to community norms and expectations (Kozinets et al., 2010), WOMM provides organizations with great potential to persuade information-seeking consumers. Still, WOMM implies a marketing relationship that is not typical for word-of-mouth 
communication. Although claims made by non-commercial communicators may generally arouse less persuasion knowledge (i.e., be less suspicious) than claims made by commercial communicators, the material blogger-organization connection implied by WOMM may be sufficient for initiating the various mechanisms that consumers have developed in order to cope with persuasion attempts. Accordingly, organizations have shown interest in communicating information that, to unsuspecting consumers, has the outward appearance of originating from a non-commercial instead of a commercial source (Ashley and Leonard, 2009). As the very idea of "covert marketing" is to keep it out of consumer consciousness (Wei, Fischer, and Main, 2008), covert marketing practitioners intentionally hide or distort information from consumers as to the tactics they use to collect consumer information and disseminate product information to consumers (Milne, Bahl, and Rohm, 2008). For example, a blogger could be provided compensation in order "to talk up a product without disclosing that compensation" (Carl, 2008 , p. 225), with the effect being that consumers could make a consumption decision "they otherwise might not have if they had gathered more information or processed the communication differently" (Milne, Bahl, and Rohm, 2008, p. 60).

Attribution theory offers a conceptual rationale for expecting disclosed involvement in a WOMM campaign to negatively affect the beliefs of blog readers about the blogger character but to positively affect the beliefs of blog readers about blogger deception intent, which refers to the extent to which a blogger has a reporting bias (Eagly, Wood, and Chaiken, 1978). A WOMM disclosure by a blogger implies that the blogger has an external reason for writing and posting a favourable product review and may lack the freedom needed to post a negative product review. In contrast, the blogger 
who makes no WOMM disclosure may be perceived to possess a desire to help consumers and to have the freedom to make honest remarks about the product, even if the remarks are negative.

HIc: The character rating of the WOMM blogger is lower than that of the non-WOMM blogger.

H1d: The deception intent rating of the WOMM blogger is higher than that of the nonWOMM blogger.

\section{Blogger Credibility Ratings}

The accuracy of experiential claims or claims regarding experience goods can only practically be determined by acting on them and judging if they were substantiated by experience (Davis, 1989; Ford, Smith, and Swasy, 1988; Jover, Montes, and Fuentes, 2004; Nelson, 1970; Raban and Rafaeli, 2006; Sussman and Siegal, 2003). Given the risk implied by evaluating claim accuracy in this manner, claim recipients develop an expectation of the extent to which the claim would be matched by experience and make an acceptance decision largely on that basis (Bailey and Pearson, 1983; Meyers-Levy and Malaviya, 1999). Accuracy expectations therefore relate to the believability of a claim and/or its source (Hilligoss and Rieh, 2008; Metzger, 2007), which in turn relates to the perceptions of claim recipients of the overall domain-specific ability and motivation of an information source to make accurate domain-specific claims (Flanagin and Metzger, 2000; Jo, 2005; Metzger, 2007; Tormala and Petty, 2004).

Attribution theory suggests that a product claim communicated by a WOMM would be less believable than one communicated by a non-WOMM blogger because 
recipients would attribute it to an external cause by discounting the likelihood of internal causation (Eagly, Wood, and Chaiken, 1978; Folkes, 1988; Kelley, 1973). It is expected that the credibility rating of the blogger who makes the WOMM disclosure will be lower than that of the blogger who does not make the WOMM disclosure. As Hunt, Smith, and Kernan (1985, p. 451) explain, the credibility and persuasiveness of communicators who are seen to have something to gain from persuasion are inherently diminished in comparison to those who are not seen in such a light; when expectations of bias are confirmed, consumers "are thought to explain the message in terms of the biasing elements" and "the validity (veridicality) of the message is discounted and the credibility of the source questioned."

H2a: The credibility rating of the WOMM blogger is lower than that of the non-WOMM blogger.

Movie reviews are important for informing movie-selection decisions by consumers. Consumers seek enjoyable movie-watching experience, but the common assumption that enjoyment derives exclusively from amusing and pleasurable (i.e., hedonic) movie-watching experiences is not appropriate (Oliver and Bartsch, 2010). Movie watchers derive enjoyment from different types of movie-watching experiences, including ones that are informative, based on true stories, and that allow them to find authenticity and discover truth (Beverland and Farrelly, 2010; Gazley, Clark, and Sinha, 2011; Oliver and Bartsch, 2010; Oliver and Raney, 2011).

Movie reviews and reviews of other experience goods are often provided by expert critics with discriminating tastes and consumers with pedestrian preferences. 
Differences exist among these communicators that could affect the extent to which they are able to satisfy the domain-specific needs of information-seeking consumers (Moon, Bergey, and Iacobucci, 2010; Yaniv, Choshen-Hillel, and Milyavsky, 2011). Research shows a relationship between taste discrimination and subject-matter expertise. For music, Yaniv, Choshen-Hillel, and Milyavsky (2011) suggest that high taste discrimination in music implies not only familiarity with music but also knowledge of performers, history, and musical instruments. Arguably, subject-matter expertise would be needed for an information source to make an accurate claim concerning an aspect of musical history. Indeed, musical history knowledge does not necessarily develop out of familiarity with contemporary music. On the other hand, authoritative knowledge may be less valuable than consumption experience for making accurate claims concerning the hedonic characteristics of a new musical release.

Like many consumer products and services, movies have objectively assessable components (e.g., historical accuracy, cultural authenticity) and subjectively assessable components (e.g., excitement level, humour level). It is predicted that a blogger with high subject-matter expertise would be positioned better than a blogger with high consumption experience to make accurate claims about historical accuracy, cultural authenticity, and other utilitarian matters in a movie-watching experience. The education, experience, and achievements of the subject-matter expert blogger (compared to the product-enthusiast blogger) should ensure it a high credibility rating when the movie review it wrote addressed the utilitarian merit of the movie. For the subject-matter expert blogger (product-enthusiast blogger) writing about this topic, alignment (misalignment) exists between its signaled ability base and the content of the product review. 
In contrast, it is predicted that a blogger with high consumption experience would be better positioned than a blogger with high subject-matter expertise to make accurate claims about excitement, humour, and other hedonic matters in a movie-watching experience. Hedonic movie merit is primarily assessed on subjective grounds, and because a product-enthusiast blogger (compared to a subject-matter expert blogger) can relate to ordinary movie watchers and is attuned to mass market movie preferences, it should receive a high credibility rating when the movie review it wrote addressed the hedonic merit of the movie. For the product-enthusiast blogger (subject-matter expert blogger) writing about this topic, alignment (misalignment) exists. between its signaled ability base and the content of the product review. At a general level, alignment between the signaled ability base of a blogger and the content of a product review is predicted to produce a higher blogger credibility rating than misalignment between blogger ability and product review content.

H2b: The credibility rating of the product-enthusiast blogger (subject-matter expert blogger) who reviewed the hedonic (utilitarian) merit of the movie will be greater than that of the subject-matter expert blogger (product-enthusiast blogger).

\section{Category-level beliefs.}

Blog readers are expected to develop beliefs about a blogger at least partially on the basis of the individual-level trust-related information it communicates. Additionally, beliefs about the overall credibility of a specific blogger may be influenced or reflective of beliefs about the overall credibility of the typical blogger. Generalized beliefs concerning distinctive groups develop through a process of socialization (e.g., hearing remarks about the group by influential peers) and evaluation of the outcomes of prior 
trust-related exchanges with members of the groups (Babin, Boles, and Darden, 1995;

Friestad and Wright, 1994; Williams, 2001). Similarly, evidence suggests that the likelihood of a consumer using the Internet to conduct a product information search is largely reflective of the favourability of attitudes of the consumer toward the internet generally (e.g., Das et al., 2003). Beliefs about the pervasiveness of credibility in the blogosphere are likely to reflect the extent to which past blog experiences have convinced readers that bloggers possess the ability and motivation necessary for making accurate claims.

H3: The credibility rating of the typical blogger who posts a movie review on a personal blog is positively related to the credibility rating of the experiment blogger.

\section{Individual-level blogger credibility and individual-level trust beliefs.}

Authoritative knowledge and consumption experience are both predicted to positively relate to the perceived credibility of the experiment blogger. Although the ability bases differ on several key dimensions (e.g., sources), they both bestow ability on the holder to fulfill the promises it makes. By posting a product or service review, the blogger is implicitly promising to its readers that the claims it is making are credible sources of information of potential value to the reader. As a result, the credibility of the experiment blogger should increase as beliefs about the authoritative knowledge and consumption experience of the blogger increase. 
H4a: The credibility rating of the experiment blogger is positively related to the authoritative knowledge rating of the experiment blogger.

H4b: The credibility rating of the experiment blogger is positively related to the consumption experience rating of the experiment blogger.

The character of a blogger is the totality of personal integrity and benevolence toward readers. Perceived integrity concerns the extent to which a trustee is believed to be unbiased and committed to moral and ethical conduct (Mayer, Davis, and Schoorman, 1995; Ridings, Gefen, and Arinze, 2002). Perceived benevolence is an assessment of the extent to which a trustee has goodwill intentions and, rather than wanting solely to benefit from a trustor, desires to do good things for it (Colquitt, Scott, and LePine, 2007; Lee and Turban, 2001; Mayer, Davis, and Schoorman, 1995; Pavlou and Dimoka, 2006; Ridings, Gefen, and Arinze, 2002). Topic-area bloggers with strong character (i.e., high benevolence and integrity) can be relied upon to perform topic-area tasks to the extent to which they are capable. Accordingly,

H4c: The credibility rating of the experiment blogger is positively related to the character rating of the experiment blogger.

Deception intent refers to the extent to which the blogger is perceived to suffer from reporting bias (Eagly, Wood, and Chaiken, 1978). To the extent that the blogger is believed to lack motivation to make accurate claims about the movie (i.e., is perceived to have reporting bias), it is expected that blog readers will doubt the credibility of the blogger. This prediction is based on similar findings concerning the "default assumption" regarding salespeople that consumers operate under which holds that salespeople are 
principally motivated to sell products rather than satisfy and build relationships with customers (Campbell and Kirmani, 2000, p. 72). When a blog reader recognizes that a blogger intends to deceive him or her, persuasion knowledge research indicates that the blog reader is likely to perform different coping mechanisms in order to guard himself or herself against any persuasion attempt of the blogger (Friestad and Wright, 1994). Specific coping mechanisms include source derogation, counter-argumentation, and discounting (Smith and Swinyard, 1988). As a result, the credibility rating of the blogger is hypothesized to negatively relate to the deception intent rating of the blogger.

H4d: The credibility rating of the experiment blogger is negatively related to the deception intent rating of the experiment blogger.

Rapport has been conceptualized in terms of similarity (Karmarkar and Tormala, 2010; Price, Feick, and Higie, 1989) and likeability (Karmarkar and Tormala, 2010; Smith, Menon, and Sivakumar, 2005). The similarity of an information source to an individual rater (e.g., blog reader) can be assessed in different ways, including on the basis of demographic similarity (Lau, Lam, and Salamon, 2008; Riordan and Wayne, 2008) or behavioural similarity (Yaniv, Choshen-Hillel, and Milyavsky, 2011). Evidence suggests that consumers trust information sources that are likeable and similar to themselves. For example, consumers have been observed to report higher purchase intentions when a friend recommends a movie than when a professional critic recommends the movie (e.g., Gazley, Clark, and Sinha, 2011).

H5: The credibility rating of the experiment blogger is positively related to bloggerrater rapport. 
The above-listed hypothesized antecedents of individual-level trust beliefs and credibility ratings are presented in Figure 5.1.

\section{Blogger Error}

\section{Blameworthiness.}

Blameworthiness for a negative occurrence can be defined as the extent to which an offended party (e.g., a customer) perceives the offending party (e.g., service provider) as being accountable for the events that lead to the negative occurrence (Grégoire, Laufer, and Tripp, 2010). When a negative event occurs, offended parties commence an attributional search in order to develop a plausible causal explanation for the event (Kelley, 1973; Weiner, 2000). Through the practice of "naïve psychology" (cf. Heider, 1958), blog readers are expected to consider the intangible or latent qualities of the blogger (e.g., character, motives, beliefs, desires, and intentions) in order to assess the extent to which the blogger is deserving of blame for the error (Gilbert and Malone, 1995). 


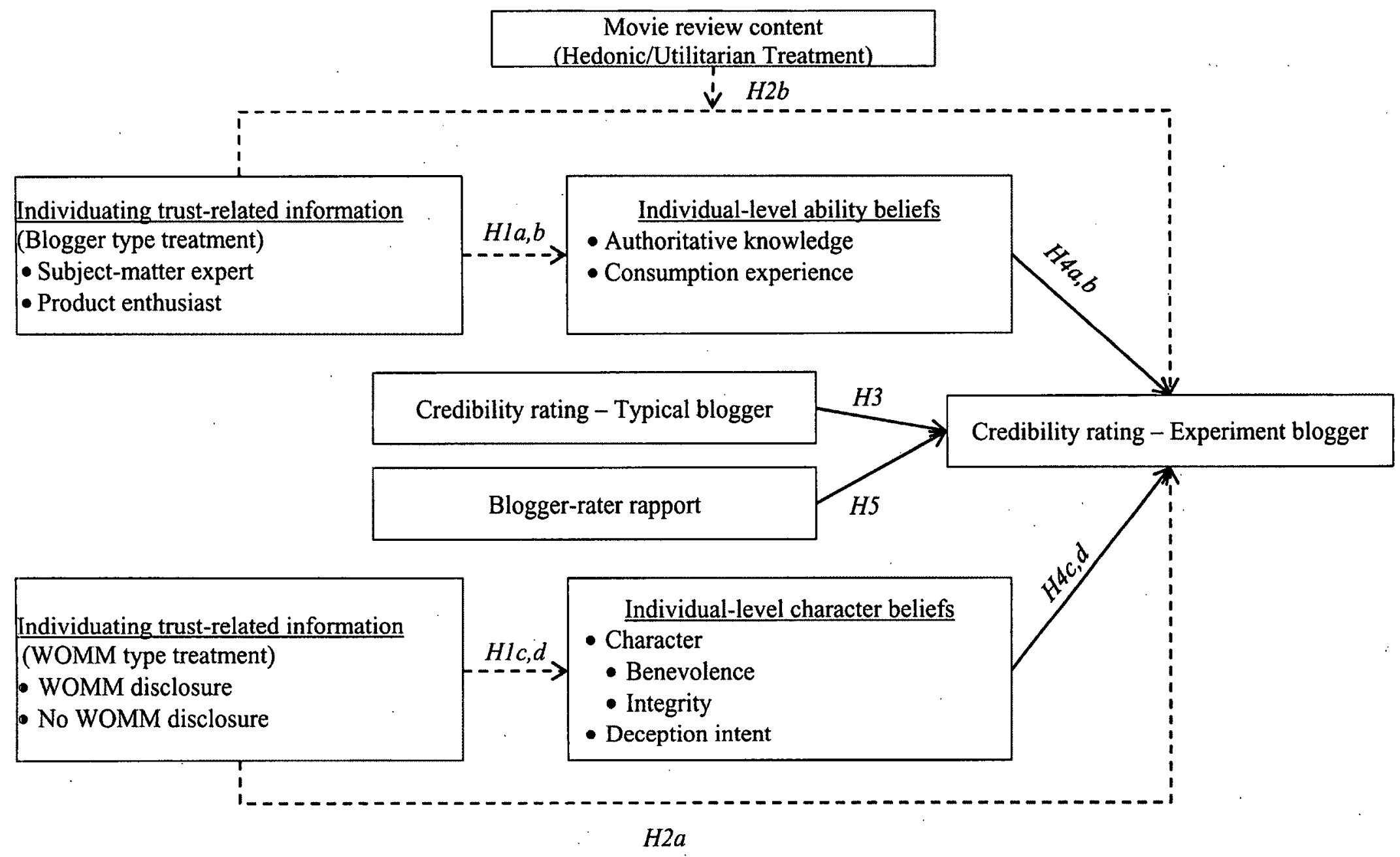

Note: Broken lines represent tests of experimental treatment effects. 
To the extent that blog readers attribute the error to an external cause (i.e., believe they did not cause the error themselves), the blogger as well as the movie company must be considered as potential targets of the blameworthiness cognitions of blog readers. Since the writing of the movie review was a purposive act, it is expected that blog readers would not attribute blogger error to inadvertence on the part of the blogger. As a result, it is expected that blog readers would consider the extent to which the content of the movie review matched the ability base of the blogger in evaluating blogger blameworthiness. Under a situation of support-source accordance, it is expected that blog readers would hold the blogger blameworthy for the error, as the blogger should have been able to make accurate remarks about the movie. When the signaled ability base of the blogger did not match the content of the movie review (i.e., support-source discordance), it is expected that blog readers would hold the blogger less accountable, since the potential for an honest mistake would be greater.

H6: $\quad$ The perceived blameworthiness of the product-enthusiast blogger (subject-matter expert blogger) for its review of the hedonic (utilitarian) merit of the movie is greater than for its review of the utilitarian (hedonic) merit of the movie.

Blogger blameworthiness is expected to vary according to whether or not the blogger disclosed its participation in a WOMM campaign to blog readers. Specifically, the blogger who admitted to blog readers that it receives compensation for writing product reviews from the company that makes the products is expected to receive more blame for the error than the blogger who did not make the admission. Like a salesperson who personally gains from overstating the quality of the products he or she sells, the WOMM blogger is likely to be perceived by blog readers either to want to overstate the 
quality of the movie or to be restricted by its WOMM relationship from disseminating an accurate review of the movie. The WOMM blogger is likely to receive more blame for the error than the non-WOMM blogger because of the controllability implied by the WOMM disclosure as compared to the non-WOMM blogger. Whereas the non-WOMM blogger could have unknowingly made the error (i.e., made an honest mistake) or could have lacked control over the content of the movie review (e.g., technical glitch), the WOMM blogger is not likely to receive the benefit of those doubts. A similar suggestion was made by Wang and Huff (2007) in their experimental manipulation of integritybased versus capability-based trust-violating events; unlike the capability-based trustviolating event, the integrity-based trust-violating event took place in a scenario that involved a clear financial benefit (additional revenue) for the trust violator as a result of committing the trust-violating act.

H7: $\quad$ The perceived blameworthiness of the WOMM blogger for the blogger error is greater than that of the non-WOMM blogger.

The beliefs that blog readers developed concerning the character and deception intent of the blogger are expected to influence the extent to which blog readers blame the blogger for the error. The character rating of the blogger is likely to protect the blogger from receiving blame for the error, and benevolent trustees who are committed to morally acceptable conduct are inherently opposed to the intentional deception of blog readers. Blog readers cannot be helped by deceptive blog content, and so it is predicted that the character rating of the blogger will negatively relate to the blame the blogger receives for the error. In contrast, the deception intent rating of the blogger is hypothesized to 
positively relate to the blame the blogger receives for the error. The relationship between deception intent and actual deceptive behaviour (e.g., writing a deceptive movie review) is presumably strong, particularly since the blogger would have had the opportunity to write a deceptive movie review if it wanted to do so (Ajzen, 1991).

H8: The perceived blameworthiness of the blogger for the blogger error is negatively related to the character rating of the blogger.

H9: The perceived blameworthiness of the blogger for the blogger error is positively related to the deception intention rating of the blogger.

\section{Affective responses to blogger error.}

Negative occurrences are noted for producing one or more emotions of dissatisfaction, regret, anger, or even moral outrage (e.g., Estelami, 2000; Iglesias, 2009; Kalamas, Laroche, and Makdessian, 2008; Weiner, 2000; Wetzer, Zeelenberg, and Pieters, 2007; Zeelenberg et al., 2000). Strong negative affective responses to a negative occurrence are to be expected when offended parties believe that the occurrence could have been prevented by the responsible offending party (Iglesias, 2009; Weiner, 2000). Negative affective responses are also to be expected when the behaviours that lead to the negative occurrence are perceived to be contrary to societal norms (Bitner, Booms, and Tetrault, 1990).

Anger and dissatisfaction are affective responses to blogger error of particular interest in this research. Anger is defined as a moderately intense (Kalamas, Laroche, and Makdessian, 2008) emotional state characterized by aggressive other-directed feelings, thoughts, and action tendencies (Bougie, Pieters, and Zeelenberg, 2003). Anger is an 
important affective response to a negative occurrence when the offended party perceives the offending party to be responsible for the occurrence and to have had control over the occurrence (Bonifield and Cole, 2007). Anger and dissatisfaction have been found to correlate positively with each other, but dissatisfaction is characterized as a general negative affective state that does not depend on the manner by which a negative event occurred but simply on the perception that an unexpected negative event occurred that was caused by somebody else or by an uncontrollable circumstance (Bougie, Pieters, and Zeelenberg, 2003; Wetzer, Zeelenberg, and Pieters, 2007; Zeelenberg et al., 2000). It is expected that the blameworthiness of the blogger and movie company will both positively relate to the anger and dissatisfaction that are produced in blog readers as a result of blogger error.

Anger and dissatisfaction are also expected to positively relate to the extent to which blog readers perceive the movie review to represent an incorrect assessment of the movie. The perceived incorrectness of the movie review can be assessed in terms of the gap that exists between the movie-related claims made by the blogger and the reality of the movie (i.e., claim-fact discrepancy; Darke and Ritchie, 2007).

H10: The anger caused by blogger error is positively related to the perceived blameworthiness of the blogger for the error.

H11: The anger caused by blogger error is positively related to the perceived blameworthiness of the movie company for the error.

H12: The anger caused by blogger error is positively related to the perceived incorrectness of the movie review. 
H13: The dissatisfaction caused by blogger error is positively related to the perceived blameworthiness of the blogger for the error.

H14: The dissatisfaction caused by blogger error is positively related to the perceived blameworthiness of the movie company for the error.

H15: The dissatisfaction caused by blogger error is positively related to the perceived incorrectness of the movie review.

\section{Post-error trust intentions.}

It is expected that blogger error will produce a negative effect on post-error trust intentions relative to pre-error trust intentions. Beyond pre-existing trust intentions, it is expected that post-error trust intentions will be related to both the cognitive (namely, blogger blameworthiness, movie company blameworthiness, and movie review incorrectness) and affective (namely, anger and disappointment) responses to blogger error. The blameworthiness of the blogger is expected to negatively relate to post-error trust intentions because it implies that the blog reader believes the blogger actually took steps to deceive him or her and that the blogger could take similar steps at a future time. This hypothesis is supported by service failure research, which has found that offended consumers require that offending service provider to at least make an attempt to repair the relationship and right the wrong that it caused (e.g., Bonifield and Cole, 2007).

H16: Post-error trust intentions are negatively related to the perceived blameworthiness of the blogger for the error. 
The relationship between movie company blameworthiness and post-error trust intentions is somewhat uncertain. Consistent with the conceptual argument made for the relationship between blogger blameworthiness and post-error trust intentions, it is predicted that movie company blameworthiness will negatively relate to post-error trust intentions. This assumption is reasonable, given that the blogger would have only received some extrinsic benefit (e.g., compensation or implied promise of future compensation) if it wrote the movie review in order to satisfy the stated or unstated expectations of the movie company. If, however, blog readers see the relationship between blogger blameworthiness and movie company blameworthiness as a trade-off between the two, then the relationship between post-error trust intentions and movie company blameworthiness could be positive.

\section{H17: Post-error trust intentions are negatively related to the perceived blameworthiness of the movie company for the error.}

The extent to which blog readers perceive the movie review to represent an incorrect assessment of the movie is expected to negatively relate to post-error trust intentions. Regardless of the cause of the error, movie review incorrectness (i.e., error size) implies considerable risk of loss to blog readers every time they read the blog and rely on assertions made in it. In addition, blog readers are unlikely to recommend the blog to their personal acquaintances because of the risk of loss their acquaintances could incur as well as the punishment they could receive from their acquaintances for recommending an unreliable blog to them.

H18: Post-error trust intentions are negatively related to the perceived incorrectness of the movie review. 
Anger and dissatisfaction are negative affect states produced by blogger error. These negative affective states are predicted to negatively relate to post-error trust intentions. Anger and disappointment are likely to dissipate over time, but these negative affective outcomes of blogger error are expected to negatively relate to post-error trust intentions because trust intentions are continuously shaped by evaluations of trustee task performance. In comparable research, dissatisfaction and anger stemming from a negative service experience were observed to positively relate to switching intentions (Bougie, Pieters, and Zeelenberg, 2003), which can be interpreted as a negative trust-intention indicator. Similarly, Bonifield and Cole (2007) found that the negative affective consequences of service failure negatively relate to consumer intentions to perform conciliatory (i.e., relationship-repairing) behaviours toward the offending service provider.

H19: Post-error trust intentions are negatively related to the anger caused by the error.

H20: Post-error trust intentions are negatively related to the dissatisfaction caused by the error.

Pre-error trust intentions are expected to buffer the effects of blogger error on post-error trust intentions. Trust intentions imply a willingness to assume risk (i.e., potential for loss) and, while post-error trust intentions are likely to be lower than preerror trust intentions, it is still expected that a positively relationship will exist between pre- and post-error trust intentions. 
H21: Post-error trust intentions are positively related to pre-error trust intentions.

\section{Negative word-of-mouth communication.}

Negative word-of-mouth communication arises from the cognitions and emotions that negative purchase or consumption experiences can inspire and is defined as any "negatively valenced, informal communication between private parties about goods and services and the evaluation thereof' (Wetzer, Zeelenberg, and Pieters, 2007, p. 662). Although word-of-mouth communication is traditionally exchanged between familiar sources and recipients (i.e., personal acquaintances; interpersonal communication), online word-of-mouth communication (e.g., online public complaining) is an increasingly relevant communication form. Negative word-of-mouth communication is characterized as a revenge-seeking behaviour because it requires that steps be taken that will inflict harm upon the original transgressor (Estelami, 2000; Grégoire, Tripp, and Legoux, 2009; Stillwell, Baumeister, and Del Priore, 2008; Thorsten Hennig-Thurau et al., 2004; Weiner, 2000; Wetzer, Zeelenberg, and Pieters, 2007). Compared to uncontrollable external attributions (i.e., when the offender caused the negative occurrence but is not held accountable for it), Weiner (2000, p. 385) states that "external attributions that are controllable are much more damaging. They do not lead merely to exit and going away from, but rather they give rise to active actions, or going against." As a result, the blameworthiness of the blogger and of the movie company is expected to relate positively to both personal communication-based and online blog-related and movie-related negative word-of-mouth communication. 
H22 $a, b: \quad$ Intentions to engage in negative a) blog-related and b) movie-related (i) interpersonal and (ii) online communication are positively related to the perceived blameworthiness of the blogger for the error.

$H 23 a, b: \quad$ Intentions to engage in negative a) blog-related and b) movie-related (i) interpersonal and (ii) online communication are positively related to the perceived blameworthiness of the movie company for the error.

As a means of re-establishing justice in the blog reader-blogger relationship, negative word-of-mouth communication is expected to positively relate to the perceived incorrectness of the movie review (Aquino, Tripp, and Bies, 2006). Whereas a negative relationship between movie review incorrectness and negative word-of-mouth communication would imply that blog readers would either over- or under-punish the blogger for the error it committed, a positive relationship implies that negative word-ofmouth communication is executed to a level that reflects the extent of the error that was committed.

$H 24 a, b: \quad$ Intentions to engage in negative a) blog-related and b) movie-related (i) interpersonal and (ii) online communication are positively related to the perceived incorrectness of the movie review.

Anger and dissatisfaction are expected to relate positively to negative word-ofmouth communication. Prior research shows that affective outcomes of service failure are predictive of retaliatory behaviours in response to service failure (Bonifield and Cole, 2007). 
$H 25 a, b: \quad$ Intentions to engage in negative a) blog-related and b) movie-related ( $i)$ interpersonal and (ii) online communication are positively related to the anger caused by blogger error.

H26 $a, b: \quad$ Intentions to engage in negative a) blog-related and b) movie-related (i) interpersonal and (ii) online communication are positively related to the dissatisfaction caused by blogger error.

Finally, it is expected that the trust that exists following blogger error will be negatively related to negative word-of-mouth communication intentions.

$H 27 a, b: \quad$ Intentions to engage in negative a) blog-related and b) movie-related (i) interpersonal and (ii) online communication are negatively related to post-error trust intentions.

\section{Methodology}

To test the hypotheses, a $2 \times 2 \times 2$ between-subjects experiment was conducted in which participants imagined themselves in a scenario that involved their exposure to an "About Me" statement and a favourable movie review posted on a personal blog. To study the effects of blogger error, the scenario for the experiment included a section in which participants were told that they watched the movie after reading the movie review and, in the process, discovered the movie review to be inaccurate. Specifically, participants were advised that they discovered that the movie did not possess the hedonic or utilitarian merit that the blogger claimed it to possess.

\section{Pretests}

Data for several rounds of pretesting as well as formal hypothesis testing were collected from undergraduate-level university students at Carleton University. Data were 
collected within the classroom or computer laboratory setting with the prior permission of course instructors. Pretest participants were drawn from the same pool as that from which formal data collection participants were drawn, since it has long been advised that pretesting be conducted using participants typical of those anticipated for formal data collection (e.g., Hunt, Sparkman, and Wilcox, 1982). Pretests were specifically conducted to verify that the scenario in which participants were to imagine themselves was familiar to them and to inform selection decisions with respect to the content of the treatment conditions involved in the study.

\section{Pretesting of the basic scenario.}

To verify the familiarity of the movie scenario to this participant profile, 184 undergraduate students at Carleton University were asked to indicate their weekly moviewatching habits, as well as their expected response to a negative movie-watching experience. Participants indicated familiarity with movies, with the average weekly viewing habits consisting of watching slightly more than two movies $(S . D .=.68)$. Participants also indicated the average amount of money they spend on watching movies in a week. Average weekly movie spending is reported in Table 5.1. 
Table 5.1: Average Weekly Spending on Watching Movies

\begin{tabular}{|c|c|c|c|}
\hline Spending categories ${ }^{a}$ & $\begin{array}{l}\text { Equivalent \# movie } \\
\text { admissions }^{b}\end{array}$ & Count & $\%$ \\
\hline$\$ 0.00$ & 0 & 52 & 30.6 \\
\hline$>\$ 0.00-\$ 14.00$ & 1 & 85 & 50.0 \\
\hline$>\$ 14.00-\$ 28.00$ & 2 & 27 & 15.9 \\
\hline$>\$ 28.00-\$ 42.00$ & 3 & 2 & 1.2 \\
\hline$>\$ 42.00-\$ 56.00$ & 4 & 3 & 1.8 \\
\hline$>\$ 56.00$ & 5 & $T$ & 0.6 \\
\hline & Total & $170^{c}$ & 100.0 \\
\hline
\end{tabular}

${ }^{a}$ Spending in Canadian dollars.

${ }^{b}$ In the Ottawa market at the time of data collection, the regular admission price to theatres owned/jointly owned/leased/operated by Cineplex Inc. was $\$ 10.99$ for regular movies and $\$ 13.99$ for 3D/UltraAVX movies (Cineplex, 2012). Similar prices were being charged by AMC theatres (\$12.75-\$13.99; AMC, 2012). Before tax, spending of up to $\$ 14.00$ is equivalent to paying to see one movie.

${ }^{c} 184-170=14$ participants who did not provide an answer to this question.

Although all participants reported watching at least one movie in an average week, many of them (30.6\%) reported not spending any money to do so. Additionally, $44.7 \%$ of the 85 participants who indicated spending no more than $\$ 14.00$ actually reported paying less than the pre-tax price of admission to a regular movie at a theatre associated with the Cineplex Inc. or AMC brands. Indeed, consumers have a variety of low-cost movie-watching options, including Netflix (paid online streaming), renting movies from Red Box self-serve kiosks, ordering movies from their television service provider (e.g., On Demand), watching movies in DVDs they already own, and freely watching movies broadcast on network or cable television or streamed online by websites such as topdocumentaryfilms.com. In addition, illegally obtained (i.e., pirated) movies are also popular among members of this Canadian demographic cohort (Ho and Weinberg, 2011).

Since movies can be seen without spending much money, it was necessary to determine whether blogger error could still be a relevant concern to participants. Participants were asked to indicate the extent to which they would be "disappointed" if 
they spent money on a movie they did not like. Disappointment is an emotional response to a negative outcome perceived to have been caused by someone else or by one or more uncontrollable circumstance (Wetzer, Zeelenberg, and Pieters, 2007). Measured on a seven-point scale on which high values indicated high disappointment, respondents indicated a negative affective response to such an occurrence $(M=4.02 ; S . D .=1.57)$. Although movie watching may not necessarily consume significant financial resources, an unlikeable movie-watching experience can still inspire negative states and behaviours that marketers would wish to avoid.

To ensure that blogs are perceived by participants to be a realistic channel for finding movie reviews, 38 pretest participants were asked to indicate the number of years they have been reading movie reviews posted on blogs or similar websites and the number of movie reviews they read in an average week in a blog or a similar website. Results generally show that blogs and similar websites are realistic channels for finding movie reviews. Table 5.2 indicates that the vast majority (nearly $85 \%$ ) of pretest participants have consulted blogs and similar websites for movie reviews in the past, and Table 5.3 shows that almost 3 out of 4 pretest participants read movie reviews on them weekly.

\section{Table 5.2: Experience with Blogs for Obtaining Movie Reviews}

\begin{tabular}{|l|c|c|}
\hline Categories $^{a}$ & $\mathbf{N}$ & $\%$ \\
\hline 0 (No time at all) & 6 & 15.8 \\
\hline Less than 1 year & 9 & 23.7 \\
\hline $1-2$ years & 8 & 21.1 \\
\hline More than 2 years & 15 & 39.5 \\
\hline Total & 38 & $100 \%$ \\
\hline
\end{tabular}

${ }^{a}$ Number of years pretest participants have been reading movie reviews posted on blogs or similar websites. 
Table 5.3: Number of Movie Reviews Read in Blogs on a Weekly Basis

\begin{tabular}{|l|c|c|}
\hline Categories $^{\alpha}$ & $\mathbf{N}$ & $\%$ \\
\hline 0 & 10 & 26.3 \\
\hline 1 or 2 & 26 & 68.4 \\
\hline 3 or 4 & 2 & 5.3 \\
\hline Total & 38 & $100 \%$ \\
\hline
\end{tabular}

${ }^{a}$ Number of movie reviews pretest participants read in an average week in blogs or on similar websites.

The scenario involved reviews of a fictitious movie. A fictitious movie was used to eliminate the potential for bias that could be caused by perceptions of a real movie (Wang and Doong, 2010). To aid in developing a suitable research scenario, forty-two pretest participants were asked to indicate the characteristics and genres of the movies they generally prefer (Appendix 5.1). Characteristics and genres rated in the top-half of a seven-point scale were deemed preferred by participants and potentially suitable for use in the scenario. Table 5.4 confirms that participants had affinity for movies with both hedonic and utilitarian properties. From a genre perspective, pretest participants expressed fondness for comedies $(M=6.17, S . D .=1.16)$, action movies $(M=5.98, S . D$. $=1.37)$, thriller movies $(M=5.22, S . D .=1.64)$, dramatic movies $(M=4.78, S . D .=1.78)$, war movies $(M=4.63, S . D .=1.51)$, science fiction movies $(M=4.65, S . D .=1.67)$, and romantic movies $(M=4.63, S . D .=1.96)$, as all were rated in the top-half of the sevenpoint scale (max. $p<.05$ ). On the basis of these findings, it was decided that a movie with hedonic and utilitarian characteristics intersecting the action, dramatic, war, and romantic genres would best suit the objectives of this study. 
Table 5.4: Preferred Movie Characteristics

\begin{tabular}{|c|c|c|c|}
\hline Characteristics & Mean & S.D. & $\begin{array}{c}\text { One-sample } t- \\
\text { test }^{a}\end{array}$ \\
\hline Are exciting (Hedonic) & 6.41 & 0.97 & $15.87^{* * *}$ \\
\hline Get you thinking (Utilitarian) & 5.61 & 1.48 & $6.96^{* * *}$ \\
\hline Are visually stimulating (Hedonic) & 5.59 & 1.22 & $8.29 * * *$ \\
\hline Get your adrenaline pumping (Hedonic) & 5.46 & 1.31 & $7.18^{* * *}$ \\
\hline Educate you (Utilitarian) & 4.85 & 1.46 & $3.75^{* * *}$ \\
\hline Focus on important issues (Utilitarian) & 4.61 & 1.53 & $2.55^{*}$ \\
\hline Represent real life (Utilitarian) & 4.60 & 1.60 & $2.38^{*}$ \\
\hline Portray life authentically (Utilitarian) & 4.59 & 1.75 & $2.15^{*}$ \\
\hline $\begin{array}{l}\text { Show what life was like before you were born } \\
\text { (Utilitarian) }\end{array}$ & 4.48 & 1.63 & 1.84 \\
\hline
\end{tabular}

${ }^{a}$ One-sample $t$-test for the significance of the difference between the variable and 4 (the midpoint on the 17 scale).

${ }^{*} p<.05 ;{ }^{* * *} p<.001$.

To encapsulate several elements of both the hedonic and utilitarian characteristics of movies that pretest participants indicated preferring, several brief movie synopses were developed and initially pretested. From this first stage development, two high-rating movie synopses were further developed and retested: These two movie synopses were:

1. "A British Soldier and an American Woman Secretly Develop a Relationship Amid the War of 1812 Between Britain and the United States."

2. "An American Soldier in Afghanistan Falls in Love with an Afghan Aid Worker and Risks it All to Help Her Protect Orphaned Children When the Army Targets the Orphanage as a Suspected Taliban Headquarters."

To pretest the perceived hedonic and utilitarian characteristics and general appeal of these two fictitious movie synopses, another group of fifty-two respondents was used. Perceived movie characteristics were assessed on seven-point scales (0-6), with high values indicating that the movie could realistically possess them. The hedonic content of the two movies was assessed with seven items adapted from research examining 
consumer evaluations of movies and advertising that indicate the extent to which each could be energetic, suspenseful/exciting, and sensual (Leavitt, 1970; Oliver and Bartsch, 2010).

Pretest participants were also asked to rate the potential of each movie to be "violent" and "brutal." A content analysis of justifications for movie ratings by the Motion Picture Association of America shows these terms to have complementary meanings (Potts and Belden, 2009). High levels of violent and/or sensual content in the movie could suggest that it warrants a "Parental Guidance-13," "Restricted," or "NC-17" rating, since violence and sexuality are among the three most commonly cited justifications for such ratings (Potts and Belden, 2009). Movies with such ratings may be objectionable to some viewers and, accordingly, films released in 2008 with them earned less, at least over their opening weekend, than those without them (Leenders and Eliashberg, 2011). It was necessary that the movie not be perceived by participants as excessively violent and/or sexual. At the same time, movies with these ratings are commonly targeted at young-adult consumers, so low ratings on these measures were also to be avoided. Exploratory factor analysis (principal components analysis with varimax rotation) of participant ratings of the two movies on the nine hedonic items revealed a three-factor solution: Excitement (Cronbach $\alpha=.92$ ); Sensuality (Cronbach $\alpha$ $=.91)$; Violence (Cronbach $\alpha=.83$ ).

The utilitarian potential of the movies was measured with six items. The variables "factual," "educational," and "informative" were used to measure the educational potential of the movies and were adapted from the advertising scepticism scale (Obermiller and Spangenberg, 1998). Whereas low values on these items suggest 
scepticism, high values indicate confidence in the education merit of the movies. The variables "authentic," "based on real life, and "a true story" were originally developed to measure how honestly the movies could depict social reality (Potts and Belden, 2009). Exploratory factor analysis (principal components analysis) of these six utilitarian movie elements revealed a one-factor solution (Cronbach $\alpha=.91$ ). Results are shown in Table 5.5 .

General movie appeal was measured by three items indicating the extent to which participants thought the movies could be "good," "interesting," and "likeable" (Schlosser, 2011). Exploratory factor analysis (principal components analysis) of these three general appeal items revealed a one-factor solution (Cronbach $\alpha=.88$ ).

Items loading together were averaged to form hedonic, utilitarian, and general appeal indices. One-sample $t$-tests were conducted for each movie synopsis on each hedonic and utilitarian movie characteristic as well as on general movie appeal. Results of these analyses are shown in Table 5.6.

The Afghanistan orphanage movie was chosen for this study because it was more generally appealing than the War of 1812 movie, and responses to a follow-up question revealed a low general appeal of historical movies. The Afghanistan orphanage movie was rated favourably and at a higher level than the War of 1812 movie and also on all hedonic dimensions scored above the lower half of the utilitarian dimension with a mean not significantly different from that of the War of 1812 movie $(t=.78, p>.1)$. 
Table 5.5: Factoring Results of Hedonic and Utilitarian Movie Characteristics

\begin{tabular}{|c|c|c|c|c|c|}
\hline \multirow{2}{*}{\multicolumn{2}{|c|}{ Movie characteristics }} & \multicolumn{4}{|c|}{ Loadings (Varimax rotation) } \\
\hline & & \multirow{2}{*}{$\begin{array}{l}1 \\
.85 \\
\end{array}$} & \multirow[t]{2}{*}{2} & \multirow[t]{2}{*}{3} & \multirow[t]{2}{*}{4} \\
\hline \multirow[t]{6}{*}{ Utilitarian } & Factual & & & & \\
\hline & Educational & .84 & & & \\
\hline & Informative & .78 & & & \\
\hline & Based on real life & .89 & & & \\
\hline & Authentic & .80 & & & \\
\hline & A true story & .85 & & & \\
\hline \multirow{4}{*}{$\begin{array}{l}\text { Hedonic } \\
\text { (Excitement) }\end{array}$} & Exciting & & .85 & & \\
\hline & Energetic & & .90 & & \\
\hline & An "edge of your seat" experience & & .90 & & \\
\hline & A heart-pounding experience & & .89 & & \\
\hline \multirow{3}{*}{$\begin{array}{l}\text { Hedonic } \\
\text { (Sensuality) }\end{array}$} & Sensitive & & & .92 & \\
\hline & Tender & & & .91 & \\
\hline & Romantic & & & .91 & \\
\hline \multirow{2}{*}{$\begin{array}{l}\text { Hedonic } \\
\text { (Violence) }\end{array}$} & Violent & & & & .83 \\
\hline & Brutal & & & & .92 \\
\hline \multicolumn{2}{|l|}{ Eigenvalue } & 4.46 & 3.68 & 2.89 & 1.64 \\
\hline \multicolumn{2}{|c|}{$\%$ variance explained } & 27.85 & 22.99 & 18.07 & 10.25 \\
\hline \multicolumn{2}{|l|}{ Cronbach $\alpha$} & .91 & .92 & .91 & .83 \\
\hline
\end{tabular}

Pretesting of the movie reviews and "About Me" statements.

Sixty-six individuals participated in pretests that were focused on ensuring that the movie reviews and "About Me" statements were comparable on message-related parameters unassociated with the variables under study (Appendix 5.2). To make this determination, the movie reviews and "About Me" statements were assessed on sevenpoint scales (0-6) across four argumentation and three acceptability measurement areas. Construct measures were developed based on the relevant literature and are shown in Table 5.7. 
Table 5.6: Movie Synopses Pretest Results

\begin{tabular}{|c|c|c|c|c|}
\hline \multirow{3}{*}{ Variables } & \multicolumn{4}{|c|}{ Movie synopses } \\
\hline & \multicolumn{2}{|c|}{$\begin{array}{c}\text { War of } 1812 \\
n=23\end{array}$} & \multicolumn{2}{|c|}{$\begin{array}{l}\text { Afghanistan orphanage } \\
n=29\end{array}$} \\
\hline & M (SD) & t-test ${ }^{a}$ & M (SD) & t-test \\
\hline \multicolumn{5}{|l|}{ Hedonic characteristics } \\
\hline \multicolumn{5}{|l|}{ Excitement } \\
\hline Exciting & \multirow{4}{*}{$3.60(1.24)$} & \multirow{4}{*}{$2.32 *$} & \multirow{4}{*}{$3.95(1.51)$} & \multirow{4}{*}{$3.38^{* *}$} \\
\hline Energetic & & & & \\
\hline Edge-of-your-seat experience & & & & \\
\hline Heart-pounding experience & & & & \\
\hline \multicolumn{5}{|l|}{ Sensuality } \\
\hline Sensitive & \multirow{3}{*}{$4.96(1.12)$} & \multirow{3}{*}{$8.37^{* * *}$} & \multirow{3}{*}{$4.43(1.51)$} & \multirow{3}{*}{$5.08^{* * *}$} \\
\hline Tender & & & & \\
\hline Romantic & & & & \\
\hline \multicolumn{5}{|l|}{ Violence } \\
\hline Violent & \multirow{2}{*}{$3.91(1.25)$} & \multirow[t]{2}{*}{$3.51^{* *}$} & \multirow[t]{2}{*}{$4.45(1.66)$} & \multirow[t]{2}{*}{$4.70^{* * *}$} \\
\hline Brutal & & & & \\
\hline \multicolumn{5}{|l|}{ Utilitarian characteristics } \\
\hline Factual & \multirow{6}{*}{$3.56(1.08)$} & \multirow{6}{*}{$2.48^{*}$} & \multirow{6}{*}{$3.29(1.39)$} & \multirow{6}{*}{$\begin{array}{c}1.12 \\
(p=.272)\end{array}$} \\
\hline Educational & & & & \\
\hline Informative & & & & \\
\hline Based on real life & & & & \\
\hline Authentic & & & & \\
\hline A true story & & & & \\
\hline \multirow{2}{*}{\multicolumn{5}{|c|}{ General movie appeal }} \\
\hline & & & & \\
\hline Good & \multirow{3}{*}{$3.88(1.28)$} & \multirow{3}{*}{$3.31 * *$} & \multirow{3}{*}{$4.37(1.32)$} & \multirow{3}{*}{$5.58^{* * *}$} \\
\hline Interesting & & & & \\
\hline Likeable & & & & \\
\hline
\end{tabular}

${ }^{a}$ One-sample $t$-test for the significance of the difference between the variable and 3 (the midpoint on the 06 scale).

${ }^{*} p<.05 ;{ }^{* *} p<.01 ;{ }^{* * *} p<.001$. 
Table 5.7: Pretest Measures for the Movie Reviews and "About Me" Statements

\begin{tabular}{|c|c|c|c|}
\hline $\begin{array}{c}\text { Measure } \\
\text { Area }\end{array}$ & Topic & Items & Source \\
\hline \multirow[t]{10}{*}{ Argumentation } & \multirow[t]{3}{*}{ 1. Strength } & a. Confident & \multirow{3}{*}{$\begin{array}{l}\text { Darley and Smith, 1993; } \\
\text { DeCarlo, 2005; Jo, 2004; } \\
\text { Leavitt, 1970; Priester and } \\
\text { Petty, } 2003\end{array}$} \\
\hline & & b. Assertive & \\
\hline & & c. Strong & \\
\hline & \multirow[t]{3}{*}{ 2. Quality } & a. Interesting & \multirow{3}{*}{$\begin{array}{l}\text { Chen and Tseng, 2011; } \\
\text { Darley and Smith, 1993; } \\
\text { DeCarlo, 2005; Homer and } \\
\text { Batra, 1994; Jo, 2004; } \\
\text { Wang and Doong, 2010; } \\
\text { Wei, Fischer, and Main, } \\
2008\end{array}$} \\
\hline & & b. Helpful & \\
\hline & & c. Informative & \\
\hline & \multirow[t]{2}{*}{ 3. Understandability } & $\begin{array}{l}\text { a. Easy to } \\
\text { understand }\end{array}$ & \multirow{2}{*}{$\begin{array}{l}\text { Darley and Smith, 1993; } \\
\text { Homer and Batra, 1994; } \\
\text { Hsieh et al., 2010; } \\
\text { Lastovicka, 1983; Wei, } \\
\text { Fischer, and Main, 2008 }\end{array}$} \\
\hline & & b. Easy to follow & \\
\hline & \multirow[t]{2}{*}{ 4. Valence } & a. Positive & \multirow[b]{2}{*}{$\begin{array}{l}\text { Adjei, Noble, and Noble, } \\
\text { 2010; Fein, 1996; Jones, } \\
\text { Aiken, and Boush, 2009; } \\
\text { Lee, Rodgers, and Kim, } \\
2009\end{array}$} \\
\hline & & b. Favourable & \\
\hline \multirow[t]{4}{*}{ Acceptability } & \multirow[t]{2}{*}{ 1. Hedonic appeal } & $\begin{array}{l}\text { a. Enjoyable to } \\
\text { read }\end{array}$ & \multirow{2}{*}{$\begin{array}{l}\text { Jo, 2004; Lastovicka, 1983; } \\
\text { Olsen and Pracejus, 2004; } \\
\text { Pollay and Mittal, 1993; } \\
\text { Wang and Sun, } 2010\end{array}$} \\
\hline & & $\begin{array}{l}\text { b. Entertaining to } \\
\text { read }\end{array}$ & \\
\hline & 2. Realism & $\begin{array}{l}\text { Comparability to } \\
\text { content on } \\
\text { blogs }{ }^{a}\end{array}$ & $\begin{array}{l}\text { Wei, Fischer, and Main, } \\
2008\end{array}$ \\
\hline & $\begin{array}{l}\text { 3. Expectancy } \\
\text { violation }\end{array}$ & $\begin{array}{l}\text { a. Surprising } \\
\text { b. Unexpected }\end{array}$ & $\begin{array}{l}\text { Karmarkar and Tormala, } \\
2010\end{array}$ \\
\hline
\end{tabular}

${ }^{a}$ Movie reviews and "About Me" statements on blogs.

\section{The movie reviews.}

Hedonic and utilitarian movie reviews were developed in accordance with studies identifying the characteristics of product reviews that appear on blogs and related media (Lee, Rodgers, and Kim, 2009; Schlosser, 2011). Schlosser (2011) observed that online movie reviews are ordinarily two or more sentences in length, and Yang, Huang, and Lin 
(2009) found that the average comment about a movie posted on an "official" movie blog contains 34 words across four lines of text. Lee, Rodgers, and Kim (2009) reported that positive product reviews, more than negative ones, must be unequivocal in order to affect consumer attitudes toward the product. Similarly, Schlosser (2011) found that one-sided online product reviews are more helpful and have more persuasive effects on productrelated attitudes when they express extreme, rather than moderate, product ratings. Both movie reviews developed for pretesting were unequivocally favourable and appropriate in length for online movie reviews (Yang, Huang, and Lin, 2009).

The hedonic (i.e., enjoyment-based) movie review read as:

MOVIE REVIEW

\section{EXCITING, ENERGETIC, AND ACTION PACKED}

This movie is very exciting, energetic, and action packed, providing a heart-pounding, edge-of-your-seat experience as it tells a story about an American soldier, Afghan aid worker, and orphaned children in the middle of the ongoing war in Afghanistan. In this movie, an American soldier in Afghanistan falls in love with an Afghan aid worker and helps her to protect orphaned children when the Army targets the orphanage as a suspected Taliban headquarters. This movie was filmed in dangerous-looking locations that were enhanced with amazing special effects, high-quality acting, and an exciting storyline. This movie is full of energy and action, as the soldier and aid worker risk everything for the orphans. (118 words).

The review emphasizing the movie's utilitarian merit read as:

\section{MOVIE REVIEW}

\section{EDUCATIONAL, INFORMATIVE, AND FACTUAL}

This movie is very educational, informative, and factual, highlighting true facts about Afghanistan and providing accurate details about the real-life issues faced by American soldiers, Afghan aid workers, and orphaned Afghan children in the middle of the ongoing war in Afghanistan. In this movie, an American soldier in Afghanistan falls in love with an Afghan aid worker and helps her to protect the orphaned children when the Army targets the orphanage as a suspected Taliban headquarters. Afghanistan is represented with a high level of authenticity throughout this movie, and it was filmed at culturally significant locations with people whose language, customs, beliefs, and values all match those of the people of Afghanistan. (118 words). 
Results are shown in Table 5.8. As in prior research (e.g., Lee, Rodgers, and Kim, 2009), independent-groups $t$-tests were conducted on the measures to establish that the movie reviews do not differ in confounding ways. Table 5.8 reveals that the hedonic and utilitarian movie reviews do not significantly differ in terms of strength, quality, understandability, valence, hedonic appeal, realism, or expectancy violation $(p>.1)$. As a result, the movie reviews were assessed as suitable for experimental purposes.

Table 5.8: Results of the Movie Review Pretest

\begin{tabular}{|c|c|c|c|c|}
\hline \multirow{2}{*}{ Variables } & \multirow{2}{*}{$\begin{array}{c}\text { Cronbach } \\
\alpha\end{array}$} & \multicolumn{2}{|c|}{ Movie Reviews } & \multirow{2}{*}{$\frac{t \text {-value }}{\text { (Hed. - Util.) }}$} \\
\hline & & Hedonic & Utilitarian & \\
\hline \multicolumn{5}{|l|}{ Argument strength } \\
\hline $\begin{array}{l}\text { Confident; assertive; } \\
\text { strong }\end{array}$ & .79 & $4.07(1.19)$ & $4.26(.94)$ & -0.71 \\
\hline \multicolumn{5}{|l|}{ Argument quality } \\
\hline $\begin{array}{l}\text { Interesting; helpful; } \\
\text { informative }\end{array}$ & .78 & $4.09(1.11)$ & $4.36(1.04)$ & -1.04 \\
\hline \multicolumn{5}{|l|}{ Understandability } \\
\hline $\begin{array}{l}\text { Easy to understand; } \\
\text { easy to follow }\end{array}$ & .78 & $5.10(.97)$ & $4.81(1.01)$ & 1.19 \\
\hline \multicolumn{5}{|l|}{ Valence } \\
\hline Positive; favourable & .84 & $4.90(.98)$ & $4.61(1.22)$ & 1.06 \\
\hline \multicolumn{5}{|l|}{ Hedonic appeal } \\
\hline $\begin{array}{l}\text { Enjoyable to read; } \\
\text { entertaining to read }\end{array}$ & .91 & $3.91(1.52)$ & $3.72(1.16)$ & 0.58 \\
\hline \multicolumn{5}{|l|}{ Realism } \\
\hline $\begin{array}{l}\text { Comparability to } \\
\text { statements people } \\
\text { make on blogs about } \\
\text { themselves / movies }\end{array}$ & $\begin{array}{c}\text { N/A } \\
\text { (Single } \\
\text { Item) }\end{array}$ & $4.09(1.08)$ & $4.00(1.32)$ & 0.30 \\
\hline \multicolumn{5}{|l|}{ Expectancy violation } \\
\hline Surprising; unexpected & .86 & $2.32(1.56)$ & $2.48(1.41)$ & -0.44 \\
\hline
\end{tabular}


"About Me" statements: Blogger type and WOMM type treatments.

Blogger type treatment: "About Me" statements were developed for a subjectmatter expert blogger and a product enthusiast blogger, and the contents of these statements are reported below. Participants received the statement of the subject-matter expert or the product enthusiast on a random basis. They were advised that it was taken directly from the blog. In order to match the subject matter of the movie, the subjectmatter expert blogger was operationalized as expert in Afghanistan and the current conditions in that country.

\begin{abstract}
ABOUT ME
I have great expertise and a specialized university education on the ongoing situation in Afghanistan and my journal papers on the ongoing conditions in Afghanistan have received awards for research excellence. Knowing about the latest developments in Afghanistan is important to me, so I research, attend conferences, and monitor official reports as much as I can. I put more effort into keeping up with the Afghanistan situation than I put into most other things. I teach university courses, study extensively, and advise international organizations about current Afghanistan conditions. I also write about these conditions in the mainstream media and have written an authoritative book about them, too. (109 words).
\end{abstract}

The product enthusiast blogger was operationalized as a movie "buff" who is a frequent consumer of movies and who remains up-to-date on movie-related developments and who is engaged with other consumers in movie-related discussions.

\title{
ABOUT ME
}

I have a great passion for movies and I watch hundreds of them across all genres every year. Knowing about the latest developments in movies is important to me, so I watch them, read all the Hollywood gossip, and engage in movie-related discussions with other movie fans as much as I can. I put more effort into keeping up with the latest developments in movies than I put into most other things, since the movie decisions I make reflect my knowledge. I am known for my movie knowledge, and I would be very disappointed if I made a bad movie decision that cost me time and money. (109 words). 
WOMM type treatment: Participants who received the word-of-mouth marketing treatment were exposed to the following statement appended to either of the two blogger type treatments (Afghanistan expert blogger; movie buff blogger) to which they were exposed: "Disclosure: I am compensated with movie tickets, merchandise, and other promotional material by the makers of this movie for writing and posting reviews of its movies on my blog" ( 29 words). The content of this disclosure statement was written to adhere to U.S.-based regulations and industry-based prescription. The Federal Trade Commission (2009) requires that "the post of a blogger who receives cash or in-kind payment to review a product is considered an endorsement" and that "bloggers who make an endorsement must disclose the material connections they share with the seller of the product or service." The Word-of-Mouth Marketing Association recommends that disclosure statements be clear and prominent, understandable and unambiguous, readable and noticeable, and placed in an easily viewed location on a website.

The same tests were conducted on the "About Me" statements as were conducted on the movie reviews. Results are presented in Table 5.9. The movie buff and Afghanistan expert treatments differed only in terms of expectancy violation. The Afghanistan expert blogger violated expectations to a greater extent than the movie buff blogger, which aligns with the observation that the majority of online product reviews are written by ordinary consumers and not subject-matter experts (Chen and Tseng, 2010). Blogs may not be the typical platforms for individuals with expertise in certain subject areas. As a result of this finding, the two "About Me" statements were subsequently pretested for their believability, since surprising and unexpected information may appear less credible than unsurprising and expected information. One-hundred and five 
participants were randomly given one of the statements and asked to rate how much they

(1) believed it and were (2) convinced and (3) persuaded by it (Cronbach alpha $=.90)$.

The two "About Me" statements were not found to differ on this dimension $(p>.1)$, as

the movie buff $(M=3.35 ; S . D .=1.32)$ and Afghanistan expert $(M=3.42 ; S . D .=1.36)$

statements were similarly believable. The "About Me" statements were deemed

satisfactory for the purposes of this research.

Table 5.9: Results of the "About Me" Pretest

\begin{tabular}{|c|c|c|c|c|}
\hline \multirow{3}{*}{ Variables } & \multirow{3}{*}{$\begin{array}{c}\text { Cronbach } \\
a\end{array}$} & \multicolumn{2}{|c|}{ About Me statements } & \multirow{2}{*}{$t$-value } \\
\hline & & \multirow{2}{*}{ Movie buff } & \multirow{2}{*}{$\begin{array}{l}\text { Afghanistan } \\
\text { expert }\end{array}$} & \\
\hline & & & & (M.b. - A.e.) \\
\hline \multicolumn{5}{|l|}{ Argument strength } \\
\hline Confident; assertive; strong & .69 & $3.97(.95)$ & $4.24(.87)$ & -1.17 \\
\hline \multicolumn{5}{|l|}{ Argument quality } \\
\hline $\begin{array}{l}\text { Interesting; helpful; } \\
\text { informative }\end{array}$ & $.41^{a}$ & $3.51(.81)$ & $3.76(.90)$ & -1.20 \\
\hline \multicolumn{5}{|l|}{ Understandability } \\
\hline $\begin{array}{l}\text { Easy to understand; easy to } \\
\text { follow }\end{array}$ & .82 & $4.77(.99)$ & $4.45(1.20)$ & 1.16 \\
\hline Valence & & & & 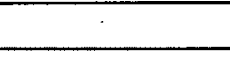 \\
\hline Positive; favourable & .77 & $3.74(1.29)$ & $4.11(1.22)$ & -1.16 \\
\hline \multicolumn{5}{|l|}{ Hedonic appeal } \\
\hline $\begin{array}{l}\text { Enjoyable to read; entertaining } \\
\text { to read }\end{array}$ & .84 & $2.40(1.26)$ & $2.83(1.26)$ & -1.34 \\
\hline Realism & & & & 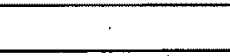 \\
\hline $\begin{array}{l}\text { Comparability to statements } \\
\text { people make on blogs about } \\
\text { themselves / movies }\end{array}$ & $\begin{array}{c}\text { N/A } \\
\text { (Single } \\
\text { Item) }\end{array}$ & $3.33(1.06)$ & $3.27(1.23)$ & 0.23 \\
\hline \multicolumn{5}{|l|}{ Expectancy violation } \\
\hline Surprising; unexpected & .94 & $2.03(1.51)$ & $3.05(1.63)$ & $-2.58 *$ \\
\hline
\end{tabular}

${ }^{a}$ Exploratory factor analysis of the argument-quality measures revealed a one-factor solution with low internal consistency. The smallest factor loading was .634 ("About Me" statement is "interesting"). Cronbach $\alpha$ could be increased to no more than .53 by removing any of the three variables.

${ }^{*} p<.05$. 


\section{Completion of pretests.}

The movie reviews and About Me statements satisfied all necessary conditions for effective experimental design. All treatments were deemed appropriate for the blogosphere, understandable, and likely to trigger differentiated trust-related beliefs and behavioural intentions. On the basis of these successful pretests, the two movies and four About Me statements (movie buff versus Afghanistan expert; WOMM disclosure versus no WOMM disclosure) were incorporated into a questionnaire of which there were eight unique versions.

\section{Procedure}

To ensure adequate participation and comparable sizes across treatment conditions (across cells), a non-probabilistic quota-based sampling approach was used (Nadeau, 2007). The questionnaire was administered in ordinary classroom and computer laboratory environments and all eight treatment conditions were featured in each. Participants were allowed to skip questions as they wished. To orient participants to the study, they were advised that it sought "to establish an understanding of consumers' trust in an online movie reviewer, expectations of movie review quality, and responses to perceived movie review quality" and that their participation would require them to "assume the role of a consumer who reads an online movie review and who sees the movie."

Study 3 unfolded over multiple stimuli and measurement stages. Participants read introductory scenario information and indicated their beliefs about the credibility of the typical blogger who posts a movie review on a personal blog. Participants then read 
an ostensibly authentic "About Me" statement from a fictitious blog and indicated their beliefs about the blogger on the basis of the experimentally manipulated content embedded in the statement. Two of the three experimental treatments used in this study were embedded in the About Me statement. The blogger was randomly presented as either a "movie buff" or an Afghanistan expert. WOMM type levels were WOMM disclosure versus no WOMM disclosure. The third experimental treatment was embedded in the movie review participants read in the next stage of the study. In the movie review, the blogger claimed the movie to be "Exciting, Energetic, and Action Packed" (i.e., to have high hedonic merit) or to be "Educational, Informative, and Factual" (i.e., to have high utilitarian merit). After reading the movie review, participants indicated their beliefs about and intentions toward the movie review, movie, blogger, and blog on the basis of the experimentally manipulated movie review. The final stage of the study.involved the discovery by participants of the erroneous nature of the movie review and the measurement of the cognitive, affective, and conative outcomes of blogger error.

The questionnaire was divided into four parts and is provided in Appendix 5.3.

\section{Questionnaire Part 1: Introductory information.}

Participants were asked to imagine themselves having plans to watch a movie with a friend at the theatre and that it was their turn to choose the movie. The friend was described in gender-neutral terms to avoid arousing sex-based movie preferences or stereotypes. Participants were advised that the Afghanistan orphanage movie fit their schedule and that they were to evaluate the likelihood they and their friend "would rate the movie positively after seeing it." Participants were informed that, in the process of 
looking for information in order to make that evaluation about the movie, they come across a review of it posted on a "personal blog."

\section{Questionnaire Part 2: Measurement of category-level beliefs.}

Category-level beliefs about movie review bloggers were measured after participants received this information. Specifically, participants indicated their beliefs about the credibility (Wang and Doong, 2010) of the typical personal blogger who posts a movie review on a blog; certain qualities (Sussman and Siegal, 2003; Wang and Doong, 2010) of the typical movie review posted on a personal blog, and their general level of scepticism (cf. Obermiller and Spangenberg, 1998) toward such a review. Exclusive of scepticism, all measures were taken on seven-point Likert scales on which high values indicate that the typical movie review or blogger is believed to possess the measured trait. Scepticism measures are interpreted differently, since Obermiller and Spangenberg (1998) defined scepticism as a general disbelief tendency while measuring the construct with items that imply a general belief tendency. High scepticism of the typical movie review posted on a blog is therefore indicated by participants who provide low values on items intended to measure that construct. Experience with blogs and similar websites as channels for reading movie reviews was also measured in this questionnaire part.

\section{Measures of the credibility of the typical blogger.}

Typical blogger credibility was measured by five items indicating the extents to which participants think the typical blogger who posts a movie review on a personal blog 
or on a similar website is generally a(n) (1) knowledgeable, (2) expert, (3) qualified, (4) trustworthy, and (5) credible source of information on the topic.

Measures of scepticism toward the typical movie review posted on a personal blog.

Nine items were used to measure scepticism toward the typical movie review posted on a personal blog. Adapted from prior scepticism research (e.g., Obermiller and Spangenberg, 1998; van Heerden et al., 2009), scepticism toward the typical movie review was measured by items asking the extents to which participants believe it to generally be (1) written to inform consumers, (2) informative, (3) truthful, (4) reliable,

(5) the truth well told, (6) accurate, (7) true, (8) dependable, and (9) based on important or essential information.

\section{Measures of experience with blogs and similar websites.}

Participants were asked to indicate the number of years $(0$, i.e., never; $<1 ; 1-2$; >2) they have been reading movie reviews in blogs or on similar websites as well as the number of movie reviews $(0$, i.e., none; $1-2 ; 3-4 ; 5-6 ; 7-8 ;>8)$ in blogs or on similar websites they read in an average week.

\section{Questionnaire Part 3: Exposure and measurement of responses to experimental treatments.}

Two excerpted parts of the personal blog were exposed to participants as the experiment unfolded, and measures were taken after each exposure. The experimental 
treatments were contained within these blog excerpts. To focus participants on the blog content, they were informed and directed as follows: "Text from the personal blog on which the movie review was posted is reproduced below. Please read the blog text as you would other text, being sure to read it thoroughly and completely."

The first excerpt to which participants were exposed was the "About Me" statement from the blog. After reading the "About Me" statement, participants indicated their beliefs about the ability, character, deception intent, and likeability of the blogger, as well as the degree to which the blogger was similar to them. In addition, participants indicated their acceptance of the "About Me" information. All measures were taken on seven-point Likert scales on which high values indicate that the blogger is believed to possess the measured trait.

\section{Measures of blogger ability.}

Blogger ability, operationalized in this study in the forms of authoritative knowledge and consumption experience, was measured by eight items developed originally for this study. Authoritative knowledge was measured with four items indicating the extent to which the blogger is believed to: (1) have an extensive formal education on, (2) know detailed facts about, (3) know much about important trends in, and (4) have done research about conditions in Afghanistan. Consumption experience was measured with four items indicating the extent to which the blogger is believed to: (1) watch a large number of, (2) know much about important trends in, (3) spend a lot of time watching, and (4) be very passionate about movies. 
Measures of blogger character.

Benevolence was measured with four items indicating the extent to which the blogger was believed to (1) want to help, (2) care about, (3) want to inform, and (4) just want to help readers of the movie review make a good decision about the movie. These measures were adapted from measures of trustor-perceived trustee benevolence (Lankton and McKnight, 2011; Ridings, Gefen, and Arinze, 2002; Schlosser, White, and Lloyd, 2006).

Integrity was measured by items indicating the extent to which the blogger was believed to be totally (1) honest, (2) truthful, and (3) sincere with readers of the movie review. Measures were also taken of the extent to which the blogger was believed to have reason to (4) misrepresent the truth about the movie, (5) deceive and (6) mislead readers about the movie, and (7) hide the truth about the movie from readers. These measures have been adapted from measures of integrity shaped by enduring trait and dynamic situational factors (Campbell and Kirmani, 2000; Karmarkar and Tormala, 2010).

\section{Measures of deception intent.}

Deception intent was measured with four items indicating the extent to which the blogger was perceived to have reason to (1) misrepresent the truth about the movie, (2) deceive readers about the movie, (3) mislead readers about the movie, and (4) hide the truth about the movie from readers. 
Measures of blogger-rater rapport - Likeability.

Blogger likeability was measured by three items indicating the extent to which the blogger was believed by participants to (1) be likeable to them, (2) have made a favourable impression on them, and (3) be someone they would like to socialize with (Karmarkar and Tormala, 2010; Smith, Menon, and Sivakumar, 2005).

\section{Measures of blogger-rater rapport - Blogger-participant similarity.}

Blogger-participant similarity was measured by four items indicating the extent to which the participant believed the blogger to (1) be similar to him or her and (2) have beliefs and values as well as (3) tastes and preferences that are similar to his or hers, and (4) have things in common with him or her (Karmarkar and Tormala, 2010; Price, Feick, and Higie, 1989).

\section{Measures of acceptance of "About Me" information.}

Participants indicated on four items the extent to which they (1) believed, were (2) convinced and (3) persuaded by, and (4) did not think the "About Me" information was deceptive.

The second excerpt to which participants were exposed was the movie review. After reading the movie review, participants completed seven-point scale measures concerning their general movie-related attitudes, acceptance of the movie review, blogger-directed trust intentions, and the credibility of both the blogger and the content of the movie review (including scepticism). Movie-review acceptance, blogger credibility, 
and movie-review content beliefs (including scepticism) were measured using the same set of items used to measure these constructs when their focus was on the typical blogger and movie review posted on a blog or a similar website.

\section{Measures of general movie-related attitudes.}

General movie-related attitudes were measured on six items indicating the extents to which participants believed that the movie seemed (1) good, (2) interesting, (3) likeable, and (4) appealing to them as well as how much they believed they would (5) enjoy and (6) appreciate watching the movie (Darke and Ritchie, 2007; Jo, 2004; Oliver and Bartsch, 2010).

\section{Measures of blogger-directed trust intentions.}

Using measures drawn from Study 2, blogger-directed trust intentions were measured on six items indicating the likelihoods to which participants, assuming they had the option in the future, would (1) take advice from the blogger and (2) try what the blogger recommends as well as (3) continue to read and (4) consult the blog and (5) pass along information on it and (6) recommend it to others. The same set of items was used to measure trust intentions following blogger error.

\section{Additional questions.}

Part three of the questionnaire concluded with several participant-profile questions. Participants were asked to indicate their age and sex. Then, participants were asked to indicate their familiarity, from 0 (Not at all) to 6 (Very familiar), with (1) English, (2) French, (3) Afghan Persian (or Dari), (4) Pashto, and (5) any other language 
used in or around Afghanistan. Language familiarity was measured on seven-point scales on which high values indicated high familiarity. English familiarity was assessed to identify participants who may have encountered difficulty in completing the questionnaire, and French familiarity was asked to distract participants from the intent of the English familiarity question. Afghan Persian (or Dari) and Pashto are the official and most commonly used languages in Afghanistan (Central Intelligence Agency, 2012), and familiarity with them was measured so as to be able to identify participants who could have had reasons independent of the blogger and the movie review to like or dislike the movie. With more than thirty unofficial or "minor" languages also being used in that country (Central Intelligence Agency, 2012), Afghanistan has high linguistic diversity, and so participants also indicated familiarity with other languages relevant to Afghanistan. It was not deemed necessary to probe further into participant culture or geography, as van Heerden et al. (2009) found that scepticism toward blogging does not vary by major geographic region.

\section{Questionnaire Part 4: Exposure and measurement of responses to blogger error.}

Each participant was then instructed to imagine that he or she and his or her friend were watching the movie when it became apparent to them that the movie is not what the blogger said it would be. Participants who received the hedonic movie-review treatment learned that, in addition to their own experience-based impressions of the movie, "ordinary moviegoers" reviewed the movie and have described it as "Not Exciting," "Boring," and "Full of Terrible Acting and Pathetic Special Effects." Those participants 
who received the utilitarian movie-review treatment were informed that, in addition to their own experience-based impressions of the movie, "Afghanistan experts" reviewed the movie and have described it as "Not What Afghanistan is Like," "Not Grounded in the Afghan Reality," and "Seriously Lacking Detail." The descriptive terms used to communicate the error to participants were chosen to be conceptually the opposite of the hedonic and utilitarian characteristics pretest participants indicated are traits of the movies they generally prefer. To establish the generality of these new reviews, participants were advised that the movie was reviewed by "many" ordinary moviegoers / Afghanistan experts, as it was important to ensure that the scenario could not be interpreted as just involving two conflicting subjective opinions of the hedonic / utilitarian merit of the movie.

After learning of blogger error, participants indicated their blogger-directed trust intentions as well as their blogger- and movie-directed word-of-mouth intentions. Participants were directed to indicate their behavioural intentions with the understanding that they would have the opportunity to perform the specific behaviours. High values on these scales indicate high likelihood that participants would perform the trust-related and word-of-mouth behaviours.

Blogger-directed trust intentions were measured using the same set of items used to measure blogger-directed trust intentions before error notification occurred. This measurement approach allows a direct assessment of post-error trust intentions as well as an indirect assessment of trust-intention change (i.e., pre-error trust intentions vs. posterror trust intentions). This indirect comparison approach is similar to the method with which Argo, White, and Dahl (2006) manipulated the discrepancy between the price their 
respondents paid for an item and the price their comparison targets paid for the same item (large discrepancy vs. small discrepancy). Studies have used direct measures of trust change (e.g., Wang and Huff, 2007), but the approach used here is arguably more versatile than that approach, since it permits determination of both post-error trust and trust deterioration outcomes. In addition, this approach allowed for greater parsimony in the questionnaire. Both outcome types will be considered in hypotheses tests.

\section{Measures of negative word-of-mouth intentions.}

Word-of-mouth measures were drawn from research that has examined the retaliatory responses of consumers to perceived service failures and trust violations (e.g., Bonifield and Cole, 2007; Grégoire, Laufer, and Tripp, 2010; Hess, Ganesan, and Klein, 2003; Wang and Huff, 2007). Word-of-mouth intentions directed at the blog (movie) were measured by items indicating the likelihoods that participants would (1a) discourage people they know from reading the blog ( $1 \mathrm{~b}-\ldots$ seeing the movie), (2a) speak negatively about the blog $(2 b-\ldots$ movie) to people they know, and (3a) criticize the blog $(3 b-\ldots$ movie) to people they know. Participants were directed to indicate their word-of-mouth intentions with the understanding that the recipients of the disparaging remarks about the blog (movie) would be people familiar to them.

The reach of negative word-of-communication is not limited to the personal acquaintances of the communicator, however. Some research has examined consumer intentions to complain to an independent third party (e.g., consumer agency) about negative service experiences (e.g., Bougie, Pieters, and Zeelenberg, 2003). Recent studies have also examined consumer intentions to engage in online complaining following 
service failure (e.g., Grégoire, Laufer, and Tripp, 2010). Since blogs and similar media typically allow multi-way communication (readers can post comments, etc.), participants were also asked about the likelihoods they would (1) leave negative feedback and (2) post a critical comment about the movie review on the blog and (3) criticize the movie review on the blog. These measures were adapted to the scenario from research on complaint behaviours directed at the provider of a negative service experience (Bougie, Pieters, and Zeelenberg, 2003).

Of interest to marketers of products and services that are the subject of online consumer discourse, participants additionally indicated the likelihoods they would (1) post a negative movie review and (2) a critical comment about the movie on a website and (3) criticize the movie on a website. Various options are available to people interested in sharing their views about movies (Yang, Huang, and Lin, 2009); they can post reviews on widely consulted websites (e.g., Rotten Tomatoes), publish Twitter "tweets" that can even display on official movie websites, and discuss their likes and dislikes on YouTube and similar online services.

\section{Measures of error attributions.}

Error attributions were measured on eight items indicating the extents to which participants believed that the blogger and movie company were responsible for the erroneous movie review and were adapted from studies of service failure, trust violation, and the deceptive practices of online retailers and other sellers (Argo, White, and Dahl, 2006; Grégoire, Laufer, and Tripp, 2010; Hess, Ganesan, and Klein, 2003; Román, 2010; Varela-Neira, Vázquez-Casielles, and Iglesias, 2010). Blogger-directed error attributions 
were measured on four items indicating the extents to which participants believed that the blogger knowingly (1) misrepresented the truth about the movie to readers and attempted to (2) deceive, (3) mislead, and (4) hide the truth about the movie from them.

Responsibility was assigned to the movie company when participants indicated that they believed the makers of the movie were (1) totally responsible, (2) at fault, and (3) totally blameworthy for the actions of the blogger, and when they indicated that the movie company (4) had total control over the actions of the blogger. The set of eight attribution measures provide an understanding of locus and controllability. Locus can be considered the extent to which the individual who personally experienced the error perceives its cause to be internal or external to him or her (Hess, Ganesan, and Klein, 2003).

Controllability is the extent to which the same individual perceives the cause to have been volitional or nonvolitional on the part of the responsible party (Hess, Ganesan, and Klein, 2003).

\section{Measures of affective responses.}

Negative disconfirmations are noted for producing one or more emotions of dissatisfaction, disappointment, regret, anger, or even moral outrage (e.g., Estelami, 2000; Kalamas, Laroche, and Makdessian, 2008; Weiner, 2000; Zeelenberg et al., 2000). Affective responses to the error were measured on seven items indicating the extents to which participants were (1) outraged, (2) angry, (3) mad, (4) disappointed, (5) dissatisfied, (6) discontented, and (7) displeased by what happened and were derived from studies examining negative affective outcomes of service failure and trust violation (e.g., Bonifield and Cole, 2007; Bougie, Pieters, and Zeelenberg, 2003; Grégoire, Laufer, 
and Tripp, 2010; Kalamas, Laroche, Makdessian, 2008; Varela-Neira, Vázquez-Casielles, and Iglesias, 2010; Wang and Huff, 2007). Items 4-7 were used to assess dissatisfaction (Bougie, Pieters, and Zeelenberg, 2003).

\section{Perceived movie review incorrectness.}

Studies sometimes use direct measures (e.g., Grégoire, Laufer, and Tripp, 2010; Hess, Ganesan, and Klein, 2003; Varela-Neira, Vázquez-Casielles, and Iglesias, 2010; Wang and Huff, 2007) or measures of resulting thoughts and feelings (e.g., Darke and Ritchie, 2007; Wang et al., 2011) to quantify the extent to which failure, violation, or deception has occurred. In this study, an indirect measurement approach that seeks to solely identify the extent of error instead of outcomes of error is used, as direct measures have been observed to produce inconsistent results. For example, the magnitude of trust violation (measured directly) had no main effect on trust decline (also measured directly) in a study of responses of buyers to trust violations by buyers (Wang and Huff, 2007). Assessment of the perceived incorrectness of the movie review starts with an assessment of how (1) truthful, (2) accurate, and (3) true participants believed the movie review to be after they discovered its erroneous nature. On the basis of these measures, the perceived incorrectness of the movie review can be operationalized in terms of the departure of the movie review from complete accuracy.

Appendix 5.4 contains summary information regarding measures used in Study 3. 


\section{Results}

\section{Preliminary Data Screening}

\section{Missing data.}

The first examination focused on the prevalence of and patterns in missing data in the 379 cases that comprised the initial dataset. Fully completed questionnaires were returned by 233 (61.5\%) participants. Of the remaining 146 questionnaires that had some missing values, $44(30.1 \%)$ featured at least $5 \%$ missing data and were deleted from the dataset because $335(233+(146-44))$ cases were sufficient for performing factor analysis and the various statistical techniques involved in hypothesis testing. The 102 $(146-44)$ cases featuring some but less than $5 \%$ missing data were examined for patterns in missing values but no pattern was visible. Additionally, there was no evidence of participant attrition during questionnaire completion, since questionnaire item number and the missing-data count for the item were effectively uncorrelated $(r=.04, p>.1)$.

\section{Univariate and multivariate outliers.}

Univariate outliers were identified by first converting all data to $\mathrm{z}$-scores. The size of the dataset mandated that any $z$-score greater than $|4|$ be interpreted as a univariate outlier (Hair et al., 2006). Univariate outliers were only detected on the English, Afghan Persian (or Dari), and Pashto language-familiarity questions. Seven participants were identified as English outliers $(z$-score $<-4.0$ ), seven participants were identified as Afghan Persian (or Dari) outliers ( $z$-score $>4.0$ ), and six participants were identified as Pashto outliers $(z$-score $>4.0)$. A total of fifteen participants were identified as language outliers, as three individuals were outliers on both official Afghanistan languages ( $z$-score 
$>4.0)$ and two individuals were outliers on both Pashto (z-score $>4.0)$ and English ( $z$ score $<-4.0)$ languages. Since these fifteen individuals differ from most participants on variables that could relate to either their ability to read and understand the questionnaire or perhaps their sensitivity to the movie storyline, they were removed from the dataset. Remaining participants reported high English familiarity $(M=5.80, S . D .=.58)$ and low familiarity with Afghan Persian (or Dari) $(M=.10, S . D .=.43)$ and Pashto $(M=.07$, S.D. $=.39$ ).

The existence of multivariate outliers was then investigated in the remaining dataset of three-hundred and twenty cases. Mahalanobis Distance $\left(D^{2}\right)$ values were calculated for each case, and the dataset was examined for $D^{2} / d . f$. values greater than three or four, as they are recommended as cut-off levels in large datasets (Hair et al., 2006). No significant $D^{2} / d . f$. values were observed (maximum $D^{2} / d . f$. $=1.69$ ), and so no multivariate outliers were identified. The dataset comprised of responses from threehundred and twenty participants was then assessed for its distributional properties.

\section{Normality.}

Univariate descriptive statistics, including skewness and kurtosis measures, are provided in Appendix 5.5. Skewness and kurtosis measures were transformed into $z$ scores by dividing them by their standard errors and then two-tailed tests examined the significance of their departure from normality (Hair et al., 2006). The appendix reveals that several items exhibited signs of nonnormality. However, Kline (2005) notes that $z$ score tests, as well as overall tests of normality (e.g., Shapiro-Wilks and KolmogorovSmirnov), are of limited appropriateness in larger samples, as they are very sensitive to 
even small departures from normality. A visual check of items revealed as possessing significantly high levels of skewness and/or kurtosis was conducted using normal probability plots. For the majority of items, departure from normality appeared relatively minor. Accordingly, no skewness or kurtosis measure exceeded the three and seven (based on normal of kurtosis $=0$ ) respective cut-offs that Kline (2005) suggests delineate tolerable and intolerable skewness and kurtosis.

\section{Measure Development}

Exploratory factor analysis, using principal components analysis, was conducted in order to derive conceptually meaningful and statistically supportable measures for testing hypotheses. Principal axis factoring was also conducted and results were highly comparable to those reported here. Mean substitution was used for cases with missing data, since missing data was generally low. Varimax rotation was used in order to identify factors orthogonal to each other. The minimum loading cut-off was .40 , although loadings lower than .50 were rare. Items that loaded together were averaged to form summary measures. Unless indicated otherwise, skewness and kurtosis statistics for final summary measures were acceptable according to the criteria described by Kline (2005).

\section{Beliefs about bloggers who post movie reviews on personal blogs.}

\section{Blogger credibility.}

Blogger credibility was measured at two points in time, before participants were exposed to any experimental treatment information (i.e., typical blogger credibility) and following exposure of participants to the About Me statement and movie review (i.e., 
experiment blogger credibility). The two assessments of blogger credibility were made using the same set of measures but participants were directed to rate the credibility of the experiment blogger in consideration of the content of the movie review (e.g., the knowledge of the blogger on the specific topic it wrote about). Principal components analyses were conducted on typical blogger credibility and experiment blogger credibility separately and results are shown in Table 5.10.

Table 5.10: Descriptives and Factoring Results of Blogger Credibility Variables

\begin{tabular}{|l|c|c|}
\hline \multirow{2}{*}{ Item measures } & \multicolumn{2}{|c|}{ PCA factor loadings } \\
\cline { 2 - 3 } & $\begin{array}{c}\text { Measures for } \\
\text { Typical Blogger }\end{array}$ & $\begin{array}{c}\text { Measures for } \\
\text { Experiment Blogger }\end{array}$ \\
\hline A knowledgeable source of information on the topic & .80 & .85 \\
\hline An expert source of information on the topic & .85 & .88 \\
\hline A qualified source of information on the topic & .88 & .91 \\
\hline A trustworthy source of information on the topic & .88 & .93 \\
\hline A credible source of information on the topic & .89 & .91 \\
\hline Eigenvalue & 3.70 & 4.00 \\
\hline \% variance explained & 74.07 & 80.00 \\
\hline Cronbach $\alpha$ & .91 & .94 \\
\hline Mean ${ }^{a}$ (S.D.) & $2.52(1.16)$ & $2.74(1.30)$ \\
\hline Assigned factor name & Typical & $\begin{array}{c}\text { Experiment } \\
\text { blogger credibility }\end{array}$ \\
\hline
\end{tabular}

${ }^{a}$ All items measured from 0 (Not at all) to 6 (Very much).

\section{Trust beliefs.}

Trust beliefs indicate the perceived ability, benevolence, and integrity of the experiment blogger and were measured after participants were exposed to the About Me statement (movie buff or Afghanistan expert; WOMM disclosure or no WOMM disclosure). Trust-belief measures were taken prior to exposure to the movie review treatment to avoid confounding them with the influences of the movie reviews. Results of principal components analysis are shown in Table 5.11. 
Table 5.11: Descriptives and Factoring Results of Trust Belief Variables

\begin{tabular}{|l|c|c|c|c|}
\hline Item measures & \multicolumn{3}{|c|}{ PCA factor loadings } \\
\hline Just wants to help readers & .70 & & & \\
\hline Cares about readers & .72 & & & \\
\hline Just wants to inform readers & .756 & & & \\
\hline Help readers make movie decision & .79 & & & \\
\hline Totally honest with readers & .88 & & & \\
\hline Totally truthful with readers & .88 & & & \\
\hline Totally sincere with readers & .87 & & & \\
\hline Extensive Afghanistan education & & .93 & & \\
\hline Knows detailed Afghanistan facts & & .95 & & \\
\hline Knows about Afghanistan trends & & .96 & & \\
\hline Researched Afghanistan & & .94 & & .89 \\
\hline Reason to misrepresent the truth & & & .96 & \\
\hline Reason to deceive readers & & & .95 & \\
\hline Reason to mislead readers & & & .91 & \\
\hline Reason to hide the truth & & & & .85 \\
\hline Watches large number of movies & & & & .82 \\
\hline Knows about movie trends & & & & .87 \\
\hline Spends time watching movies & & & & .85 \\
\hline Very passionate about movies & & & & \\
\hline Eigenvalue & 7.07 & 4.38 & 3.21 & 1.23 \\
\hline \% variance explained & 37.23 & 23.06 & 16.88 & 6.47 \\
\hline Cronbach $\alpha$ & .93 & .98 & .96 & .96 \\
\hline Mean ${ }^{\alpha}$ (S.D.) & $3.08(1.29)$ & $3.15(1.95)$ & $3.03(1.66)$ & $3.83(1.75)$ \\
\hline Assigned factor name & Character & Authoritative & Deception & Consumption \\
intent & experience \\
\hline
\end{tabular}

${ }^{a}$ All items measured from 0 (Not at all) to 6 (Very much).

\section{Blogger-rater rapport.}

Six items indicating the likeability and similarity of the blogger to the rater loaded on a single factor and were combined into a single summary measure of blogger-rater rapport $(M=2.54, S . D .=1.03$, Cronbach $\alpha=.91)$. Consistent with conceptualizations of rapport (e.g., Gremler and Gwinner, 2000; Macintosh, 2009), this single summary measure assesses blogger-rater rapport by relating to the prospect of enjoyable interaction and the existence of a personal connection between the blogger and participants. 


\section{Beliefs about the movie reviews posted on personal blogs.}

\section{The typical movie review.}

The perceived completeness, relevance, and understandability of the typical movie review posted on personal blogs as well as consumer scepticism toward it were assessed and then factor analyzed (Table 5.12). The typical movie review is perceived as being moderately to highly understandable, complete, and relevant. Consistent with prior scepticism research (e.g., Obermiller and Spangenberg, 1998; van Heerden et al., 2009), low values on the measures (e.g., low accuracy rating) denote high scepticism toward the typical movie review posted on personal blogs. Instead of the unidimensional result observed by these researchers, two factors were revealed by the analysis, labelled here as "Truthfulness" and "Information intention." The information intent of the blogger writing the typical movie review is greater than the mean of the other adapted scepticism measures which indicate the perceived accuracy of the typical movie review $\left(M_{D i f f e r e n c e}=\right.$ $.89 p<.001)$. Participants were therefore less sceptical of the motivation of bloggers who post movie reviews on personal blogs than of the accuracy of the movie reviews. van Heerden et al. (2009) found a similar result in their survey of public relations bloggers, as the questionnaire item "the aim of blogging is to inform the reader" was rated more favourably than "blogging is truth well told" $(M=4.80, S . D .=1.60$ vs. $M=4.00, S . D .=$ 1.50). 
Table 5.12: Descriptives and Factoring Results of Typical Movie Reviews Posted on a Personal Blog Variables

\begin{tabular}{|c|c|c|c|c|c|}
\hline Item measures & & & factor load & ngs & \\
\hline Truthful & .75 & & & & \\
\hline Reliable & .80 & & & & \\
\hline Truth well told & .81 & & & & \\
\hline Accurate & .74 & & & & \\
\hline True & .80 & & & & \\
\hline Dependable & .63 & & & & \\
\hline $\begin{array}{l}\text { Based on important } \\
\text { or essential information }\end{array}$ & - & - & & & \\
\hline Complete & & .72 & & & \\
\hline Consistent & & .70 & & & \\
\hline Specific & & .67 & & 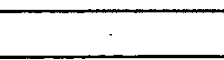 & \\
\hline Objective & & .42 & & & \\
\hline Interesting & & .58 & & & \\
\hline Strongly worded & & .55 & & & \\
\hline Valuable to you & & & .84 & & \\
\hline Helpful to you & & & .85 & & \\
\hline Relevant to you & & & .84 & & \\
\hline Easy to follow & & & & .89 & \\
\hline Easy to understand & & & & .89 & \\
\hline Written to inform & & & & & .86 \\
\hline Informative & & & & & .74 \\
\hline Eigenvalue & 7.16 & 2.29 & 1.46 & 1.25 & 1.11 \\
\hline$\%$ variance explained & 35.78 & 11.45 & 7.31 & 6.25 & 5.54 \\
\hline Cronbach $\alpha$ & .88 & .76 & .91 & .90 & .68 \\
\hline $\operatorname{Mean}^{a}(S . D)$. & $3.02(.90)$ & $3.27(.94)$ & $3.16(1.29)$ & $4.13(1.08)$ & $3.92(1.05)$ \\
\hline Assigned factor name & Truthfulness & $\begin{array}{l}\text { Complete- } \\
\text { ness }\end{array}$ & Relevance & $\begin{array}{l}\text { Understand- } \\
\text { ability }\end{array}$ & $\begin{array}{l}\text { Information } \\
\text { intent }\end{array}$ \\
\hline
\end{tabular}

${ }^{a}$ All items measured from 0 (Not at all) to 6 (Very much).

\section{Experiment movie review.}

The experiment movie review was assessed and factor-analysis results are shown in Table 5.13. Factor structures are comparable to those observed regarding the typical movie review, with one key difference. For the typical movie review, scepticism was found to have a two-factor structure ("truthfulness" and "information intent;" see Table 5.12), but only a one-factor structure for the experiment movie review was found. It may be that participants were able to assess the information intent of the blogger and 
incorporate it into their assessment of the accuracy of the movie review. The information intent of the typical blogger may be much more uncertain, making it a separate consideration for people reading blog entries with no knowledge of the information intent of the blogger.

Table 5.13: Descriptives and Factoring Results of Blogger-Disseminated Movie Review Variables

\begin{tabular}{|c|c|c|c|c|}
\hline Item measures & & PCA fact & loadings & \\
\hline Written to inform & .59 & & & 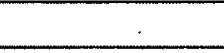 \\
\hline Informative & .68 & - & & \\
\hline Truthful & .86 & & & \\
\hline Reliable & .87 & & & \\
\hline Truth well told & .83 & & & \\
\hline Accurate & .83 & & & \\
\hline True & .84 & & & \\
\hline Dependable & .81 & & & \\
\hline $\begin{array}{l}\text { Based on important } \\
\text { or essential information }\end{array}$ & - & - & & \\
\hline Complete & & .76 & & \\
\hline Consistent & & .63 & & \\
\hline Specific & & .79 & & \\
\hline Objective & & .59 & & \\
\hline Interesting & & .55 & & \\
\hline Strongly worded & & .71 & & \\
\hline Valuable to you & & & .85 & \\
\hline Helpful to you & & & .83 & \\
\hline Relevant to you & & & .86 & \\
\hline Easy to follow & & & & .93 \\
\hline Easy to understand & & & & .92 \\
\hline Eigenvalue & 9.86 & 1.93 & 1.58 & 1.40 \\
\hline$\%$ variance explained & 49.31 & 9.66 & 7.89 & 6.98 \\
\hline Cronbach $\alpha$ & .95 & .87 & .92 & .91 \\
\hline $\operatorname{Mean}^{a}$ (S.D.) & $3.27(1.14)$ & $3.20(1.15)$ & $2.71(1.38)$ & $4.45(1.18)$ \\
\hline Assigned factor name & Accuracy & Completeness & Relevance & $\begin{array}{c}\text { Understand- } \\
\text { ability }\end{array}$ \\
\hline
\end{tabular}

${ }^{a}$ All items measured from 0 (Not at all) to 6 (Very much).

In general, the movie review was rated by participants as moderately to highly understandable, complete, and relevant. Compared to the typical movie review (see Table 
5.12), the experiment movie review exhibited similar completeness $(|t|(319)=1.06, p>$ $.1)$, better ease of understanding $(|t|(318)=4.17, p<.001)$, but less relevance $(|t|(296)=$ $5.14, p<.001)$. Helpful for ensuring that blogger error would produce measurable cognitive, affective, and behavioural results, participants reported less scepticism toward the experiment movie review than the typical movie review $(|t|(319)=3.39, p=.001)$.

\section{Acceptance of claims made by bloggers.}

Acceptance of the About Me statement (movie buff vs. Afghanistan expert; WOMM admission vs. no WOMM admission) and the movie review (hedonic vs. utilitarian) was assessed following exposure to each. Principal components analysis revealed single-factor acceptance structures for both blogger claims. Three items were averaged together to form a single measure of acceptance of the About Me statement (Cronbach $\alpha=.88$ ) and of the movie review (Cronbach $\alpha=.90$ ). To ensure that the experimental treatments were not creating unintended effects on acceptance of the About Me statement, both blogger claims were examined in relationship to the treatment conditions. Results are shown in Table 5.14 and Table 5.15. A two-way ANOVA indicated that acceptance of the About Me statement did not differ on the basis of blogger type, WOMM type, or their interaction. An independent-samples t-test showed that acceptance of the movie review was not dependent on movie review type. 
Table 5.14: ANOVA of "About Me" Statement Acceptance by Blogger and WOMM Types

\begin{tabular}{|c|c|c|c|}
\hline \multicolumn{2}{|c|}{ Treatment conditions } & \multirow{2}{*}{$M(S . D)}$. & \multirow{2}{*}{ ANOVA Results } \\
\hline \multicolumn{2}{|l|}{ Blogger type } & & \\
\hline \multicolumn{2}{|l|}{ Movie buff } & $3.09(1.11)$ & \multirow{2}{*}{$F(1,316)=3.18, p>.05, \eta^{2}=.010$} \\
\hline \multicolumn{2}{|c|}{ Afghanistan expert } & $2.84(1.39)$ & \\
\hline \multicolumn{4}{|c|}{ WOMM type } \\
\hline \multicolumn{2}{|c|}{ WOMM disclosure } & $2.94(1.25)$ & \multirow{2}{*}{$F(1,316)=.10, p>.05, \eta^{2}=.000$} \\
\hline \multicolumn{2}{|c|}{ No WOMM disclosure } & $2.99(1.27)$ & \\
\hline \multicolumn{4}{|c|}{ Blogger type x WOMM type } \\
\hline \multirow{2}{*}{ Movie buff } & WOMM disclosure & $3.07(1.02)$ & \multirow{4}{*}{$F(1,316)=.01, p>.05, \eta^{2}=.000$} \\
\hline & No WOMM disclosure & $3.11(1.20)$ & \\
\hline \multirow{2}{*}{$\begin{array}{l}\text { Afghanistan } \\
\text { expert }\end{array}$} & WOMM disclosure & $2.81(1.44)$ & \\
\hline & No WOMM disclosure & $2.87(1.34)$ & \\
\hline
\end{tabular}

Total: $M=2.96, S . D .=1.26$.

Table 5.15: Independent-Samples t-Test Results - Acceptance of the Movie Review by Movie Review Type

\begin{tabular}{|c|c|c|}
\hline Treatment conditions & $M(S . D)$. & $\begin{array}{c}\text { Independent-samples } \\
\text { t-test results }\end{array}$ \\
\cline { 1 - 2 } Movie review type & $3.08(1.29)$ & $|t|(316)=1.83, p>.05$ \\
\hline Hedonic & $3.34(1.24)$ & \\
\hline
\end{tabular}

Total: $M=3.21, S . D .=1.27$.

\section{Movie attitudes.}

Principal components analysis of six attitudinal measures revealed a single-factor movie attitudes structure (Cronbach $\alpha=.97)$. To ensure that the experimental treatments were not creating unintended effects on the movie attitudes of blog readers, a three-way ANOVA was conducted and results are shown in Table 5.16. Interaction effects are not shown as they were not significant. As the table shows, no evidence of any significant experimental-treatment effect on movie attitudes was observed. Overall movie attitudes 
were acceptable for this research, as they were deemed high enough to warrant a response to blogger error.

Table 5.16: ANOVA of Movie Attitudes by Blogger, WOMM, and Movie Review Types

\begin{tabular}{|c|c|c|}
\hline Treatment conditions & \multirow{2}{*}{$M(S . D)}$. & \multirow{2}{*}{ ANOVA Results } \\
\hline Blogger type & & \\
\hline Movie buff & $3.31(1.40)$ & \multirow{2}{*}{$F(1,311)=.43, p>.1, \eta^{2}=.001$} \\
\hline Afghanistan expert & $3.20(1.46)$ & \\
\hline \multicolumn{3}{|l|}{ WOMM type } \\
\hline WOMM disclosure & $3.29(1.50)$ & \multirow{2}{*}{$F(1,311)=.18, p>.10, \eta^{2}=.001$} \\
\hline No WOMM disclosure & $3.22(1.35)$ & \\
\hline \multicolumn{3}{|l|}{ Movie review type } \\
\hline Hedonic & $3.34(1.47)$ & \multirow{2}{*}{$F(1,311)=1.25, p>.10, \eta^{2}=.004$} \\
\hline Utilitarian & $3.17(1.40)$ & \\
\hline
\end{tabular}

Total: $M=3.26, S . D .=1.43$.

\section{Trust intentions.}

Trust intentions were assessed both before and after participants were advised of blogger error. Principal components analysis revealed single-factor trust-intention structures at both times (Cronbach $\alpha_{\text {Preerror }}=.93$; Cronbach $\alpha_{\text {Post-error }}=.98$ ). Before blogger error, trust intentions were measured by averaging six items $(M=2.38, S . D .=$ 1.40), and trust intentions after blogger error were measured by averaging the same six items $(M=1.27$, S.D. $=1.52)$.

\section{Negative word-of-mouth intentions.}

Blog-directed negative word-of-mouth intentions were measured with six items that distinguished between interpersonal communication with familiar message recipients and online communication with unfamiliar message recipients. Participants indicated 
their intentions to speak negatively about the blog to people they know (i.e., interpersonal communication) as well as to criticize the movie review on the blog itself (i.e., online communication). A similar distinction was made for movie-directed negative word-ofmouth intentions, where participants indicated their intentions to speak negatively about the movie to people they know as well as to criticize the movie on a website. The distinction between interpersonal and online communication has direct implications for the potential reach of the negative communication, which in turn has important implications for the scale of any harm that could result from the negative word-of-mouth communication. Negative blog-related and movie-related communication intentions were examined in separate factor analyses, and results are shown in Table 5.17.

Although hypotheses were directed at explaining these behaviours but not their relative prominence, initial analyses were conducted to determine the extent to which the behaviours were realistic responses to blogger error. Behavioural intentions to engage in negative interpersonal communication were stronger than those for engaging in negative online communication for both the blog and the movie $(p<.001)$. The blog and movie, as objects of the negative interpersonal communication, could be expected to experience similar responses, as a paired $t$-test revealed no difference between them on this measure $(p>.1)$. An independent-samples t-test indicated that the blog could expect to be the focus of more negative online communication than the movie, however $(p<.001)$. 
Table 5.17: Descriptives and Factoring Results of Negative Word-of-Mouth Intentions Variables

\begin{tabular}{|c|c|c|c|c|}
\hline \multirow{3}{*}{$\begin{array}{l}\text { Item measures } \\
\text { Negative feedback about movie } \\
\text { review posted on blog }\end{array}$} & \multicolumn{4}{|c|}{ PCA factor loadings } \\
\hline & \multicolumn{2}{|c|}{$\begin{array}{l}\text { Analysis 1: Blog-directed } \\
\text { negative word-of-mouth } \\
\text { communication }\end{array}$} & \multicolumn{2}{|c|}{$\begin{array}{l}\text { Analysis 2: Movie-directed } \\
\text { negative word-of-mouth } \\
\text { communication }\end{array}$} \\
\hline & . & & & \\
\hline Leave negative feedback & .90 & 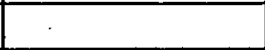 & & \\
\hline Post a critical comment & .94 & & & \\
\hline Criticize & .92 & & & \\
\hline \multicolumn{5}{|l|}{$\begin{array}{l}\text { Negative interpersonal } \\
\text { communication about blog }\end{array}$} \\
\hline Discourage & & .89 & & \\
\hline Speak negatively & & .89 & & \\
\hline Criticize & & .86 & & \\
\hline \multicolumn{5}{|l|}{$\begin{array}{l}\text { Negative online communication } \\
\text { about movie }\end{array}$} \\
\hline Post a negative review & & & .94 & \\
\hline Post a critical comment & & & .95 & \\
\hline Criticize & & & .94 & \\
\hline \multicolumn{5}{|l|}{$\begin{array}{l}\text { Negative interpersonal } \\
\text { communication about movie }\end{array}$} \\
\hline Discourage & & & & .92 \\
\hline Speak negatively & & & & .95 \\
\hline Criticize & & & & .93 \\
\hline Eigenvalue & 4.10 & 1.20 & 3.70 & 1.73 \\
\hline$\%$ variance explained & 68.27 & 20.04 & 61.70 & 28.88 \\
\hline Cronbach $\alpha$ & .95 & .91 & .95 & .94 \\
\hline $\operatorname{Mean}^{a}$ (S.D.) & $2.26(1.83)$ & $3.08(1.74)$ & $1.73(1.67)$ & $3.24(1.80)$ \\
\hline Assigned factor name & \begin{tabular}{|c|} 
Negative \\
blog-related \\
online \\
communication
\end{tabular} & \begin{tabular}{|c|} 
Negative \\
blog-related \\
interpersonal \\
communication
\end{tabular} & \begin{tabular}{|c|} 
Negative \\
movie-related \\
online \\
communication
\end{tabular} & \begin{tabular}{|c|} 
Negative \\
movie-related \\
interpersonal \\
communication
\end{tabular} \\
\hline
\end{tabular}

${ }^{a}$ All items measured from 0 (Not at all) to 6 (Very much).

\section{Blogger and movie company blameworthiness.}

The causal source of blogger error was measured with a focus on both the blogger and the makers of the movie. Results of the factor analysis are shown in Table 5.18.

Blogger blameworthiness for the error and movie-company blameworthiness for the error 
are positively related $(r=.283, p<.001)$, but a paired t-test showed that blogger

blameworthiness is greater than movie-company blameworthiness $(p<.001)$.

Table 5.18: Descriptives and Factoring Results of Blogger and Movie Company Blameworthiness Variables

\begin{tabular}{|l|c|c|}
\hline Item measures & \multicolumn{2}{|c|}{ PCA factor loadings } \\
\hline The blogger knowingly misrepresented the truth & .93 & \\
\hline The blogger knowingly attempted to deceive readers & .96 & \\
\hline The blogger knowingly attempted to mislead readers & .96 & \\
\hline The blogger knowingly hid the truth from readers & .94 & .93 \\
\hline $\begin{array}{l}\text { The makers of the movie are totally responsible for the } \\
\text { blogger's actions }\end{array}$ & & .96 \\
\hline $\begin{array}{l}\text { The makers of the movie are totally at fault for the } \\
\text { blogger's actions }\end{array}$ & & .96 \\
\hline $\begin{array}{l}\text { The makers of the movie are totally blameworthy for the } \\
\text { blogger's actions }\end{array}$ & & .92 \\
\hline $\begin{array}{l}\text { The makers of the movie had total control over the } \\
\text { blogger's actions }\end{array}$ & & 2.60 \\
\hline Eigenvalue & 4.66 & 32.53 \\
\hline$\%$ variance explained & 58.23 & .97 \\
\hline Cronbach $\alpha$ & $3.32(1.59)$ & $1.83(1.59)$ \\
\hline Mean ${ }^{\alpha}$ (S.D.) & $\begin{array}{c}\text { Blogger } \\
\text { blameworthiness }\end{array}$ & $\begin{array}{l}\text { Movie company } \\
\text { blameworthiness }\end{array}$ \\
\hline Assigned factor name & & \\
\hline
\end{tabular}

${ }^{a}$ All items measured from 0 (Not at all) to 6 (Very much).

\section{Affective response to blogger error.}

Dissatisfaction and anger as affective responses to blogger error were examined.

Results are shown in Table 5.19. A paired t-test showed that the degree of dissatisfaction caused by blogger error was greater than that of anger caused by blogger error $(p<.001)$, but the two affective responses are positively related to each other $(r=.654, p<.001)$. 
Table 5.19: Descriptives and Factoring Results of Affective Responses to Blogger Error Variables

\begin{tabular}{|l|c|c|}
\hline Item measures & \multicolumn{2}{|c|}{ PCA factor loadings } \\
\hline You are disappointed by what happened & .84 & \\
\hline You are dissatisfied by what happened & .85 & \\
\hline You feel discontented by what happened & .85 & .88 \\
\hline You are displeased by what happened & & .90 \\
\hline You are outraged by what happened & & .88 \\
\hline You are angry because of what happened & & .84 \\
\hline You are mad because of what happened & 4.94 & 1.04 \\
\hline Eigenvalue & 70.51 & 14.81 \\
\hline \% variance explained & .93 & .93 \\
\hline Cronbach $\alpha$ & $2.97(1.61)$ & $2.14(1.55)$ \\
\hline Mean ${ }^{\boldsymbol{a}}$ (S.D.) & Dissatisfaction & Anger \\
\hline Assigned factor name & & \\
\hline
\end{tabular}

${ }^{a}$ All items measured from 0 (Not at all) to 6 (Very much).

\section{Discovered movie review accuracy and perceived incorrectness.}

After participants were advised of the error by the blogger, they indicated their beliefs of the truthfulness, accuracy, and trueness of the movie review. Low (high) values on these measures denoted low (high) discovered movie review accuracy. The items were averaged together to form an index of discovered movie review accuracy (Cronbach $\alpha=$ $.95 ; M=1.35, S . D .=1.45)$. The perceived incorrectness of the movie review was operationalized as the extent to which the discovered accuracy of the movie review fell short of complete accuracy; a completely accurate movie review would be equivalent to 6 on a 0-6 scale, since high values on the scale denote high accuracy. To obtain this movie review incorrectness measure, discovered movie review accuracy was subtracted from a constant of 6. High (low) values on this calculated measure indicated high (low) levels of perceived movie review incorrectness. The discovered accuracy of the movie review was poor in comparison to a completely accurate movie review $\left(M_{\text {Difference }}=4.65, p<.001\right)$. 
Descriptive Analysis

\section{Demographic information.}

Of the 320 participants retained for analysis, $53 \%$ are male and $96 \%$ were between eighteen and twenty-six years of age. As the independent-samples $t$-tests reported in Table 5.20 show, participant sex is unrelated in many of the key variables of this study, including blogger credibility, movie review acceptance, movie attitudes, preerror trust, and post-error trust. ANOVAs reported in Table 5.21 show that participant age was unrelated to the same set of key variables. As a result, participant demographics are not considered further in this study.

Table 5.20: Tests of Sex-Based Differences on Key Variables

\begin{tabular}{|l|c|c|c|}
\hline \multirow{2}{*}{ Variables } & Males & Females & Independent- \\
\cline { 2 - 3 } & $M(S . D)$. & $M(S . D)$. & .22 \\
\hline Blogger credibility & $2.75(1.29)$ & $2.72(1.31)$ & .60 \\
\hline Movie review acceptance & $3.16(1.33)$ & $3.25(1.20)$ & .67 \\
\hline Movie attitudes & $3.30(1.38)$ & $3.20(1.48)$ & .01 \\
\hline Pre-error trust & $2.37(1.38)$ & $2.37(1.42)$ & .74 \\
\hline Post-error trust & $1.32(1.52)$ & $1.19(1.50)$ & \\
\hline
\end{tabular}

${ }_{a}$ All $t$-tests non-significant $(p>.10)$.

Table 5.21: Tests of Age-Based Differences on Key Variables

\begin{tabular}{|l|c|c|c|c|}
\hline \multirow{2}{*}{ Variables } & $\begin{array}{c}\mathbf{1 8 - 2 0} \\
\text { years }\end{array}$ & $\begin{array}{c}\mathbf{2 1 - 2 3} \\
\text { years }\end{array}$ & $\begin{array}{c}\mathbf{2 4 - 2 6} \\
\text { years }\end{array}$ & $\begin{array}{c}\text { ANOVA results } \\
(F \text {-values) }\end{array}$ \\
\cline { 2 - 5 } & $M(S . D)$. & $M(S . D)$. & $M(S . D)$. & .05 \\
\hline Blogger credibility & $2.73(1.29)$ & $2.75(1.34)$ & $2.62(1.80)$ & .83 \\
\hline Movie review acceptance & $3.24(1.25)$ & $3.03(1.38)$ & $2.85(1.61)$ & .83 \\
\hline Movie attitudes & $3.28(1.39)$ & $2.95(1.78)$ & $3.35(1.40)$ & .37 \\
\hline Pre-error trust & $2.33(1.37)$ & $2.55(1.57)$ & $2.32(1.63)$ & 2.07 \\
\hline Post-error trust & $1.17(1.46)$ & $1.72(1.66)$ & $1.35(1.82)$ & \\
\hline
\end{tabular}

${ }^{a}$ All $F$-values non-significant $(p>.10)$. 


\section{Typical blogger credibility and blog usage.}

Participants were asked to rate the credibility of the typical blogger and to report their experience with blogs and similar websites for obtaining movie reviews. Most participants (79.1\%) indicated at least some experience with blogs and similar websites for this purpose (Table 5.22). Participants also indicated that they consult blogs and similar websites for movie reviews on a regular basis, with two-thirds of them reported consulting at least one in an average week (Table 5.23). The results reported in Table 5.22 and Table 5.23 confirm the relevance and familiarity of the use of blogs for accessing movie reviews to the majority of participants. Beliefs of the credibility of the typical blogger are also reported in the tables. ANOVA tests indicate that the perceived credibility of the typical blogger does not vary on the basis of blog-usage experience. Participants indicated a slight negative bias in their beliefs about the credibility of the typical blogger, as a one-sample means test showed the credibility rating to be less than the midpoint on the 0-6 scale used in this study $(p<.001)$.

Table 5.22: ANOVA of Typical Blogger Credibility by Experience with Blogs and Similar Websites for Obtaining Movie Reviews

\begin{tabular}{|l|c|c|c|}
\hline Categories $^{a}$ & $\mathbf{N}$ & \multirow{2}{*}{$\%$} & Typical blogger credibility $^{c}$ \\
\cline { 3 - 4 } & & & $M(S . D)$. \\
\hline 0 (No time at all) & 68 & 21.3 & $2.26(1.15)$ \\
\hline Less than 1 year & 80 & 25.0 & $2.45(1.16)$ \\
\hline 1-2 years & 76 & 23.8 & $2.63(1.17)$ \\
\hline More than 2 years & 96 & 30.0 & $2.63(1.17)$ \\
\hline Total & 320 & $100 \%^{b}$ & $2.51(1.17)^{d}$ \\
\hline
\end{tabular}

${ }^{a}$ Number of years participants have been reading movie reviews posted on blogs or similar websites.

${ }^{b}$ May not exactly add to $100 \%$ due to rounding.

${ }^{c} F(3,300)=1.59, p>.10$.

${ }^{d}$ Assessed against the midpoint, $M_{\text {Difference }}=-.48, t(318)=-7.35, p<.001$ 
Table 5.23: ANOVA of Typical Blogger Credibility by Number of Movie Reviews Read in Blogs on a Weekly Basis

\begin{tabular}{|l|c|c|c|}
\hline Categories $^{a}$ & \multirow{N}{*}{} & \multirow{2}{*}{$\%$} & Typical blogger credibility \\
\cline { 4 - 4 } & & & $M(S . D)$. \\
\hline 0 & 106 & 33.2 & $2.32(1.22)$ \\
\hline 1 or 2 & 179 & 56.1 & $2.60(1.16)$ \\
\hline 3 or 4 & 23 & 7.2 & $2.51(1.15)$ \\
\hline 5 or more & 11 & 3.4 & $2.93(.63)$ \\
\hline Total & $319^{b}$ & $100 \%^{c}$ & $2.51(1.17)$ \\
\hline
\end{tabular}

${ }^{a}$ Number of movie reviews pretest participants read in an average week in blogs or on similar websites.

${ }_{1} 1$ missing.

${ }^{c}$ May not exactly add to $100 \%$ due to rounding.

${ }^{d} F(5,297)=1.36, p>.10$.

The general perception of typical blogger credibility implies that information seekers may have reservations about bloggers as an information-source category. The implications of this finding may be most profound for consumers engaged in a low involvement information search, since source credibility is most persuasive under low processing motivation (Petty and Cacioppo, 1984). When information seekers lack the motivation to invest resources in the search, they turn to information sources they believe are credible in order to form their own beliefs. As a result, information seekers may choose to avoid the blogosphere altogether, as long as the topic of their interest is being discussed outside the blogosphere.

Turning to blog content, a one-way MANOVA was conducted to examine if beliefs about the completeness, relevance, and understandability of the typical movie review differed across blog-usage levels. Measures of these constructs were reported in Table 5.12 and results of the analysis are summarized in Table 5.24. Blog-usage experience does appear to account for some differences within these beliefs, although the effect is small. Blog-usage experience is related to beliefs about the relevance of the 
typical movie review posted on a personal blog and how easy it is to understand, but not to its completeness.

\section{Hypothesis Testing}

The 320 participants were randomly divided across the eight experimental treatments as indicated in Table 5.25. The distribution of participants across treatments is essentially uniform, with cell-size disparity (i.e., largest group size / smallest group size) well within the level $(<1.5)$ recommended by Hair et al. $(2006)$.

Table 5.24: MANOVA of Beliefs About the Typical Movie Review by Experience with Blogs and Similar Websites for Obtaining Movie Reviews

\begin{tabular}{|l|c|c|c|}
\hline \multirow{2}{*}{ Categories $^{a}$} & \multicolumn{3}{|c|}{ Beliefs about the typical movie review } \\
\cline { 2 - 4 } & Completeness & Relevance & Understandability \\
\cline { 2 - 4 } & $M(S . D)$. & $M(S . D)$. & $M(S . D)$. \\
\hline 0 (No time at all) & $3.15(.98)$ & $2.77(1.36)$ & $3.99(1.09)$ \\
\hline Less than 1 year & $3.22(.87)$ & $3.07(1.21)$ & $3.98(1.10)$ \\
\hline 1-2 years & $3.19(1.01)$ & $3.18(1.32)$ & $4.10(1.04)$ \\
\hline More than 2 years & $3.44(.87)$ & $3.49(1.21)^{b}$ & $4.38(1.07)$ \\
\hline Total & $3.27(.94)$ & $3.16(1.29)$ & $4.13(1.08)$ \\
\hline ANOVA results & $F(3,315)=1.73$ & $F(3,315)=4.41^{* *}$ & $F(3,315)=2.68^{*}$ \\
& $\eta^{2}=.02$ & $\eta^{2}=.04$ & $\eta^{2}=.03$ \\
\hline
\end{tabular}

${ }^{a}$ Number of years participants have been reading movie reviews posted on blogs or similar websites.

${ }^{b}$ Significantly different from corresponding mean of participants with no blog-reading experience $(p<$ $.01)$.

${ }^{*} p<.05 ;{ }^{* *} p<.01$.

Table 5.25: Participant Breakdown Across Experimental Treatments

\begin{tabular}{|l|c|c|c|c|}
\hline \multirow{2}{*}{ Movie reviews } & \multicolumn{4}{|c|}{ About Me statements } \\
\cline { 2 - 5 } & \multicolumn{3}{|c|}{ Movie Buff } & \multicolumn{2}{c|}{ Afghanistan Expert } \\
\cline { 2 - 5 } & WOMM & No WOMM & WOMM & No WOMM \\
\hline Hedonic & 38 & 40 & 41 & 41 \\
\hline Utilitarian & 43 & 38 & 39 & 40 \\
\hline
\end{tabular}




\section{Blogger trust beliefs: Hypothesis one.}

H1 predicted that the movie buff and Afghanistan expert bloggers would differ on blogger ability measures and that the WOMM and non-WOMM bloggers would differ on character measures. An initial check indicated that the four About Me statements were equally believable to participants $(p<.05)$. MANOVA was conducted to assess the effects of the blogger and WOMM type treatments on blogger trust beliefs and results are summarized in Table 5.26 .

H1a and H1b serve as checks of the effectiveness of the blogger type manipulation. H1a predicted that the Afghanistan expert blogger would receive higher authoritative knowledge ratings than the movie buff blogger and evidence supporting this hypothesis was observed $\left(M_{\text {Difference }}=2.67, p<.001\right)$. There was no evidence that authoritative knowledge varied by WOMM type or that the main effect of blogger type on the authoritative knowledge rating was contingent on WOMM type. H1b predicted that the consumption experience rating of the movie buff blogger would be higher than that of the Afghanistan expert blogger and this hypothesis was supported. Regardless of the WOMM status of either blogger, the movie buff received higher consumption experience ratings than the Afghanistan expert received $\left(M_{D i f f e r e n c e}=2.39, p<.001\right)$. On the basis of these results, the blogger type manipulation was deemed effective. 
Table 5.26: MANOVA of Blogger Trust Beliefs by Blogger and WOMM Types

\begin{tabular}{|c|c|c|c|c|c|c|c|c|c|}
\hline \multirow{3}{*}{\multicolumn{2}{|c|}{$\begin{array}{l}\text { Treatment conditions } \\
\text { (MANOVA Results) }\end{array}$}} & \multicolumn{8}{|c|}{ Univariate Results } \\
\hline & & \multicolumn{2}{|c|}{ Authoritative knowledge } & \multicolumn{2}{|c|}{ Consumption experience } & \multicolumn{2}{|c|}{ Character } & \multicolumn{2}{|c|}{ Deception intent } \\
\hline & & $M(S . D)$. & $F$ & $M(S . D)$. & $F$ & $M(S . D)$. & $F$ & M(S.D.) & $F$ \\
\hline \multicolumn{10}{|c|}{$\begin{array}{l}\text { Blogger type } \\
F(4,313)=144.25^{* * *}, \eta 2=.65\end{array}$} \\
\hline \multicolumn{2}{|c|}{ Movie buff } & $1.80(1.40)$ & \multirow{2}{*}{$282.85^{* * *}$} & $5.03(.91)$ & \multirow{2}{*}{$285.09 * * *$} & $3.45(1.20)$ & \multirow{2}{*}{$30.09 * * *$} & $2.95(1.70)$ & \multirow{2}{*}{1.00} \\
\hline \multicolumn{2}{|c|}{ Afghanistan expert } & $4.48(1.45)$ & & $2.65(1.57)$ & & $2.71(1.26)$ & & $3.11(1.62)$ & \\
\hline \multicolumn{10}{|c|}{$\begin{array}{l}\text { WOMM type } \\
F(4,313)=9.31^{* * *}, \eta 2=.11\end{array}$} \\
\hline \multicolumn{2}{|c|}{ WOMM disclosure } & $3.07(1.89)$ & \multirow{2}{*}{.54} & $4.01(1.59)$ & \multirow{2}{*}{$5.07^{*}$} & $2.94(1.34)$ & \multirow{2}{*}{$4.35^{*}$} & $3.48(1.68)$ & \multirow{2}{*}{$26.59 * * *$} \\
\hline No WOMM & losure & $3.22(2.02)$ & & $3.66(1.90)$ & & $3.22(1.21)$ & & $2.57(1.51)$ & \\
\hline \multicolumn{10}{|c|}{$\begin{array}{l}\text { Blogger type x WOMM type } \\
F(4,313)=3.31^{* *}, \eta 2=.04\end{array}$} \\
\hline \multirow{2}{*}{ Movie buff } & $\begin{array}{l}\text { WOMM } \\
\text { disclosure }\end{array}$ & $1.85(1.38)$ & \multirow{4}{*}{2.11} & $4.99(.90)^{a}$ & \multirow{4}{*}{$8.19 * *$} & $3.19(1.32)^{b}$ & \multirow{4}{*}{$\begin{array}{c}3.24 \\
(p=.073)\end{array}$} & $3.54(1.68)$ & \multirow{4}{*}{2.84} \\
\hline & $\begin{array}{l}\text { No WOMM } \\
\text { Disclosure }\end{array}$ & $1.74(1.42)$ & & $5.08(.92)^{a}$ & & $3.73(1.01)^{a}$ & & $2.32(1.50)$ & \\
\hline \multirow{2}{*}{$\begin{array}{l}\text { Afghanistan } \\
\text { expert }\end{array}$} & $\begin{array}{l}\text { WOMM } \\
\text { Disclosure }\end{array}$ & $4.30(1.51)$ & & $3.01(1.51)^{b}$ & & $2.69(1.33)^{c}$ & & $3.42(1.70)$ & \\
\hline & $\begin{array}{l}\text { No WOMM } \\
\text { Disclosure }\end{array}$ & $4.65(1.37)$ & & $2.29(1.56)^{c}$ & & $2.73(1.20)^{c}$ & & $2.80(1.49)$ & \\
\hline
\end{tabular}

${ }^{*} p<.05 ; * * p<.01 ; * * * p<.001$.

Note for interaction effects: Trust belief ratings with the same alphabetical superscript are not significantly different from each other. Trust belief ratings with different alphabetical superscripts are significantly different from each other $(p<.05)$. " $a$ " denotes the highest mean(s), " $b$ " the second highest mean(s), and so on. 
Although not central to $\mathrm{H} 1 \mathrm{~b}$, further examination of blogger type effect on consumption experience within the context of WOMM revealed an interaction effect. WOMM type was specifically observed to influence the consumption experience rating of the Afghanistan expert blogger. As Figure 5.2 shows, the Afghanistan expert blogger who made the WOMM disclosure received a higher consumption experience rating than the Afghanistan expert blogger who did not $\left(M_{\text {Difference }}=.72, p<.01\right)$. In contrast, the WOMM status of the movie buff blogger had no effect on its consumption experience rating $\left(M_{\text {WOMM }}=4.99\right.$ versus $M_{\text {No }}$ พомM $\left.=5.08, p>.05\right)$.

$\mathrm{H} 1 \mathrm{c}$ and $\mathrm{H} 1 \mathrm{~d}$ respectively predicted that the blogger who made the WOMM disclosure would receive a lower character rating but a higher deception intent rating than the blogger who did not. WOMM was observed to have a significant main effect on both character and deception intent ratings. In further analysis of possible differences across blogger type, the effect of WOMM on the character rating did show an interaction (albeit marginally; $p=.073$ ) with blogger type. As Figure 5.3 shows, WOMM disclosure type had no effect on the character rating of the Afghanistan expert blogger $\left(M_{\text {WOMM }}=2.69\right.$ versus $M_{\text {No } о \text { พоMM }}=2.73, p>.05$ ). In contrast, the character of the movie buff blogger who made the WOMM disclosure was rated lower than that of the movie buff blogger who did not $\left(M_{\text {Difference }}=-.53, p<.01\right)$. As a result, $\mathrm{Hlc}$ received partial support.

H1d was also supported, since the deception intent rating of the WOMM blogger was higher than that of the non-WOMM blogger $\left(M_{\text {Difference }}=.92, p<.001\right)$. This result is consistent with that observed for Hlc. The bivariate correlation between character and deception intent is negative $(r=-.253, p<.001)$, so the lower deception intent of the non-WOMM blogger relative to the WOMM blogger aligns with the higher character. No 
evidence of a main effect of blogger type or an interaction effect between WOMM type and blogger type on the deception intent rating of the blogger was observed.

Figure 5.2: Consumption Experience Beliefs - Blogger type by WOMM type

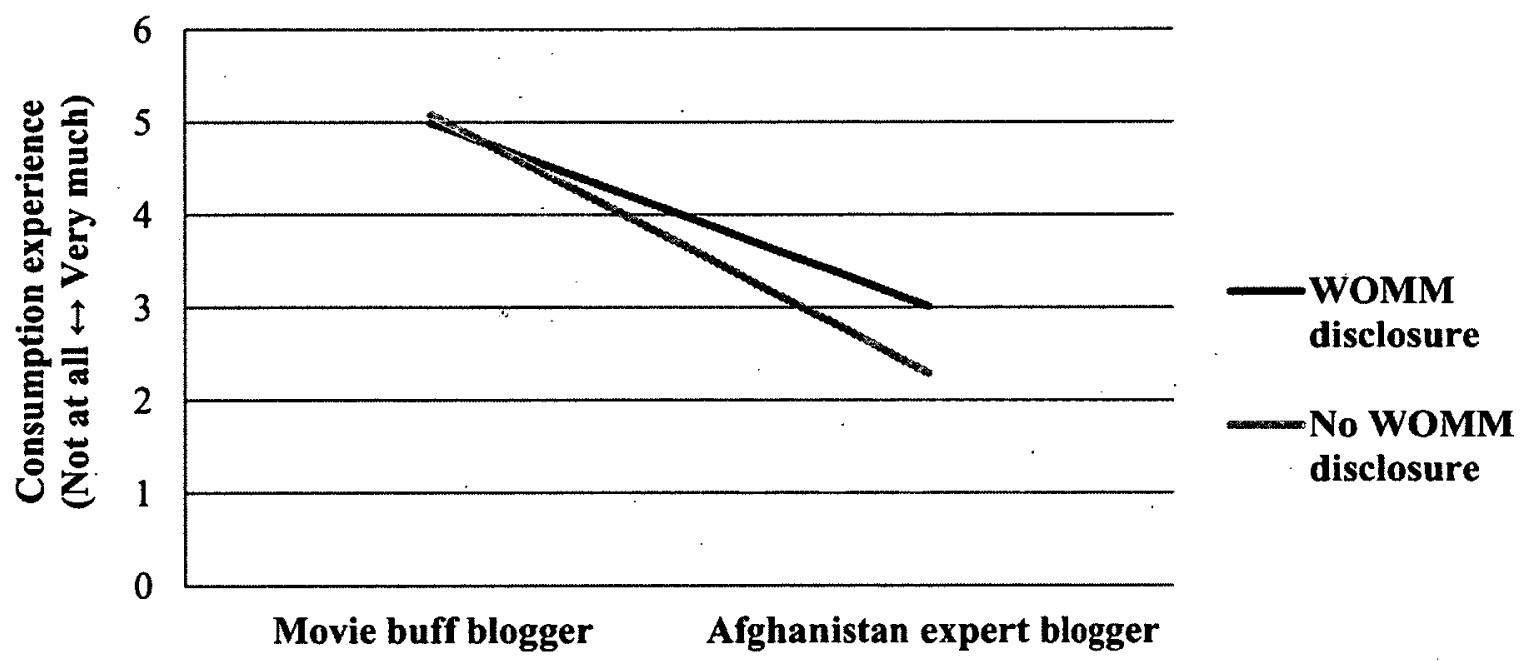

Figure 5.3: Character Beliefs - Blogger type by WOMM type

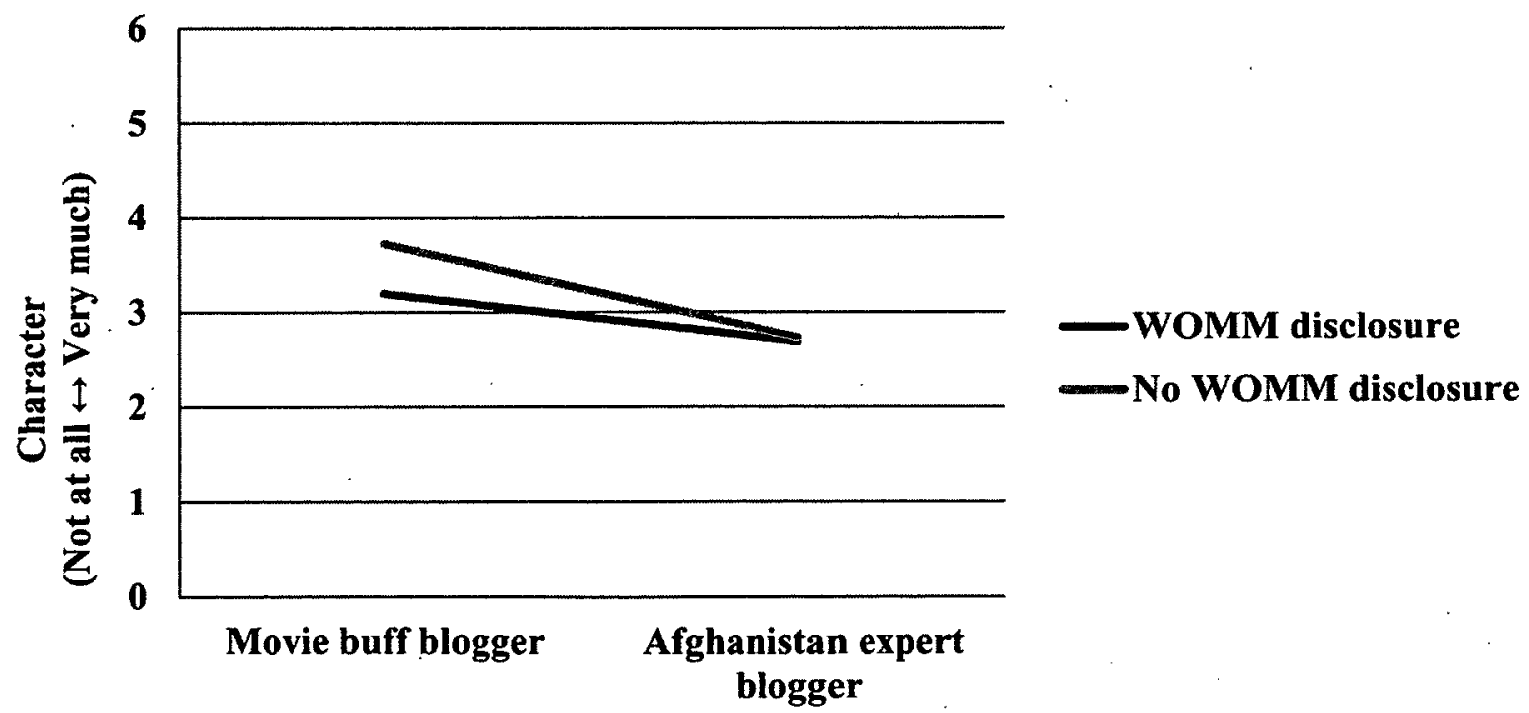


Blogger credibility rating: Hypotheses two through five.

To test $\mathrm{H} 2 \mathrm{a}-\mathrm{H} 2 \mathrm{c}$, a three-way ANOVA was conducted in order to identify the effects of the experimental treatments on the credibility rating of the blogger. Results are summarized in Table 5.27. The ANOVA involved tests of three two-way interactions and one three-way interaction, but to economize on space the results of the non-significant interactions $(p>.05)$ are excluded from the table.

H2a predicted that blogger credibility would differ on the basis of the WOMM treatment. Contrary to this expectation, there was no observable main effect of WOMM admission, as the credibility of the WOMM blogger was not significantly different from that of the non-WOMM blogger $\left(M_{\text {WOMM }}=2.80\right.$ versus $\left.M_{\text {No } \text { WOMM }}=2.68, p>.05\right)$. WOMM type was also not observed to interact with blogger or movie review type in influencing the blogger credibility rating.

$\mathrm{H} 2 \mathrm{~b}$ predicted that the movie buff (Afghanistan expert) blogger would be more credible to participants when it reviewed the hedonic (utilitarian) merit of the movie than when it reviewed the utilitarian (hedonic) merit of the movie. The ANOVA provided evidence of a significant interaction effect between blogger and movie review types on blogger credibility. The interaction effect is illustrated in Figure 5.4. Contrary to the hypothesis, the credibility of the movie buff blogger was no greater when it reviewed the hedonic merit of the movie than when it reviewed the utilitarian merit of the movie $\left(M_{\text {Hedonic }}=2.49\right.$ versus $\left.M_{\text {Utilitarian }}=2.55, p>.05\right)$. Moreover, there was no significant difference in the credibility ratings of the movie buff blogger and the Afghanistan expert blogger when they reviewed the hedonic merit of the movie $\left(M_{\text {Movie buff }}=2.49\right.$ versus $M_{\text {Afghanistan expert }}=2.55, p>.05$ ). Support for the hypothesis was observed between the 
movie reviews made by the Afghanistan expert blogger, however. The Afghanistan expert blogger was regarded as more credible to participants when it reviewed the utilitarian merit of the movie than when it reviewed the hedonic merit of the movie $\left(M_{D i f e r e n c e}=.84, p<.001\right)$. Whereas knowledge requirements for making accurate claims regarding hedonic characteristics are few and not domain specific, they are substantial and very domain specific for utilitarian subject matter.

Table 5.27: ANOVA of Blogger Credibility Rating by Blogger, WOMM, and Movie Review Types

\begin{tabular}{|c|c|c|}
\hline \multicolumn{2}{|c|}{ Treatment conditions (ANOVA Results) } & $M(S . D)$. \\
\hline \multicolumn{3}{|c|}{ Blogger type $F(1,311)=10.15^{* *}, \eta^{2}=.03$} \\
\hline \multicolumn{2}{|c|}{ Movie buff } & $2.52(1.26)$ \\
\hline \multicolumn{2}{|c|}{ Afghanistan expert } & $2.96(1.31)$ \\
\hline \multicolumn{3}{|c|}{ WOMM type $F(1,311)=.77, \eta^{2}=.002$} \\
\hline \multicolumn{2}{|c|}{ WOMM disclosure } & $2.80(1.37)$ \\
\hline \multicolumn{2}{|c|}{ No WOMM disclosure } & $2.68(1.24)$ \\
\hline \multicolumn{3}{|c|}{ Movie review type $F(1,311)=10.29^{* * *}, \eta^{2}=.03$} \\
\hline \multicolumn{2}{|c|}{ Hedonic } & $2.52(1.22)$ \\
\hline \multicolumn{2}{|c|}{ Utilitarian } & $2.97(1.35)$ \\
\hline \multicolumn{3}{|c|}{ Blogger type x movie review type $F(1,311)=7.59 * *, \eta^{2}=.02$} \\
\hline \multirow{2}{*}{ Movie buff } & Hedonic & $2.49(1.19)^{b}$ \\
\hline & Utilitarian & $2.55(1.33)^{b}$ \\
\hline \multirow{2}{*}{$\begin{array}{l}\text { Afghanistan } \\
\text { expert }\end{array}$} & Hedonic & $2.55(1.25)^{b}$ \\
\hline & Utilitarian & $3.39(1.24)^{a}$ \\
\hline \multicolumn{3}{|c|}{$\begin{array}{l}\text { (Follow-up test) } \\
\text { Blogger-movie review match } / \text { mismatch } F(1,317)=7.39 * *, \eta^{2}=.02\end{array}$} \\
\hline \multicolumn{2}{|c|}{ Match } & $2.94(1.29)$ \\
\hline \multicolumn{2}{|l|}{ Mismatch } & $2.55(1.29)$ \\
\hline
\end{tabular}

${ }^{*} p<.05 ;{ }^{* *} p<.01 ;{ }^{* * *} p<.001$.

Interaction effect(s): Trust belief ratings with the same alphabetical superscript are not significantly different from each other. Trust belief ratings with different alphabetical superscripts are significantly different from each other $(p<.05)$. " $a$ " denotes the highest mean $(s)$, " $b$ " the second highest mean(s), and so on.

Match: Movie buff and hedonic movie review; Afghanistan expert and utilitarian movie review Mismatch: Movie buff and utilitarian movie review; Afghanistan expert and hedonic movie review 
Figure 5.4: Blogger Credibility Rating - Blogger Type by Movie Review Type

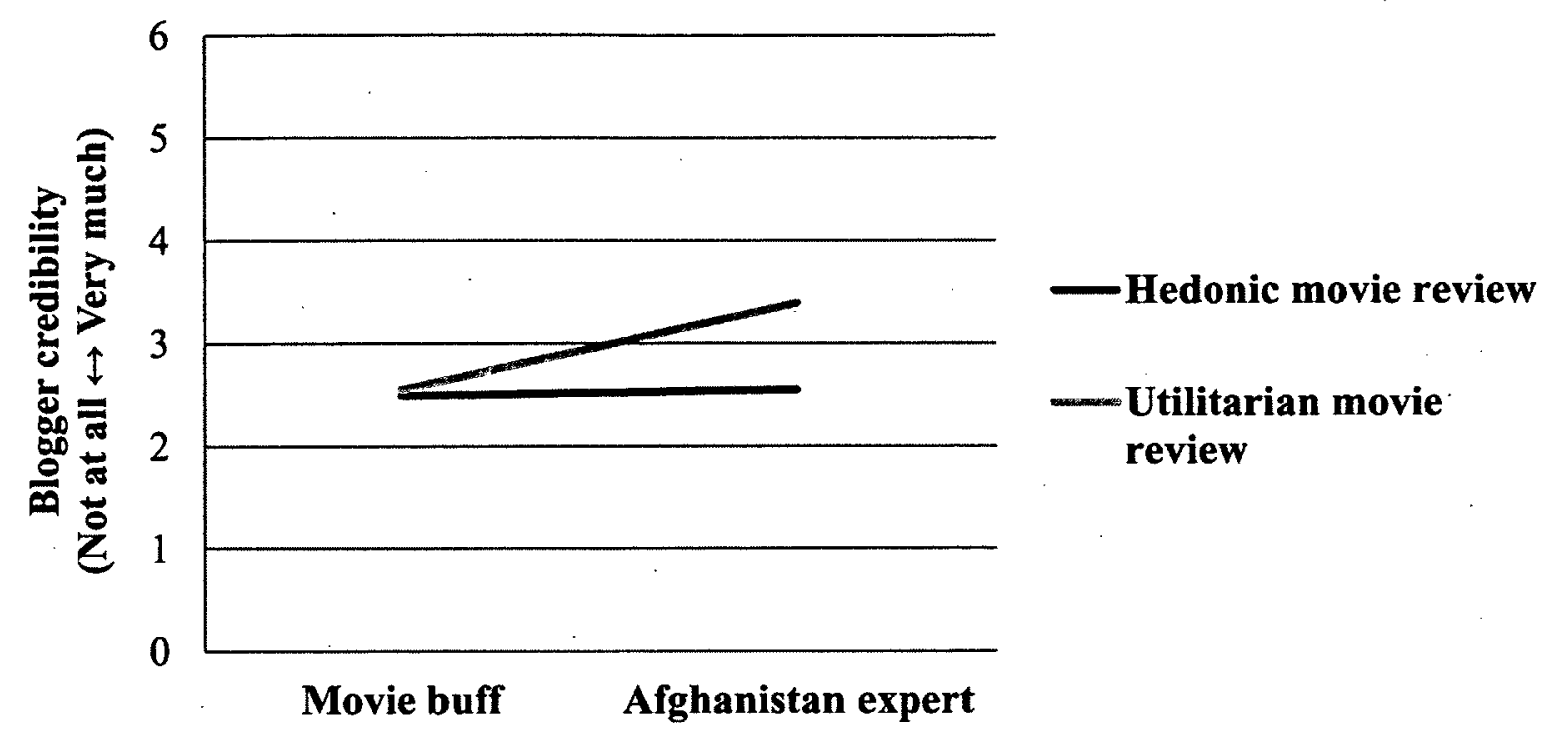

An additional ANOVA was conducted to determine whether any general evidence existed for the effect of matched versus mismatched blogger-type and movie review-type combinations on blogger credibility. Results of this test and the treatment combinations that constitute matches and mismatches are also reported in Table 5.27. As the table shows, a general match between blogger type and movie review type attracted better credibility ratings than a mismatch between the types $\left(M_{D i f f e r e n c e}=.39, p<.01\right)$.

Hypotheses 3-5 predicted that the cognitive basis of the credibility rating of the experiment blogger is formed from a set of beliefs blog readers hold concerning the credibility of the typical blogger, and the ability, character, and likeability/similarity (i.e., blogger-rater rapport) of the experiment blogger. Bivariate correlations between the credibility rating of the experiment blogger and each of these other beliefs are reported in Table 5.28. Since the results of $\mathrm{H} 2 \mathrm{~b}$ show that blogger credibility can differ by blogger and movie review types, the strength of association between each belief and the blogger 
credibility rating was examined at the full study level as well as at the levels of the blogger type and of movie review type treatments. Cohen's $q$ statistic is reported as an indication of the magnitude of treatment-level differences in the belief-credibility associations (Cohen, 1992). Preliminary conclusions regarding H3-H5 on the basis of the bivariate correlations are also indicated in the table.

The credibility of the experiment blogger significantly correlates with the perceived credibility of the typical blogger as well as the perceived authoritative knowledge, character, deception intent, and likeability/similarity (i.e., blogger-rater rapport) of the experiment blogger. Consumption experience was observed to have no significant bivariate relationship with experiment blogger credibility. Therefore, preliminary full or partial support was therefore observed for $\mathrm{H} 3, \mathrm{H} 4 \mathrm{a}, \mathrm{H} 4 \mathrm{c}, \mathrm{H} 4 \mathrm{~d}$, and H5.

With two exceptions, the majority of Cohen's $q$ effect sizes were small. A medium-sized difference ( $\mid$ Cohen's $q \mid=.39$ ) was observed in the relationship between authoritative knowledge and blogger credibility between movie review types. Consistent with the results of the test of $\mathrm{H} 2 \mathrm{c}$, authoritative knowledge was more strongly associated with blogger credibility when the movie review addressed the utilitarian versus the hedonic merit of the movie. Although authoritative knowledge was still relevant to blogger credibility when the movie review focused on the hedonic merit of the movie, it appears that participants particularly valued authoritative knowledge when the possession of that type of knowledge would be necessary for making accurate claims about conditions surrounding an actual major event. 
Table 5.28: Bivariate Correlations with Experiment Blogger Credibility Ratings - Full Study; Across Blogger and Movie Review Types

\begin{tabular}{|c|c|c|c|c|c|c|c|c|}
\hline \multirow[b]{2}{*}{ Blogger beliefs } & \multirow{2}{*}{$\begin{array}{l}\text { Full } \\
\text { study }\end{array}$} & \multicolumn{3}{|c|}{ Blogger type } & \multicolumn{3}{|c|}{ Movie review type } & \multirow{2}{*}{$\begin{array}{l}\text { Preliminary results } \\
\text { of hypothesis tests }\end{array}$} \\
\hline & & $\begin{array}{c}\text { Movie } \\
\text { buff }\end{array}$ & $\begin{array}{c}\text { Afghan. } \\
\text { Expert }\end{array}$ & $|q|$ & Hed. & Util. & $|q|$ & \\
\hline $\begin{array}{l}\text { H3: Typical blogger } \\
\text { credibility }\end{array}$ & $.31 * * *$ & $.40^{* * *}$ & $.28^{* * *}$ & .13 & $.37 * * *$ & $.25^{* *}$ & .13 & $\begin{array}{l}\text { H3 supported; small differences across } \\
\text { blogger and movie review types }\end{array}$ \\
\hline $\begin{array}{l}\text { H4a: Authoritative } \\
\text { knowledge }\end{array}$ & $.38 * * *$ & $.46^{* * *}$ & $.29 * * *$ & .21 & $.22^{* *}$ & $.54 * * *$ & .39 & $\begin{array}{l}\text { H4a supported; medium-sized blogger- } \\
\text { type difference; large(r) movie review- } \\
\text { type difference }\end{array}$ \\
\hline $\begin{array}{l}\mathrm{H} 4 \mathrm{~b} \text { : Consumption } \\
\text { experience }\end{array}$ & -.05 & .09 & .11 & .02 & .01 & -.10 & .10 & $\begin{array}{l}\text { H4b not supported; no difference across } \\
\text { blogger types; no meaningful difference } \\
\text { across movie review types (due to non- } \\
\text { significant correlations) }\end{array}$ \\
\hline H4c: Character & $.29 * * *$ & $.37^{* * *}$ & $.36^{* * *}$ & .02 & $.28^{* * *}$ & $.29 * * *$ & .01 & $\begin{array}{l}\text { H4c supported; no difference across } \\
\text { blogger and movie review types }\end{array}$ \\
\hline H4d: Deception intent & $-.10^{*}$ & -.03 & $-.18^{*}$ & .15 & -.02 & $-.15^{*}$ & .13 & $\begin{array}{l}\text { H4d partially supported since not } \\
\text { always significant; small but significant } \\
\text { differences across blogger and movie } \\
\text { review types }\end{array}$ \\
\hline . & & & & & & & & \\
\hline H5: Blogger-rater rapport & $.34 * * *$ & $.36^{* * *}$ & $.32 * * *$ & .05 & $.29 * * *$ & $.35^{* * *}$ & .07 & $\begin{array}{l}\text { H5 supported; small differences across } \\
\text { blogger and movie review types }\end{array}$ \\
\hline
\end{tabular}

${ }^{*} p<.05 ; * * p<.01 ; * * * p<.001$.

Note: Cohen (1992) suggests that $|.10|,|.30|$, and $|.50|$ are respectively small, medium, and large Cohen's $q$ effect sizes. To focus on the magnitude of the effect, only the absolute value of Cohen's q statistic is reported here. 
To probe further, a two-way ANOVA examined whether movie review type was relevant to the credibility rating of the blogger on the basis of its authoritative knowledge. Authoritative knowledge ratings were divided into quartiles, with quartiles ascending with authoritative knowledge ratings. The interaction effect was significant $(F(3,311)=$ $6.71, p<.001$ ). As Figure 5.5 shows, bloggers rated as being in the top two authoritative knowledge categories received significantly higher credibility ratings when they reviewed the utilitarian merit of the movie than when they reviewed the hedonic merit of the movie $\left(M_{\text {Difference }}=.94, p<.001\right)$. As the figure also shows, ascending levels of authoritative knowledge appear to be of little benefit to the credibility of the blogger who reviewed the hedonic merit of the movie. A one-way ANOVA revealed that blogger credibility did not vary on the basis of authoritative knowledge level when the movie review addressed the hedonic merit of the movie $(F(3,155)=2.54, p>.05)$. There was no appreciable movie review-type difference in the credibility ratings of the bloggers associated with the bottom two authoritative knowledge categories $\left(M_{\text {Hedonic }}=2.37\right.$ versus $\left.M_{\text {Utilitarian }}=2.26, p>.05\right)$.

The second exception concerned the relationship between deception intent and blogger credibility. At the full study level, a significant negative relationship was observed between the two variables, but this relationship was not consistently observed across experimental treatments. Deception intent was relevant to the credibility of the Afghanistan expert blogger but not to that of the movie buff blogger $(\mid$ Cohen's $q \mid=.15)$. Similarly, deception intent was relevant to the credibility of the blogger who reviewed the utilitarian merit of the movie but not to that of the blogger who reviewed the hedonic merit of the movie ( $\mid$ Cohen's $q \mid=.13)$. 
Figure 5.5: Blogger Credibility Rating - Authoritative Knowledge Rating by Movie Review Type

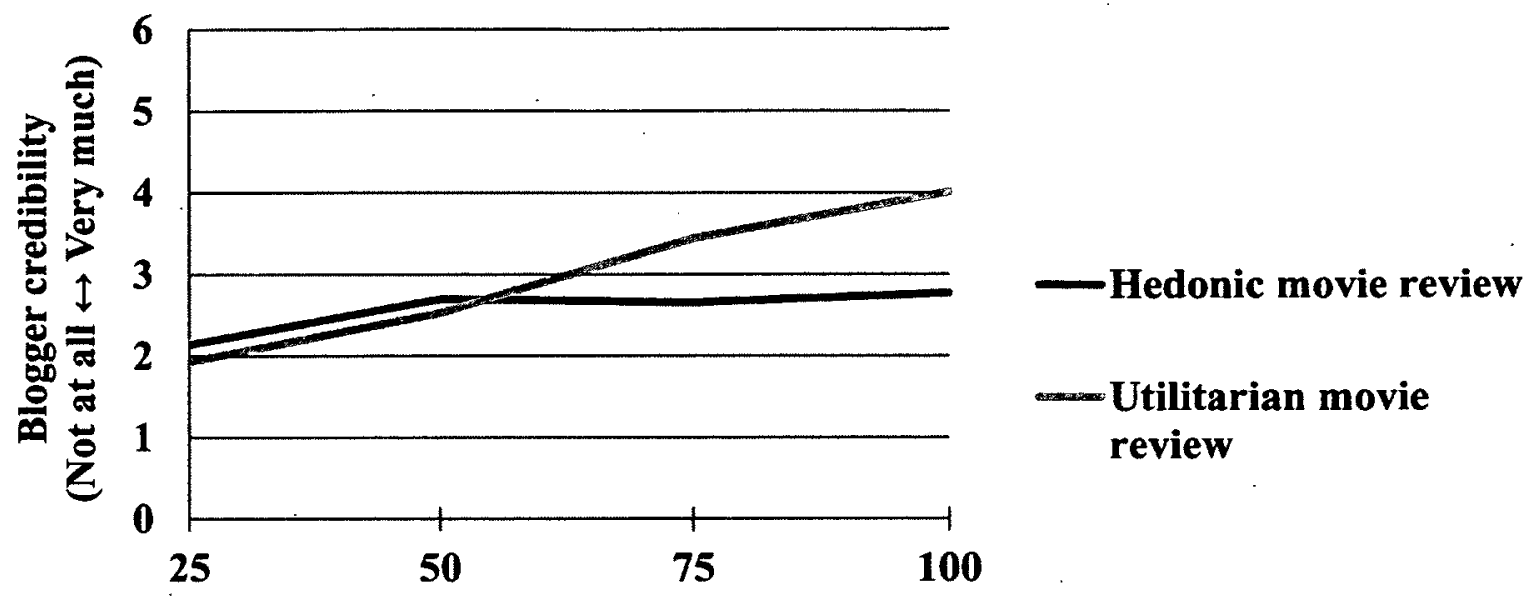

Authoritative knowledge groups

(Percentiles)

ANOVAs were conducted to test for the presence of significant interactions between deception intent and each of blogger and movie review types but none were observed. As the bivariate correlations showed, deception intent appeared not to be an issue for movie buff or when the blogger reviewed the hedonic merit of the movie. For the Afghanistan expert blogger, however, deception intent was relevant: independentsamples t-tests showed that the credibility of the blogger with a deception intent rating at or below the $25^{\text {th }}$ percentile was higher than that of blogger with deception intent ratings between the $50^{\text {th }}$ and $75^{\text {th }}$ percentile $\left(M_{\text {Difference }}=.50, p<.05\right)$ and between the $76^{\text {th }}$ and $100^{\text {th }}$ percentile $\left(M_{\text {Difference }}=.68, p<.05\right)$.

To further examine the relationships among variables involved in hypotheses 3-5, two approaches were used. First, multiple regression analyses involving blocks of independent variables of blogger beliefs and the experiment treatments regressed on 
experiment blogger credibility were conducted and results are reported in Table 5.29

(Model 1). Second, tests of the possible mediation effects of blogger type on the blogger credibility rating by certain blogger trust beliefs were conducted and results are reported in the table as well (Models 2 and 3).

\section{Model 1: Regression-based hypothesis tests.}

Using multiple regression analysis, blogger credibility was regressed against typical blogger credibility $(\mathrm{H} 3)$ and the perceived authoritative knowledge ( $\mathrm{H} 4 \mathrm{a})$, consumption experience (H4b), character ( $\mathrm{H} 4 \mathrm{c})$, deception intent $(\mathrm{H} 4 \mathrm{~d})$, and likeability/similarity (i.e., blogger-rater rapport; H5) of the blogger. Multicollinearity checks for all blogger beliefs were satisfactory ( $\min$. tolerance was .525; recommended tolerance > .1; Hair et al., 2006).

As predicted, typical blogger credibility was positively related to blogger credibility; $\mathrm{H} 3$ was supported by the multiple regression analysis. Although bloggers communicate personal information to their readers within their About Me statements and other areas of their blogs (e.g., sidebar areas), it appears that readers base their assessment of the credibility of new individual bloggers substantially on the basis of their past blog experiences and category-level stereotypes. At the very least, these results suggest that credibility ratings of specific bloggers are reflective of credibility ratings of the typical blogger. The credibility of the typical blogger could operate as a reference or a starting point as a reader evaluates the credibility of a specific blogger. 
Table 5.29: Multiple Regression Analyses - Three Experiment Blogger Credibility Rating Models

\begin{tabular}{|c|c|c|c|c|c|c|c|c|c|}
\hline \multirow[b]{3}{*}{ Independent variables } & \multicolumn{9}{|c|}{ Dependent variable: Blogger credibility rating } \\
\hline & \multicolumn{3}{|c|}{ Model 1: Hypothesis tests } & \multicolumn{3}{|c|}{$\begin{array}{c}\text { Model 2: Experimental } \\
\text { treatments }\end{array}$} & \multicolumn{3}{|c|}{ Model 3: Combined model } \\
\hline & $\boldsymbol{B}$ & $(S E)$ & $t$ & $\boldsymbol{B}$ & $(S E)$ & $t$ & $\boldsymbol{B}$ & $(S E)$ & $t$ \\
\hline H3: Typical blogger credibility & .22 & .06 & $3.92 * * *$ & & & & .23 & .06 & $3.60^{* * *}$ \\
\hline H4a: Authoritative knowledge & .21 & .04 & $5.27^{* * *}$ & & & & .22 & .05 & $4.63^{* * *}$ \\
\hline H4b: Consumption experience & -.05 & .05 & -0.98 & & & & & & \\
\hline H4c: Character & .22 & .06 & $3.33 * * *$ & & & & .21 & .06 & $3.31^{* * *}$ \\
\hline H4d: Deception intent & -.04 & .04 & -1.03 & & & & & & \\
\hline H5: Blogger-rater rapport & .17 & .07 & $2.34 * *$ & & & & .15 & .08 & $1.99 * *$ \\
\hline Blogger tyne & & & & 22 & 07 & $3.18 * * *$ & .04 & .09 & 0.44 \\
\hline Movie review type & & & & .23 & .08 & $3.24 * * *$ & .14 & .06 & $2.19^{* * *}$ \\
\hline Blogger type $x$ movie review type & & & & .19 & .07 & $2.74 * *$ & .27 & .06 & $4.46^{* * *}$ \\
\hline Adiusted $R^{2} /(F$ yalue $)$ & & 21.44 & & & $3\left(94^{5}\right.$ & & & $\overline{(19.44}$ & \\
\hline
\end{tabular}

* $p<.05 ;{ }^{* *} p<.01 ; * * * p<.001$. 
Authoritative knowledge was found to positively relate to blogger credibility, and so $\mathrm{H} 4 \mathrm{a}$ was supported. Contrary to prediction, consumption experience was not related to blogger credibility; H4b was not supported by the multiple regression analysis. As predicted, character was positively related to blogger credibility. $\mathrm{H} 4 \mathrm{c}$ was, therefore, supported. Contrary to prediction, deception intention was not related to blogger credibility. Although partial support for a relationship between deception intention and credibility was observed on the basis of their bivariate correlation, deception intention was not observed to significantly explain variance in the credibility rating of the blogger beyond the variance explained by the other independent variables. H4d was not supported by the multiple regression analysis. Consistent with prediction, blogger-rater rapport was positively related to blogger credibility. $\mathrm{H} 5$ was, therefore, supported.

\section{Model 2: Experimental treatments.}

Based on the results of tests of $\mathrm{H} 4$ and the findings that authoritative knowledge, consumption experience, character, and credibility ratings varied on the basis of blogger type, an inquiry was made to determine whether blogger beliefs mediate the effect of blogger type on blogger credibility. Model 2 was executed in order to establish a reference point for evaluating the extent of mediation, if any, by the relevant trust belief variables. In this model, blogger credibility was regressed against the main and interaction effects of blogger and movie review types. Consistent with the ANOVA test, the two main effects and one interaction effect were significantly related to the credibility rating of the experiment blogger. The main effect of blogger type observed in model 2 ( $B$ 
$=.22, t=3.18, p<.001)$ served as the reference point for determining whether blogger beliefs operated as significant mediator variables.

\section{Model 3: Combined model.}

Model 3 included blogger and movie review types (i.e., model 2) as well as the blogger beliefs that hypothesis tests showed to relate to both blogger type and blogger credibility. Results are shown in Table 5.29 (models 2 and 3) and illustrated in Figure 5.6. The significant main effect of blogger type from model 2 became non-significant in model 3. All other blogger credibility predictors retained their significance, including movie review type and the interaction between blogger and movie review types. 


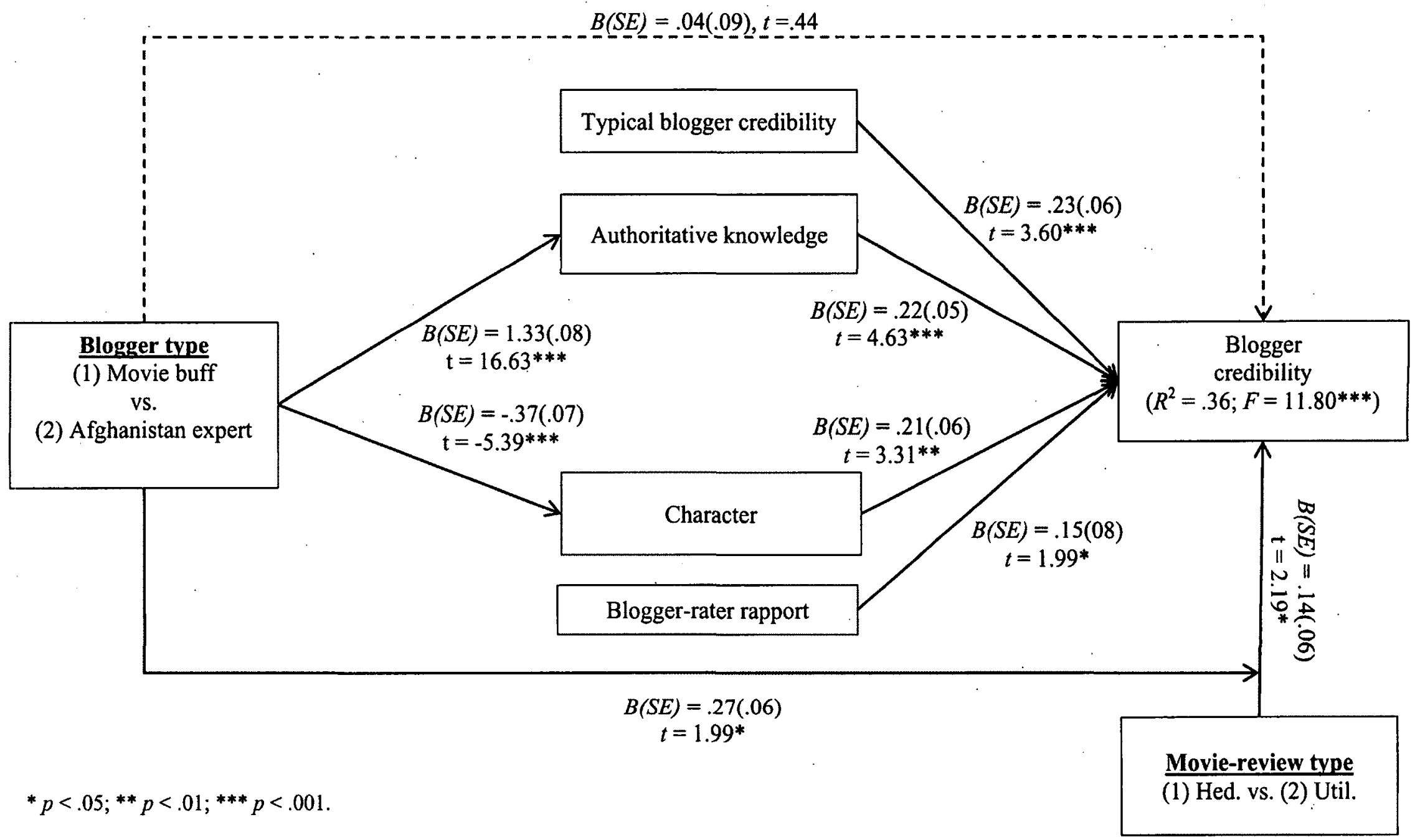


The PROCESS macro for SPSS (Model 5; Hayes, 2012a) was utilized for testing the extent to which the significant main effect of blogger type was mediated by the relevant trust belief variables. The PROCESS macro is a computational tool for testing multiple mediation, sequential mediation, and models that combine mediation and moderation (i.e., "mediated moderation" and "moderated mediation;" Hayes, 2012b). Together, authoritative knowledge and character fully mediated the effect of blogger type on blogger credibility. Blogger type was therefore not observed to explain variance in the credibility rating of the blogger beyond its main effects on the authoritative knowledge and character ratings of the blogger and its interaction with movie review type. The total effect of blogger type on blogger credibility was therefore fully comprised of two indirect paths: (1) blogger type $\rightarrow$ authoritative knowledge $\rightarrow$ blogger credibility and (2) blogger type $\rightarrow$ character $\rightarrow$ blogger credibility. The magnitude of each of these indirect effects can be represented by the product of the individual paths that link blogger type and blogger credibility. The indirect effect of blogger type on blogger credibility through authoritative knowledge was greater (in magnitude and direction) than that which operates through character $\left(B_{\text {Authoritative knowledge }}=1.33 \times .22=.29\right.$ versus $B_{\text {Character }}=-.37 \times$ $.21=-.08)$.

Bootstrapped bias-corrected $95 \%$ confidence intervals were created using the PROCESS macro in order to assess the stability of these indirect effects.

Notwithstanding the statistical significance of any individual path, when a bootstrapped bias-corrected $95 \%$ confidence interval includes zero or comes very close to including zero, then caution is warranted in interpreting the results. When the bootstrapped biascorrected $95 \%$ confidence interval of a particular path does not include zero, it can 
concluded that the path is stable. The confidence intervals reported for authoritative knowledge $\{.18, .43\}$ and for character $\{-.14,-.03\}$ both exclude zero, indicating the stability of findings that they mediate the effect of blogger type on the blogger credibility rating.

\section{Outcomes of blogger error: Hypotheses six through twenty-seven.}

Blogger error was operationalized in this study as the inaccurate review of either the hedonic or utilitarian merit of the Afghan orphanage movie. To the extent that a blogosphere norm is for bloggers to make accurate domain-specific claims, blogger error represents a situation of negative disconfirmation. In the hedonic movie review condition, the blogger overstated the extent to which the movie was "Exciting," "Energetic," and “Action Packed." In the utilitarian movie review condition, the blogger overstated the extent to which the movie was "Educational," "Informative," and "Factual." In both conditions, participants were advised using the scenario that the error became apparent to them as they were watching the movie. Furthermore, their beliefs as to the erroneous nature of the movie review were substantiated upon reading independent, third-party movie reviews that corresponded with their own assessments of the hedonic or utilitarian merit, as applicable, of the movie.

\section{Blogger blameworthiness.}

Weiner (2000) suggests that negative disconfirmation can prompt people to conduct an attributional search for the cause(s) of the negative disconfirmation and the results of this search can influence the ways in which people respond to the disconfirming 
occurrence. Blogger blameworthiness was operationalized as the extent to which blog readers attributed the error to the intentionally deceptive conduct of the blogger manifest in the review of the hedonic or utilitarian merit of the movie. The extent to which blog readers blamed the blogger for the error implies that they did not hold themselves to be responsible for the error, and instead see the blogger as having had control over the conduct that produced the error (Weiner, 2000). Specifically, a blog reader who attributes the error to the blogger and who believes that the blogger had control over the error (instead of the error being caused by a technical glitch or some other uncontrollable event) does so because he or she believes that the blogger intentionally attempted to deceive him or her about the hedonic or utilitarian merit of the movie.

Hypotheses six and seven dealt with the effects of the three experimental treatments on the perceived blameworthiness of the blogger. Specifically, H6 predicted that the blameworthiness of the movie buff (Afghanistan expert) blogger would be higher when its review focussed on the hedonic (utilitarian) merit of the movie than when it reviewed the utilitarian (hedonic) merit of the movie. $\mathrm{H} 7$ predicted that the blameworthiness of the WOMM blogger would be higher than that of the non-WOMM blogger. A three-way ANOVA was conducted to test the hypotheses and findings from the analysis are summarized in Table 5.30. There was no evidence of any significant twoor three-way interaction effect, so H6 was not supported by the analysis. The interaction effect implied by $\mathrm{H} 6$ is presented in Table 5.30 but no other interaction effect is included in the table. There was a significant main effect of blogger type on blogger blameworthiness. Independent of movie review type, the blameworthiness of the Afghanistan expert blogger was higher than that of the movie buff blogger $\left(M_{D i f f e r e n c e}=\right.$ 
$.34, p<.05)$. Blog readers did not exhibit sensitivity to the particular blogger type and movie review type combination embedded in the About Me statement and movie review they read. As a result, the perceived capability of the blogger to make accurate domainspecific hedonic and utilitarian statements does not appear to be a relevant factor to blog readers in assigning blame for an error. This result conflicts with attribution theory, as Weiner (2000) implies that a match situation (i.e., one in which the blogger should have been able to state the truth about the hedonic or utilitarian merit of the movie) would be one that would lead to a higher assignment of blame than a mismatch situation.

Table 5.30: ANOVA of Blogger Blameworthiness by Blogger, WOMM, and Movie Review Types

\begin{tabular}{|c|c|c|}
\hline \multicolumn{2}{|c|}{\begin{tabular}{|l} 
Treatment conditions (ANOVA Results) \\
\end{tabular}} & $M(S . D)$. \\
\hline \multicolumn{3}{|c|}{ Blogger type $F(1,312)=4.15^{*}, \eta^{2}=.01$} \\
\hline \multicolumn{2}{|c|}{ Movie buff } & $3.15(1.69)$ \\
\hline \multicolumn{2}{|c|}{ Afghanistan expert } & $3.49(1.46)$ \\
\hline \multicolumn{3}{|c|}{ WOMM type $F(1,312)=9.96^{* *}, \eta^{2}=.03$} \\
\hline \multicolumn{2}{|c|}{ WOMM disclosure } & $3.59(1.56)$ \\
\hline \multicolumn{2}{|c|}{ No WOMM disclosure } & $3.05(1.57)$ \\
\hline \multicolumn{3}{|c|}{ Movie review type $F(1,312)=1.47, \eta^{2}=.01$} \\
\hline \multicolumn{2}{|c|}{ Hedonic } & $3.21(1.64)$ \\
\hline \multicolumn{2}{|c|}{ Utilitarian } & $3.43(1.53)$ \\
\hline \multicolumn{3}{|c|}{ Blogger type $\mathbf{x}$ movie review type $F(1,312)=1.75, \eta^{2}=.01$} \\
\hline \multirow{2}{*}{ Movie buff } & Hedonic & $3.14(1.76)$ \\
\hline & Utilitarian & $3.15(1.63)$ \\
\hline \multirow{2}{*}{$\begin{array}{l}\text { Afghanistan } \\
\text { expert }\end{array}$} & Hedonic & $3.27(1.53)$ \\
\hline & Utilitarian & $3.71(1.37)$ \\
\hline \multicolumn{3}{|c|}{$\begin{array}{l}\text { (Follow-up test) } \\
\text { Blogger-movie review match / mismatch } F(1,318)=1.43, \eta^{2}=.004\end{array}$} \\
\hline \multicolumn{2}{|c|}{ Match } & $3.21(1.58)$ \\
\hline \multicolumn{2}{|c|}{ Mismatch } & $3.43(1.60)$ \\
\hline
\end{tabular}

${ }^{*} p<.05 ;{ }^{* *} p<.01$.

Notes

Match: Movie buff and hedonic movie review; Afghanistan expert and utilitarian movie review Mismatch: Movie buff and utilitarian movie review; Afghanistan expert and hedonic movie review 
H7 predicted that blogger blameworthiness would be greater for the WOMM blogger than for the non-WOMM blogger. The WOMM treatment was significantly related to the blogger blameworthiness rating, with the WOMM blogger receiving more blame for the error than the non-WOMM blogger $\left(M_{\text {Difference }}=.54, p<.05\right)$. H7 was therefore supported by the analysis. Although WOMM disclosures may not pose a serious threat to credibility assessments (see $\mathrm{H} 2 \mathrm{a}$ ), when error occurs such disclosures appear to influence the conclusions that blog readers reach as to the cause of the error. The WOMM disclosure indicated that the blogger received "movie tickets, merchandise, and other promotional material" from the "makers of this movie" for writing the movie review, and this form and/or level of compensation appears sufficient for blog readers to at least partially attribute the error to the relationship between the blogger and the movie company. Blog readers may have believed that receiving compensation for writing a movie review makes the blogger a de facto advertising voice for the makers of the movie or that the blogger may not have wanted to jeopardize its relationship with the makers of the movie by criticizing the hedonic or utilitarian merit of the movie.

Movie company blameworthiness was also measured in this study. Movie company blameworthiness was operationalized as the extent to which participants perceived the movie company to be responsible for the erroneous content of the movie review. The bivariate relationship between the blameworthiness of the movie company and that of the blogger was positive $(r=.186, p<.01)$. To the extent that blog readers assigned blame to the blogger for the error, this positive correlation implies that blog readers are conscious of the movie company being a driving force of the error or the situation that made error possible. To probe further, a separate ANOVA was conducted to 
determine whether WOMM type could be observed to have the same effect on movie company blameworthiness that it had on blogger blameworthiness. Results of the ANOVA are summarized in Table 5.31.

Table 5.31: ANOVA of Movie Company Blameworthiness by Blogger, WOMM, and Movie Review Types

\begin{tabular}{|c|c|c|}
\hline \multicolumn{2}{|c|}{\begin{tabular}{|l} 
Treatment conditions (ANOVA Results) \\
\end{tabular}} & $M(S . D)$. \\
\hline \multicolumn{3}{|c|}{ Blogger type $F(1,312)=.01, \eta^{2}=.000$} \\
\hline \multicolumn{2}{|c|}{ Movie buff } & $1.85(1.58)$ \\
\hline \multicolumn{2}{|c|}{ Afghanistan expert } & $1.81(1.60)$ \\
\hline \multicolumn{3}{|c|}{ WOMM type $F(1,312)=19.65^{* * *}, \eta^{2}=.06$} \\
\hline \multicolumn{2}{|c|}{ WOMM disclosure } & $2.21(1.56)$ \\
\hline \multicolumn{2}{|c|}{ No WOMM disclosure } & $1.44(1.53)$ \\
\hline \multicolumn{3}{|c|}{ Movie review type $F(1,312)=1.57, \eta^{2}=.01$} \\
\hline \multicolumn{2}{|l|}{ Hedonic } & $1.71(1.55)$ \\
\hline \multicolumn{2}{|c|}{ Utilitarian } & $1.95(1.63)$ \\
\hline \multicolumn{3}{|c|}{ WOMM type $\mathrm{x}$ movie review type $F(1,312)=5.24^{*}, \eta^{2}=.02$} \\
\hline \multirow{2}{*}{$\begin{array}{l}\text { WOMM } \\
\text { disclosure }\end{array}$} & Hedonic & $1.90(1.52)^{a, d}$ \\
\hline & Utilitarian & $2.52(1.54)^{a, b, c}$ \\
\hline \multirow{2}{*}{$\begin{array}{l}\text { No WOMM } \\
\text { disclosure }\end{array}$} & Hedonic & $1.53(1.56)^{b}$ \\
\hline & Utilitarian & $1.35(1.50)^{c, d}$ \\
\hline
\end{tabular}

${ }^{*} p<.05 ;{ }^{* * *} p<.001$.

Note(s): For the interaction effect, means with the same alphabetical superscript are significantly different $(p<.05)$. Means that do not share the same alphabetical superscript are not significantly different from each other.

The significant WOMM-type $\mathrm{x}$ movie review-type interaction revealed that, for the utilitarian movie review, movie company blameworthiness was higher for the blogger who made the WOMM disclosure than for the blogger who did not $\left(M_{D i f f e r e n c e}=1.16, p<\right.$ $.001)$. In contrast, the blogger who made the WOMM disclosure and reviewed the hedonic merit of the movie triggered no higher movie company blameworthiness ratings than the blogger who did not make the disclosure $\left(M_{\text {Difference }}=.37, p>.05\right)$. The interaction effect is illustrated in Figure 5.7. Across movie review types, the blogger who 
made the WOMM disclosure was associated with higher movie company blameworthiness ratings than the blogger who did not $\left(M_{\text {Difference }}=.77, p<.001\right)$.

Figure 5.7: Movie Company Blameworthiness - WOMM Type by Movie Review Type

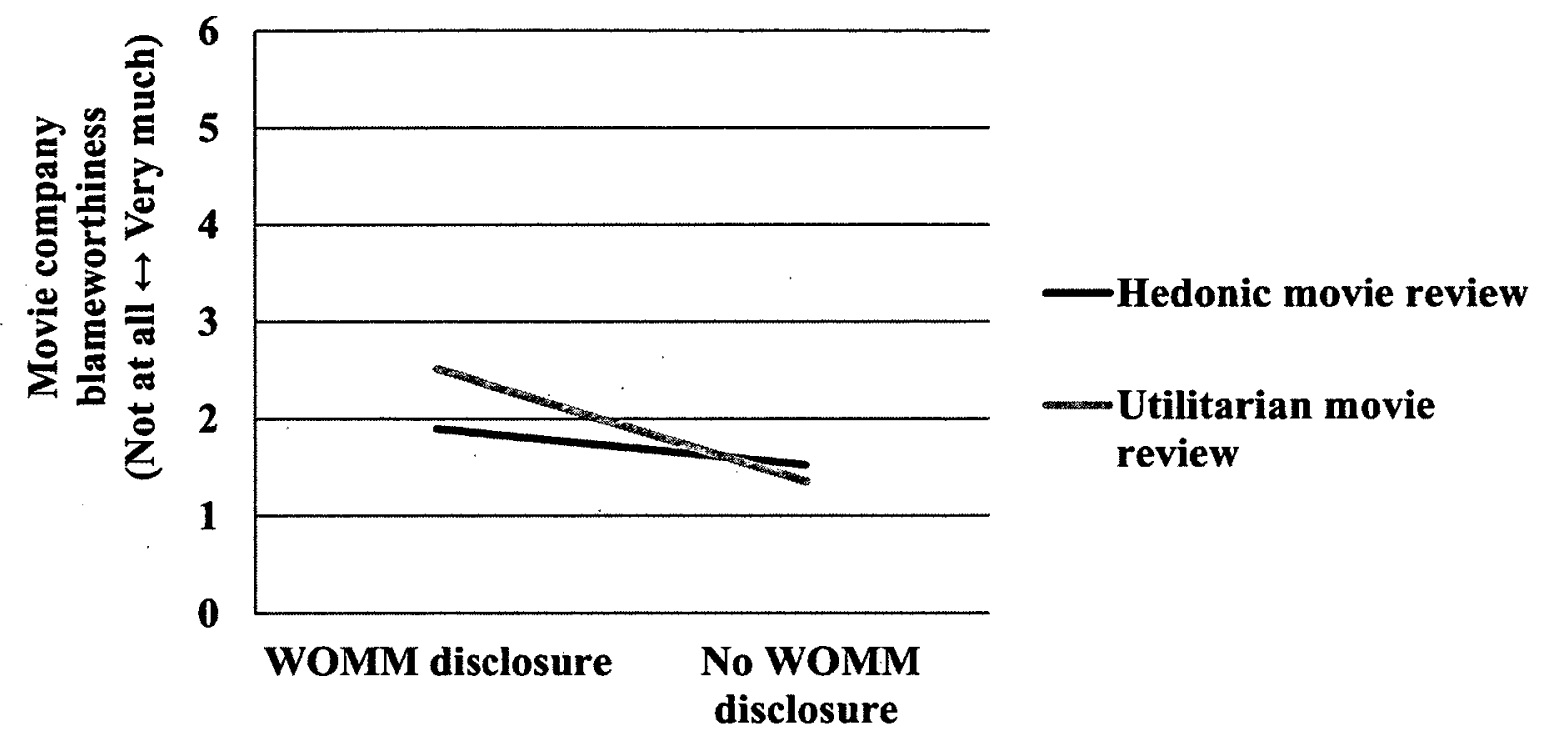

H8 predicted that the pre-existing character rating of the blogger would negatively relate to blogger blameworthiness. $\mathrm{H} 9$ predicted that the pre-existing deception intent rating of the blogger would positively relate to blogger blameworthiness. Correlations were inspected at the full study level as well as at individual treatment levels in order to initially test the hypotheses. Results of the correlation analyses are reported in Table 5.32. With one exception, $\mathrm{H} 8$ was supported by the correlation analysis. The relationship between the character rating of the blogger and the perceived blameworthiness of the blogger for the error was negative in all cases, except for the Afghanistan expert blogger which was in the hypothesized direction but was not significant. H9 was supported at all 
analysis levels. Deception intent is positively related to the perceived blameworthiness of the blogger for the erroneous movie review.

Table 5.32: Correlations Between Blogger Blameworthiness and Each of Character and Deception Intent Ratings

\begin{tabular}{|l|c|c|}
\hline \multirow{2}{*}{ Analysis levels } & \multicolumn{2}{|c|}{ Blogger blameworthiness correlations } \\
\cline { 2 - 3 } & H8: Character & H9: Deception intent \\
\hline Full study & $-.18^{* * *}$ & $.30^{* * *}$ \\
\hline Blogger type & & \\
\hline Movie buff & & $.35^{* * *}$ \\
\hline Afghanistan expert & $-.25^{* * *}$ & $.22^{* *}$ \\
\hline$|q|$ & -.05 & .14 \\
\hline & .20 & \\
\hline WOMM disclosure type & & $.28^{* * *}$ \\
\hline WOMM disclosure & & $.25^{* * *}$ \\
\hline No WOMM disclosure & $-.14^{*}$ & .03 \\
\hline$|q|$ & $-.18^{*}$ & \\
\hline & .04 & $.33^{* * *}$ \\
\hline Movie review type & & $.27^{* * *}$ \\
\hline Hedonic & & .07 \\
\hline Utilitarian & $-.19^{* *}$ & \\
\hline$|q|$ & $-.18^{*}$ & \\
\hline & .01 & . \\
\hline $\begin{array}{l}\text { Preliminary results of } \\
\text { hypothesis tests }\end{array}$ & $\begin{array}{c}\text { Supported. Small-to-medium } \\
\text { sized difference between } \\
\text { blogger types. }\end{array}$ & $\begin{array}{c}\text { Supported. Small-to-medium } \\
\text { sized difference between } \\
\text { blogger types. }\end{array}$ \\
\hline
\end{tabular}

${ }^{*} p<.05 ; * * p<.01 ; * * * p<.001$.

Note: Cohen (1992) suggests that $|.10|,|.30|$, and $|.50|$ are respectively small, medium, and large Cohen's q effect sizes. To focus on the magnitude of the effect, only the absolute value of Cohen's q statistic is reported here.

Further analysis involved modeling relationships among WOMM and blogger type, character, deception intent, and blogger blameworthiness. Since blogger blameworthiness was found to vary on the basis of WOMM type and because WOMM 
type is a significant predictor of character and deception intent ratings (see H1c and H1d), character and deception intent were modeled as antecedents of blogger blameworthiness and potential mediators of the effect of WOMM type on the blogger blameworthiness rating. As blogger blameworthiness and character ratings were found to vary by blogger type, tests were also conducted to determine whether the blogger beliefs could explain the high blameworthiness rating of the Afghanistan expert blogger relative to that of the movie buff blogger. Results of the analyses are shown in Table 5.33. The character and deception intention ratings of the blogger were first regressed against blogger and WOMM types and results of these two regressions are reported in the second and third columns of the table. Blogger and WOMM types were both revealed as significant predictors of the character rating of the blogger. This finding confirms that the perceived character of the movie buff was higher than that of the Afghanistan expert and that the perceived character of the blogger who made the WOMM disclosure was less than that of the blogger who did not. WOMM type was the only significant predictor of deception intent, i.e., the blogger who made the WOMM disclosure received a higher deception intent rating than the blogger who did not. 
Table 5.33: Multiple Regression Models of Character, Deception Intent, and Blogger Blameworthiness Ratings

\begin{tabular}{|c|c|c|c|c|c|c|c|c|c|}
\hline & \multicolumn{3}{|c|}{ Character } & \multicolumn{3}{|c|}{ Deception intent } & \multicolumn{3}{|c|}{ Blogger blameworthiness } \\
\hline Model: Treatment effects only & $B(S E)$ & $\beta$ & $t$ & $B(S E)$ & $\beta$ & $t$ & $B(S E)$ & $\boldsymbol{\beta}$ & $t$ \\
\hline Blogger type $^{a}$ & $-.75(.14)$ & -.29 & $-5.46^{* * *}$ & $.18(.18)$ & .05 & 0.99 & $.35(.17)$ & .11 & $1.99 *$ \\
\hline WOMM type $^{b}$ & $.28(.14)$ & .11 & $2.07 *$ & $-.92(.18)$ & -.28 & $-5.13 * * *$ & $-.54(.17)$ & -.17 & $-3.12^{* *}$ \\
\hline Adjusted $R^{2} /(F$ value $)$ & \multicolumn{3}{|c|}{$.09 / 16.88^{* * *}$} & \multicolumn{3}{|c|}{$.07 / 13.59^{* * *}$} & \multicolumn{3}{|c|}{$.04 / 6.78^{* * *}$} \\
\hline Model: Blogger beliefs only & . & & & & & & & & \\
\hline Character & & & & & & & $-.13(.07)$ & -.11 & $-1.97^{*}$ \\
\hline Deception intent & & & & & & & $.26(.05)$ & .27 & $4.89 * * *$ \\
\hline Adjusted $R^{2} /(F$ value $)$ & & & & & & & \multicolumn{3}{|c|}{$.09 / 17.45^{* * *}$} \\
\hline \multicolumn{10}{|l|}{$\begin{array}{l}\text { Model: Treatment effects }+ \\
\text { blogger beliefs }\end{array}$} \\
\hline Blogger type & & & & & & & $.23(.18)$ & .07 & 1.30 \\
\hline WOMM type & & & & & & & $-.30(.18)$ & -.09 & $-1.71^{*}$ \\
\hline Character & & & & & & & $-.10(.07)$ & -.08 & -1.45 \\
\hline Deception intent & & & & & & & $.24(.05)$ & .25 & $4.34^{* * *}$ \\
\hline Adjusted $R^{2} /(F$ value $)$ & & & & & & & & $9.90^{\circ}$ & \\
\hline
\end{tabular}

${ }^{*} p<.05 ;{ }^{* *} p<.01 ;{ }^{* * *} p<.001$.

${ }^{a}$ Blogger type: 1 = movie buff; 2 = Afghanistan expert. The negative coefficient representing the relationship between blogger type and character indicates that the movie buff received higher character ratings than the Afghanistan expert.

${ }^{b}$ WOMM type: 1 = WOMM disclosure; 2 = No WOMM disclosure. The positive coefficient representing the relationship between WOMM type and character indicates that the blogger who made the WOMM disclosure $(\operatorname{code}=1)$ received a lower character rating than the blogger who did not $(\operatorname{code}=2)$. 
Blogger blameworthiness was then regressed against blogger and WOMM types. Results of this regression are shown in the upper part of the fourth column of the table. Blogger and WOMM types were both found to significantly predict the extent to which blog readers considered the blogger blameworthy for the error that had occurred. The paths between blogger blameworthiness and each of blogger and WOMM types served as reference points for assessing whether the character and deception intent ratings of the blogger could be observed to mediate the effects of the two experimental treatments on the perceived blameworthiness of the blogger $\left(B_{\text {Blogger type }}=.35, t=1.99, p<.05 ; B_{\text {WOMM }}\right.$ type $=-.54, t=-3.12, p<.01)$.

Blogger blameworthiness was then regressed against the character and deception intent ratings of the blogger. The bivariate correlation between character and deception intent ratings was significant $(r=-.25, p<.001)$, but a multicollinearity check showed the relationship to be acceptable for the purposes of the analysis (min. tolerance was .86; recommended tolerance $>.10$; Hair et al., 2006). Results are shown in the middle section of the fourth column of the table. H8 predicted that the blameworthiness of the blogger would be negatively related to the character rating of the blogger, and this prediction was supported by the analysis. H9 was also supported by the analysis. The deception intent rating of the blogger was found to positively relate to the perceived blameworthiness of the blogger for the error.

To test whether the character and deception intent ratings of the blogger mediated the effects of blogger and WOMM types on blogger blameworthiness, the two blogger beliefs were added into the regression analysis. The full model was tested using the PROCESS macro for SPSS (Model 4; Hayes, 2012a). Results of this part of the analysis 
are shown in the lower part of the fourth column of the table and are summarized in Figure 5.8. As the results show, blogger type was no longer a significant predictor of blogger blameworthiness when the character and deception intent ratings of the blogger were added to the analysis ( $B_{\text {Blogger type }}=.23, t=1.30, p>.05$ ). The strength of the relationship between WOMM type and blogger blameworthiness decreased when the two blogger beliefs were added to the analysis, but WOMM type still remained a significant predictor of the variable $\left(B_{\text {WOMM }}\right.$ type $\left.=-.30, t=-1.71, p<.05\right)$. WOMM type therefore related to blogger blameworthiness both directly and indirectly. The direct effect of WOMM type on blogger blameworthiness is represented by the WOMM type $\rightarrow$ blogger blameworthiness path $(B=-.30)$. The indirect effect of WOMM type on blogger blameworthiness is equal to the product of the WOMM type $\rightarrow$ deception intent path and the deception intent $\rightarrow$ blogger blameworthiness path $(-.92 \times .24=-.22)$. The total effect of WOMM type on blogger blameworthiness can therefore be represented by $B=-.30+$ $(-.22)=-.52$

The regression results provide additional support for $\mathrm{H} 9$ but not for $\mathrm{H} 8$. When blogger blameworthiness was regressed against character and deception intent together, character was not revealed as a significant predictor of blogger blameworthiness. As a result, no significant indirect path linking blogger type to the perceived blameworthiness of the blogger was observed. 


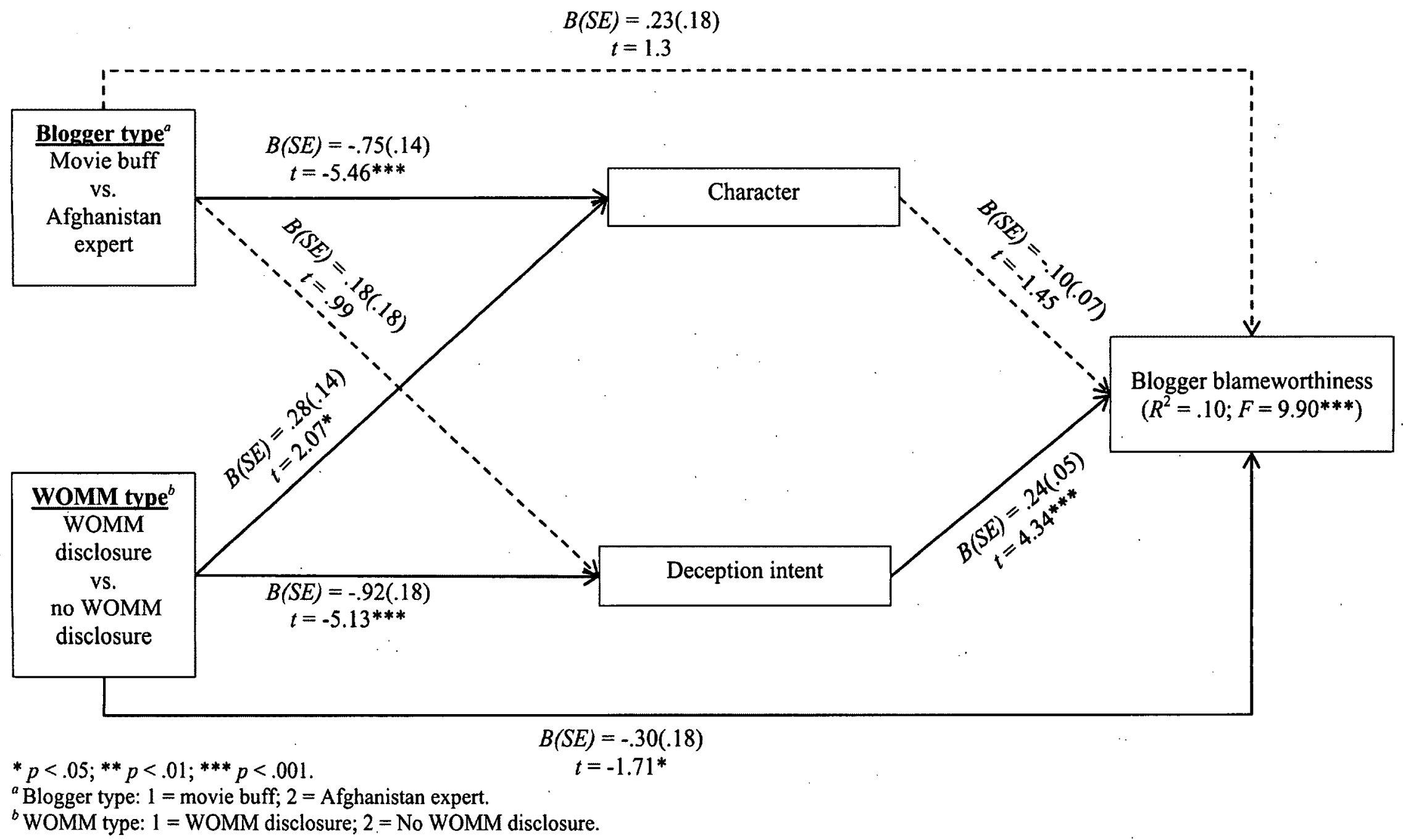


To assess the stability of these direct and indirect WOMM paths, bootstrapped bias-corrected $95 \%$ confidence intervals were established. Although the regression analysis revealed that the effect of WOMM type on blogger blameworthiness retained statistical significance when character and deception intent were added to the analysis ( $B$ $=-.30)$, the bootstrapped bias-corrected $95 \%$ confidence interval for that direct path $\{-$ $.65, .06\}$ included zero and so was unstable. In contrast, the bootstrapped bias-corrected $95 \%$ confidence interval for the indirect path $(B=-.22)$ did not include zero $\{-.39,-.10\}$. As a result, WOMM type reliably affects blogger blameworthiness in the context of blogger error through its association with deception intent.

\section{Affective responses to blogger error.}

Participants indicated the anger and dissatisfaction they felt as a result of blogger error. $\mathrm{H} 10, \mathrm{H} 11$, and $\mathrm{H} 12$ predicted that anger would respectively relate to the blameworthiness ratings of the blogger and the movie company for the error as well as to the perceived incorrectness of the movie review. $\mathrm{H} 13, \mathrm{H} 14$, and $\mathrm{H} 15$ predicted that dissatisfaction would respectively relate to the blameworthiness ratings of the blogger and the movie company for the error as well as to the perceived incorrectness of the movie review.

A preliminary three-way MANOVA was conducted in order to test whether feelings of anger and dissatisfaction varied by treatment condition. The analysis revealed that anger and dissatisfaction did not vary on the basis of any interaction between or main effect of blogger, WOMM, or movie review type. Results are summarized in Table 5.34; interactions were excluded from the table as they were all non-significant. 
Table 5.34: MANOVA of Anger and Dissatisfaction by Blogger, WOMM, and Movie Review Types

\begin{tabular}{|c|c|c|c|c|}
\hline \multirow{3}{*}{$\begin{array}{l}\text { Treatment conditions } \\
\text { (MANOVA Results) }\end{array}$} & \multicolumn{4}{|c|}{ Univariate Results } \\
\hline & \multicolumn{2}{|c|}{ Anger } & \multicolumn{2}{|c|}{ Dissatisfaction } \\
\hline & $M(S . D)$. & $\boldsymbol{F}$ & $M($ S.D. $)$ & $\boldsymbol{F}$ \\
\hline \multicolumn{5}{|l|}{$\begin{array}{l}\text { Blogger type } \\
F(2,311)=1.04, \eta^{2}=.01\end{array}$} \\
\hline Movie buff & $2.11(1.67)$ & \multirow{2}{*}{.233} & $2.85(1.66)$ & \multirow{2}{*}{1.80} \\
\hline Afghanistan expert & $2.18(1.43)$ & & $3.09(1.55)$ & \\
\hline \multicolumn{5}{|l|}{$\begin{array}{l}\text { WOMM type } \\
F(2,311)=1.60, \eta^{2}=.01\end{array}$} \\
\hline WOMM disclosure & $2.30(1.50)$ & \multirow{2}{*}{3.17} & $3.06(1.54)$ & \multirow{2}{*}{.98} \\
\hline No WOMM disclosure & $1.99(1.60)$ & & $2.88(1.67)$ & \\
\hline \multicolumn{5}{|l|}{$\begin{array}{l}\text { Movie review type } \\
F(2,311)=1.10, \eta^{2}=.01\end{array}$} \\
\hline Hedonic & $2.03(1.51)$ & \multirow{2}{*}{1.73} & $2.94(1.62)$ & \multirow{2}{*}{.11} \\
\hline Utilitarian & $2.26(1.59)$ & & $3.00(1.61)$ & \\
\hline
\end{tabular}

As has also been reported in studies of affective responses to negative service experiences (e.g., Bougie, Pieters, and Zeelenberg, 2003), anger and dissatisfaction were found to be positively related to each other $(r=.65, p<.001)$. Blogger error was observed to arouse stronger feelings of dissatisfaction than anger $\left(M_{D i f f e r e n c e}=.83, p<\right.$ $.001)$. Studies have examined negative affective outcomes in different consumption contexts (Bonifield and Cole, 2007; Bougie, Pieters, and Zeelenberg, 2003; Gelbrich, 2010; Gelbrich, 2011; Grégoire, Laufer, and Tripp, 2010) and, by comparison, it appears that blogger error induces weak-to-moderate negative affective outcomes. Typically, however, these studies are based on more expensive service and semi-durable product consumption circumstances.

Bivariate correlations between blogger blameworthiness, the perceived incorrectness of the movie review, and affective responses to blogger error were first 
examined. Results are provided in Table 5.35. Consistent with prediction, anger and dissatisfaction were significantly related to the blameworthiness ratings of both the blogger and the movie company. $\mathrm{H} 10, \mathrm{H} 11, \mathrm{H} 13$, and $\mathrm{H} 14$ were all supported by the analysis of bivariate correlations.

Table 5.35: Anger and Dissatisfaction Bivariate Correlations - Blameworthiness and Movie Review Incorrectness

\begin{tabular}{|c|c|c|}
\hline & Anger & Dissatisfaction \\
\hline \multicolumn{3}{|l|}{ Blameworthiness } \\
\hline Blogger & $.32 * * *$ & $.31^{* * *}$ \\
\hline Movie company & $.47^{* * *}$ & $.18 * * *$ \\
\hline \multicolumn{3}{|l|}{ Movie review perceptions } \\
\hline \multicolumn{3}{|l|}{ Accuracy measures } \\
\hline Discovered accuracy (i.e., post-error accuracy) & $-.18 * * *$ & -.05 \\
\hline $\begin{array}{l}\text { Incorrectness } \\
\text { (6 - Discovered movie review accuracy) }\end{array}$ & $-.18 * * *$ & .05 \\
\hline
\end{tabular}

${ }^{*} p<.05 ;{ }^{* *} p<.01 ;{ }^{* * *} p<.001$.

Correlations between the two affective responses to blogger error and perceived movie review incorrectness were examined. Movie review incorrectness was operationalized as the difference between 6 (i.e., complete movie review accuracy) and the discovered accuracy of the movie review. Unexpected bivariate correlations between perceived movie review incorrectness and both anger and dissatisfaction were observed. First, perceived movie review incorrectness was negatively related to the anger induced by blogger error. Second, perceived movie review incorrectness was not significantly related to the dissatisfaction caused by blogger error. As a result, $\mathrm{H} 12$ and $\mathrm{H} 15$ were not supported by the bivariate correlation analysis. 
Anger and dissatisfaction were each regressed against blogger blameworthiness and the perceived incorrectness of the movie review for additional tests of $\mathrm{H} 10-\mathrm{H} 15$ and results are shown in Table 5.36 .

Table 5.36: Multiple Regression Analyses of Anger and Dissatisfaction

\begin{tabular}{|l|c|c|c|c|c|c|}
\hline \multirow{2}{*}{ Independent variables } & \multicolumn{3}{|c|}{ Anger } & \multicolumn{3}{c|}{ Dissatisfaction } \\
\cline { 2 - 7 } & $\boldsymbol{B}(\boldsymbol{S} E)$ & $\boldsymbol{\beta}$ & $\boldsymbol{t}$ & $\boldsymbol{B}(\boldsymbol{S E})$ & $\boldsymbol{\beta}$ & $\boldsymbol{t}$ \\
\hline Blogger blameworthiness & $.23(.05)$ & .24 & $4.39 * * *$ & $.27(.06)$ & .27 & $4.51^{* * *}$ \\
\hline $\begin{array}{l}\text { Movie company } \\
\text { blameworthiness }\end{array}$ & $.36(.06)$ & .36 & $6.49^{* * *}$ & $.12(.06)$ & .12 & $1.86^{*}$ \\
\hline Movie review incorrectness & $-.12(.06)$ & -.11 & $-1.99^{*}$ & $.03(.07)$ & .02 & 0.38 \\
\hline Adjusted $\boldsymbol{R}^{2} /(\boldsymbol{F}$ value $)$ & \multicolumn{3}{|c|}{$.26 / 37.94^{* * *}$} & \multicolumn{3}{c|}{$.10 / 12.28^{* * *}$} \\
\hline
\end{tabular}

${ }^{*} p<.05 ;{ }^{* *} p<.01 ;{ }^{* * *} p<.001$.

Consistent with the bivariate correlation analyses, both anger and dissatisfaction were shown to positively relate to the extent to which blog readers perceived the blogger and the movie company to have been worthy of blame for the error. $\mathrm{H} 10, \mathrm{H} 11, \mathrm{H} 13$, and H14 were therefore supported by the analysis. Although anger was shown to significantly relate to movie review incorrectness, the coefficient was negative, and so $\mathrm{H} 12$ was not supported. Dissatisfaction was not shown to relate significantly to movie review incorrectness, and so $\mathrm{H} 15$ was also not supported. Below, emotional reactions to blogger error are included in model testing with respect to behavioural intentions that stem from blogger error. 


\section{Intentions.}

\section{Trust intentions.}

Trust intentions were measured both in response to the treatment conditions (i.e., pre-error trust intentions) and in response to the blogger error notification (i.e., post-error trust intentions). Across the treatment conditions, pre-error trust intentions were moderate $(M=2.38, S . D .=1.40)$. As the ANOVA results in Table 5.37 show, evidence of a WOMM type-movie review type interaction effect on pre-error trust intentions was observed. Pre-error trust intentions did not vary on the basis of any main effect of blogger, WOMM, or movie review type. The interaction effect between WOMM type and movie review type on pre-error trust intentions is shown in Table 5.37 and in Figure 5.9. Though pre-error trust intentions between hedonic and utilitarian movie reviews were no different in the WOMM condition $\left(M_{\text {WOMM-Hedonic }}=2.50\right.$ versus $M_{\text {WOMM-Utilitarian }}=$ $2.35, p>.10$ ), the utilitarian movie review was associated with more pre-error trust than the hedonic movie review in the non-WOMM condition $\left(M_{\text {Difference }}=.52, p<.01\right)$. Table 5.37 also shows that post-error trust intentions $(M=1.27, S . D .=1.52)$ were not directly affected by any interaction effect between or any main effect of blogger type, WOMM type, or movie review type.

$\mathrm{H} 16$ and $\mathrm{H} 17$ predicted that post-error trust intentions would be negatively related to the perceived blameworthiness of the blogger and the movie company for the erroneous movie review. $\mathrm{H} 18$ predicted that post-error trust intentions would be negatively related to the perceived incorrectness of the movie review. $\mathrm{H} 19$ and $\mathrm{H} 20$ predicted that post-error trust intentions would respectively be negatively related to the 
anger and dissatisfaction caused by blogger error. $\mathrm{H} 21$ predicted that post-error trust intentions would be positively related to pre-error trust intentions.

Table 5.37: ANOVAs of Pre- and Post-Error Trust Intentions by Blogger, WOMM, and Movie Review Types

\begin{tabular}{|c|c|c|c|}
\hline \multicolumn{2}{|c|}{ Treatment conditions (ANOVA Results) } & $\begin{array}{c}\text { Pre-error } \\
\text { trust intentions }\end{array}$ & $\begin{array}{c}\text { Post-error } \\
\text { trust intentions }\end{array}$ \\
\hline \multicolumn{2}{|c|}{$\begin{array}{l}\text { Blogger type } \\
\text { Pre-error trust: } F(1,312)=1.54, \eta^{2}=.01 \\
\text { Post-error trust: } F(1,312)=2.10, \eta^{2}=.01\end{array}$} & & \\
\hline \multicolumn{2}{|c|}{ Movie buff } & $2.28(1.30)$ & $1.40(1.59)$ \\
\hline \multicolumn{2}{|c|}{ Afghanistan expert } & $2.48(1.50)$ & $1.15(1.45)$ \\
\hline \multicolumn{2}{|c|}{$\begin{array}{l}\text { WOMM type } \\
\text { Pre-error trust: } F(1,312)=.27, \eta^{2}=.001 \\
\text { Post-error trust: } F(1,312)=.63, \eta^{2}=.002\end{array}$} & & \\
\hline \multicolumn{2}{|c|}{ WOMM disclosure } & $2.42(1.45)$ & $1.34(1.53)$ \\
\hline \multicolumn{2}{|c|}{ No WOMM disclosure } & $2.34(1.35)$ & $1.20(1.53)$ \\
\hline \multicolumn{2}{|c|}{$\begin{array}{l}\text { Movie review type } \\
\text { Pre-error trust: } F(1,312)=1.48, \eta^{2}=.01 \\
\text { Post-error trust: } F(1,312)=1.22, \eta^{2}=.004\end{array}$} & 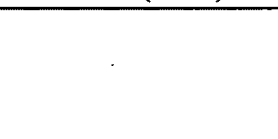 & \\
\hline \multicolumn{2}{|c|}{ Hedonic } & $2.29(1.36)$ & $1.17(1.46)$ \\
\hline \multicolumn{2}{|c|}{ Utilitarian } & $2.47(1.45)$ & $1.37(1.59)$ \\
\hline \multicolumn{4}{|c|}{$\begin{array}{l}\text { WOMM type } \times \text { movie review type } \\
F(1,312)=4.20^{*}, \eta^{2}=.01\end{array}$} \\
\hline \multirow{2}{*}{$\begin{array}{l}\text { WOMM } \\
\text { disclosure }\end{array}$} & Hedonic & $2.50(1.38)$ & - \\
\hline & Utilitarian & $2.35(1.52)$ & - \\
\hline \multirow{2}{*}{$\begin{array}{l}\text { No WOMM } \\
\text { disclosure }\end{array}$} & Hedonic & $2.09(1.31)^{b}$ & - \\
\hline & Utilitarian & $2.60(1.36)^{a}$ & - \\
\hline
\end{tabular}

${ }^{*} p<.05 ;{ }^{* *} p<.01 ;{ }^{* * *} p<.001$.

Notes

Interaction effect(s): Trust-intention ratings with different alphabetical superscripts are significantly different from each other $(p<.05)$. " $a$ " denotes the highest mean(s), " $b$ " the second highest mean(s), and so on. Trust-intention ratings with no alphabetical superscript differ from neither the highest nor the lowest trust-intention rating.

Hypotheses were first examined using bivariate correlations. Bivariate correlations offered limited preliminary support for the hypotheses; predicted post-error trust relationships were observed for blogger blameworthiness $(r=-.11, p<.05)$, perceived movie review incorrectness $(r=-.49, p<.001)$, and pre-error trust intentions $(r$ 
$=.49, p<.001)$. Unexpectedly, post-error trust intentions were observed to have a positive relationship with movie company blameworthiness $(r=.36, p<.001)$ as well as anger $(r=.20, p<.001)$. Moreover, the relationship between post-error trust intentions and dissatisfaction was not significant $(r=-.02$, n.s. $)$.

Figure 5.9: Pre-Error Trust Intention - WOMM Type by Movie Review Type

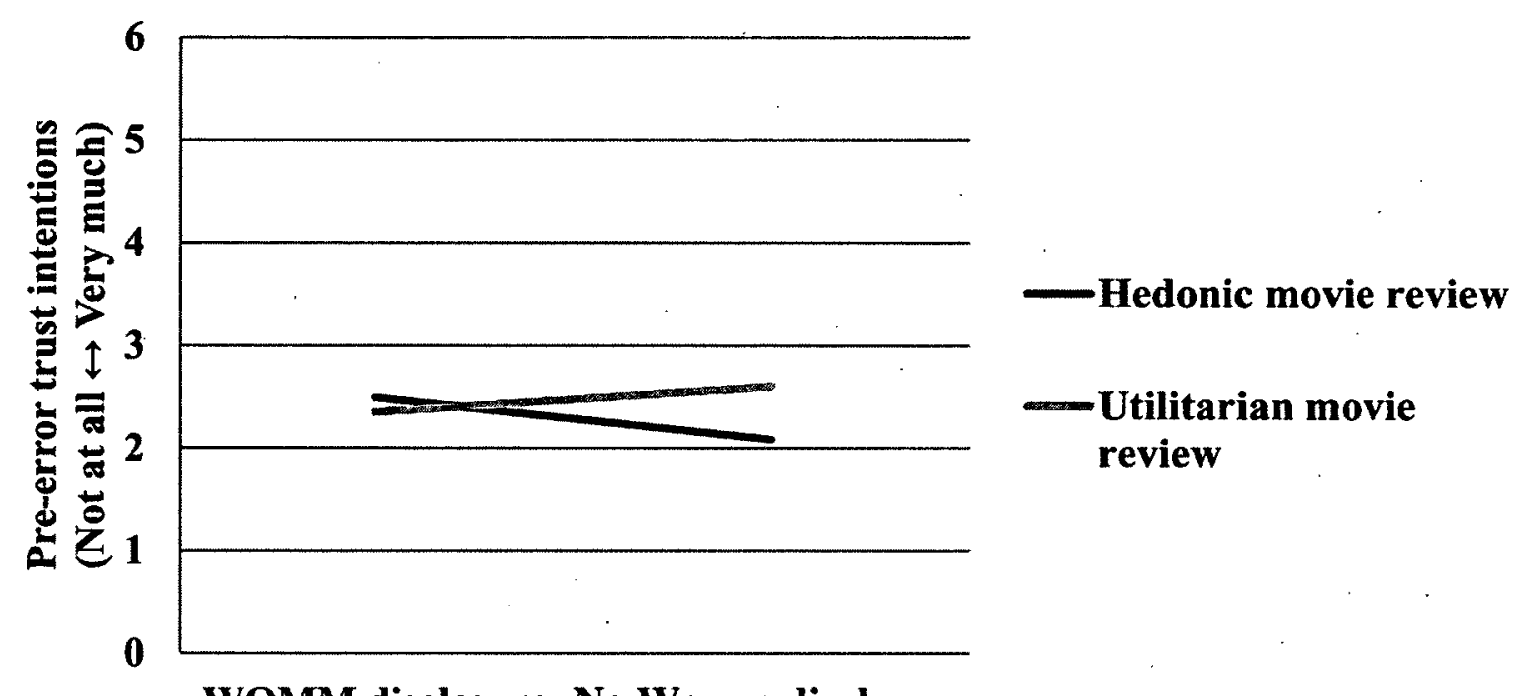

WOMM disclosure No Womm disclosure

To further assess the hypothesized relationships, multiple regression analysis was conducted and results are shown in Table 5.38. Post-error trust intentions were negatively related to perceptions of the blameworthiness of the blogger for the error, implying that when blog readers believe the blogger to be at fault, they are less ready to trust the blogger in the future. H16 was supported by the analysis. H17 was not supported by the analysis; movie company blameworthiness was positively related to post-error trust intentions. Although not tested, movie company blameworthiness would presumably be negatively related to trust intentions associated with the movie company. Consistent with 
prediction, the perceived incorrectness of the movie review was negatively related to post-error trust intentions. H18 was supported by the analysis. Since anger was not observed to be a significant predictor of post-error trust intentions, H19 was not supported by the analysis. However, $\mathrm{H} 20$ was supported by the analysis; post-error trust intentions were negatively related to the dissatisfaction caused by blogger error. $\mathrm{H} 21$ was also supported by the analysis. Pre-error trust intentions were positively related to those following the error, suggesting that pre-error trust may have a buffering effect on the reactions of blog readers to blogger error.

Table 5.38: Multiple Regression Analysis of Post-Error Trust Intentions

\begin{tabular}{|l|c|c|c|}
\hline Independent variables & $\boldsymbol{B}(\boldsymbol{S E})$ & $\boldsymbol{\beta}$ & $\boldsymbol{t}$ \\
\hline Blogger blameworthiness & $-.07(.04)$ & -.08 & $-1.72^{*}$ \\
\hline Movie company blameworthiness & $.17(.05)$ & .18 & $3.64^{* * *}$ \\
\hline Movie review incorrectness & $-.38(.04)$ & -.42 & $-9.72^{* * *}$ \\
\hline Anger & $.08(.06)$ & .08 & 1.39 \\
\hline Dissatisfaction & $-.11(.05)$ &. .12 & $-2.15^{*}$ \\
\hline Pre-error trust intentions & $.51(.04)$ & .47 & $11.54^{* * *}$ \\
\hline & & & \\
\hline Adjusted $\boldsymbol{R}^{2} /(\boldsymbol{F}$ value $)$ & & $.51 / 56.44^{* * *}$ \\
\hline
\end{tabular}

${ }^{*} p<.05 ;{ }^{* *} p<.01 ;{ }^{* * *} p<.001$.

Negative word-of-mouth communication.

Four forms of negative word-of-mouth communication were examined as specific conative outcomes of blogger error. Qualitative descriptions of the four forms of negative word-of-mouth communication are provided in Table 5.39. Paired $t$-tests showed that intentions to engage in negative blog- and movie-related interpersonal communication were higher than those to engage in negative blog- and movie-related online communication. Specifically, participants reported higher intentions to recommend that 
their personal acquaintances avoid reading the blog than to complain on the blog about the content of the movie review $\left(M_{D i f f e r e n c e}=.82, p<.001\right)$. Similarly, participants reported higher intentions to recommend that their personal acquaintances avoid seeing the movie than to criticize the movie on a website $\left(M_{\text {Difference }}=1.51, p<.001\right)$. This is a notable finding, as research shows that word-of-mouth communication is more persuasive when it originates from a familiar source than when it originates from an unfamiliar source (e.g., Pan and Chiou, 2011). There was no significant difference between the intentions of participants to recommend to their personal acquaintances that they avoid reading the blog and avoid seeing the movie $\left(M_{D i f f e r e n c e}=.16, p>.1\right)$. Of the online communication types, the blog received higher intentions than the movie $\left(M_{D i f f e r e n c e}=.53, p<.001\right)$. The blogger could expect to see more critical content regarding the movie review on the blog than the movie company could expect to see on websites featuring movie reviews and other movie-related content.

A three-way MANOVA was performed to determine whether the treatment conditions were affecting the four forms of negative word-of-mouth communication. The analysis is summarized in Table 5.40. There was no evidence of any two- or three-way interaction effects on the four forms of negative word-of-mouth communication. As the table shows, movie review type was observed to have a significant overall effect on the four forms of negative word-of-mouth communication. Negative blog-related online communication, movie-related interpersonal communication, and movie-related online communication all differed on the basis of movie review type. 
Table 5.39: Descriptions of Negative Word-of-Mouth Communication Types

\begin{tabular}{|l|l|l|l|l|}
\hline $\begin{array}{l}\text { Negative word-of- } \\
\text { mouth communication }\end{array}$ & Audience & Medium / Media & Sample statements \\
\hline $\begin{array}{l}\text { Blog- } \\
\text { related }\end{array}$ & Interpersonal & $\begin{array}{l}\text { Personal } \\
\text { acquaintances } \\
\text { (e.g., friends, } \\
\text { family) }\end{array}$ & $\begin{array}{l}\text { Interpersonal } \\
\text { communication (e.g., } \\
\text { face-to-face); possibly } \\
\text { social media sites } \\
\text { (e.g., Facebook) }\end{array}$ & $\begin{array}{l}\text { "There is inaccurate } \\
\text { content on this blog and } \\
\text { Irecommend you avoid } \\
\text { reading it." }\end{array}$ \\
\cline { 2 - 5 } & Online & $\begin{array}{l}\text { Blogger; readers } \\
\text { of the blog; } \\
\text { readers of the } \\
\text { movie review }\end{array}$ & $\begin{array}{l}\text { Blog (Comments } \\
\text { section, typically } \\
\text { below blog post) }\end{array}$ & $\begin{array}{l}\text { "You claimed that the } \\
\text { movie is 'exciting, } \\
\text { energetic, and action } \\
\text { packed' but it is actually } \\
\text { unexciting, boring, and } \\
\text { full of terrible acting and } \\
\text { pathetic special effects." }\end{array}$ \\
\hline $\begin{array}{l}\text { Movie- } \\
\text { related }\end{array}$ & Interpersonal & $\begin{array}{l}\text { Personal } \\
\text { acquaintances } \\
\text { (e.g., friends, } \\
\text { family) }\end{array}$ & $\begin{array}{l}\text { Interpersonal } \\
\text { communication (e.g., } \\
\text { face-to-face); possibly } \\
\text { social media sites } \\
\text { (e.g., Facebook) }\end{array}$ & $\begin{array}{l}\text { "This movie is } \\
\text { unexciting, boring, and } \\
\text { full of terrible acting and } \\
\text { pathetic special effects } \\
\text { and I recommend you } \\
\text { avoid seeing it." }\end{array}$ \\
\cline { 2 - 5 } & $\begin{array}{l}\text { Online } \\
\text { movie reviews } \\
\text { (e.g., } \\
\text { "browsers," } \\
\text { "shoppers). }\end{array}$ & $\begin{array}{l}\text { Movie review website } \\
\text { (e.g., } \\
\text { rottentomatoes.com); } \\
\text { personal website; } \\
\text { possibly social media } \\
\text { sites (e.g., Facebook) }\end{array}$ & $\begin{array}{l}\text { "This movie is } \\
\text { unexciting, boring, and } \\
\text { full of terrible acting and } \\
\text { pathetic special effects." }\end{array}$ \\
\hline
\end{tabular}

Negative online communication was greater when the movie review addressed the utilitarian merit of the movie than when it addressed the hedonic merit of the movie $\left(M_{\text {Difference-Blog-related }}=.43, p<.05 ; M_{\text {Difference }- \text { Movie-related }}=.43, p<.05\right)$. Since there are many online outlets for communicating about and reviewers who critique the hedonic merit of movies, participants may have felt relatively little need to criticize the movie on a website. The utilitarian merit of movies is not as commonly discussed in movie reviews as the hedonic merit. Participants could have believed there was a greater need and potential for making a unique contribution to movie-related discourse by remarking about the lack of utilitarian merit of the movie. Alternatively, participants could have perceived 
utilitarian aspects to be important and objective enough to express an opinion about them but hedonic aspects to be less important and inherently subjective such that any opinion about them is defensible.

In contrast, negative movie-related interpersonal communication was greater for the hedonic movie review than the utilitarian movie review $\left(M_{D i f f e r e n c e}=.68, p<.001\right)$. Notwithstanding the claim of Oliver and Bartsch (2010, p. 54) that consumers enjoy "serious, poignant, and pensive media experiences," participants may be indirectly expressing an opinion that their personal acquaintances value hedonism in movies and that the movie would not be enjoyable to their personal acquaintances because it was revealed to lack hedonic merit. In contrast, the inaccurate statements regarding the utilitarian merit of the movie may have left participants assuming that the movie could still have hedonic or some other form of merit. It is not uncommon for a movie company to mock a historically or culturally significant event or person with a storyline that adheres little to the documented truth for the setting. There was no significant difference in intentions to speak negatively about the blog to personal acquaintances on the basis of movie review type $\left(M_{\text {Hedonic }}=2.98\right.$ versus $\left.M_{\text {Utilitarian }}=3.18, p>.10\right)$.

Since the MANOVA revealed movie review type to be a significant overall predictor of the four forms of negative word-of-mouth communication, movie review type was included as a control variable in the multiple regression analyses reported in Table 5.41. Similar to the findings reported in Table 5.40, movie review type emerged as a significant predictor of negative movie-related interpersonal and online communication $(p=.055)$. Although Table 5.40 reported a significant movie review-type effect on 
negative blog-related online communication, that effect was lost in the multiple regression analysis.

$\mathrm{H} 22 \mathrm{a}(\mathrm{i}, \mathrm{ii})$ was supported by the analysis. Intentions to (i) recommend that acquaintances avoid reading the blog and to (ii) criticize the movie review on the blog were positively related to the perceived blameworthiness of the blogger for the error. $\mathrm{H} 22 \mathrm{~b}(\mathrm{i}, \mathrm{ii})$ was not supported by the analysis. The perceived blameworthiness of the blogger for the error was not significantly related to (i) intentions to recommend that acquaintances avoid seeing the movie or to (ii) criticize the movie on a website. $\mathrm{H} 23 \mathrm{a}(\mathrm{i}, \mathrm{ii})$ was not supported by the analysis. Movie company blameworthiness was not related to intentions to (i) recommend that acquaintances avoid reading the blog or to (ii) criticize the movie review on the blog. $\mathrm{H} 23 \mathrm{~b}(\mathrm{i})$ was not supported by the analysis but $\mathrm{H} 23 \mathrm{~b}(\mathrm{ii})$ was supported by it. The blameworthiness of the movie company was not related to intentions to (i) recommend that acquaintances avoid seeing the movie but was positively related to intentions to (ii) criticize the movie on a website.

Movie review incorrectness was found to positively relate to negative blog-related and movie-related interpersonal communication but not to negative blog-related and movie-related online communication. Consistent with $\mathrm{H} 24 \mathrm{a}(\mathrm{i})$, the incorrectness of the movie review positively relates to intentions to recommend to acquaintances that they avoid reading the blog. Inconsistent with $\mathrm{H} 24 \mathrm{a}$ (ii), the incorrectness of the movie review was not found to significantly relate to intentions to criticize the movie review on the blog. The incorrectness of the movie review was positively related to intentions to recommend to acquaintances that they avoid seeing the movie $(\mathrm{H} 24 \mathrm{~b}(\mathrm{i}))$ but negatively related to intentions to criticize the movie on a website ( $\mathrm{H} 24 \mathrm{~b}$ (ii). 
Table 5.40: MANOVA of Four Types of Negative Word-of-Mouth Communication by Blogger, WOMM, and Movie Review Types

\begin{tabular}{|c|c|c|c|c|c|c|c|c|}
\hline \multirow{4}{*}{$\begin{array}{l}\text { Treatment conditions } \\
\text { (MANOVA Results) }\end{array}$} & \multicolumn{8}{|c|}{ Univariate Results } \\
\hline & \multicolumn{4}{|c|}{ (a) Blog } & \multicolumn{4}{|c|}{ (b) Movie } \\
\hline & \multicolumn{2}{|c|}{ (i) Interpersonal } & \multicolumn{2}{|c|}{ (ii) Online } & \multicolumn{2}{|c|}{ (i) Interpersonal } & \multicolumn{2}{|c|}{ (ii) Online } \\
\hline & $M(S . D)$. & $F$ & $M(S . D)$. & $F$ & $M(S . D)$. & $F$ & $M(S . D)$. & $F$ \\
\hline \multicolumn{9}{|l|}{$\begin{array}{l}\text { Blogger type } \\
F(4,309)=1.44, \eta^{2}=.02\end{array}$} \\
\hline Movie buff & $2.96(1.78)$ & \multirow{2}{*}{1.75} & $2.09(1.85)$ & \multirow{2}{*}{3.06} & $3.05(1.77)$ & \multirow{2}{*}{3.61} & $1.67(1.64)$ & \multirow{2}{*}{0.50} \\
\hline Afghanistan expert & $3.21(1.70)$ & & $2.43(1.79)$ & & $3.42(1.81)$ & & $1.78(1.70)$ & \\
\hline \multicolumn{9}{|l|}{$\begin{array}{l}\text { WOMM type } \\
F(4,309)=1.52, \eta^{2}=.02\end{array}$} \\
\hline WOMM disclosure & $3.12(1.72)$ & \multirow{2}{*}{0.12} & $2.36(1.79)$ & \multirow{2}{*}{1.06} & $3.24(1.76)$ & \multirow{2}{*}{.01} & $1.94(1.70)$ & \multirow{2}{*}{$5.07^{*}$} \\
\hline No WOMM disclosure & $3.04(1.77)$ & & $2.15(1.87)$ & & $3.23(1.85)$ & & $1.51(1.61)$ & \\
\hline & & & . & & & & & \\
\hline \multicolumn{9}{|l|}{$\begin{array}{l}\text { Movie review type } \\
E(4,309)=8.60^{* * *}, \eta^{2}=.10 \\
\end{array}$} \\
\hline Hedonic & $2.98(1.75)$ & \multirow{2}{*}{1.10} & $2.04(1.78)$ & \multirow{2}{*}{$4.55^{*}$} & $3.58(1.76)$ & \multirow{2}{*}{$11.92^{* * *}$} & $1.51(1.58)$ & \multirow{2}{*}{$5.25^{*}$} \\
\hline Utilitarian & $3.18(1.74)$ & & $2.48(1.85)$ & & $2.90(1.78)$ & & $1.94(1.72)$ & \\
\hline
\end{tabular}

${ }^{*} p<.05 ;{ }^{* *} p<.01 ;{ }^{* * *} p<.001$. 
Table 5.41: Multiple Regression Analyses of Four Types of Negative Word-of-Mouth Communication

\begin{tabular}{|c|c|c|c|c|c|c|c|c|c|c|c|c|}
\hline & \multicolumn{6}{|c|}{ (a) Blog } & \multicolumn{6}{|c|}{ (b) Movie } \\
\hline & \multicolumn{3}{|c|}{ (i) Interpersonal } & \multicolumn{3}{|c|}{ (ii) Online } & \multicolumn{3}{|c|}{ (i) Interpersonal } & \multicolumn{3}{|c|}{ (ii) Online } \\
\hline & $B(S E)$ & $\boldsymbol{\beta}$ & $t$ & $B(S E)$ & $\boldsymbol{\beta}$ & $t$ & $B(S E)$ & $\beta$ & $t$ & $B(S E)$ & $\beta$ & $t$ \\
\hline \begin{tabular}{|l|} 
Control variable \\
Movie review type $^{a}$ \\
\end{tabular} & $.13(.17)$ & .04 & 0.76 & $.27(.18)$ & .07 & 1.47 & $-.71(.18)$ & -.20 & $-3.94^{* * * *}$ & $.26(.16)$ & .08 & 1.61 \\
\hline $\begin{array}{l}\text { Blogger } \\
\text { Blameworthiness }\end{array}$ & $.28(.06)$ & .25 & $4.45^{* * *}$ & $.26(.07)$ & .22 & $3.90 * * *$ & $.10(.07)$ & .09 & 1.48 & $.08(.06)$ & .07 & 1.31 \\
\hline $\begin{array}{l}\text { Movie company } \\
\text { blameworthiness }\end{array}$ & $.04(.07)$ & .04 & 0.58 & $.11(.07)$ & .10 & 1.58 & $.04(.07)$ & .04 & 0.56 & $.18(.06)$ & .17 & $2.89^{* *}$ \\
\hline $\begin{array}{l}\text { Movie review } \\
\text { incorrectness }\end{array}$ & $.21(.09)$ & .18 & $2.49^{* *}$ & $-.08(.09)$ & -.06 & -0.84 & $.16(.09)$ & .13 & $1.82^{*}$ & $-.02(.08)$ & -.01 & -0.21 \\
\hline Anger & $.08(.08)$ & .07 & 0.96 & $.27(.09)$ & .23 & $3.05^{* *}$ & $.01(.09)$ & .01 & 0.16 & $.33(.08)$ & .31 & $4.28 * * *$ \\
\hline Dissatisfaction & $.25(.07)$ & .23 & $3.45^{* * *}$ & $.08(.08)$ & .07 & 1.06 & $.39(.08)$ & .35 & $5.04^{* * *}$ & $.02(.07)$ & .02 & 0.36 \\
\hline Post-error trust & $-.01(.08)$ & -.01 & -0.13 & $.01(.08)$ & .01 & 0.13 & $-.02(.08)$ & -.01 & -0.20 & $.18(.07)$ & .16 & $2.45 * *$ \\
\hline Adjusted $R^{2} /(F$ value $)$ & \multicolumn{3}{|c|}{$.24 / 15.32 * * *$} & \multicolumn{3}{|c|}{$.22 / 13.93^{* * *}$} & \multicolumn{3}{|c|}{$.20 / 12.70^{* * *}$} & \multicolumn{3}{|c|}{$.28 / 19.00^{* * *}$} \\
\hline
\end{tabular}

${ }^{*} p<.05 ;{ }^{* *} p<.01 ;{ }^{* * *} p<.001$.

${ }^{a}$ Movie review type: $1=$ Hedonic; $2=$ Utilitarian. 
Anger was positively related to intentions to criticize the movie review on the blog (H25a(ii)) and the movie on a website (H25b(ii)) but not to recommend to acquaintances that they avoid reading the blog $(\mathrm{H} 25 \mathrm{a}(\mathrm{i}))$ or seeing the movie $(\mathrm{H} 25 \mathrm{~b}(\mathrm{i}))$. Opposite findings were observed for dissatisfaction. Consistent with H26a(i), intentions to recommend to acquaintances that they avoid reading the blog were positively related to the dissatisfaction caused by blogger error. It is notable for bloggers that dissatisfaction was a more prominent negative affective outcome of blogger error than anger. While blogger error may lead to a relatively weak-to-moderate feeling of anger, the more prominent feeling of dissatisfaction appears to motivate blog readers to encourage people in their social networks not to read the blog. Still, interpersonal communication is limited in its reach, since it is restricted to direct interactions between blog readers and people they know. Inconsistent with $\mathrm{H} 26 \mathrm{a}$ (ii), intentions to criticize the movie review on the blog were not related to the dissatisfaction caused by blogger error. Consistent with $\mathrm{H} 26 \mathrm{~b}(\mathrm{i})$, intentions to recommend to acquaintances that they avoid seeing the movie were positively related to the dissatisfaction caused by blogger error. Inconsistent with $\mathrm{H} 26 \mathrm{~b}$ (ii), intentions to criticize the movie on a website were not related to the dissatisfaction caused by blogger error.

$\mathrm{H} 27$ predicts that post-error trust intentions are negatively related to intentions to engage in negative blog-related and movie-related communication. Post-error trust intentions were observed to be significantly negatively related only to negative movierelated online communication. $\mathrm{H} 27 \mathrm{~b}$ (ii) was therefore supported. Inconsistent with the hypotheses, post-error trust intentions were not significantly related to intentions to recommend to acquaintances that they avoid reading the blog $(\mathrm{H} 27 \mathrm{a}(\mathrm{i}))$ or seeing the 
movie (H27b(i)) or to criticize the movie review on the blog (H27a(ii)). Bivariate correlations were inspected to determine whether the lack of support for hypotheses $\mathrm{H} 27 \mathrm{a}(\mathrm{i}, \mathrm{ii})$ and $\mathrm{b}(\mathrm{i})$ should be taken to indicate that the trust implications of blogger error are independent of negative communication implications. Post-error trust intentions were revealed to be significantly related to negative blog-related interpersonal communication $(r=-.13, p<.01)$ and online communication $(r=.11, p<.05)$ as well as negative movierelated interpersonal communication $(r=-.12, p<.05)$. Partial correlation coefficients all retained significance and did not change direction when the relationship between preerror and post-error trust intentions $(r=.49, p<.001)$ was removed from the correlations. Trust is therefore relevant to intentions to engage in negative blog-related and movierelated communication, although bivariate relationships showed inconsistent support for the general prediction that post-error trust intentions are negatively related to the negative communication intentions. Post-error trust intentions were only negatively related to intentions to recommend to acquaintances that they avoid reading the blog and seeing the movie. This result implies that blogger error can have readership implications that extend beyond the reader(s) who experienced the error personally. In contrast, post-error trust intentions were positively correlated with intentions to criticize the movie review on the blog and the movie on a web site.

To calculate bootstrapped bias-corrected effect sizes, PROCESS model 4 (see Hayes, 2012a) was used. Indirect effects were not observed in the model of movie-related interpersonal communication. For that specific type of negative communication, the perceived incorrectness of the movie review, the feeling of dissatisfaction caused by blogger error, and movie review type all had main-effect relationships with intentions to 
advise acquaintances against watching the movie. This main-effects model of movierelated interpersonal communication is illustrated in Figure 5.10.

Figure 5.10: Main-Effects Model of Movie-Related Interpersonal Communication

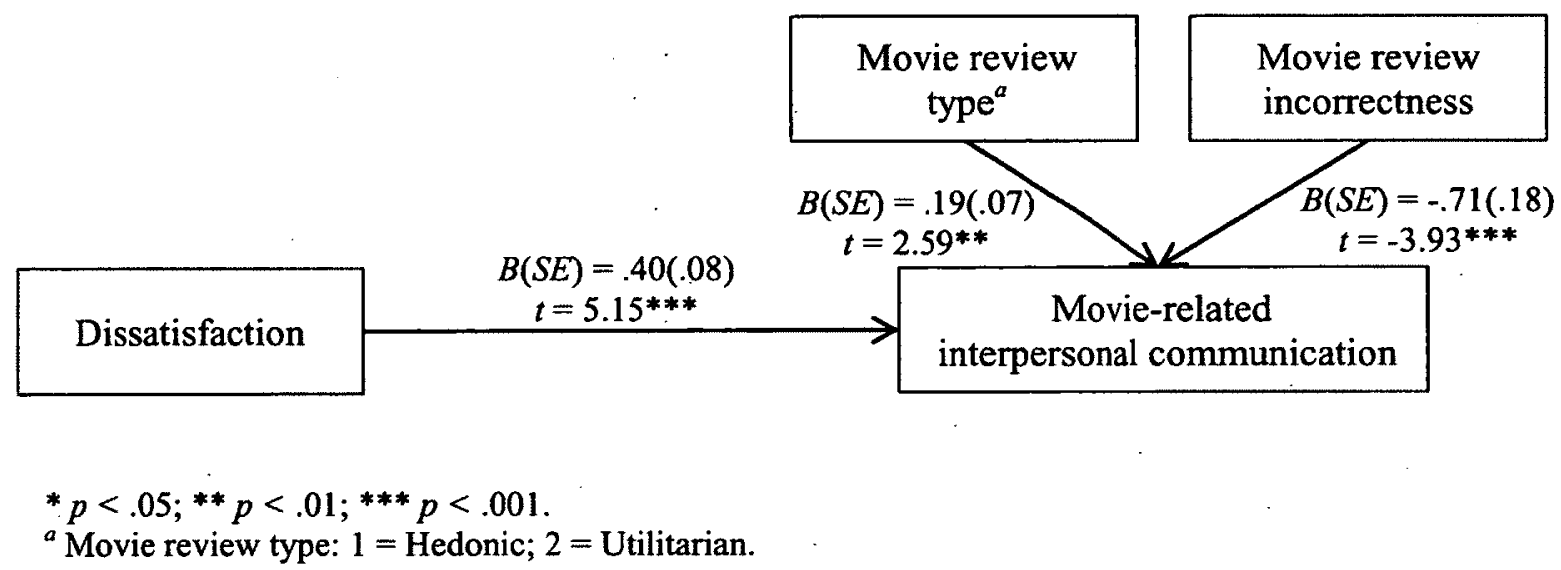

Indirect effects were observed for blog-related interpersonal and online communication as well as movie-related online communication and are shown with bootstrapped bias-corrected $95 \%$ confidence intervals in Table 5.42. All bootstrapped bias-corrected $95 \%$ confidence intervals do not include zero and are considered stable. Models showing significant direct and indirect effects on these three forms of negative word-of-mouth communication are illustrated in Figure 5.11. As the figure shows, blogger and movie blameworthiness relate to negative blog-related and movie-related communication both directly and indirectly. Table 5.41, Table 5.42, and Figure 5.11 reveal the relevance of both the perceived causal source of blogger error and the affective response to blogger error to specific negative word-of-mouth communication intentions. Blameworthiness is an essential evaluation that offended blog readers make in the event of blogger error, since analyses reported in Table 5.35 and Table 5.36 showed that the 
extent of movie review incorrectness is not in itself a general or stable sufficient predictor of the anger and dissatisfaction that offended blog readers experience when error occurs. The extent to which blogger error is attributable to a particular causal source (blogger; movie company) is clearly related to the level of negative behavioural intentions directed at that source; negative word-of-mouth communication therefore appears to be a reasoned response to a negative occurrence. Negative movie-related interpersonal communication is a notable caveat to this general observation. The bivariate correlation between movie company blameworthiness and negative movie-related interpersonal communication was not significant $(r=.06, p>.1)$, even though the bivariate relationships between movie company blameworthiness and dissatisfaction $(r=: 18, p<.001)$ and between dissatisfaction and negative movie-related interpersonal communication $(r=.39, p<$ $.001)$ were.

Table 5.42: Total, Direct, and Indirect Effect Sizes of Blameworthiness and Anger/Dissatisfaction and Negative Word-of-Mouth Communication

\begin{tabular}{|c|c|c|c|c|}
\hline \multirow{2}{*}{ Relationship } & \multirow{2}{*}{$\begin{array}{l}\text { Mediator } \\
\text { Variables }\end{array}$} & \multicolumn{3}{|c|}{ Effect Coefficients $(B)$} \\
\hline & & Direct & Indirect & Total \\
\hline $\begin{array}{l}\text { Blogger blameworthiness } \rightarrow \\
\text { blog-related interpersonal } \\
\text { communication }\end{array}$ & Dissat. & $\begin{array}{c}.31 \\
\{.20, .42\}\end{array}$ & $\begin{array}{c}.09 \\
\{.05, .16\}\end{array}$ & .40 \\
\hline $\begin{array}{l}\text { Blogger blameworthiness } \rightarrow \\
\text { blog-related online communication }\end{array}$ & Anger & $\begin{array}{c}.26 \\
\{.15, .38\}\end{array}$ & $\begin{array}{c}.12 \\
\{.07, .21\}\end{array}$ & .38 \\
\hline \multirow[b]{2}{*}{$\begin{array}{l}\text { Movie company blameworthiness } \rightarrow \\
\text { movie-related online communication }\end{array}$} & Ang & \multirow{2}{*}{$\begin{array}{c}.20 \\
\{.07, .34\}\end{array}$} & $\begin{array}{c}.17 \\
\{.11, .26\}\end{array}$ & \multirow[b]{2}{*}{.43} \\
\hline & $\begin{array}{l}\text { Post-error } \\
\text { trust } \\
\text { intentions }\end{array}$ & & $\{.06$ & \\
\hline
\end{tabular}

Note: Effect sizes relate to the direct, indirect, and total relationships between blameworthiness (blogger or movie company, as applicable) and negative word-of-mouth communication. 
Figure 5.11: Models of Direct and Indirect Effects of Blameworthiness and Negative Affective States on Negative Word-ofMouth Communication

\section{a (i) Negative blog-related interpersonal communication}

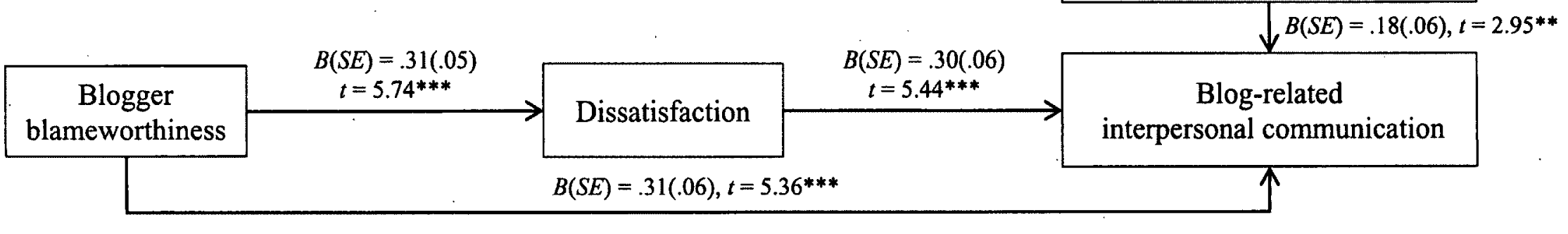

a (ii) Negative blog-related online communication

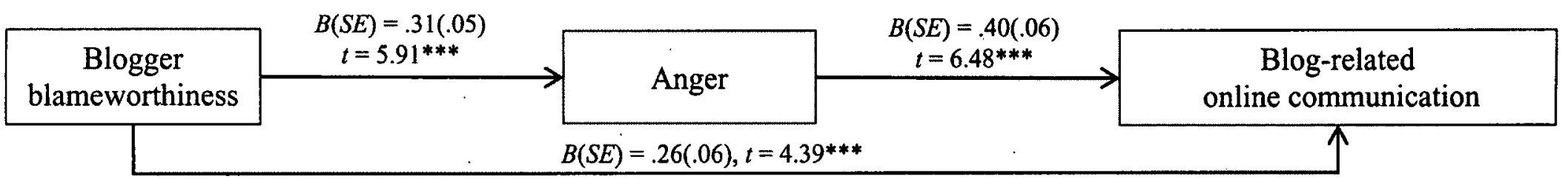

\section{b (ii) Negative movie-related online communication}

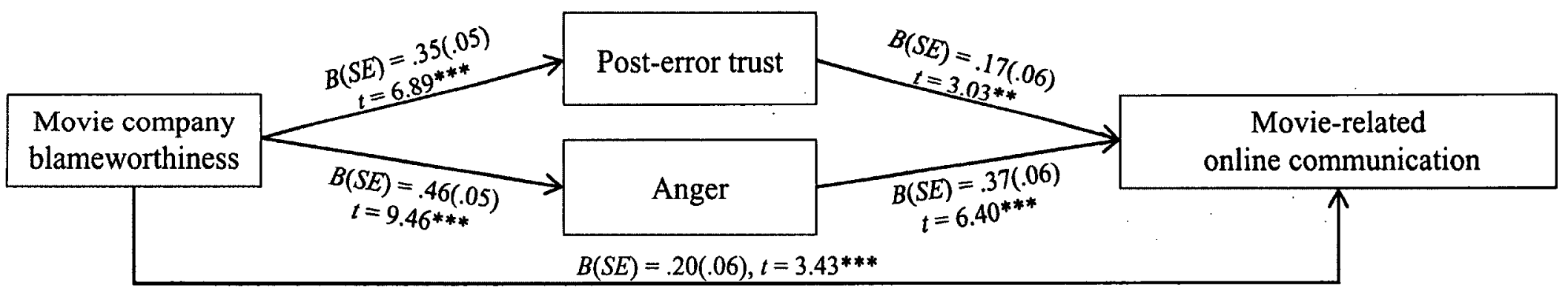

${ }^{*} p<.05 ;{ }^{* *} p<.01 ;{ }^{* * *} p<.001$. 


\section{Results of hypothesis tests.}

Results of hypothesis tests are summarized in Table 5.43. This study examined several blogosphere dynamics that have received limited or no prior research attention, and so the results summarized in the table shed considerable light onto priorities for future research. Priorities for future research are discussed in the concluding section of this chapter as well as in the final chapter of this dissertation. Blocks of related hypotheses are discussed in the discussion section of this chapter, which immediately follows the table. Table 5.43 reveals that hypotheses received mixed support, but the exploratory nature of this study implies less concern for hypothesis validation than for hypothesis testing, open inquiry, and priority making. 
Table 5.43: Summary of Hypotheses Testing Outcomes

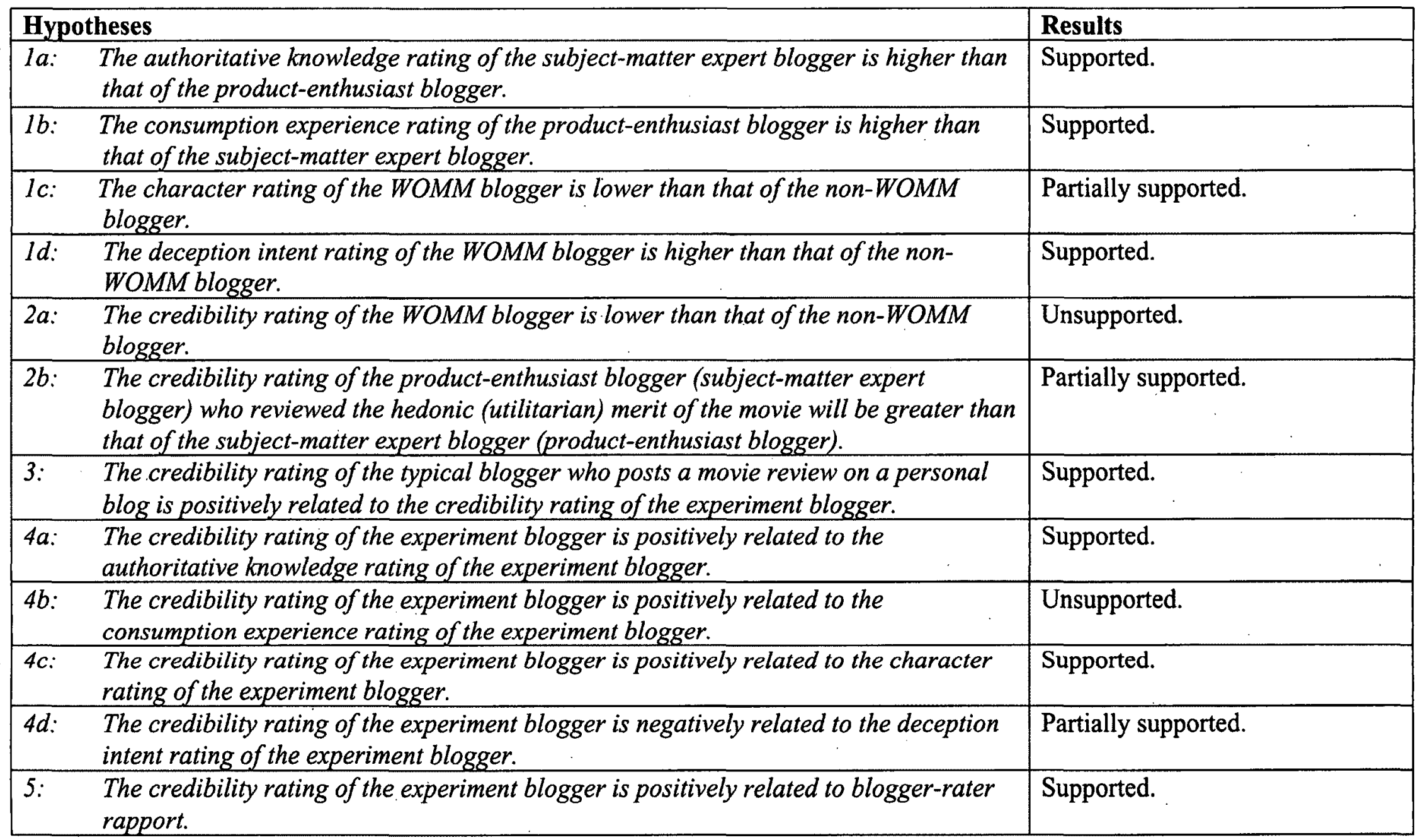




\begin{tabular}{|c|c|}
\hline Hypotheses & Results \\
\hline $\begin{array}{l}\text { 6: The perceived blameworthiness of the product-enthusiast blogger (subject-matter } \\
\text { expert blogger) for its review of the hedonic (utilitarian) merit of the movie is greater } \\
\text { than for its review of the utilitarian (hedonic) merit of the movie. }\end{array}$ & Unsupported. \\
\hline $\begin{array}{l}\text { The perceived blameworthiness of the WOMM blogger for the blogger error is greater } \\
\text { than that of the non-WOMM blogger. }\end{array}$ & Supported. \\
\hline $\begin{array}{l}\text { The perceived blameworthiness of the blogger for the blogger error is negatively } \\
\text { related to the character rating of the blogger. }\end{array}$ & Partially supported. \\
\hline $\begin{array}{l}\text { The perceived blameworthiness of the blogger for the blogger error is positively } \\
\text { related to the deception intention rating of the blogger. }\end{array}$ & Supported. \\
\hline $\begin{array}{l}\text { 10: The anger caused by blogger error is positively related to the perceived } \\
\text { blameworthiness of the blogger for the error. }\end{array}$ & Supported. \\
\hline $\begin{array}{l}\text { 11: The anger caused by blogger error is positively related to the perceived } \\
\text { blameworthiness of the movie company for the error. }\end{array}$ & Supported. \\
\hline $\begin{array}{l}\text { 12: The anger caused by blogger error is positively related to the perceived incorrectness } \\
\text { of the movie review. }\end{array}$ & Unsupported. \\
\hline $\begin{array}{l}\text { 13: The dissatisfaction caused by blogger error is positively related to the perceived } \\
\text { blameworthiness of the blogger for the error. }\end{array}$ & Supported. \\
\hline $\begin{array}{l}\text { 14: The dissatisfaction caused by blogger error is positively related to the perceived } \\
\text { blameworthiness of the movie company for the error. }\end{array}$ & Supported. \\
\hline $\begin{array}{l}\text { 15: The dissatisfaction caused by blogger error is positively related to the perceived } \\
\text { incorrectness of the movie review. }\end{array}$ & Unsupported. \\
\hline $\begin{array}{l}\text { 16: Post-error trust intentions are negatively related to the perceived blameworthiness of } \\
\text { the blogger for the error. }\end{array}$ & Supported. \\
\hline $\begin{array}{l}\text { 17: Post-error trust intentions are negatively related to the perceived blameworthiness of } \\
\text { the movie company for the error. }\end{array}$ & Unsupported. \\
\hline $\begin{array}{l}\text { 18: } \begin{array}{l}\text { Post-error trust intentions are negatively related to the perceived incorrectness of the } \\
\text { movie review. }\end{array} \\
\end{array}$ & Supported. \\
\hline 19: $\quad$ Post-error trust intentions are negatively related to the anger caused by the error. & Unsupported. \\
\hline
\end{tabular}




\begin{tabular}{|c|c|c|}
\hline \multicolumn{2}{|c|}{ Hypotheses } & \multirow{2}{*}{$\begin{array}{l}\text { Results } \\
\text { Partially supported. }\end{array}$} \\
\hline 20: & $\begin{array}{l}\text { Post-error trust intentions are negatively related to the dissatisfaction caused by the } \\
\text { error. }\end{array}$ & \\
\hline 21: & Post-error trust intentions are positively related to pre-error trust intentions. & Supported. \\
\hline $22:$ & $\begin{array}{l}\text { Intentions to engage in negative a) blog-related and b) movie-related (i) interpersonal } \\
\text { and (ii) online communication are positively related to the perceived blameworthiness } \\
\text { of the blogger for the error. }\end{array}$ & $\begin{array}{l}22 \mathrm{a}(\mathrm{i}, \mathrm{ii}) \text { supported. } \\
22 \mathrm{~b}(\mathrm{i}, \mathrm{ii}) \text { unsupported. }\end{array}$ \\
\hline 23: & $\begin{array}{l}\text { Intentions to engage in negative a) blog-related and b) movie-related (i) interpersonal } \\
\text { and (ii) online communication are positively related to the perceived blameworthiness } \\
\text { of the movie company for the error. }\end{array}$ & $\begin{array}{l}23 \mathrm{~b}(\mathrm{ii}) \text { supported. } 23 \mathrm{a}(\mathrm{i}, \mathrm{ii}) \text { and } \\
23 \mathrm{~b} \text { (i) unsupported. }\end{array}$ \\
\hline 24: & $\begin{array}{l}\text { Intentions to engage in negative a) blog-related and b) movie-related (i) interpersonal } \\
\text { and (ii) online communication are positively related to the perceived incorrectness of } \\
\text { the movie review. }\end{array}$ & $\begin{array}{l}24 \mathrm{a}(\mathrm{i}) \text { and } 24 \mathrm{~b}(\mathrm{i}) \text { supported. } \\
24 \mathrm{a}(\mathrm{ii}) \text { and } 24 \mathrm{~b} \text { (ii) unsupported. }\end{array}$ \\
\hline 25: & $\begin{array}{l}\text { Intentions to engage in negative a) blog-related and b) movie-related (i) interpersonal } \\
\text { and (ii) online communication are positively related to the anger caused by blogger } \\
\text { error. }\end{array}$ & $\begin{array}{l}25 \mathrm{a}(\mathrm{ii}) \text { and } 25 \mathrm{~b}(\mathrm{ii}) \text { supported. } \\
25 \mathrm{a}(\mathrm{i}) \text { and } 25 \mathrm{~b}(\mathrm{i}) \text { unsupported. }\end{array}$ \\
\hline 26: & $\begin{array}{l}\text { Intentions to engage in negative a) blog-related and } b \text { ) movie-related (i) interpersonal } \\
\text { and (ii) online communication are positively related to the dissatisfaction caused by } \\
\text { blogger error. }\end{array}$ & $\begin{array}{l}26 \mathrm{a}(\mathrm{i}) \text { and } 26 \mathrm{~b} \text { (i) supported. } \\
26 \mathrm{a} \text { (ii) and } 26 \mathrm{~b} \text { (ii) unsupported. }\end{array}$ \\
\hline & $\begin{array}{l}\text { Intentions to engage in negative a) blog-related and b) movie-related (i) interpersonal } \\
\text { and (ii) online communication are negatively related to post-error trust intentions. }\end{array}$ & $\begin{array}{l}27 \mathrm{a}(\mathrm{i}, \mathrm{ii}) \text { and } 27 \mathrm{~b}(\mathrm{i}) \text { unsupported. } \\
27 \mathrm{~b} \text { (ii) supported. }\end{array}$ \\
\hline
\end{tabular}


Trustee ability and motivation have long been considered to be trust antecedents, and the results of this study suggest comparable trust requirements for the blogosphere. The trust-building efficacy of authoritative knowledge versus consumption experience, at least in terms of the variance they explained in the credibility rating of the experiment blogger, suggests the importance of the information-seeking context for blog readers, since the results of study 2 differed from those of this study. Beyond trustee ability and motivation, blogger-rater rapport and typical blogger credibility were found to positively relate to experiment blogger credibility, which suggests that credibility evaluations in the blogosphere may be complex, based on individual and group perceptions, and more favourable for bloggers who develop affective bonds with their readers than for bloggers who maintain relational distance from their readers.

Blogger credibility hypothesis tests revealed a stronger general support pattern than blogger error hypothesis tests, but it is apparent that the service failure, deceptive advertising, and trust violation literatures were appropriate for informing measurement and analysis choices pertaining to blogger error hypothesis tests. Distinctions between the cognitive outcomes of blogger error and the affective outcomes of blogger error appear salient on the basis of the results of this study. Post-error trust intentions were found to significantly negatively relate to the perceived incorrectness of the movie review, but the affective outcomes of blogger error were not significantly positively related to it. Whereas trust intentions appear to have a strong cognitive foundation, anger and dissatisfaction seem more sensitive to the apparent motivation of the offending blogger than to the extent of the error itself. Still, bloggers must generally ensure that their claims are accurate, as intentions to engage in negative word-of-mouth communication directed 
at the offending blog were positively related to the perceived incorrectness of the movie review. Organizations working with bloggers should ensure that blog content is accurate and attempt to avoid any assignment of blame in the event of error, since some evidence suggests that the organization could itself be a target of negative word-of-mouth communication if offended blog readers perceive it to have played a role in the error. Future research could examine the unique roles of anger and dissatisfaction in terms of the specific forms of negative word-of-mouth communication, as only mixed support was observed for the relationships between the two affective outcomes of blogger error and intentions to engage in negative word-of-mouth communication.

\section{Discussion}

\section{Blogger Ability Ratings and Experimental Treatments}

Ratings of the authoritative knowledge and consumption experience of the experiment blogger were affected by the blogger type treatment in expected ways. The evidence showing that a WOMM disclosure can function as an important consumption experience signal to blog readers was not expected. Although the WOMM disclosure did not impact consumption experience assessments of the movie buff, it did increase consumption experience ratings of the subject-matter expert (i.e., the Afghanistan expert). The WOMM disclosure did not impact the authoritative knowledge assessments of either blogger. Authoritative knowledge and consumption experience were observed to negatively relate to each other $(r=-.47, p<.001)$, but WOMM disclosures can apparently have a mitigating effect on the perceived trade-off between the two ability bases. WOMM disclosures may be interpreted by blog readers as a signal that the blogger 
has been vetted by the marketer who enlisted the blogger to post reviews of its products. It may specifically seem sensible to consumers that marketers would choose experienced product users, but not product novices, to write on their behalf. Blog readers may believe that marketers do not enlist bloggers to discuss their products or services on the basis of the authoritative knowledge that bloggers possess.

\section{Blogger Character Ratings and Experimental Treatments}

Although a similar finding was observed in study 2 , it was not expected that the character rating of the movie buff blogger would be higher than that of the subject-matter expert blogger. Given the strong associations of blogger type with the authoritative knowledge and consumption experience ratings, bivariate relationships between blogger character and the two ability bases were assessed. The character-authoritative knowledge bivariate correlation was negative but non-significant $(r=-.03, p>.1)$. In contrast, the character-consumption experience bivariate correlation was positive $(r=.50, p<.001)$. Although this result suggests independence between authoritative knowledge and character, it is clear that bloggers associated with high consumption experience are perceived as possessing relatively high character, even if they make no specific claim as to their benevolence or integrity.

Since the subject-matter expert and movie buff bloggers did not differ on their deception intent ratings, blogger-rater rapport and certain social network characteristics (of the movie buff blogger) were examined to possibly explain the character difference between the bloggers. Blogger-rater rapport was operationalized as the perceived likeability and similarity (to the individual participant) of the blogger. Character and 
blogger-rater rapport ratings were positively related to each other $(r=.42, p<.001)$.

ANOVA indicated no significant difference in blogger-rater rapport ratings on the basis of blogger type, WOMM type, or their interaction. The higher character rating of the movie buff blogger compared to the subject-matter expert blogger could therefore not be explained by the perceived likeability and similarity of the blogger.

The higher character rating of the movie buff blogger than the subject-matter expert blogger could be a reflection of the social-network prominence and engagement of the movie buff blogger. In its About Me statement, the movie buff blogger signaled its reputation for having movie knowledge and frequent engagement in movie-related discussions with other movie fans. Although the movie buff blogger made no specific claim as to wanting to help readers make good movie-related decisions or always being honest and sincere in its movie-related discussions, the reputation and social-network prominence of the movie buff blogger could nonetheless bind it to benevolent and morally acceptable conduct. Deceptive movie-related claims by the movie buff blogger could harm its movie-knowledge reputation and movie-community relationships and even provoke a backlash by members of that community (e.g., embarrassing comments posted on the blog, removal from blogrolls, online feuds, etc.) The subject-matter expert blogger made similar types of claims (e.g., attends conferences, advises international organizations), but the perceived reputational and/or relational consequences of deceptive movie-related blog content or potential for being caught may not have been the same.

Although it was always higher than that of the subject-matter expert blogger, the character rating of the movie buff blogger was affected by WOMM type. When the movie buff blogger made the WOMM disclosure, its character rating was lower than 
when it did not. In contrast, the character rating of the subject-matter expert blogger was unaffected by WOMM type. The subject-matter expert blogger was generally observed to benefit by making the WOMM disclosure but the movie buff blogger was not. The movie buff blogger experienced no gain in its authoritative knowledge rating by making the WOMM disclosure but did experience deterioration in its character rating. In contrast, the subject-matter expert blogger experienced better consumption experience ratings but no worse character ratings by making the WOMM disclosure.

\section{Credibility}

Since the relevance of WOMM type to the character and deception intent ratings of the blogger was established, the finding that blogger credibility did not vary on the basis of WOMM type was not expected. Consistent with online-trust research (e.g., Hahn and Kim, 2009), blogger ability appeared in this study to be a strong predictor of the credibility rating of the experiment blogger. Although consumption experience is a documented ability source of communicators of product information (e.g., Alba and Hutchinson, 1987), it was not helpful to the credibility rating of the experiment blogger in this study. To a degree, this finding may relate to the suggestion by Redden and Steiner (2000) that fanatical consumers can have little tolerance for the opinions of others and be biased, dogmatic, single-minded, and uncompromising. At least when blog readers are engaged in a purchase-related information search (i.e., searching, as opposed to browsing or reading simply for entertainment), authoritative knowledge appears to be a very valuable ability base for bloggers to possess. In contrast, the consumption experience rating of the experiment blogger was unrelated to the credibility rating of the experiment 
blogger. Additional study would be needed to confirm that authoritative knowledge is an overriding ability-based credibility antecedent across all domains for blog readers engaged in an information search in support of a purchase decision.

Owing to the credibility difference between them, the movie buff blogger was relatively ineffective in its attempts to persuade blog readers about the hedonic or utilitarian merit of the Afghan orphanage movie. Whereas the subject-matter expert blogger was most credible when it reviewed the utilitarian merit of the movie, the credibility of the movie buff blogger was unaffected by the hedonic versus utilitarian focus of the movie review. In addition, the evidence suggests that the movie buff blogger was not even more credible to blog readers than the subject-matter expert blogger when they reviewed the hedonic merit of the movie. Movie buffs (and perhaps other bloggers who define themselves primarily in terms of their consumption experience) may need to take steps to acquire authoritative knowledge or otherwise signal their possession of authoritative knowledge to blog readers as a step in enhancing their perceived credibility in the blogosphere. Authoritative knowledge is not easily or quickly acquired, however, given that it is commonly a result of formal education, relevant work experience, and other types of resource-intensive investments. Still, an authoritative knowledge investment could produce considerable returns for this type of blogger, as the correlation between blogger credibility and authoritative knowledge was even greater for the movie buff blogger than for the Afghanistan expert blogger.

Given the negative correlation between consumption experience and authoritative knowledge, a blogger with high consumption experience may find that there is some benefit in simply de-emphasizing its consumption experience in any blog content that 
readers could consult to rate its credibility. Blog readers could question the credibility of a blogger who presents itself as too immersed in a particular topic area. The movie buff blogger may have unknowingly caused concern in readers as to its domain-specific ability or overall credibility by indicating that it watches hundreds of movie every year, keeps up-to-date on all the Hollywood gossip, and puts more effort into keeping up with the latest developments in movies that into most other things. The effectiveness of this tactic needs separate study, particularly since blogs are not always read to achieve functional, purchase-related ends. Moreover, this tactic would likely instill significant uncertainty in the minds of readers as to whether the blogger possesses domain-specific ability at all. It appears that there may be no authoritative knowledge-building shortcut for bloggers interested in improving perceptions of blog readers of their possession of that particularly ability base. Whereas bloggers with high authoritative knowledge could make a WOMM disclosure simply to improve their consumption experience ratings, those with high consumption experience could not do the same to improve their authoritative knowledge rating.

On the basis of the credibility gap observed between the Afghanistan expert blogger and the movie buff blogger, it appears that blog readers who are seeking to satisfy a particular purchase-related objective are inclined to believe subject-matter experts before writers with high consumption experience. This inclination was most apparent in the context of the utilitarian movie review, but the movie buff blogger did not even enjoy a higher credibility rating than the Afghanistan expert blogger when they reviewed the hedonic merit of the movie. Even when movie buff bloggers discuss matters that do not require authoritative knowledge (e.g., excitement level, romance level), they 
must recognize that they are effectively competing for readers against not only other movie buffs but also bloggers with high authoritative knowledge who are writing about matters that are not relevant to the nature of their expertise.

The credibility rating of the experiment blogger was also highly reflective of its character rating. Despite the relationship between character and deception intent ratings $(r=-.25, p<.001)$, the latter was not found to be significantly related to the credibility of the experiment blogger. Although deception intent was significantly related to blogger credibility $(r=-.10, p<.05)$, the partial correlation coefficient between the two constructs when blogger character was controlled was not significant $(r=-.02, p>.10)$. The strong relationship between blogger character and blogger credibility $(r=.29, p<$ $.001)$ is likely the empirical cause of this deception intent finding. WOMM type was observed to significantly affect both the character and deception intent ratings of the experiment blogger. To mitigate the implications of these WOMM effects on blogger character and deception intent ratings, WOMM bloggers could signal their benevolence and commitment to morally acceptable conduct in various locations of their blogs (e.g., About Me statement, blog posts, and responses to reader comments). For example, a WOMM blogger could communicate to readers in its About Me statement how much it likes to help readers as well as other indicators of its good-naturedness (e.g., volunteering, donations to important causes). From an integrity perspective, WOMM bloggers could consider posting explicit policy statements that would be directed at marketers but viewable by all readers that would clearly indicate what they would and would not be willing to do within the context of a WOMM relationship (e.g., "There is no guarantee that I will make complimentary remarks about your product(s) on my blog.") 


\section{Blogger Error}

\section{Blameworthiness.}

Although the WOMM disclosure appeared beneficial (or, at least not harmful) to beliefs about the trustworthiness and credibility of the blogger, several serious implications of it were observed once participants were advised that blogger error had occurred. The blameworthiness of the blogger who made the WOMM disclosure was greater than that of the blogger who did not make the WOMM disclosure. Blog readers appeared less willing to rule out inadvertence, uncontrollable factors (e.g., a technical glitch), or a legitimate opinion difference as causes of blogger error in the WOMM condition as compared to the non-WOMM condition. It would seem that little cognitive effort would be needed to associate WOMM status with blogger blameworthiness, particularly given the effects of WOMM disclosures on character and deception intent ratings.

The positive relationship between the blameworthiness ratings of the blogger and the movie company suggests that the consequences of blogger error may be experienced by not only the offending blogger. Movie company blameworthiness was greater for the WOMM blogger than for the non-WOMM blogger, with the movie company being perceived as particularly blameworthy when the WOMM blogger made comments about the utilitarian versus the hedonic merit of the movie. When the Afghanistan expert blogger made the erroneous review of the utilitarian merit of the movie, blog readers could have assumed that the Afghanistan expert blogger effectively accepted compensation in exchange for making statements it knew to be untrue. When the movie 
buff blogger made the same erroneous review, blog readers may have perceived that the movie company would have needed to provide the blogger with the erroneous content in the first place. Regardless of blogger type, however, the movie company was clearly implicated by the erroneous movie review.

Marketers may wish to monitor the statements that are being made by WOMM bloggers about their products and services as they may not be immune to the negative consequences of inaccurate product claims. Marketers may also consider monitoring statements that are made about their products and services by bloggers who are not engaged with them in a WOMM relationship; although movie company blameworthiness was greater for the WOMM blogger than for the non-WOMM blogger, movie company blameworthiness for the non-WOMM blogger was still significantly greater than zero (i.e., "not at all blameworthy;" $t(158)=11.90, p<.001$ ). While a less probable causal attribution in the non-WOMM condition than the WOMM condition, blogger error could still be explained by some intervention by the movie company. Evidence of corporate hacking of product or service reviews has not been recorded widely, but covert marketing (i.e., marketer masquerading as a consumer reviewer) and a perceived paucity of disclosure regulations could explain why the movie company could still be suspected to have directly or indirectly influenced the content of the movie review in the non-WOMM condition.

Certain responses to blogger error were more severe for the Afghanistan expert blogger than for the movie buff blogger. Regardless of the content of its movie review, the Afghanistan expert blogger was perceived by participants as being more worthy of blame for the error than the movie buff blogger. Participants believed that the 
Afghanistan expert blogger actually took steps to deceive them about the hedonic and utilitarian merit of the movie to a greater extent than the movie buff blogger. This finding may relate to the high authoritative knowledge believed to have been possessed by the Afghanistan expert blogger, particularly as compared to the movie buff blogger. With its high level of authoritative knowledge, the Afghanistan expert blogger could have been perceived by readers to be blameworthy for the error because it should have been able to determine the accurate merit of the movie, irrespective of the focus (hedonic versus utilitarian) of the review. The Afghanistan expert is arguably better suited than the movie buff for making accurate claims about the utilitarian merit of the movie. In contrast, blog readers may have perceived the ability to make accurate hedonic claims to not derive from any particular source but instead to be widely distributed throughout the blogosphere (i.e., anyone could make them). Indeed, the Afghanistan expert was no less credible than the movie buff for the hedonic movie review condition. Blog readers could expect bloggers with high authoritative knowledge to be able to accurately comment on both domain-specific and non-specific issues, such as the hedonic merit of a movie. Hedonic movie aspects could partially derive from realism and insightfulness in movies, but these utilitarian movie aspects are not likely to derive from hedonic ones.

Another potential explanation for this finding relates to the character implications of consumption experience relative to authoritative knowledge. The movie buff blogger was rated as having significantly more consumption experience than the Afghanistan expert blogger. Compared to the movie buff blogger, the Afghanistan expert blogger could have been perceived by blog readers as lacking benevolence and integrity and so they assumed that the Afghanistan expert blogger could have actually taken specific steps 
to deceive them. This is unlikely, however, since the Afghanistan expert blogger was not rated as having more deception intent than the movie buff blogger. Still, the movie buff blogger was rated as having more character than the Afghanistan expert blogger. Relative to the erroneous movie review written by the Afghanistan expert blogger, blog readers could have perceived the erroneous movie review written by the movie buff blogger to have been caused by innocent inadvertence or an uncontrollable external occurrence. Consumers may have the general perception that they should be able to trust subjectmatter experts to provide accurate information, since their reputation hinges on their truth-telling track records. Consumers may not have the same general perception of communicators with high consumption experience, and may particularly guard themselves against persuasion when these communicators reveal their WOMM relationships.

\section{Affective outcomes of blogger error.}

Anger has been examined in a variety of service failure studies and a small convenience sample of these studies (scale adjusted) reveals that the anger produced by blogger error $(M=2.14$, S.D. $=1.55)$ may be less than that which can be produced by an unexpectedly low-quality hotel stay $(M=3.41, S . D .=1.70$; Gelbrich, 2010), long restaurant wait $(M=5.59, S . D .=.59$; Bonifield and Cole, 2007), high product price $(M=$ 2.85, S.D. $=1.55 ;$ Gelbrich, 2011), or a general service failure $(M=4.79$; Bougie, Pieters, and Zeelenberg, 2003; $M=4.60, S . D .=1.80$; Grégoire, Laufer, and Tripp, 2010). Dissatisfaction was a more prominent affective response to blogger error than anger in this study. 
The perceived incorrectness of the movie review was not observed to predict anger or dissatisfaction as it was expected to. Instead, blogger and movie company blameworthiness were the relevant cognitive drivers of these affective responses to blogger error. The anger and dissatisfaction produced by blogger error appear more related to how the error occurred than to the size (i.e., incorrectness) of the error. Bloggers and companies should take precautions to avoid receiving blame in the event of blogger error. Blame-avoiding tactics should not include illegal conduct, however; for example, companies should not compel their WOMM bloggers to conceal the material connections that join them (Federal Trade Commission, 2009). Bloggers and companies should also consider the likely effectiveness of overt attempts to shift blame, particularly when it would be reasonable for blog readers to believe it to be in the self-interest of the blame shifter to attempt to do so. In general, precautions should be taken so as to minimize the probability of blogger error in the first place. Bloggers do not always verify the accuracy of the statements they make (Lenhart and Fox, 2006), which is a dangerous practice since anger and disappointment were found in this study to predict post-error trust intentions and negative word-of-mouth communication.

When error occurs, bloggers and companies should consider the appropriateness and expected payoff of a genuine attempt to recover from the error. Service failure research indicates that failures are often less important to consumers than how organizations respond to the failures (Bitner, Booms, and Tetrault, 1990). A recovery effort is an attempt to move an offended individual (e.g., a blog reader) from a state of dissatisfaction to one of satisfaction (Andreassen, 2001). Potential may even exist for a dissatisfied blog reader to become a delighted blog reader, although this requires that the 
expectation a blog reader has in terms of a recovery attempt be exceeded by the actual recovery attempt (i.e., positive disconfirmation; Oliver, 1977) and this may be difficult to achieve in the blogosphere (Estelami, 2000). Still, correcting erroneous content in a blog post is far from being a universal blogger practice (Lenhart and Fox, 2006). It is nonetheless difficult to imagine a blogger offering readers little more than an apology for an error. Moreover, research on the "service recovery paradox" has been equivocal, showing that strong recovery attempts do not always result in better-than-original satisfaction levels or even in restored repurchase and word-of-mouth intentions or corporate image perceptions (de Matos, Henrique, and Rossi, 2007). Since participants in this study had no prior relationship with the blogger or the movie company, it is conceivable that the blogger and movie company would need to make very substantial affective, informative, or functional reparations to improve reader relations and encourage readers to return to the blog and refrain from retaliating against them for the error (Grégoire, Tripp, and Legoux, 2009; Xie and Peng, 2009).

\section{Intentions}

Results clearly indicated that blogger error has a negative effect on trust intentions. Although post-error trust intentions were significantly greater than zero ("not at all;" $M_{\text {Difference }}=1.27, p<.001$ ), they were significantly lower than pre-error trust intentions. The perceived incorrectness of the movie review was a strong negative predictor of post-error trust intentions. The blameworthiness of the blogger was also a negative predictor of post-error trust intentions. Whereas anger and dissatisfaction appeared primarily linked to how the error occurred, it is apparent that trust intentions 
relate to how the error occurred as well as the extent of the error (i.e., the incorrectness of the claim). From a trust perspective, bloggers should make every attempt to provide their readers with accurate information as a failure to do so may instigate lower message acceptance (i.e., readers will believe their claims less than before the error occurred), readership, and referral levels. Along the same line, participants reported stronger intentions to recommend to their personal acquaintances that they avoid reading the blog than to criticize the movie review on the blog. Post-error trust intentions were negatively related to intentions to engage in negative blog-related interpersonal communication $(r=$ $-.13, p<.01$ ), so the decreased patronage of the blog by the offended blog reader may be accompanied by fewer new readers as disillusioned people warn their personal acquaintances of the perils of reading the blog. This negative relationship was also observed for negative movie-related interpersonal communication $(r=-.12, p<.05)$.

It was not expected that movie company blameworthiness would positively predict post-error trust intentions. Although movie company blameworthiness and blogger blameworthiness were positively related to each other, this finding suggests that participants may have perceived blogger error to have little chance of reoccurring to the extent that they saw the movie company as worthy of blame for the error. Attribution theory offers an explanation of this finding. Since trust intentions relate to the bloggerblog reader relationship (and not the blog reader-movie company relationship), the blameworthiness of the movie company appears to make the blogger less culpable for error. Bloggers write about a variety of topics, and so participants may expect the claims of the blogger, in general, to be accurate. 
Whereas post-error trust intentions were negatively related to both types of negative interpersonal communication, they were positively related to negative blogrelated online communication $(r=.11, p<.05)$ and negative movie-related online communication $(r=.29, p<.001)$. The positive relationship between post-error trust intentions and both blog-related and movie-related online communication is curious, particularly because anger is the relevant affective driver of blog-related and movierelated online communication. Anger is an affective state that has been shown to follow negative service experiences, especially those involving broken promises, unfairness, and expressed hostility (Funches, 2011). The co-existence of trust intentions with anger and blame could reflect less of a desire of participants to exact revenge or inflict harm on the blogger than to engage the blogger in discussion related to its evaluation of the movie. The online commentary is very likely to have a strong negative valence, but tonal and word choices may not necessarily reflect the intent of the blog reader to unilaterally dissolve the blogger-blog reader relationship. Instead, the blog reader may need to set the record straight, correct the blogger, or even punish the blogger but could still intend to repatronize the blog at a future point in time. Dissatisfaction, in contrast, appears more relevant to interpersonal communication intentions. In general, however, intentions to engage in negative interpersonal and online communication were positively related to each other for both the blog $(r=.55, p<.001)$ and the movie $(r=.36, p<.001)$. 


\section{Conclusion}

\section{Research Limitations}

Sample appropriateness for research scenario.

Concerns have been raised regarding the external-validity implications of studentbased research samples (Ok, Shanklin, and Back, 2008; Wells, 1993) as well as the ability of scenario-based studies to provide an appropriate substitute to reality (Wang and Huff, 2007; Wells, 1993). Tests revealed no particular validity-related effect of the use of student participants or a scenario in this study. Results showed that the participants in this study watch movies and, consistent with prior research (Lenhart and Fox, 2006), use blogs for obtaining information about movies and related products. Students were therefore deemed appropriate for use in this study. Results also showed that the contents of the About Me statements and movie reviews were at least moderately comparable to content that is typically posted on blogs. Moreover, significant cognitive, affective, and conative responses to the treatment conditions and the blogger error occurrence were observed in this study. The research scenario was reasonably suitable for the purposes of this research and provides a good basis for deriving some practical implications and guiding future research.

\section{Message acceptance versus blogger credibility.}

Message acceptance depends on characteristics of both the information source and the message itself. As the accuracy of an experiential claim cannot be fully assessed until it has been acted upon (Jover, Montes, and Fuentes, 2004), message acceptance was not specifically examined in this study. Instead, this study focused on the perceived 
credibility of the blogger in light of the About Me statement and movie review it communicated to readers. To ensure that differential message characteristics would not confound the results of this study, the treatment conditions used in this study were pretested for their strength, quality, understandability, valence, and hedonic appeal. Analyses showed no significant differences between the About Me statements or the movie reviews on these message characteristic variables.

\section{Blogger error.}

In this study, blogger error was operationalized in terms of inaccurate blog-post content that resulted in one or more types of loss (e.g., negative movie-watching experience). As a result, blogger error differs from a pure claim-fact discrepancy, which Darke and Ritchie (2007, p. 115) describe as the gap between "the impression that the advertisement generated and the performance of the product." Since movies are experience goods (Nelson, 1970), blogger error could only have been discovered by participants as they watched the movie and were able to assess the hedonic or utilitarian merit of the movie. Although a consumer can read product reviews by multiple consumers, personal experience is necessary for the consumer to personally assess the extent of the error and to attribute the error to a causal source. Therefore, it was not possible to operationalize blogger error in the absence of loss, as both time and money are necessarily expensed in watching a movie. Moreover, this blogger error operationalization is appropriate for study in a trust context, since potential for loss (i.e., risk) is inherent to trust (Levin and Cross, 2004; Mayer, Davis, and Schoorman, 1995; Moorman, Deshpandé, and Zaltman, 1993; Yousafzai, Pallister, and Foxall, 2003). 
Correspondingly, conceptualizations and operationalizations of service failure involve some sort of economic or social loss (Smith, Bolton, and Wagner, 1999).

\section{Research Contributions}

\section{Blogger-communicated trust-related information.}

This study sheds light on several implications of trustworthiness signaling behaviours in the blogosphere. First, the credibility advantage of the subject-matter expert blogger over the product enthusiast blogger implies that the authoritative knowledge liability observed in study 2 is not inherent to the blogosphere. It is apparent that the context surrounding blog readership influences the type of ability readers are seeking. The credibility advantage of the subject-matter expert blogger when it reviewed the utilitarian merit of the movie compared to when it reviewed the hedonic merit of the movie implies that authoritative knowledge is particularly valuable in the context of claims that would be necessarily based on authoritative knowledge in order to be accurate. Second, the consumption-experience benefit of disclosing participation in a WOMM campaign that was experienced by the subject-matter expert blogger but not the product enthusiast blogger suggests that, notwithstanding the findings of study 2 , it is possible for a blogger with high authoritative knowledge to take steps to make itself appear a well-rounded information source for blog readers seeking product information. Third, the character difference between the subject-matter expert blogger and the product enthusiast blogger implies a need for subject-matter expert bloggers to specifically employ tactics for remediating blog reader beliefs of their benevolence and integrity. It generally appears that bloggers with high consumption experience enjoy a character 
benefit relative to bloggers with high subject-matter expertise. Product enthusiasts and other information sources with high consumption experience should recognize the character implications of becoming involved in a WOMM campaign.

Consumer responses to WOMM have been identified as an important research topic (Libai et al., 2010). It is notable that, although the WOMM blogger was negatively perceived in terms of character and deception intent as compared to the non-WOMM blogger, WOMM type had no significant effect on the credibility rating of the experiment blogger. From a theoretical perspective, this finding suggests a stronger link between blogger ability and blogger credibility ratings than between blogger character and blogger credibility ratings (i.e., credibility has an ability bias). Online trust research reveals ability beliefs to have a great deal of influence on overall trust intentions, and so the findings of this study suggest a certain applicability of online trust research to the blogosphere.

\section{Blogger error.}

Blogger error, and its implications for blog readers, bloggers, and organizations, has not been examined in prior research. This research makes several contributions through its inquiry into blogger error. First, the importance of trust is again revealed in the context of blogger error, as trust intentions reported before the error appeared to buffer the effects of blogger error on trust intentions reported following the error. Second, the significance of blameworthiness and the counterintuitive findings with respect to the perceived incorrectness of the movie review imply a heavy influence of attributional cognition as offended blog readers assess their behavioural responses to the error. Although results indicate that blog readers will avoid a blog (i.e., have lower trust 
intentions) at least partially on the basis of the extent to which a claim on it was erroneous, negative word-of-mouth intentions appear more influenced by the blog readers' interpretations as to who is to blame and how the error occurred. To the extent that blogger error may be unavoidable, findings reported in this study make covert marketing a sensible practice since blog readers rely on their blameworthiness evaluations in forming their negative word-of-mouth intentions. Legality notwithstanding, organizations appear to be advised by these findings to distance themselves from a blogger in the event it communicates, or is found to communicate, an erroneous claim.

Third, the high blameworthiness assignment the Afghanistan expert blogger received relative to the movie buff blogger informs the trustworthiness literature by pointing to implications of different ability bases with a trustee fails to deliver on its implicitly or explicitly made promises. The favourable credibility assessment of the Afghanistan expert blogger appears to work against that blogger when error occurs, particularly since blameworthiness is such an important predictor of behavioural responses to blogger error. It is clear that any step taken that is effective at influencing a credibility rating creates an accuracy expectation in claim recipients that limits the scope of plausible causal explanations when error occurs. Fourth, the counterintuitive relationships observed between anger, dissatisfaction, and behavioural intentions imply that outcomes of blogger error, although generally negative, are complex and diverse. It is clear that the behavioural outcomes of blogger error are closely related to its affective outcomes and that the negative affective states of anger and dissatisfaction are themselves closely related to blame assignments for the error. 


\section{Future Research}

\section{Expectancy violation.}

Research could be conducted to investigate the implications of expectancy violation by the subject-matter expert blogger relative to the product-enthusiast blogger. Pretests ensured that the content of the "About Me" statements of the Afghanistan expert blogger and the movie buff blogger were comparable, so the expectancy violation result must stem from inherent perceived qualities of the Afghanistan expert blogger as compared to the movie buff blogger. Additional study could examine whether or not expectancy violation is common to all subject-matter experts in the blogosphere. Studied longitudinally, tests could also examine whether expectancy violation by subject-matter experts decreases over time as blogs become integrated as a mainstream medium and subject-matter experts turn to blogs for self-expression and communication purposes.

\section{Claim characteristics.}

Studies show the importance of claim characteristics as predictors of claim acceptance and related phenomena. Additional research could complement the present study by examining the perceived characteristics of a claim as well as the perceived characteristics (namely, trustworthiness) of the communicator of the claim for their respective relationships with claim acceptance and trust intentions. Recent research has approached a similar topic from an expectation (dis)confirmation perspective (Hsieh et al., 2010), and this approach could be helpful for studying trust in the blogosphere given 
perceptions of bias and the consequences of these perceptions on expectations of information accuracy.

\section{Blogger error.}

To test the outcomes of pure blogger error (i.e., error with no personal loss), search claims could be an appropriate choice. Claims such as nightly hotel rate, restaurant hours of operation, and computer processing speed are amenable to objective verification without personal loss as a necessary condition. Differences between responses to pure blogger error and those to error involving loss could be assessed, but the usefulness of such an examination is limited by the predominance of experiential word-of-mouth communication (Bughin et al., 2010).

\section{Cognitive, affective, and conative outcomes of blogger error.}

Additional study of the cognitive, affective, and conative outcomes of blogger error could extend the findings reported here. It would be useful to assess whether or not the trust effect (i.e., decreased trust intentions) of blogger error is limited to the offending blogger. Darke and Ritchie (2007) observed that deceptive advertising produces a generalized distrust effect that makes offended consumers less likely to accept advertising claims, even those disseminated by advertisers not involved with the initial deception. Future research could involve claims disseminated by the same versus a different blogger after the initial blogger error occurrence in order to examine the generality of the trust effect of blogger error. Future research could also examine pre- 
error versus post-error beliefs about the credibility of the typical blogger and accuracy of the typical claim posted on a blog.

Further inquiry into the respective relationships of anger and dissatisfaction with negative online and interpersonal word-of-mouth communication could be useful. The relationships between anger, post-error trust intentions, and negative online word-ofmouth communication require additional study, as it was not expected that angry blog readers would criticize the blog online but still have positive trust intentions for it. The motives of angry blog readers are not particularly clear; for example, it is unclear whether angry blog readers are seeking revenge against the blogger for error, looking for an apology from the blogger for the error, or simply wanting their own voices to be heard. Additional studies of outcomes of blogger error could more thoroughly investigate the implications of bloggers associated with high subject-matter expertise versus consumption experience, WOMM, and deception intent.

\section{Recovery from blogger error.}

The effectiveness of different types of recovery attempts was not studied in this research. The effectiveness of any recovery attempt could be studied in terms of forgiveness for the error by blog readers and could look at how blog reader perceptions of justice and faimess of any recovery attempt impact their readiness to forgive. Forgiveness implies emotional reengagement on the part of the offended party as well as abandonment of the right to punish the offender (Heslop, Lu, and Cray, 2009) and, as such, is an important mediating step in order for people to willingly expose themselves to risk by again placing trust in the offender (Xie and Peng, 2009). Although bloggers are 
limited in the reparations they can make for error, at a basic level they can choose to either apologize for the error or deny either that error occurred or that they are responsible for the error (Kim et al. 2004). An apology, presuming it is pleasant, empathetic, and offered quickly, may be an appropriate blogger response to blogger error (Hocutt, Bowers, and Donavan, 2006). The appropriateness of denial may depend on the extent to which blog readers believe (or the blogger is able to convince blog readers) that the erroneous blog content actually reflects the true opinion of the blogger or that the blogger is not responsible for error. The practice is not widespread, but any blogger who otherwise makes blog posts accessible only to paying subscribers could compensate blog readers by reducing the subscription price or refunding an amount back to readers. The time at which the offending blogger attempts to recover its relationships with readers could affect the cognitive, affective, and conative outcomes of blogger error. If a blogger admits that it erred before a reader draws public attention to the error, then blog readers may respond differently than if the blogger is accused of the error and has to address the accusation at a later time.

\section{Methodology and analysis.}

Replications of this study could investigate the existence of any validity-relevant difference between consumers (1) aged nineteen to twenty-six on the basis of educational status (student versus non-student) as well as (2) within and outside that age range. Netnographic methods (Kozinets, 2002) could offer rich insight into the cognitive, affective, and conative effects of blogger-communication trust-related information and blogger error. Although methods and statistical analyses were appropriate for hypothesis 
testing purposes, confirmation of measurement models and analysis of structural models using structural equations modelling techniques could advance this area of research. 


\section{CHAPTER 6: CONCLUSION}

\section{Overview of the Three Studies}

This dissertation research is comprised of three studies that collectively examine trust-building and trust-deteriorating phenomena in the blogosphere. Study 1 is a contextspecific content analysis of the trustworthiness signals that commercial and noncommercial bloggers transmit to information-seeking consumers that engender trust to the extent they are effective at influencing trust beliefs and expectations of information accuracy. Study 2 is a survey of blog readers that examines the belief- and experiencebased determinants of trust in bloggers and the topic-related claims they make. Study 3 involves experimental manipulation of blogger-communicated trust-related information and a product claim for examining antecedents of blogger trust and credibility ratings. Study 3 also assesses outcomes of blogger error for blog readers, bloggers, and organizations.

\section{Summary of Findings}

\section{Consistency with Prior Research}

The various dimensions of trust and trust development as seen in blogs are in line with trust studies and theory developed in a variety of other fields in many ways. The results of the three studies indicate this from the perspectives of both bloggers and blog readers. Specifically, findings reported over the three studies align with research indicating the multi-dimensional nature of the trustworthiness construct (e.g., Mayer, Davis, and Schoorman, 1995), the importance of ability beliefs for driving intentions (Bruwer and Wood, 2005; Schlosser, White, and Lloyd, 2006), and the relationship 
between trustworthiness beliefs and trust intentions (Bart et al., 2005; Doney and Cannon, 1997; Levin and Cross, 2004).

The evidence from the first study indicates that bloggers send signals that reflect their desire to support trust development. Trustworthiness signals disseminated by bloggers span the ability and character dimensions of trustworthiness but reveal great diversity within the dimensions in terms of how they can be developed and communicated. Studies 2 and 3 indicate that readers decode and respond to bloggercommunicated trustworthiness signals and other trust-related information, the blog content about the topic and about the connected community, and the blog presentation. Blogger readers assess the signals and information in terms of the different dimensions and sources of trustworthiness and base their implicit calculations regarding the expected accuracy of the blog content and overall value from engaging with the blog on them.

Findings are also consistent with research pointing to the importance of providing consumers with high-quality media experiences (Davis, 1989) and the implications of failing to fulfil all implied or expressed service-delivery promises (Iglesias, 2009; Weiner, 2000).

\section{Trust and Trustworthiness}

Bloggers and blog readers both have agendas in terms of the outcomes they are seeking from their interactions and these agendas should be considered in order to understand the dynamics and value of their interactions. Whereas bloggers seek to influence, blog readers are focused on obtaining topic-area information that furthers their topic-area knowledge and enables them to make effective decisions within it. The 
believability of a claim whose accuracy cannot be reliably assessed on the basis of content alone has been shown to relate to beliefs about the ability and motivation of the information source to make accurate claims (Buda and Zhang, 2000; Cable and Yu, 2006; Flanagin \& Metzger, 2000; Jo, 2004; Mack, Blose, and Pan, 2008; Metzger, 2007; Tormala and Petty, 2004). Studies 2 and 3 offer evidence that blog readers will not accept the claims of a blogger or otherwise trust a blogger who they believe possesses inadequate domain-specific ability, lacks a goodwill orientation to them, or is not committed to morally acceptable conduct. Blogger trustworthiness is a critical trust determinant and information need for blog readers (Grant, Clarke, and Kyriazis, 2007).

Since many blog connections are initiated with little information regarding the person who writes the blog, signals sent through "About Me" statements and blog posts as well as additional information about to whom the blogger is connected, and blog appearance and dynamics are critical to the formation of initial trust-based relationship establishment and for ongoing trust extension. Bloggers appear to appreciate this, as study 1 reveals a high level of blogger activity aimed at influencing the trustworthiness beliefs of blog readers. Effective trustworthiness signaling efforts by bloggers will increase accuracy expectations of blog readers and facilitate claim acceptance and other behavioural trust manifestations. To ensure trustworthiness signaling effectiveness, bloggers will need to communicate their domain-specific ability as well as benevolence and integrity with attention to the relative importance of each trustworthiness dimension to blog readers. Trustworthiness dimension importance levels can be inferred from studies 2 and 3. 
Study 3 shows that consumers fall short of having complete confidence in the accuracy of the typical movie review posted on a personal blog. Blogs did not originate within the corporate domain and consumer knowledge of word-of-mouth marketing and covert marketing is limited (Lee and Youn, 2009; Milne, Bahl, and Rohm, 2008; Wei, Fischer, and Main, 2008), so consumer scepticism toward blog-based content cannot be fully explained by concerns of reporting bias. Indeed, knowledge bias is a noted concern in the blogosphere and studies 2 and 3 reveal the importance for bloggers to overcome perceptions of this bias. Consistent with this concern, scepticism toward the accuracy of the typical movie review was significantly greater than toward the information-giving intent of the typical blogger who posts a movie review. It is therefore understandable that wine bloggers, the community specifically examined in study 1 , signal ability more frequently than either benevolence or integrity. Attention must be given to the particular ability base that blog readers in specific topic areas value most in bloggers. Whereas authoritative knowledge is a conventional human-capital ability base for making accurate topic-area assertions, study 2 revealed that authoritative knowledge is generally an undesirable characteristic of topic area bloggers, both in terms of topic-area knowledge acquisition and future trust intentions.

Evidence shows that the respective effectiveness of authoritative knowledge and consumption experience signals may depend on the blog reading task at the individual blog reader level. Studies show pluralistic online information seeking motivations and behaviours, and important differences exist on the basis of whether or not a search is instrumentally related to a purchase decision (Chen and Dibb, 2010; Hennig-Thurau and Walsh, 2003; Schlosser, 2003; Schlosser, White, and Lloyd, 2006). For readers of topic- 
area blogs who are not specifically seeking information to inform a purchase decision, study 2 shows that topic-area engagement is a valued ability base upon which topic-area claims can be made. For blog readers interested in purchase-related problem solving, study 3 reveals that topic-area authoritative knowledge is a valued ability base. Irrespective of blog reading task, studies 2 and 3 show that readers must believe a blogger has a goodwill orientation toward them (i.e., is benevolent) and is committed to morally acceptable behaviour (i.e., has integrity). Even though readers of blogs about sports, entertainment, business, and other topics that may not specifically relate to a purchase decision do not seek the perspective of topic-area authorities, these readers are still looking to acquire important topic-area knowledge and will presumably not respond well to inaccurate or inconsequential topic-area blog posts

\section{Implications of Accurate Versus Inaccurate Blog Content}

From a blog content perspective, accuracy is vital. Study 2 indicates that bloggers must provide their readers with unique and informative reading experiences that result in topic-area knowledge gains for readers. Bloggers who provide their readers with these reading experiences can expect their readers to continue reading them, relying on assertions they make, and referring the blog to their personal acquaintances. Evidence points to the perils of providing blog readers with inaccurate information.

Blog readers should not be expected to continue trusting a blog that has misinformed them. Offended blog readers exhibit post-error trust intentions that reflect the extents of the error and the blameworthiness of the blogger as well as pre-error trust intentions, which should reinforce to bloggers the necessity of developing trusting 
relationships with their readers. Bloggers must also realize that the consequences of inaccurate blog content do not stop at the trust intentions of the offended blog reader. When blog readers attribute the erroneous blog content to the intentional conduct of the blogger and are angered and/or dissatisfied by the experience, results of study 3 reveal that blog readers encourage their personal acquaintances to avoid reading the blog and to criticize the erroneous content on the blog itself. Attribution decisions are largely based on the background of the offending blogger which blog readers learn about through the various types of trust-related information that bloggers reveal about themselves, including disclosures of personal gain. Although online criticism offers the blogger an opportunity to respond to the allegation, the criticism will be publicly viewable and potentially aggressive in tone and disconcerting for other readers. Interestingly, however, blog readers who report intentions to criticize the erroneous content also report intentions, albeit diminished, to continue trusting the blog. Limited opportunities for relationship reparation may be available to bloggers facing criticism for an inaccurate claim it is accused of making.

\section{Implications of Word-of-Mouth Marketing}

Marketers are increasingly interested in the blogosphere as a venue for disseminating information to and collecting information from their existing and potential customers. Although blog readers recognize that word-of-mouth marketing relationships between marketers and bloggers instill reporting bias, disclosures of these relationships do not appear to hinder the potential persuasiveness of a blogger. In limited situations, word-of-mouth marketing disclosures can even help trustworthiness beliefs for bloggers. 
If bloggers are consistently communicating accurate information to their readers, then bloggers and marketers are likely to mutually benefit from their word-of-mouth marketing relationships. Marketers should be cautious, however, because error can occur easily in the blogosphere. Marketers who receive blame from blog readers for erroneous blog content can expect results comparable to those potentially experienced by offending bloggers.

\section{Limitations of the Three Studies}

The three studies that comprise this dissertation build upon, complement, and ameliorate each other, with the end result being that the total set of methodological strengths of the studies outweighs the total set of methodological weaknesses. The use of multiple designs allows for triangulation of results and balancing off of the constraints of one design with another. Each study does have limitations as has been described within each of the relevant chapters. Study 1 examined the actual trustworthiness signaling behaviours of wine bloggers. Wine is a complex and highly experiential product category that is well-suited to a study of trustworthiness since wine knowledge is not universally held and is highly complex. Study 1 was not able to assess the effectiveness of the trustworthiness signaling behaviours of wine bloggers, but study 2 revealed the important trustworthiness dimensions bloggers active in different topic areas ought to focus their signaling efforts. Study 2 made use of a research sample that is active in the blogosphere across a wide range of topic areas, so findings reported in it are based on the lived personal experience of actual blog readers. The research sample used in study 2 is appropriate for a study of trust building in the blogosphere, since respondents possessed a 
demographic profile that matches that of the blogosphere generally. The research sample strength of study 2 is extended to study 3 . Study 3 makes use of an experimental design which allows for more direct tests and assertions of causality than a survey-based design. While a great deal more can be learned, the collection of studies provides a good basis for what is a relatively under-researched area.

\section{Research Contributions}

\section{Contributions to Scholarship}

Information exchange within the blogosphere occurs differently than it does within conventional media, and the applicability of interpersonal communication theories to the blogosphere has been questioned (e.g., Brown, Broderick, and Lee, 2007). A specific need to identify the characteristics of influential online communicators has been identified (Huffaker, 2010). This need has attracted some research attention (e.g., Trammell and Keshelashvili, 2005), but strategic attempts by bloggers to enhance their perceived trustworthiness have not been examined. In study 1, a trustworthiness signaling typology was developed on the basis of trust research in the offline domain (Mayer, Davis, and Schoorman, 1995; Schoorman, Mayer, and Davis., 2007) and an examination of a broad selection of wine blogs to ensure the domain relevance and content validity of the operational definitions and signal categories derived from the research (Neuendorf, 2002). The resource-based and compensatory signaling approaches evidenced in the blogging behaviours of commercial and non-commercial wine bloggers in study 1 shed light on this strategic communication behaviour. Specifically, the behaviours of commercial and non-commercial bloggers reveal their appreciation of the category-level 
beliefs of blog readers and their focus on exploiting or remediating the beliefs through a resource-based or a compensatory signaling approach. This finding extends attribution theory by confirming its operation in the blogosphere, primarily in terms of the behaviours of bloggers that are aimed at managing the causal cognitions of blog readers.

Study 1 also revealed the appropriateness of categorizing wine blogs on the basis of their commercial orientation, as the behaviours of these wine blogger types was observed to differ in a number of respects. Study 1 examined trustworthiness signaling behaviours not only at the trustworthiness dimension level (i.e., ability, benevolence, integrity), but also at the sub-dimension level (e.g., authoritative knowledge versus consumption experience). The sub-dimension level analysis and commercial versus noncommercial wine blog contrast allowed for rich study of not only what is being said in the blogosphere but also who is saying it.

Online trust research reveals a lengthy list of website features and performance parameters that make consumers more or less likely to trust a website or an organization represented by a website (Bart et al., 2005; Chen and Dibb, 2010; Lee and Turban, 2001; Richard et al., 2010; Schlosser, White, and Lloyd, 2006). The applicability of the functional orientation evident in online trust research has been questioned, since blogs do not directly facilitate buyer-seller transactions and reading them can be as much of a social or hedonic experience as an instrumental one (e.g., Huang, Chou, and Lin, 2008). Indeed, blog readers may be seeking information, entertainment, or social interaction in line with their perceptions of whether the blogosphere facilitates learning, recreation, or both. This research helps to understand the diversity of blog readers and the blogger- and blog-based determinants of trust for them. Blog-reading context appears to be very 
important in this regard. For example, study 2 results show that blogger character affects trust intentions through its important influence on the extent to which the blogger has provided valuable topic-area knowledge to the reader. In the purchase-decision context of study 3 , blogger character was shown to have a strong relationship with the credibility rating of the blogger, suggesting that character is a particularly important trustworthiness dimension when the opportunity exists for a blog reader to make a dissatisfying purchase decision or when at least some information sources available to readers can realize extrinsic gains by making certain claims. Study 1 revealed character signaling to be a secondary focus of wine bloggers, which informs understanding of blogosphere dynamics by revealing the assumption of bloggers that their readers are looking for valuable information but are likely to incorporate claims from multiple sources in order to overcome the effects of bias from any one source.

The studies also contribute to the understanding of the trust-building effects of different trustworthiness dimensions from the perspective of blog readers. Perceptions of the credibility of the typical blogger reported in study 3 provided general support for the need to signal trustworthiness to blog readers. The findings of study 2 show that, in addition to their direct trust implications, blogger ability types are relevant to the extents to which blog readers realize their knowledge acquisition and community engagement goals. Blogs must provide instrumental knowledge improvements and unique information in support of topic-area knowledge outcomes, and it is notable these may derive more from engagement knowledge than authoritative knowledge. The relationship between community engagement and the engagement knowledge of bloggers offers further evidence of an engagement knowledge advantage in the blogosphere. The authoritative 
knowledge liability suggests that the blogosphere may differ from other communication domains in terms of the various goals of participants. The character implications for subject-matter experts observed in study 3 are further evidence of challenges for bloggers with high authoritative knowledge. Study 3 suggests that bloggers may benefit from attempts to build rapport with their readers, even if conditions exist that limit the degree to which the bloggers are free from bias. However, blogs that provide important information are the ones that both directly and indirectly support trust and continued use. While much has been made concerning the community-building potential of blogs, the key is knowledge access derived from community engagement knowledge sources rather than the social functions of communities.

There was no organizing blog-characteristic framework evident in blog studies when the research was conducted, so this research used an inductive approach to conceptualizing and measuring blog characteristics. The features, perceived accomplishments, and other characteristics of topic-area blogs that are included in the measures represent a comprehensive assessment framework for measuring the trustbuilding influence of non-blogger related factors that should be useful for future research and for practitioners developing measures of their reader/consumer needs. In addition, the blog characteristics examined in study 2 align in many ways with the online trust and trustworthiness literatures, which offers evidence in support of their value.

To the knowledge of the researcher, this is the first study to examine blogger error and the implications of word-of-mouth marketing in that context. Word-of-mouth marketing is a growing marketing practice that has received attention from researchers and regulators. Still, need has been expressed for a better understanding of consumer 
attitudes toward and the implications of the encroachment by marketers in "customer-tocustomer interactions" (Libai et al., 2010). Word-of-mouth marketing studies have reported inconsistent results, with some even reporting that disclosed involvement in a word-of-mouth marketing campaign can have a beneficial effect on communicatorrelated trust beliefs and product evaluations (e.g., Carl, 2008; Wei, Fischer, and Main, 2008). Although disclosed involvement in a word-of-mouth marketing campaign negatively affects character and deception intent beliefs, its credibility implications appear innocuous. Blog readers seem to recognize that word-of-mouth marketing is appropriate for bloggers, as blog readers did not significantly penalize the WOMM blogger for the disclosure it made. In fact, for bloggers with consumption experience, WOMM disclosures seem to enhance authoritative knowledge beliefs and make the bloggers appear well-rounded, at least from an ability perspective, to blogger readers. However, WOMM is out of context for subject-matter experts and was not helpful to their credibility or trustworthiness ratings.

However, the implications of word-of-mouth marketing when blogger error occurs appear more dramatic. The implications of word-of-mouth marketing when blogger error occurs that were not previously identified in the literature include the likelihoods that the organization will receive blame for error and be the target of specific negative word-of-mouth communications. This research identified specific types and targets of negative word-of-mouth communication and revealed their cognitive and affective antecedents. Offended blog readers do evaluate the circumstances surrounding the error in order to assign blame for the error and do experience negative affective states as a result of blogger error. The differential implications of anger and dissatisfaction 
stemming from blogger error in terms of the negative word-of-mouth communication that offended blog readers will disseminate reveal that blogger error produces complex outcomes in different directions and imply that any effort to recover from the error will be multidimensional in nature in order to cope with differences between anger and dissatisfaction, online and interpersonal negative word-of-mouth communication, bloggers and organizations as targets.

\section{Contributions to Practice}

Blogging is a two-way street, with bloggers and blog readers having their own agendas and the implications of these agendas, including the extent to which they complement or conflict, must be considered in determining the dynamic of how blogging works and the value of blogs. Bloggers pursue self-expression, influence building, and community engagement and blog readers, as results here show, value accurate and unique reading experiences that improve topic-area knowledge. Thus, there is much to be gained for bloggers and blog readers through accurate information dissemination. Since many blog connections are initiated with little information regarding the person who writes the blog, blog signals sent through "About Me" statements, blog posts, additional information about to whom the blogger is connected, and blog appearance are critical to the formation of initial trust-based relationship establishment and for ongoing trust extension.

As consumer use of blogs for products increases, marketers need greater insight into the blogosphere than ever before. Opportunities for partnership between organizations and bloggers may have high potential value from a market-impact 
perspective. Simple attention to blog-based discourse (e.g., blog posts, blog-reader comments) may provide organizations with considerable market intelligence. Bloggers, regardless of commercial orientation, similarly need insight into the beliefs and behaviours of blog readers. For example, a blogger approached by an organization with an invitation to engage it in a word-of-mouth marketing relationship should at least partially base its response to the invitation on the likely response readers will have toward the relationship. Results of this research indicate that bloggers need not be too worried about the responses of their readers to their involvement in a word-of-mouth marketing campaign, as long as the information they communicate to readers is accurate. This research indicates the specific blogger and blog characteristics that matter to blog readers and reinforces the importance of knowledge acquisition as a trust antecedent.

Findings reported in this research can be used by bloggers as they make blogrelated investment decisions. Bloggers must recognize that the most profitable blogrelated investments they can make will likely be those that facilitate unique and highvalue information experiences for their readers. From the results of this research, it should also be clear to bloggers that any step they take to enhance their perceived ability, benevolence, or integrity will produce desired results only if their readers value higher levels of that trustworthiness dimension. Whereas a blogger who reviews wines for wine drinkers would likely benefit by obtaining additional wine education (e.g., WSET certification), a blogger who reports on Hollywood gossip would gain little by receiving comparable topic-area instruction. In general, however, the results of this research should convince bloggers of the importance of their ability to make accurate topic-area claims. Whether or not a blog reader is seeking information to inform a purchase decision, it is 
clear that the reader is interested in obtaining accurate information that will in turn make him or her more knowledgeable about the topic area

Although consumers read blogs in order to acquire information on a variety of topic areas and to inform their purchase decisions, it is clear from this research that consumers do not have complete confidence in the accuracy of information posted on them. It is also clear that erroneous information communicated in the blogosphere can have considerable negative implications for any blogger or organization to whose conduct blog readers attribute the error. Organizations are advised to monitor online discourse since erroneous claims can have implications for them in addition to the blogger.

\section{Future Research}

As identified in the relevant study, additional research could first focus on the motivations of bloggers who communicate signals of ability, benevolence, and integrity and then on the effectiveness of those signals. From a motivational perspective, understanding of whether bloggers communicate trustworthiness signals with the explicit intention of influencing readers could be a valuable addition to the understanding of the blogosphere. From an effectiveness perspective, research could be conducted to determine if signal frequency (i.e., counts) relates to some blog-based popularity measure. In the blogosphere, the popularity of a blog can be assessed in terms of how frequently it is listed on "blog rolls," its "authority" score, its award-winning track record, and/or the number and nature of readers' comments posted on it. The content analysis could also be extended to other experience goods as well as to product categories 
characterized in terms of search versus credence claims to examine potential differences in overall, dimension-level, and sub-dimension-level signaling by commercial and noncommercial communicators. For example, a blogger who reports on daily financial indicators (e.g., exchange rates) could signal a different trustworthiness profile from a blogger who claims to report on economic negotiations among high-level government representatives, since blog readers could consult a variety of sources for financial indicators but could never completely know what occurred during the economic negotiations.

To enhance the external validity of the findings reported in this research, studies 2 and 3 could be replicated in different cultural environments and using different demographic (i.e., non-student) groups. The cultural dimensions of power distance, individualism / collectivism, uncertainty avoidance, masculinity / femininity, and longterm orientation identified by Hofstede (1980) could be used to guide replications of these studies in different cultural environments.

Implications of word-of-mouth marketing and covert marketing warrant additional study. In the United States, bloggers must disclose their material connections to organizations that have engaged them in a word-of-mouth marketing relationship, but there is flexibility in terms of the language used in such disclosures (Federal Trade Commission, 2009). Experimental manipulation of different types of disclosure statements could allow for tests of differential persuasion-knowledge activation and coping behaviour (e.g., avoidance, counter argumentation).

Future research could also examine opportunities for bloggers to recover from instances of blogger error. Studies of blogger error in contexts associated with different 
levels of personal involvement and risk of financial, social, or other types of loss could be useful for determining the wider existence of the cognitive, affective, and conative outcomes of inaccurate blog content. It would also be useful to assess whether the generalized trust effects of deceptive advertising observed by Darke and Ritchie (2007) extend to erroneous content in blog posts.

\section{Last Words}

The blogosphere is a diverse, complex, and growing online information environment. The realistic prospect of inaccurate content in blog posts makes trust necessary in productive blogger-blog reader relationships. Similar to other domains, unique and high-quality blog reading experiences that result in measurable knowledge acquisition for blog readers will impel them to return to the blog, rely on claims made by the blogger, and recommend the blog to their personal acquaintances. To facilitate trust, bloggers need to establish their trustworthiness with readers, recognizing that the blogosphere is at once similar and dissimilar to conventional communication domains in terms of the determinants of trust. Bloggers and organizations must understand the implications of their increase collaboration, as opportunities and threats lay hidden as they make and disseminate claims to information-seeking blog readers.

Inaccurate messaging produces negative outcomes for blog readers, bloggers, and organizations. Information accuracy is an implicit expectation of blog readers and failure by a blogger to fulfill its implicitly or explicitly made promises is anger-inducing, dissatisfying, and damaging not only to blogger-blog reader relationships but also to blogger and organizational performance. 


\section{REFERENCES}

Ahmed, W., Minnaert, A., VanderWerf, G., \& Kuyper, H. (2010). Perceived social support and early adolescents' achievement: The mediational roles of motivational beliefs and emotions. Journal of Youth and Adolescence, 39, 36-46.

Aiken, K., \& Boush, D. (2006). Trustmarks, objective-source ratings, and implied investments in advertising: Investigating online trust and the context-specific nature of Internet signals. Journal of the Academy of Marketing Science, 34(3), 308-323.

Ajzen, I. (1991). The theory of planned behavior. Organizational Behavior and Human Decision Processes, 50, 179-211.

Alba, J., \& Hutchinson, J. (1987). Dimensions of customer expertise. Journal of Consumer Research, 13, 411-454.

Albrycht, E. (2004). Turning blogs into useful communications tools. Public Relations Tactics, 11(3), 14-15.

AMC. (2012). Movietickets.com. Retrieved from https://amc.movietickets.com/.

American Marketing Association. (2011, Oct. 3). Social media code of conduct. Retrieved from http://www.marketingpower.com/_layouts/Survey/SurveyResults.aspx.

Andreassen, T. (2001). From disgust to delight. Do customers hold a grudge? Journal of Service Research, 4(1), 39-49.

Aquino, K., Tripp, T., \& Bies, R. (2006). Getting even or moving on? Power, procedural justice, and types of offense as predictors of revenge, forgiveness, reconciliation, and avoidance in organizations. Journal of Applied Psychology, 91(3), 653-668.

Argo, J., White, K., \& Dahl, D. (2006). Social comparison theory and deception in the interpersonal exchange of consumption information. Journal of Consumer Research, 33, 99-108.

Arndt, J. (1968). Selective processes in word of mouth. Journal of Advertising, 8(3), 1922.

Ashley, C., \& Leonard, H. (2009). Betrayed by the buzz? Covert content and consumerbrand relationships. Journal of Public Policy \& Marketing, 28(2), 212-220.

Astley, W. (1985), Administrative science as socially constructed truth. Administrative Science Quarterly, 30, 497-513. 
Babin, B., Boles, J., \& Darden, W. (1995). Salesperson stereotypes, consumer emotions, and their impact on information processing. Journal of the Academy of Marketing Science, 23(2), 94-105.

Bagozzi, R., \& Dholakia, U. (2002). Intentional social action in virtual communities", Journal of Interactive Marketing, 16(2), 2-21.

Bailey, J., \& Pearson, S. (1983). Development of a tool for measuring and analyzing computer user satisfaction. Management Science, 29(5), 530-545.

Barber, N., Almanza, B., \& Donovan, J. (2006). Motivational factors of gender, income and age on selecting a bottle of wine. International Journal of Wine Marketing, $18(1), 218-232$.

Bart, Y., Shankar, V., Sultan, F. \& Urban, G. (2005). Are the drivers and role of online trust the same for all web sites and consumers? A large scale exploratory empirical study. Journal of Marketing, 69, 133-152.

Becker, G. (1975). Human Capital. National Bureau of Economic Research, New York, NY.

Belanger, F., Hiller, J., \& Smith, W. (2002). Trustworthiness in electronic commerce: The role of privacy, security, and site attributes. Journal of Strategic Information Systems, 11, 245-270.

Bentzen, J.. \& Smith, V. (2008). Do expert ratings or economic models explain champagne prices? International Journal of Wine Business Research, 20(3), 230243.

Berlo, D., Lemert, J., \& Mertz, R. (1969). Dimensions for evaluating the acceptability of message sources. Public Opinion Quarterly, 33(4), 563-576.

Beverland, M., \& Farrelly, F. (2010). The quest for authenticity in consumption: Consumers' purposive choice of authentic cues to shape experienced outcomes. Journal of Consumer Research, 36, 838-856.

Bickart, B., \& Schindler, R. (2001). Internet forums as influential sources of consumer information. Journal of Interactive Marketing, 15(3), 31-40.

Bitner, M., Booms, B., \& Tetrault, M. (1990). The service encounter: Diagnosing favourable and unfavourable incidents. Journal of Marketing, 54(January), 71-84.

Bloch, P., Sherrell, D., \& Ridgway, N. (1986). Consumer search: An extended framework. Journal of Consumer Research, 13(1), 119-126.

Blog Pulse. 2011. Discontinued service of NM Incite, a joint venture between Nielsen and McKinsey \& Company. For information, go to: http://nmincite.com. 
Bonifield, C., \& Cole, C. (2007). Affective responses to service failure: Anger, regret, and retaliatory versus conciliatory responses. Marketing Letters, 18, 85-99.

Bougie, R., Pieters, R., \& Zeelenberg, M. (2003). Angry customers don't come back, they get back: The experience and behavioral implications of anger and dissatisfaction in services. Journal of the Academy of Marketing Science, 31(4), 377-393.

Brakus, J., Schmitt, B., \& Zarantonello, L. (2009). Brand experience: What is it? How is it measured? Does it affect loyalty? Journal of Marketing, 73, 52-68.

Brown, J., Broderick, A., \& Lee, N. (2007). Word of mouth communication within online communities: Conceptualizing the online social network. Journal of Interactive Marketing, 21(3), 2-20.

Bruner, G. (1986). Problem recognition styles and search patterns: An empirical investigation. Journal of Retailing, 62(3), 281-297.

Bruwer, J., \& Wood, G. (2005). The Australian online wine-buying consumer: Motivational and behavioural perspectives. Journal of Wine Research, 16(3), 193211.

Bughin, J., Doogan, J., \& Vetvik, O. (2010). A new way to measure word-of-mouth marketing. McKinsey Quarterly, April.

Buda, R., \& Zhang, Y. (2000). Consumer product evaluation: The interactive effect of message framing, presentation order, and source credibility. Journal of Product \& Brand Management, 9(4), 229-242.

Cable, D., \& Yu, K. (2006). Managing job seekers' organizational image beliefs: The role of media richness and media credibility. Journal of Applied Psychology, 91(4), 828-840.

Cacioppo, J., Harkins, S., \& Petty, R. (1981). The nature of attitudes and cognitive responses and their relationships to behavior. In R. Petty, T. Ostrom, \& T. Brock (Eds.), Cognitive Responses in Persuasion (pp. 31-54). Hillsdale, New Jersey: Lawrence Erlbaum Associates, Inc.

Campbell, M., \& Kirmani, A. (2000). Consumers' use of persuasion knowledge: the effects of accessibility and cognitive capacity on perceptions of an influence agent. Journal of Consumer Research, 27, 69-83.

Carl, W. (2008). The role of disclosure in organized word-of-mouth marketing programs. Journal of Marketing Communications, 14(3), 225-241.

Casalo, L., Flavián, C., \& Guinalíu, M. (2007). The influence of satisfaction, perceived reputation and trust on a consumer's commitment to a website. Journal of Marketing Communications, 13(1), 1-17. 
Castaldo, S., Premazzi, K and Zerbini, F. (2010). The meaning(s) of trust. A content analysis on the diverse conceptualizations of trust in scholarly research on business relationships. Journal of Business Ethics, 96, 657-668.

Central Intelligence Agency. 2012. The World Factbook: Afghanistan. Retrieved from https://www.cia.gov/library/publications/the-world-factbook/geos/af.html.

Chen, C., \& Tseng, Y. (2010). Quality evaluation of product reviews using an information quality framework. Decision Support Systems, In Press, 1-14.

Chen, J., \& Dibb, S. (2010). Consumer trust in the online retail context: Exploring the antecedents and consequences. Psychology \& Marketing, 27(4), 323-346.

Chiu, C., Hsu, M., \& Wang, E. (2006). Understanding knowledge sharing in virtual communities: An integration of social capital and social cognitive theories. Decision Support Systems, 42, 1872-1888.

Chow, W., \& Chan, L. (2008). Social network, social trust and shared goals in organizational knowledge sharing. Information \& Management, 45, 458-465.

Chung, S., \& Fink, E. (2008). The cognitive dynamics of beliefs: The effect of information on message processing. Human Communication Research, 34, 477504.

Cineplex, Inc. (2012). Retrieved from http://www.cineplex.com/default.aspx.

Cohen, J. (1992). A power primer. Psychological Bulletin, 112(1), 155-159.

Colquitt, J., Scott, B. \& LePine, J. (2007). Trust, trustworthiness, and trust propensity: A meta-analytic test of their unique relationships with risk taking and job performance. Journal of Applied Psychology, 92(4), 909-927.

Connolly-Ahern, C., \& Broadway, S. (2007). The importance of appearing competent: An analysis of corporate impression management strategies on the World Wide Web. Public Relations Review, 33, 343-345.

Cooper-Martin, E. (1992). Consumers and movies: Information sources for experiential products. Advances in Consumer Research, 19, 756-761.

Corritore, C., Kracher, B., \& Wiedenbeck, S. (2003). On-line trust: concepts, evolving themes, a model. International Journal of Human-Computer Studies, 58, 737-758.

Cowan, C. (1991). Coverage issues in sample surveys: A component of measurement error. Marketing Research, 3(2), 65-68.

Cox, J., Martinez, E., \& Quinlan, K. (2008). Blogs and the corporation: Managing the risk, reaping the benefits. Journal of Business Strategy, 29(3), 4-12. 
Creswell, J., \& Miller, D. (2000). Determining validity in qualitative inquiry. Theory into Practice, 39(3), 124-130.

Cyr, D. (2008). Modeling web site design across cultures: Relationships to trust, satisfaction, and e-loyalty. Journal of Management Information Systems, 24(4), 47-72.

Darke, P., \& Ritchie, R. (2007). The defensive consumer: Advertising deception, defensive processing, and distrust. Journal of Marketing Research, XLIV (February), 114-127.

Darley, W., \& Smith, R. (1993). Advertising claim objectivity: Antecedents and effects. Journal of Marketing, 57(4), 100-113.

Das, S., Echambadi, R., McCardle, M., \& Luckett, M. (2003). The effect of interpersonal trust, need for cognition, and social loneliness on shopping, information seeking and surfing on the Web. Marketing Letters, 14(3), 185-202.

Davies, M. (2001). Perceived information quality: An information processing perspective. Journal of International Consumer Marketing, 13(4), 29-50.

Davis, F. (1989). Perceived usefulness, perceived ease of use, and user acceptance of information technology. MIS Quarterly, 13(3), 319-340.

Day, G. (1971). Attitude change, media and word of mouth. Journal of Advertising Research, 11(6), 31-40.

de Janasz, S., \& Forret, M. (2008). Learning the art of networking: A critical skill for enhancing social capital and career success. Journal of Management Education, 32(5), 629-650.

de Matos, C., Henrique, J., \& Rossi, C. (2007). Service recovery paradox: A metaanalysis. Journal of Service Research, 10(1), 60-77.

DeCarlo, T. (2005). The effects of sales message and suspicion of ulterior motives on salesperson evaluation. Journal of Consumer Psychology, 15(3), 238-249.

Dewald, B. (2008). The role of the sommeliers and their influence on US restaurant wine sales. International Journal of Wine Business Research, 20(2), 111-123.

Dichter, E. (1966). How word-of-mouth advertising works. Harvard Business Review, 44(6), 147-166.

Dodd, T., Pinkleton, B., \& Gustafson, A. (1996). External information sources of product enthusiasts: Differences between variety seekers, variety neutrals, and variety avoiders. Psychology \& Marketing, 13(3), 291-304. 
Doney, P., \& Cannon, J. (1997). An examination of the nature of trust in buyer-seller relationships. Journal of Marketing, 61, 35-51.

Du, H., \& Wagner, C. (2006). Weblog success: Exploring the role of technology. International Journal of Human-Computer Studies, 64, 789-798.

Durrieu, F. (2005). The buying experience and impact of the expertise an exploratory approach. Paper presented at the $2^{\text {nd }}$ International Academy of Wine Business Research Conference, 2010, available at: http://academyofwinebusiness.com/wpcontent/uploads/2010/05/TheBuyingExperienceAndImpact.pdf.

Eagly, A., Wood, W., \& Chaiken, S. (1978). Causal inferences about communicators and their effect on opinion change. Journal of Personality and Social Psychology, $36(4), 424-435$.

Estelami, H. (2000). Competitive and procedural determinants of delight and disappointment in consumer complaint outcomes. Journal of Service Research, $2(3), 285-300$.

Federal Trade Commission. (2009). FTC Publishes Final Guides Governing Endorsements, Testimonials. http://www.ftc.gov/opa/2009/10/endortest.shtm.

Fein, S. (1996). Effects of suspicion on attributional thinking and the correspondence bias. Journal of Personality \& Social Psychology, 70(6), 1164-1184.

Ferguson, J., \& Ellen, P. (2006). The devil you know: Effects of suspicion of an information source's identity. Advances in Consumer Research, 33(1), 273-274.

Fieseler, C., Fleck, M., \& Meckel, M. (2009). Corporate social responsibility in the Blogosphere. Journal of Business Ethics, 91, 599-614.

Finkel, E., Rusbult, C., Kumashiro, M., \& Hannon, P. (2002). Dealing with betrayal in close relationships: Does commitment promote forgiveness? Journal of Personality and Social Psychology, 82(6), 956-974.

Fishbein, M., \& Ajzen, I. (1975). Belief, Attitude, Intention, and Behavior: An Introduction to Theory and Research. Reading, MA: Addison-Wesley Publishing Company.

Flanagin, A., \& Metzger, M. (2000). Perceptions of internet information credibility. Journalism \& Mass Communication Quarterly, 77(3), 515-540.

Flanagin, A., \& Metzger, M. (2007). The role of site attributes, user attributes, and information verification behaviors on the perceived credibility of web-based information. New Media \& Society, 9(2), 319-342.

Flavian, C., \& Guinaliu, M. (2006). Consumer trust, perceived security and privacy policy. Industrial Management \& Data Systems, 106(5), 601-620. 
Folkes, V. (1988). Recent attribution research and consumer behavior: A review and new directions. Journal of Consumer Research, 14(March), 548-565.

Ford, G., Smith, D., \& Swasy, J. (1988). An empirical test of the search, experience and credence attributes framework. Advances in Consumer Research, 15, 239-244.

Franke, G., Huhmann, B., \& Mothersbaugh, D. (2004). Information content and consumer readership of print ads: A comparison of search and experience products. Journal of the Academy of Marketing Science, 32(1), 20-31.

Friestad, M., \& Wright, P. (1994). The persuasion knowledge model: How people cope with persuasion attempts. Journal of Consumer Research, 23, 1-31.

Fritch, J., \& Cromwell, R. (2001). Evaluating Internet resources: Identity, affiliation, and cognitive authority in a networked world. Journal of the American Society for Information Science and Technology, 52(6), 499-507.

Funches, V. (2011). The consumer anger phenomena: Causes and consequences. Journal of Services Marketing, 25(6), 420-428.

Gardner, W., \& Martinko, M. (1988). Impression management in organizations. Journal of Management, 14(2), 321-338.

Gazley, A., Clark, G., \&. Sinha, A. (2011). Understanding preferences for motion pictures. Journal of Business Research, 64, 854-861.

Gelbrich, K. (2010). Anger, frustration, and helplessness after service failure: Coping strategies and effective informational support. Journal of the Academy of Marketing Science, 38, 567-585.

Gelbrich, K. (2011). I have paid less than you! The emotional and behavioral consequences of advantage price inequality. Journal of Retailing, 87(2), 207-224.

Gilbert, D., \& Malone, P. (1995). The correspondence bias. Psychological Bulletin, - 117(1), 21-38.

Grant, R., Clarke, R., \& Kyriazis, E. (2007). A review of factors affecting online consumer search behaviour from an information value perspective. Journal of Marketing Management, 23(5-6), 519-533.

Grégoire, Y., Laufer, D., \& Tripp, T. (2010). A comprehensive model of customer direct and indirect revenge: Understanding the effects of perceived greed and customer power. Journal of the Academy of Marketing Science, 38, 738-758.

Grégoire, Y., Tripp, T., \& Legoux, R. (2009). When customer love turns into lasting hate: The effects of relationship strength and time on customer revenge and avoidance. Journal of Marketing, 73(Nov.), 18-32. 
Gremler, D., \& Gwinner, K. (2000). Customer-employee rapport in service relationships. Journal of Service Research, 3(1), 82-104.

Guadagno, R., Okdie, B.; \& Eno, C. (2007). Who blogs? Personality predictors of blogging. Computers in Human Behavior. In press.

Gupta, P., Yadav, M., \& Varadarajan, R. (2009). How task-facilitative interactive tools foster buyers' trust in online retailers: A process view of trust development in the electronic marketplace. Journal of Retailing, 85(2), 159-176.

Ha, L., \& James, E. (1998). Interactivity reexamined: A baseline analysis of early business web sites. Journal of Broadcasting \& Electronic Media, 42(4), 456-474.

Haan, P., \& Berkey, C. (2002). A study of the believability of the forms of puffery. Journal of Marketing Communications, 8, 243-256.

Habel, C., Veale, R., \& Lu, V. (2010). I heard it through the grapevine! Exploring drivers of participation in virtual communities. Paper presented at the $5^{\text {th }}$ International Academy of Wine Business Research Conference, 8-10 February, 2010, Auckland, New Zealand, available at: http://academyofwinebusiness.com/wpcontent/uploads/2010/04/HabelVealeLu-I-Heard-it-through-the-Grapevine.pdf (March 30, 2011).

Hahn, K., \& Kim, J. (2009). The effect of offline brand trust and perceived internet confidence on online shopping intention in the integrated multi-channel context. International Journal of Retail \& Distribution Management, 37(2), 126-141.

Hair, J., Black, W., Babin, B., Anderson, R., \& Tatham, R. (2006). Multivariate Data Analysis $\left(6^{\text {th }}\right.$ ed.), Pearson Prentice Hall, Upper Saddle River, NJ.

Hanks, L., \& Matilla, A. (2012). Verifying the hedonic vs. utilitarian consumer attitudes categorization: The case of spas and salons. Managing Leisure, 17(1): 47-53.

Hayami, Y. (2009). Social capital, human capital and the community mechanism: Toward a conceptual framework for economists. Journal of Development Studies, 45(1), 96-123.

Hayes, A. (2012a). SPSS PROCESS documentation. Retrieved from http://www.afhayes.com/public/process.pdf.

Hayes, A. (2012b). An analytical primer and computational tool for observed variable mediation, moderation, and conditional process modeling. Retrieved from http://www.afhayes.com/public/process2012.pdf.

Heider, F. (1958). The Psychology of Interpersonal Relations. John Wiley \& Sons, Inc. 
Hennig-Thurau, T., \& Walsh, G. (2003). Electronic word-of-mouth: Motives for and consequences of reading customer articulations on the Internet. International Journal of Electronic Commerce, 8(2), 51-74.

Herdenstam, A., Hammarén, M., Ahlström, R., \& Wiktorsson, P. (2009). The professional language of wine: Perception, training and dialogue. Journal of Wine Research, 20(1), 53-84.

Heslop, L., Lu, I., \& Cray, D. (2009). Australian consumers' attitudes toward France a decade after nuclear testing: evidence of forgiveness. Journal of Consumer Behavior, 8, 192-210.

Hess, R., Ganesan, S., \& Klein, N. (2003). Service failure and recovery: The impact of relationship factors on customer satisfaction. Journal of the Academy of Marketing Science, 31(2), 127-145.

Hilligoss, B., \& Rieh, S. (2008). Developing a unifying framework of credibility assessment: Construct, heuristics, and interaction in context. Information Processing and Management, 44, 1467-1484.

Hirschman, E., \& Holbrook, M. (1982). Hedonic consumption: Emerging concepts, methods and propositions. Journal of Marketing, 46(Summer), 92-101.

Ho, J., \& Weinberg, C. (2011). Segmenting consumers of pirated movies. Journal of Consumer Marketing, 28(4), 252-260.

Hocutt, M., Bowers, M., \& Donavan, D. (2006). The art of service recovery: Fact or fiction? Journal of Services Marketing, 20(3), 199-207.

Hofstede, G. (1980). Culture's Consequences: International Differences in Work-Related Values. Beverly Hills, CA: Sage Publications, Inc.

Holbrook, M. (1999). Popular appeal versus expert judgments of motion pictures. Journal of Consumer Research, 26(2), 144-155.

Homer, P., \& Batra, R. (1994). Attitudinal effects of character-based versus competencebased negative political communications. Journal of Consumer Psychology, 3(2), 163-185.

Houston, M. (1979). Consumer evaluations of product information sources. Current Issues and Research in Advertising, 2(1), 135-144.

Hovland, C., Janis, I., \& Kelley, H. (1953). Communication and Persuasion. Yale University Press, New Haven, CT. 
Hsieh, C., Kuo, P., Yang, S., \& Lin, S. (2010). Assessing blog-user satisfaction using the expectation and disconfirmation approach. Computers in Human Behavior, 26, 1434-1444.

Huang, C., Shen, Y., Lin, H., \& Chang, S. (2007). Bloggers' motivations and behaviors: A model. Journal of Advertising Research, 47(4), 472-484.

Huang, L., Chou, Y., \& Lin, C. (2008). The influence of reading motives on the responses after reading blogs. CyberPsychology \& Behavior, 11(3), 351-355.

Huffaker, D. (2010). Dimensions of leadership and social influence in online communities. Human Communication Research, 36, 593-617.

Hunt, J., Smith, M., \& Kernan, J. (1985). The effects of expectancy disconfirmation and argument strength on message processing level: An application to personal selling. Advances in Consumer Research, 12(1), 450-454.

Hunt, S., Sparkman, R., \& Wilcox, J. (1982). The pretest in survey research: Issues and preliminary findings. Journal of Marketing Research, XIX(May), 269-273.

Iglesias, V. (2009). The attribution of service failures: Effects on consumer satisfaction. The Service Industries Journal, 29(2), 127-141.

Insko, C. (1967). Theories of Attitude Change. New York: Appleton-Century-Crofts.

Jacoby, J., Troutman, T., Kuss, A., \& Mazursky, D. (1986). Experience and expertise in complex decision making. Advances in Consumer Research, 13(1), 469-472.

Jain, S., \& Posavac, S. (2001). Prepurchase attribute verifiability, source credibility, and persuasion. Journal of Consumer Psychology, 11(3), 169-180.

Jo, S. (2004). Effect of content type on impact: Editorial vs. advertising. Public Relations Review, 30, 503-512.

Johnson, E., \& Russo, E. (1984). Product familiarity and learning new information. Journal of Consumer Research, 11(1), 542-550.

Johnson, T., \& Kaye, B. (2004). Wag the blog: How reliance on traditional media and the Internet influence credibility perceptions of weblogs among blog users. Journalism \& Mass Communication Quarterly, 81(3), $622-642$.

Jones, S., Aiken, K., \& Boush, D. (2009). Integrating Experience, Advertising, and Electronic Word of Mouth. Journal of Internet Commerce, 8(3-4), 246-267.

Jones, Q., Ravid, G., \& Rafaeli, S. (2004). Information overload and the message dynamics of online interaction spaces: A theoretical model and empirical exploration. Information Systems Research, 15(2), 194-210. 
Jover, A., Montes, F., \& Fuentes, M. (2004). Measuring perceptions of quality in food products: The case of red wine. Food Quality and Preference, 15, 453-469.

Kálamas, M., Laroche, M., \& Makdessian, L. (2008). Reaching the boiling point: Consumers' negative affective reactions to firm-attributed service failures. Journal of Business Research, 61, 813-824.

Karmarkar, U., \& Tormala, Z. (2010). Believe me, I have no idea what I'm talking about: The effects of source certainty on consumer involvement and persuasion. Journal of Consumer Research, 36(April), 1033-1049.

Kelley, H. (1973). The processes of causal attribution. American Psychologist, 28(2), 107-128.

Kent, M. (2008). Critical analysis of blogging in public relations. Public Relations Review, 34, 32-40.

Kim, D., \& Benbasat, I. (2003). Trust related arguments in Internet stores: A framework for evaluation. Journal of Electronic Commerce Research, 4(2), 49-64.

Kim, D., \& Benbasat, I. (2006). The effects of trust-assuring arguments on consumer trust in Internet stores: Application of Toulmin's model of argumentation. Information Systems Research, 17(3), 286-300.

Kim, P., Ferrin, D., Cooper, C., \& Dirks, K. (2004). Removing the shadow of suspicion: The effects of apology versus denial for repairing competence- versus integritybased trust violations. Journal of Applied Psychology, 89(1), 104-118.

Kirmani, A., \& Rao, A. (2000). No pain, no gain: A critical review of the literature on signalling unobservable product quality. Journal of Marketing, 64, 66-79.

Klein, L., \& Ford, G. (2003). Consumer search for information in the digital age: An empirical study of prepurchase search for automobiles. Journal of Interactive Marketing, 17(3), 29-49.

Kline, R. (2005). Principles and Practice of Structural Equation Modeling. $2^{\text {nd }}$ ed. New York: The Guilford Press.

Kolbe, R., \& Burnett, M. (1991). Content-analysis research: An examination of applications with directives for improving research reliability and objectivity. Journal of Consumer Research, 18, 243-250.

Koufaris, M., \& Hampton-Sosa, W. (2004). The development of initial trust in an online company by new customers. Information \& Management, 41, 377-397.

Kozinets, R. (2001). Utopian enterprise: Articulating the meaning of Star Trek's culture of consumption. Journal of Consumer Research, 28(June), 67-88. 
Kozinets, R. (2002). The field behind the screen: Using Netnography for marketing research in online communities. Journal of Marketing Research, 39(February), 61-72.

Kozinets, R., de Valck, K., Wojnicki, A., \& Wilner, S. (2010). Networked narratives: Understanding word-of-mouth marketing in online communities. Journal of Marketing, 74(March), 71-89.

Krippendorf, K. (2009). Testing the reliability of content analysis data: What is involved and why. Krippendorf, K. and Bock M. (Eds.), The Content Analysis Reader, SAGE Publications, Inc., Thousand Oaks, CA, 350-357.

Kumar, R., Novak, J., Raghavan, P., \& Tomkins, A. (2004). Structure and evolution of blogspace. Communications of the ACM, 47(12), 35-39.

Lankton, N., \& McKnight, D. (2011). What does it mean to trust Facebook? Examining technology and interpersonal trust beliefs. The DATA BASE for Advances in Information Systems, 42(2), 32-54.

Lastovicka, J. (1983). Convergent and discriminant validity of television commercial rating scales. Journal of Advertising, 12(2): 14-23.

Lau, D., Lam, L., \& Salamon, S. (2008). The impact of relational demographics on perceived managerial trustworthiness: Similarity or norms? The Journal of Social Psychology, 148(2), 187-208.

Lazarova, M., \& Taylor, S. (2009). Boundaryless careers, social capital, and knowledge management: Implications for organizational performance. Journal of Organizational Behavior, 30, 119-139.

Leavitt, C. (1970). A multidimensional set of rating scales for television commercials. Journal of Applied Psychology, 54, 427-429.

Lee, B., Ang, L. \& Dubelaar, C. (2005). Lemons on the web: A signaling approach to the problem of trust in Internet commerce. Journal of Economic Psychology, 26, 607623.

Lee, D., Im, S., \& Taylor, C. (2008). Voluntary self-disclosure of information on the Internet: A multimethod study of the motivations and consequences of disclosing information on blogs. Psychology \& Marketing, 25(7), 692-710.

Lee, M., \& Turban, E. (2001). A trust model for consumer Internet shopping. International Journal of Electronic Commerce, 6(1), 75-91.

Lee, M., \& Youn, S. (2009). Electronic word of mouth (eWOM): How eWOM platforms influence consumer product judgement. International Journal of Advertising, $28(3), 473-499$. 
Lee, M., Rodgers, S., \& Kim, M. (2009). Effects of valence and extremity of eWOM on attitude toward the brand and website. Journal of Current Issues and Research in Advertising, 31(2), 1-11.

Lee, S., Cotte, J., \& Noseworthy, T. (2010). The role of network centrality in the flow of consumer influence. Journal of Consumer Psychology, 20, 66-77.

Lee, S., Hwang, T., \& Lee, H. (2006). Corporate blogging strategies of the Fortune 500 companies. Management Decision, 44(3), 316-334.

Leenders, M., \& Eliashberg, J. (2011). The antecedents and consequences of restrictive age-based ratings in the global motion picture industry. International Journal of Research in Marketing, 28, 367-377.

Lenhart, A. and Fox, S. (2006). Bloggers: A portrait of the Internet's new storytellers. Pew Internet \& American Life Project, Washington, D.C.

Levin, D., \& Cross, R. (2004). The strength of weak ties you can trust: The mediating role of trust in effective knowledge transfer. Management Science, 50(11), 1477 1490.

Li, D., \& Walejko, G. (2008). Splogs and abandoned blogs. Information, Communication \& Society, 11(2), 279-296.

Li, D., Browne, G., \& Wetherbe, J. (2007). Online consumers' switching behaviour: A buyer-seller relationship perspective. Journal of Electronic Commerce in Organizations, 5(1), 30-42.

Li, F., \& Miniard, P. (2006). On the potential for advertising to facilitate trust in the advertised brand. Journal of Advertising, 35(4), 101-112.

Libai, B., Bolton, R., Bügel, M., de Ruyter, K., Götz, O., Risselada, H., \& Stephen, A. (2010). Customer-to-customer interactions: Broadening the scope of word of mouth research. Journal of Service Research, 13(3), 267-282.

Lim, B., \& Chung, C. (2011). The impact of word-of-mouth communication on attribute evaluation. Journal of Business Research, 64, 18-23.

Macintosh, G. (2009). Examining the antecedents of trust and rapport in services: Discovering new interrelationships. Journal of Retailing and Consumer Services, 16(4), 298-305.

Mack, R., Blose, J., \& Pan, B. (2008). Believe it or not: Credibility of blogs in tourism. Journal of Vacation Marketing, 14(2), 133-144.

Mangold, W., \& Faulds, D. (2009). Social media: The new hybrid element of the promotion mix. Business Horizons, 52(4), 357-365. 
Mattila, A. (2001). The impact of relationship type on customer loyalty in a context of service failures. Journal of Service Research, 4(2), 91-101.

Mayer, R., Davis, J., \& Schoorman, F. (1995). An integrative model of organizational trust. Academy of Management Review, 20(3), 709-734.

McGuire, W. (1973). Persuasion, resistance, and attitude change. In I. de Sola Pool, F. Frey, W. Schramm, N. Maccoby, \& E. Parkers (Eds.), Handbook of Communication (pp. 216-252). Chicago, Il: Rand McNally College Publishing Company.

McKnight, D., Choudhury, V., \& Kacmar, C. (2002). Developing and validating trust measures for e-Commerce: An integrative typology. Information Systems Research, 13(3), 334-359.

McMillan, S. (2000). The microscope and the moving target: The challenge of applying content analysis to the World Wide Web. Journalism \& Mass Communication, 77(1), 80-98.

Metzger, M. (2007). Making sense of credibility on the web: Models for evaluating online information and recommendations for future research. Journal of the American Society for Information Science and Technology, 58(13), 2078-2091.

Meyers-Levy, J., \& Malaviya, P. (1999). Consumers' processing of persuasive advertisements: An integrative framework of persuasion theories. Journal of Marketing, 63, 45-60.

Milne, G., Bahl, S., \& Rohm, A. (2008). Toward a framework for assessing covert marketing practices. Journal of Public Policy \& Marketing, 27(1), 57-62.

Mittal, B. (2004). Lack of attribute searchability: Some thoughts. Psychology \& Marketing, 21(6), 443-462.

Moon, S., Bergey, P., \& Iacobucci, D. (2010). Dynamic effects among movie ratings, movie revenues, and viewer satisfaction. Journal of Marketing, 74(January), 108121.

Moorman, C., Deshpandé, R., \& Zaltman, G. (1993). Factors affecting trust in market research relationships. Journal of Marketing, 57(January), 81-101.

Mourali, M., Laroche, M., \& Pons, F. (2005). Antecedents of consumer relative preference for interpersonal information sources in pre-purchase search. Journal of Consumer Behaviour, 4(5), 307-318.

Mũniz, A., \& O'Guinn, T. (2001). Brand community. Journal of Consumer Research, $27(4), 412-432$. 
Nadeau, J. (2007). Personality correlates of response to motivated-based branding appeals of developing countries. Retrieved from ProQuest Dissertations \& Theses. (NR33505)

Nahapiet, J., \& Ghoshal, S. (1998). Social capital, intellectual capital and the organizational advantage. Academy of Management Review, 23(2), 242-266.

Nardi, B., Schiano, D., Gumbrecht, M., \& Swartz, L. (2004). Why we blog. Communications of the ACM, 47(12): 41-46.

Nelson, P. (1970). Information and consumer behaviour. Journal of Political Economy, 78(2), 311-329.

Neuendorf, K. (2002). The Content Analysis Guidebook, Sage Publications, Inc. Thousand Oaks, CA.

Nicolaou, A., \& McKnight, D. (2006). Perceived information quality in data exchanges: Effects of risk, trust, and intention to use. Information Systems Research, 17(4), 332-351.

Obermiller, C., \& Spangenberg, E. (1998). Development of a scale to measure consumer skepticism toward advertising. Journal of Consumer Psychology, 7(2), 159-186.

Ok, C., Shanklin, C., \& Back, K. (2008). Generalizing survey results from student samples: Implications from service recovery research. Journal of Quality Assurance in Hospitality \& Tourism, 8(4), 1-23.

Oliver, M., \& Bartsch, A. (2010). Appreciation as audience response: Exploring entertainment gratifications beyond hedonism. Human Communication Research, $36,53-81$.

Oliver, M., \& Raney, A. (2011). Entertainment as pleasurable and meaningful: Identifying hedonic and eudaimonic motivations for entertainment consumption. Journal of Communication, 61, 984-1004.

Oliver, R. (1977). Effect of expectation and disconfirmation on postexposure product evaluations: An alternative explanation. Journal of Applied Psychology, 62(4), 480-486.

Olsen, G., \& Pracejus, J. (2004). Integration of positive and negative affective stimuli. Journal of Consumer Psychology, 14(4), 374-384.

Ostrom, T. (1969). The relationship between affective, behavioral, and cognitive components of attitude. Journal of Experimental Social Psychology, 5, 12-30.

Overby, J., \& Lee, E. (2006). The effects of utilitarian and hedonic online shopping value on consumer preference and intentions. Journal of Business Research, 59(10-11), 1160-1166. 
Pan, L., \& Chiou, J. (2011). How much can you trust online information? Cues for perceived trustworthiness of consumer-generated online information. Journal of Interactive Marketing, 25, 67-74.

Pavlou, P., \& Dimoka, A. (2006). The nature and role of feedback text comments in online marketplaces: Implications for trust building, price premiums, and seller differentiation. Information Systems Research, 17(4), 392-414.

Pentina, I., \& Taylor, D. (2010). Exploring source effects for online sales outcomes: The role of avatar-buyer similarity. Journal of Customer Behaviour, 9 (2), 135-150.

Perrouty, J., d'Hauteville, F., \& Lockshin, L. (2006). The influence of wine attributes on region of origin equity: An analysis of the moderating effect of consumer's perceived expertise. Agribusiness, 22(3), 323-341.

Peterson, R. (2007). Consumer magazine advertisement portrayal of models by race in the US: An assessment. Journal of Marketing Communications, 13(3), 199-211.

Petty, R., \& Cacioppo, J. (1984). Source factors and the Elaboration Likelihood Model of Persuasion. Advances in Consumer Research, 11(1), 668-672.

Pollach, I. (2008). Media richness in online consumer interactions: An exploratory study of consumer-opinion web sites. Information Resources Management Journal, 21(4), 49-65.

Pollay, R., \& Mittal, B. (1993). Here's the beef: Factors, determinants, and segments in consumer criticism of advertising. Journal of Marketing, 57(July), 99-114.

Ponterotto; J. (2005). Qualitative research in counseling psychology: A primer on research paradigms and philosophy of science. Journal of Counseling Psychology, 52(2), 126-136.

Potts, R., \& Belden, A. (2009). Parental guidance: A content analysis of MPAA motion picture rating justifications 1993-2005. Current Psychology, 28, 266-283.

Preacher, K., \& Hayes, A. (2004). SPSS and SAS procedures for estimating indirect effects in simple mediation models. Behavior Research Methods, Instruments, \& Computers, 36(4), 717-731.

Preacher, K., \& Hayes, A. (2008). Asymptotic and resampling strategies for assessing and comparing indirect effects in multiple mediator models. Behavior Research Methods, 40(3), 879-891.

Price, L., Feick, L., \& Higie, R. (1989). Preference heterogeneity and coorientation as determinants of perceived informational influence. Journal of Business Research, $19,227-242$. 
Priester, J., \& Petty, R. (2003). The influence of spokesperson trustworthiness on message elaboration, attitude strength, and advertising effectiveness. Journal of Consumer Psychology, 13(4), 408-421.

Raban, D., \& Rafaeli, S. (2006). The effect of source nature and status on the subjective value of information. Journal of the American Society for Information Science and Technology, 57(3), 321-329.

Ratchford, B., Talukdar, D., \& Lee, M. (2001). A model of consumer choice of the Internet as an information source. International Journal of Electronic Commerce, 5(3), 7-21.

Redden, J., \& Steiner, C. (2000). Fanatical consumers: Towards a framework for research. Journal of Consumer Marketing, 17(4), 322-337.

Richard, M., Chebat, J. Yang, Z. and Putrevu, S. (2010). A proposed model of online consumer behavior: Assessing the role of gender. Journal of Business Research, 63(9-10), 926-934.

Ridings, C., Gefen, D., \& Arinze, B. (2002). Some antecedents and effects of trust in virtual communities. Journal of Strategic Information Systems, 11, 271-295.

Riordan, C., \& Wayne, C. (2008). A review and examination of demographic similarity measures used to assess relational demography within groups. Organizational Research Methods, 11(3), 562-592.

Robertson, T., \& Rossiter, R. (1974). Children and commercial persuasion: An attribution theory analysis. Journal of Consumer Research, 1(June), 13-20.

Román, S. (2010). Relational consequences of perceived deception in online shopping: The moderating roles of type of product, consumer's attitude toward the Internet and consumer's demographics. Journal of Business Ethics, 95, 373-391.

Romani, S. (2006). Price misleading advertising: effects on trustworthiness toward the source of information and willingness to buy. Journal of Product \& Brand Management, 15(2), 130-138.

Rosenbloom, A. (2004). The Blogosphere. Communications of the $A C M, 47(12), 32-33$.

Schlosser, A. (2003). Experiencing products in the virtual world: The role of goal and imagery in influencing attitudes versus purchase intentions. Journal of Consumer Research, 30(2), 184-198.

Schlosser, A. (2011). Can including pros and cons increase the helpfulness and persuasiveness of online reviews? The interactive effects of ratings and arguments. Journal of Consumer Psychology, 21, 226-239. 
Schlosser, A., White, T., \& Lloyd, S. (2006). Converting web site visitors into buyers: How web site investment increases consumer trusting beliefs and online purchase intentions. Journal of Marketing, 70, 133-148.

Schmidt, J. (2007). Blogging practices: An analytical framework. Journal of ComputerMediated Communication, 12, 1409-1427.

Schoorman, F., Mayer, R., \& Davis, J. (2007). An integrative model of organizational trust: Past, present, and future. Academy of Management Review, 32(2), 344-354.

Sindhav, B., \& Adidam, P. (2012). Hedonic and utilitarian values of a service experience with a nonprofit: The role of identification. International Management Review, $8(1), 37-43$.

Smith, A., Bolton, R., \& Wagner, J. (1999). A model of customer satisfaction with service encounters involving failure and recovery. Journal of Marketing Research, 36(3), 356-372.

Smith, D., Menon, S., \& Sivakumar, K. (2005). Online peer and editorial recommendations, trust, and choice in virtual markets. Journal of Interactive Marketing, 19(3), 15-37.

Smith, R.., \& Swinyard, W. (1988). Cognitive response to advertising and trial: Belief strength, belief confidence and product curiosity. Journal of Advertising, 17(3), 314.

Sprott, D. (2008). The policy, consumer, and ethical dimensions of covert marketing: An introduction to the special section. Journal of Public Policy \& Marketing, 27(1), 4-6.

Smith, S., Fisher, D., \& Cole, S. (2007). The lived meanings of fanaticism: Understanding the complex role of labels and categories in defining the self in consumer culture. Consumption Markets \& Culture, 10(2), 77-94.

Stillwell, A., Baumeister, R., \& Del Priore, R. (2008). We're all victims here: Toward a psychology of revenge. Basic \& Applied Social Psychology, 30(3), 253-263.

Sussman, S., \& Siegal, W. (2003). Informational influence in organizations: An integrated approach to knowledge adoption. Information Systems Research, 14(1), 47-65.

Szulanski, G., Cappetta, R., \& Jensen, R. (2004). When and how trustworthiness matters: Knowledge transfer and the moderating effect of causal ambiguity. Organization Science, 15(5), 600-613.

Tormala, Z., \& Petty, R. (2004). Source credibility and attitude certainty: A metacognitive analysis of resistance to persuasion. Journal of Consumer Psychology, 14(4), 427-442. 
Thach, L. (2010). Wine blogs: Expressing diverse wine opinions in a new realm of online wine relationship marketing. Paper presented at the $5^{\text {th }}$ International Academy of Wine Business Research Conference, 8-10 February, 2010, Auckland, New Zealand, available at: http://academyofwinebusiness.com/wpcontent/uploads/2010/04/Thach-Wine-Blogs.pdf (March 30, 2011).

Thorne, S., \& Bruner, G. (2006). An exploratory investigation of the characteristics of consumer fanaticism. Qualitative Market Research: An International Journal, $9(1), 51-72$.

Thorsten Hennig-Thurau, F., Gwinner, K., Walsh, G., \& Gremler, D. (2004). Electronic word-of-mouth via consumer-opinion platforms: What motivates consumers to articulate themselves on the Internet? Journal of Interactive Marketing, 18(1), 3852.

Trammell, K., \& Keshelashvili, A. (2005). Examining the new influencers: A selfpresentation of A-list blogs. Journalism \& Mass Communication Quarterly, 82(4), 968-982.

Trusov, M., Bucklin, R., \& Pauwels, K. (2009). Effects of word-of-mouth versus traditional marketing: Findings from an internet social networking site. Journal of Marketing, 73(September), 90-102.

Tsai, W., \& Ghoshal, S. (1998). Social capital and value creation: The role of intrafirm networks. Academy of Management Journal, 41(4), 464-476.

Tseng, S. and Fogg, B. (1999). Credibility and computing technology. Communications of the $A C M, 42(5), 39-44$.

Urban, G., Amyx, C., \& Lorenzon, A. (2009). Online trust: state-of-the-art, new frontiers, and research potential. Journal of Interactive Marketing, 23, 179-190.

van Heerden, G., Salehi-Sangari, E., Pitt, L., \& Caruana, A. (2009). Do b2b bloggers believe blogs? PR insights on blogger skepticism. Asia Pacific Public Relations Journal, 10, 123-132.

Varela-Neira, C., Vázquez-Casielles, R., \& Iglesias, V. (2010). Lack of preferential treatment: Effects on dissatisfaction after a service failure. Journal of Service Management, 21(1), 45-68.

Wang, A. (2005). Integrating and comparing others' opinions: The effects of third-party endorsements on online purchasing. Journal of Website Promotion, 1(1), 105-129.

Wang, H., \& Doong, H. (2010). Argument form and spokesperson type: The recommendation strategy of virtual salespersons. International Journal of Information Management, 30, 493-501. 
Wang, S., \& Huff, L. (2007). Explaining buyers' responses to sellers' violation of trust. European Journal of Marketing, 41(9/10), 1033-1052.

Wang, Y., \& Sun, S. (2010). Assessing beliefs, attitudes, and behavioural responses toward online advertising in three countries. International Business Review, 19, 333-344.

Wang, Y., Wu, S., Lin, H., \& Wang, Y. (2011). The relationship of service failure severity, service recovery justice and perceived switching costs with customer loyalty in the context of e-tailing. International Journal of Information Management, 31, 350-359.

Wei, M., Fischer, E., \& Main, K. (2008). An examination of the effects of activating persuasion knowledge on consumer response to brands engaging in covert marketing. Journal of Public Policy \& Marketing, 27(1), 34-44.

Weiner, B. (2000). Attributional thoughts about consumer behavior. Journal of Consumer Research, 27(3), 382-387.

Wells, W. (1993). Discovery-oriented consumer research. Journal of Consumer Research, 19, 489-504.

Wetzer, I., Zeelenberg, M., \& Pieters, R. (2007). "Never eat in that restaurant, I did!": Exploring why people engage in negative word-of-mouth communication. Psychology \& Marketing, 24(8), 661-680.

Williams, M. (2001). In whom we trust: Group membership as an affective context for trust development. Academy of Management Review, 26(3), 377-396.

Word of Mouth Marketing Association. (2007). WOM 101. Retrieved from http://womma.org/wom101/wom101.pdf. [Accessed 5 March 2011].

Wu, J., \& Tsang, A. (2008). Factors affecting members' trust belief and behaviour intention in virtual communities. Behaviour \& Information Technology, 27(2), 115-125.

Xie, Y., \& Peng, S. (2009). How to repair customer trust after negative publicity: The roles of competence, integrity, benevolence, and forgiveness. Psychology \& Marketing, 26(7), 572-589.

Yang, W., Huang, Y., \& Lin, Y. (2009). Study of comments on official movie blogs. International Journal of Electronic Business Management, 7(3), 201-210.

Yaniv, I., Choshen-Hillel, S., \& Milyavsky, M. (2011). Receiving advice on matters of taste: Similarity, majority influence, and taste discrimination. Organizational Behavior and Human Decision Processes, 115, 111-120. 
Yousafzai, S., Pallister, J., \& Foxall, G. (2003). A proposed model of e-trust for electronic banking. Technovation, 23, 847-860.

Zaichkowsky, J. (1985a). Familiarity: Product use, involvement or expertise? Advances in Consumer Research, 12(1), 296-299.

Zaichkowsky, J. (1985b). Measuring the involvement construct. Journal of Consumer Research, 12, 341-352.

Zeelenberg, M., van Dijk, W., Manstead, A., \& van der Pligt, J. (2000). On bad decisions and disconfirmed expectancies: The psychology of regret and disappointment. Cognition and Emotion, 14(4), 521-541.

Zeithaml, V., Berry, L., \& Parasuraman, A. (1993). The nature and determinants of customer expectations of service. Journal of the Academy of Marketing Science, $21(1), 1-12$.

Zhu, Y., Basil, D., \& Hunter, G. (2009). The extended website stage model: A study of Canadian winery websites. Canadian Journal of Administrative Sciences, 26(4), 286-300. 


\section{APPENDICES}


CHAPTER 3 APPENDIX

Appendix 3.1: Operationalizations of Ability, Benevolence, and Integrity Signals

\begin{tabular}{|c|c|}
\hline Ability & \\
\hline $\begin{array}{l}\text { Access to special sources } \\
\text { of information }\end{array}$ & $\begin{array}{l}\text { Code when blog makes use of guest writers with special } \\
\text { expertise, etc. }\end{array}$ \\
\hline $\begin{array}{l}\text { Amount of time, effort, } \\
\text { and money invested in } \\
\text { interest in wine }\end{array}$ & $\begin{array}{l}\text { Code when blogger mentions dedication to wine, extensive } \\
\text { travelling to wine regions, frequent attendance at wine } \\
\text { tastings, etc. }\end{array}$ \\
\hline $\begin{array}{l}\text { Amount of wine } \\
\text { education }\end{array}$ & $\begin{array}{l}\text { Code when blogger indicates that he or she undertook } \\
\text { some type of formal wine education (to become a } \\
\text { Sommelier, etc.) }\end{array}$ \\
\hline $\begin{array}{l}\text { Awards for writing about } \\
\text { wine }\end{array}$ & $\begin{array}{l}\text { Code when blogger indicates that he or she has received } \\
\text { (or been nominated for) one or more awards for writing } \\
\text { about wine. Example awards include James Beard awards } \\
\text { or American Wine Blog awards. }\end{array}$ \\
\hline $\begin{array}{l}\text { Heavy current product } \\
\text { usage }\end{array}$ & $\begin{array}{l}\text { Code when blogger indicates that he or she is a frequent, } \\
\text { current consumer of wine. }\end{array}$ \\
\hline Institutional links & $\begin{array}{l}\text { Code when blogger mentions an association with some } \\
\text { type of organization from which product knowledge could } \\
\text { be obtained (e.g., The American Association of Wine } \\
\text { Economists). }\end{array}$ \\
\hline $\begin{array}{l}\text { Links to informational } \\
\text { web sites that are not } \\
\text { blogs }\end{array}$ & $\begin{array}{l}\text { Code when blogger provides links to informational web } \\
\text { sites related to wine (e.g., Wine Research Centre - } \\
\text { http://www.landfood.ubc.ca/wine/). }\end{array}$ \\
\hline Links to other wine blogs & $\begin{array}{l}\text { Code when blogger provides links to other wine blogs } \\
\text { (e.g., blogroll). }\end{array}$ \\
\hline $\begin{array}{l}\text { Longstanding product } \\
\text { usage }\end{array}$ & $\begin{array}{l}\text { Code when blogger indicates that he or she has consumed } \\
\text { wine over a long period of time. }\end{array}$ \\
\hline Non-wine education & $\begin{array}{l}\text { Code when blogger mentions his or her education that is } \\
\text { not specific to wine (e.g., journalism degree). }\end{array}$ \\
\hline Other relevant resources & $\begin{array}{l}\text { Code when blogger mentions that he or she has access to } \\
\text { relevant resources that could be used to provide product } \\
\text { information (e.g., subscribes to relevant periodicals, has } \\
\text { extensive wine collection, etc.) }\end{array}$ \\
\hline $\begin{array}{l}\text { Other sources of } \\
\text { expertise }\end{array}$ & $\begin{array}{l}\text { Code when blogger indicates sources of expertise (skills, } \\
\text { knowledge, etc.) not captured by other ability signals. }\end{array}$ \\
\hline Overall intelligence & $\begin{array}{l}\text { Code when blogger mentions overall intelligence or } \\
\text { cognitive ability (e.g., has interest in obscure, complicated } \\
\text { matters) }\end{array}$ \\
\hline References & $\begin{array}{l}\text { Code when blogger posts references from others who have } \\
\text { benefited from information provided by him or her. }\end{array}$ \\
\hline Wine training & $\begin{array}{l}\text { Code when blogger indicates that he or she has undergone } \\
\text { wine training (not formal education). }\end{array}$ \\
\hline
\end{tabular}




\begin{tabular}{|c|c|}
\hline Work experience & $\begin{array}{l}\text { Code when blogger indicates that he or she has relevant } \\
\text { work experience. Examples of relevant work experience } \\
\text { could be working as a wine salesperson, a grape grower, a } \\
\text { Sommelier, etc. }\end{array}$ \\
\hline \multicolumn{2}{|l|}{ Benevolence } \\
\hline $\begin{array}{l}\text { Desire to do good things } \\
\text { rather than simply } \\
\text { making a profit }\end{array}$ & $\begin{array}{l}\text { Code when blogger argues that he or she is somehow } \\
\text { genuinely interested in helping readers (rather than making } \\
\text { a profit) and/or has some type of emotional attachment to } \\
\text { readers. This form of benevolence is reader focused. }\end{array}$ \\
\hline $\begin{array}{l}\text { Other people recognize } \\
\text { the blogger for doing } \\
\text { good things }\end{array}$ & $\begin{array}{l}\text { Code when blogger argues that he or she is recognized by } \\
\text { others (e.g., blog readers, customers, etc.) for doing good } \\
\text { things. This form of benevolence is reader focused. }\end{array}$ \\
\hline $\begin{array}{l}\text { Other types of } \\
\text { benevolence }\end{array}$ & $\begin{array}{l}\text { Code when blogger argues a more generalized form of } \\
\text { benevolence (e.g., desire to protect the environment, give } \\
\text { to charity, etc.) }\end{array}$ \\
\hline \multicolumn{2}{|l|}{ Integrity } \\
\hline Blogger is accurate & $\begin{array}{l}\text { Code when blogger argues that he or she provides truthful } \\
\text { information and does not mislead readers intentionally. }\end{array}$ \\
\hline Blogger is fair & $\begin{array}{l}\text { Code when blogger argues that he or she is fair by } \\
\text { considering multiple perspectives and by remaining open } \\
\text { to new wine experiences, etc. }\end{array}$ \\
\hline Blogger is trustworthy & $\begin{array}{l}\text { Code when blogger makes an explicit reference to being } \\
\text { trustworthy. An example reference could be "Readers can } \\
\text { trust me to only recommend wines that I would feel } \\
\text { comfortable serving to my friends, family, and associates." }\end{array}$ \\
\hline Blogger is unbiased & $\begin{array}{l}\text { Code when blogger argues that he or she is not biased in } \\
\text { providing product information by, perhaps, showing that } \\
\text { he or she has no financial interest in the brands being } \\
\text { reviewed or by arguing that the basis for product reviews is } \\
\text { common to all consumers (rather than just those with } \\
\text { special training, etc.) }\end{array}$ \\
\hline $\begin{array}{l}\text { Blogger tells the whole } \\
\text { story }\end{array}$ & $\begin{array}{l}\text { Code when blogger argues that he or she does not hold } \\
\text { information from readers, is comfortable admitting to } \\
\text { biases, and spends time investigating all relevant aspects of } \\
\text { a particular issue or product. }\end{array}$ \\
\hline $\begin{array}{l}\text { Blogger will not exploit } \\
\text { vulnerabilities of } \\
\text { information seekers }\end{array}$ & $\begin{array}{l}\text { Code when blogger argues that he or she does not use his } \\
\text { or her ability (which is asymmetric with respect to blog } \\
\text { readers) or credentials in an exploitative fashion. }\end{array}$ \\
\hline Other types of integrity & $\begin{array}{l}\text { Code when other forms of integrity are indicated by the } \\
\text { blogger. These forms of integrity should nonetheless. } \\
\text { pertain to the honesty and sincerity of the blogger. }\end{array}$ \\
\hline
\end{tabular}


CHAPTER 4 APPENDIX

\section{Appendix 4.1: Study 2 Questionnaire Items}

\begin{tabular}{|c|c|}
\hline Constructs & Measures \\
\hline $\begin{array}{l}\text { Topic-area involvement: The extent } \\
\text { to which the blog topic area is } \\
\text { personally relevant is proposed to be } \\
\text { measured with six items adapted } \\
\text { from Zaichkowsky (1985b). } \\
\text { Description: } 7 \text {-point Likert scale on } \\
\text { which respondents indicate the extent } \\
\text { to which they strongly disagree (1) or } \\
\text { strongly agree (7) with each measure } \\
\text { concerning the blog topic area. }\end{array}$ & $\begin{array}{l}\text { I put more effort into keeping up with (the } \\
\text { subject area) than I put into most other areas. } \\
\text { Knowing about the latest developments in } \\
\text { (subject area) is important to me. } \\
\text { I would be very disappointed if I made a bad } \\
\text { decision on a (subject area) issue that cost me } \\
\text { time or money. } \\
\text { The (subject area) decisions I make are a } \\
\text { reflection of my knowledge and expertise. } \\
\text { My friends rely on my knowledge of (subject } \\
\text { area) issues. } \\
\text { I would be embarrassed if others knew I made a } \\
\text { mistake about a (subject area) issue. }\end{array}$ \\
\hline $\begin{array}{l}\text { Motivations for reading blogs: } \\
\text { Respondents will self-report their } \\
\text { motivations for reading blogs on } 18 \\
\text { measures. } \\
\text { Description: 7-point Likert scale on } \\
\text { which respondents indicate the extent } \\
\text { to which each of } 18 \text { reasons for } \\
\text { reading blogs is very unimportant (1) } \\
\text { or extremely important (7) to them. } \\
\text { Question stem: "The next section } \\
\text { asks about your reasons for reading } \\
\text { blogs about the blog area you } \\
\text { indicated. On a scale of } 1-7, \text { rate the } \\
\text { importance of each of the following } \\
\text { reasons for reading the blogs you do } \\
\text { about this topic? Choose a number } \\
\text { from } 1 \text { - very unimportant to } 7- \\
\text { extremely important for each of the } \\
\text { following reasons." }\end{array}$ & $\begin{array}{l}\text { To increase my knowledge and expertise } \\
\text { To get information that is freely available } \\
\text { To get the best value for the time or money I } \\
\text { spend } \\
\text { To get information without spending any money } \\
\text { To access links to websites of interest } \\
\text { To get answers to my questions } \\
\text { To read about the topic of my passion } \\
\text { To connect with others who share my interests } \\
\text { To be part of a community with similar interests } \\
\text { To learn to appreciate what is important about the } \\
\text { topic } \\
\text { To hear the opinions of many other people } \\
\text { It's entertaining and fun } \\
\text { To make new blog friends with shared interests } \\
\text { To hear what others think } \\
\text { To get help because I don't know much about the } \\
\text { topic } \\
\text { To improve the offerings available on the market } \\
\text { To read conversations and interactions } \\
\text { To engage in lively discussions about the topic }\end{array}$ \\
\hline
\end{tabular}




\begin{tabular}{|c|c|}
\hline Constructs & Measures \\
\hline $\begin{array}{l}\text { Blogger characteristics: } 33 \text { items } \\
\text { will be used to assess the perceived } \\
\text { characteristics of topic-area bloggers. } \\
\text { Description: 7-point Likert scale on } \\
\text { which respondents indicate the extent } \\
\text { to which each of } 33 \text { blogger } \\
\text { characteristics is very unimportant } \\
\text { (1) or extremely important (7) to } \\
\text { them. } \\
\text { Question stem: "The next section } \\
\text { asks about why you read your } \\
\text { favourite blog(s) on the topic area } \\
\text { you indicated. } \\
\text { On a scale of 1-7, how important is } \\
\text { each of the following } \\
\text { CHARACTERISTICS OF THE } \\
\text { BLOG CREATOR (by blog creator, } \\
\text { we mean the person who determines } \\
\text { the content of the blog) in } \\
\text { determining whether or not YOU } \\
\text { read their blog? (Choose a number } \\
\text { from } 1 \text { - very unimportant to } 7 \text { - } \\
\text { extremely important for each of the } \\
\text { following statements.)" }\end{array}$ & $\begin{array}{l}\text { Engagement knowledge } \\
\text { Has wide-ranging experience } \\
\text { Has extensive experience in the area } \\
\text { Has resources that that others do not } \\
\text { Is heavily involved in the area } \\
\text { Is passionate about the topic } \\
\text { Is very critical in discussing the topic } \\
\text { Is very engaged in the topic field } \\
\text { Is interested in topic-area improvements } \\
\text { Spends a lot of time studying the topic } \\
\text { Knows about unusual aspects of the topic } \\
\text { Uses correct terminology } \\
\text { Authoritative knowledge } \\
\text { Has a business on the topic area } \\
\text { Has one or more university degrees } \\
\text { Has specialized education in the topic area } \\
\text { Has won awards related to the area } \\
\text { Has written a book about the topic } \\
\text { Teaches courses on the topic } \\
\text { Works in the industry } \\
\text { Writes about the topic in mainstream media } \\
\text { Blogger's social network connections } \\
\text { Attends major events on the topic area } \\
\text { Has contacts with other topic experts } \\
\text { Promotes good social causes } \\
\text { Shows concern for me as a reader } \\
\text { Says their information is trustworthy } \\
\text { Says they are accurate, fair and unbiased } \\
\text { Says they are trustworthy } \\
\text { Answers questions posed on their blog } \\
\text { Is concerned with the environment } \\
\text { Has no commercial interest in the topic area } \\
\text { Responds to posted comments on their blog } \\
\text { Seems sincere and honest } \\
\text { Shom to }\end{array}$ \\
\hline
\end{tabular}




\begin{tabular}{|c|c|}
\hline Constructs & Measures \\
\hline $\begin{array}{l}\text { Blog characteristics: } 25 \text { items will } \\
\text { be used to assess the perceived } \\
\text { characteristics of topic-area blogs. } \\
\text { Description: } 7 \text {-point Likert scale on } \\
\text { which respondents indicate the extent } \\
\text { to which each of } 25 \text { blog } \\
\text { characteristics is very unimportant } \\
\text { (1) or extremely important (7) to } \\
\text { them. } \\
\text { Question stem: "On a scale of } 1-7 \text {, } \\
\text { how important do you think each of } \\
\text { the following characteristics ABOUT } \\
\text { A BLOG are in determining its } \\
\text { successfulness with you, i.e., you } \\
\text { will read it and return to it? (Choose } \\
\text { a number from } 1 \text { - very unimportant } \\
\text { to } 7 \text { - extremely important for each } \\
\text { of the following statements.)" }\end{array}$ & $\begin{array}{l}\text { Instrumental improvements to topic } \\
\text { Has won awards } \\
\text { Improves outcomes of topic-area decisions } \\
\text { Improves topic-area value that people receive } \\
\text { Increases topic-area knowledge effectively } \\
\text { Is helping create a better industry } \\
\text { Is well written } \\
\text { Makes better offerings known and available } \\
\text { Involvement of topic-area community } \\
\text { Has created a strong sense of community } \\
\text { Has guest bloggers } \\
\text { Has many comments posted by readers } \\
\text { Reader comments are very informative } \\
\text { Reader comments express a range of opinions } \\
\text { Reader comments lead to lively discussions } \\
\text { Freshness of the reading experience } \\
\text { Has information not available elsewhere } \\
\text { Has information which is unique } \\
\text { Is updated frequently } \\
\text { Is visually attractive } \\
\text { Site is well designed } \\
\text { Connected to topic-area materials } \\
\text { Has a lot of links } \\
\text { Has lots of visual materials } \\
\text { Has many resources on the site } \\
\text { Has very high quality links } \\
\text { Uses highly advanced technology } \\
\text { Information quality } \\
\text { Information is accurate } \\
\text { Information is easy to understand }\end{array}$ \\
\hline
\end{tabular}




\begin{tabular}{|l|l|}
\hline Constructs & Measures \\
\hline Topic-area outcomes: 9 items will & Knowledge outcome \\
be used to assess perceived & I am a better judge of issues on the topic \\
achievement of desirable topic-area & I am better at finding good topic-area offerings \\
outcomes as a result of reading blogs. & I am satisfied with the topic-area blogs I read \\
& I get better quality for my time or money \\
Description: 7-point Likert scale on & I get better value for the money I spend \\
which respondents indicate from 1 & My appreciation of the topic has increased \\
(Not at all) to 7 (A great deal) the & My knowledge of the topic has increased \\
extent to which they have realized & \\
each of 9 topic-area outcomes as a & Community engagement outcome \\
result of the topic-area blogs they & I can relate to the others in the community \\
read. & I feel like I am a part of the community \\
$\begin{array}{l}\text { Question stem: 'Next, a few scales } \\
\text { about the OUTCOMES FOR YOU }\end{array}$ & \\
OF BLOG READING. Please choose & \\
a number for each of the following \\
outcomes to indicate to what extent \\
each has resulted from the blogs you \\
read, where 1 is 'not at all' and 7 is \\
'a great deal.' Because of the blogs I \\
read:"
\end{tabular}




\section{CHAPTER 5 APPENDICES}

\section{Appendix 5.1: Movie Pretest Rating Scale}

INSTRUCTIONS: Please indicate your own opinion from 0 (Not important at all) to 6 (Very important) of how important it is to your overall evaluation of a movie that it is:

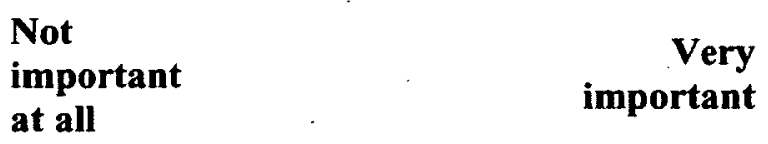

Fun $\begin{array}{llllllll}0 & 1 & 2 & 3 & 4 & 5 & 6\end{array}$

$\begin{array}{llllllll}\text { Entertaining } & 0 & 1 & 2 & 3 & 4 & 5 & 6\end{array}$

$\begin{array}{llllllll}\text { Exciting } & 0 & 1 & 2 & 3 & 4 & 5 & 6\end{array}$

$\begin{array}{llllllll}\text { Energetic } & 0 & 1 & 2 & 3 & 4 & 5 & 6\end{array}$

$\begin{array}{llllllll}\text { An "edge-of-your-seat" experience } & 0 & 1 & 2 & 3 & 4 & 5 & 6\end{array}$

$\begin{array}{llllllll}\text { A "heart-pounding" experience } & 0 & 1 & 2 & 3 & 4 & 5 & 6\end{array}$

Sensitive $\begin{array}{llllllll}0 & 1 & 2 & 3 & 4 & 5 & 6\end{array}$

Tender $\begin{array}{llllllll}0 & 1 & 2 & 3 & 4 & 5 & 6\end{array}$

$\begin{array}{lllllllll}\text { Romantic } & 0 & 1 & 2 & 3 & 4 & 5 & 6\end{array}$

$\begin{array}{llllllll}\text { Violent } & 0 & 1 & 2 & 3 & 4 & 5 & 6\end{array}$

$\begin{array}{llllllll}\text { Brutal } & 0 & 1 & 2 & 3 & 4 & 5 & 6\end{array}$

$\begin{array}{llllllll}\text { Factual } & 0 & 1 & 2 & 3 & 4 & 5 & 6\end{array}$

$\begin{array}{llllllll}\text { Educational } & 0 & 1 & 2 & 3 & 4 & 5 & 6\end{array}$

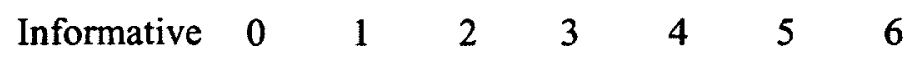

$\begin{array}{lllllllll}\text { Based on real life } & 0 & 1 & 2 & 3 & 4 & 5 & 6\end{array}$

$\begin{array}{llllllll}\text { Authentic } & 0 & 1 & 2 & 3 & 4 & 5 & 6\end{array}$

$\begin{array}{llllllll}\text { A true story } & 0 & 1 & 2 & 3 & 4 & 5 & 6\end{array}$

$\begin{array}{llllllll}\text { Good } & 0 & 1 & 2 & 3 & 4 & 5 & 6\end{array}$

$\begin{array}{llllllll}\text { Interesting } & 0 & 1 & 2 & 3 & 4 & 5 & 6\end{array}$

$\begin{array}{llllllll}\text { Likeable } & 0 & 1 & 2 & 3 & 4 & 5 & 6\end{array}$ 


\section{Appendix 5.2: “About Me" Statement and Movie Review Pretest Instrument}

\section{INTRODUCTORY INFORMATION}

Imagine that you and a friend have plans to see a movie at the theatre and that it is your turn to choose the movie. The movie that fits your schedules is about an American soldier, an Afghan aid worker, and children living in an orphanage in modern-day Afghanistan. You are evaluating the likelihood that you and your friend would rate this movie positively after seeing it. You look for information about the movie and have come across a movie review posted on a BLOG.

\section{THE BLOG}

A statement taken directly from the blog is provided below:

\begin{tabular}{|l||}
\hline ABOUT ME \\
I have a great passion for movies and I watch hundreds of them across all genres \\
every year. Knowing about the latest developments in movies is important to me, so I \\
watch them, read all the Hollywood gossip, and engage in movie-related discussions \\
with other movie fans as much as I can. I put more effort into keeping up with the \\
latest developments in movies than I put into most other things, since the movie \\
decisions I make reflect my knowledge. I am known for my movie knowledge, and I \\
would be very disappointed if I made a bad movie decision that cost me time and \\
money. \\
(Disclosure: I am compensated with movie tickets, merchandise, and other \\
promotional material by the makers of this movie for writing and posting reviews of \\
its movies on my blog.)
\end{tabular}

ABOUT ME
I have great expertise and a specialized university education on the ongoing
situation in Afghanistan and my journal papers on the ongoing conditions in
Afghanistan have received awards for research excellence. Knowing about the
latest developments in Afghanistan is important to me, so I research, attend
conferences, and monitor official reports as much as I can. I put more effort into
keeping up with the Afghanistan situations than I put into most other things. I
teach university courses, study extensively, and advise international organizations
about current Afghanistan conditions. I also write about these conditions in the
mainstream media and have written an authoritative book about them, too.
(Disclosure: I am compensated with movie tickets, merchandise, and other
promotional material by the makers of this movie for writing and posting reviews
of its movies on my blog.)


INSTRUCTIONS: Please indicate your opinion from 0 (Not at all) to 6 (Very much) of how much the blog Not Very statement:

Contains an appropriate amount of information about the blogger

Contains confident statements about the blogger

Contains assertive statements about the blogger

Contains interesting statements about the blogger

Contains strong statements about the blogger

Contains favourable statements about the blogger

Contains positive statements about the blogger

Contains complete statements about the blogger

Contains helpful statements about the blogger

Contains informative statements about the blogger

Contains surprising statements about the blogger

Contains unexpected statements about the blogger

Contains suspicious statements about the blogger

Is easy to follow

Is easy to understand

Is enjoyable to read

Is entertaining to read

Is honest

Is sincere

Is believable

Is convincing

Is truthful

Is credible

Is persuasive

Is comparable to statements people make on blogs about themselves

$\begin{array}{lllllll}0 & 1 & 2 & 3 & 4 & 5 & 6 \\ 0 & 1 & 2 & 3 & 4 & 5 & 6 \\ 0 & 1 & 2 & 3 & 4 & 5 & 6 \\ 0 & 1 & 2 & 3 & 4 & 5 & 6 \\ 0 & 1 & 2 & 3 & 4 & 5 & 6 \\ 0 & 1 & 2 & 3 & 4 & 5 & 6 \\ 0 & 1 & 2 & 3 & 4 & 5 & 6 \\ 0 & 1 & 2 & 3 & 4 & 5 & 6 \\ 0 & 1 & 2 & 3 & 4 & 5 & 6 \\ 0 & 1 & 2 & 3 & 4 & 5 & 6 \\ 0 & 1 & 2 & 3 & 4 & 5 & 6 \\ 0 & 1 & 2 & 3 & 4 & 5 & 6 \\ 0 & 1 & 2 & 3 & 4 & 5 & 6 \\ 0 & 1 & 2 & 3 & 4 & 5 & 6 \\ 0 & 1 & 2 & 3 & 4 & 5 & 6 \\ 0 & 1 & 2 & 3 & 4 & 5 & 6 \\ 0 & 1 & 2 & 3 & 4 & 5 & 6 \\ 0 & 1 & 2 & 3 & 4 & 5 & 6 \\ 0 & 1 & 2 & 3 & 4 & 5 & 6 \\ 0 & 1 & 2 & 3 & 4 & 5 & 6 \\ 0 & 1 & 2 & 3 & 4 & 5 & 6 \\ 0 & 1 & 2 & 3 & 4 & 5 & 6 \\ 0 & 1 & 2 & 3 & 4 & 5 & 6 \\ 0 & 1 & 2 & 3 & 4 & 5 & 6 \\ 0 & 1 & 2 & 3 & 4 & 5 & 6\end{array}$


THE MOVIE REVIEW

About the movie, the blogger specifically wrote and posted:

\section{MOVIE REVIEW}

\section{EXCITING, ENERGETIC, AND ACTION PACKED}

This movie is very exciting, energetic, and action packed, providing a heartpounding, edge-of-your-seat experience as it tells a story about an American soldier, Afghan aid worker, and orphaned children in the middle of the ongoing war in Afghanistan. In this movie, an American soldier in Afghanistan falls in love with an Afghan aid worker and helps her to protect orphaned children when the Army targets the orphanage as a suspected Taliban headquarters. This movie was filmed in dangerous-looking locations that were enhanced with amazing special effects, highquality acting, and an exciting storyline. This movie is full of energy and action, as the soldier and aid worker risk everything for the orphans.

\section{MOVIE REVIEW}

\section{EDUCATIONAL, INFORMATIVE, AND FACTUAL}

This movie is very educational, informative, and factual, highlighting true facts about Afghanistan and providing accurate details about the real-life issues faced by American soldiers, Afghan aid workers, and orphaned Afghan children in the middle of the ongoing war in Afghanistan. In this movie, an American soldier in Afghanistan falls in love with an Afghan aid worker and helps her to protect the orphaned children when the Army targets the orphanage as a suspected Taliban headquarters. Afghanistan is represented with a high level of authenticity throughout this movie, and it was filmed at culturally significant locations with people whose language, customs, beliefs, and values all match those of the people of Afghanistan. 
INSTRUCTIONS: Please indicate your opinion from 0 (Not at all) to 6 (Very much) of how much Not Very the movie review:

Contains an appropriate amount of information about the movie

Contains confident statements about the movie Contains assertive statements about the movie

Contains interesting statements about the movie Contains strong statements about the movie Contains favourable statements about the movie Contains positive statements about the movie Contains complete statements about the movie Contains helpful statements about the movie Contains informative statements about the movie Contains surprising statements about the movie Contains unexpected statements about the movie Contains suspicious statements about the movie Is easy to follow Is easy to understand Is enjoyable to read Is entertaining to read Is honest

Is sincere

Is believable

Is convincing

Is truthful

Is credible

Is persuasive

Is comparable to movie reviews people write and post on their blogs

$\begin{array}{lllllll}0 & 1 & 2 & 3 & 4 & 5 & 6 \\ 0 & 1 & 2 & 3 & 4 & 5 & 6 \\ 0 & 1 & 2 & 3 & 4 & 5 & 6 \\ 0 & 1 & 2 & 3 & 4 & 5 & 6 \\ 0 & 1 & 2 & 3 & 4 & 5 & 6 \\ 0 & 1 & 2 & 3 & 4 & 5 & 6 \\ 0 & 1 & 2 & 3 & 4 & 5 & 6 \\ 0 & 1 & 2 & 3 & 4 & 5 & 6 \\ 0 & 1 & 2 & 3 & 4 & 5 & 6 \\ 0 & 1 & 2 & 3 & 4 & 5 & 6 \\ 0 & 1 & 2 & 3 & 4 & 5 & 6 \\ 0 & 1 & 2 & 3 & 4 & 5 & 6 \\ 0 & 1 & 2 & 3 & 4 & 5 & 6 \\ 0 & 1 & 2 & 3 & 4 & 5 & 6 \\ 0 & 1 & 2 & 3 & 4 & 5 & 6 \\ 0 & 1 & 2 & 3 & 4 & 5 & 6 \\ 0 & 1 & 2 & 3 & 4 & 5 & 6 \\ 0 & 1 & 2 & 3 & 4 & 5 & 6 \\ 0 & 1 & 2 & 3 & 4 & 5 & 6 \\ 0 & 1 & 2 & 3 & 4 & 5 & 6 \\ 0 & 1 & 2 & 3 & 4 & 5 & 6 \\ 0 & 1 & 2 & 3 & 4 & 5 & 6 \\ 0 & 1 & 2 & 3 & 4 & 5 & 6 \\ 0 & 1 & 2 & 3 & 4 & 5 & 6 \\ 0 & 1 & 2 & 3 & 4 & 5 & 6\end{array}$


Appendix 5.3: Study 3 Questionnaire

\section{INTRODUCTORY INFORMATION}

Imagine that you and a friend have plans to see a movie at the theatre and that it is your turn to choose the movie. The movie that fits your schedule is about an American soldier, an Afghan aid worker, and children living in an orphanage in modern-day Afghanistan. You are evaluating the likelihood that you and your friend would rate the movie positively after seeing it. You look for information about the movie and have come across a movie review posted on a PERSONAL BLOG. Before reading the personal blog, please indicate your general opinion about the typical movie review that is posted on a personal blog or a similar website.

INSTRUCTIONS: Please indicate from 0 (Not at all) to 6 (Very much) how much you think that the typical movie review that is posted on a personal blog or a similar website is generally:

Not at

Written to inform consumers Informative Truthful Reliable Truth well told Accurate True Dependable Based on important or essential information Complete Consistent Specific Objective Interesting Strongly worded

Easy to follow Easy to understand Valuable to you Helpful to you Relevant to you all

Very much

$\begin{array}{lllllll}0 & 1 & 2 & 3 & 4 & 5 & 6 \\ 0 & 1 & 2 & 3 & 4 & 5 & 6 \\ 0 & 1 & 2 & 3 & 4 & 5 & 6 \\ 0 & 1 & 2 & 3 & 4 & 5 & 6 \\ 0 & 1 & 2 & 3 & 4 & 5 & 6 \\ 0 & 1 & 2 & 3 & 4 & 5 & 6 \\ 0 & 1 & 2 & 3 & 4 & 5 & 6 \\ 0 & 1 & 2 & 3 & 4 & 5 & 6 \\ 0 & 1 & 2 & 3 & 4 & 5 & 6 \\ 0 & 1 & 2 & 3 & 4 & 5 & 6 \\ 0 & 1 & 2 & 3 & 4 & 5 & 6 \\ 0 & 1 & 2 & 3 & 4 & 5 & 6 \\ 0 & 1 & 2 & 3 & 4 & 5 & 6 \\ 0 & 1 & 2 & 3 & 4 & 5 & 6 \\ 0 & 1 & 2 & 3 & 4 & 5 & 6 \\ 0 & 1 & 2 & 3 & 4 & 5 & 6 \\ 0 & 1 & 2 & 3 & 4 & 5 & 6 \\ 0 & 1 & 2 & 3 & 4 & 5 & 6 \\ 0 & 1 & 2 & 3 & 4 & 5 & 6 \\ 0 & 1 & 2 & 3 & 4 & 5 & 6\end{array}$

INSTRUCTIONS: Please indicate from 0 (Not at all) to 6 (Very much) how much you think that the typical blogger who posts a movie review on a personal blog or a Not Very similar website is generally:

A knowledgeable source of information on the topic

An expert source of information on the topic A qualified source of information on the topic A trustworthy source of information on the topic A credible source of information on the topic at all much

$\begin{array}{lllllll}0 & 1 & 2 & 3 & 4 & 5 & 6 \\ 0 & 1 & 2 & 3 & 4 & 5 & 6 \\ 0 & 1 & 2 & 3 & 4 & 5 & 6 \\ 0 & 1 & 2 & 3 & 4 & 5 & 6 \\ 0 & 1 & 2 & 3 & 4 & 5 & 6\end{array}$


INSTRUCTIONS: Please indicate the number of years you have been reading movie reviews posted on blogs or similar websites:

0 (Never)

Less than 1 year

1-2 years

More than 2 years

INSTRUCTIONS: Please indicate the number of movie reviews you read in an average week in a blog or a similar website:

$0 \quad$ 1-2 movie

(None)

review(s)/week reviews / week

5-6 movie

reviews / week

7-8 movie

reviews / week

+8 movie

reviews / week

\section{The personal blog: "ABOUT ME"}

Text from the personal blog on which the movie review was posted is reproduced below. Please read the blog text as you would other text, being sure to read it thoroughly and completely.

\section{About Me statement goes here.}

INSTRUCTIONS: Please indicate from 0 (Not at all) to 6 (Very much) how much you think the blogger:

Not at

all

Is someone you could like as a person

Made a favourable impression on you

Is someone you would like to socialize with

Is similar to you

Has beliefs and values that are similar to yours

Has tastes and preferences that are similar to yours

Has things in common with you

Watches a large number of movies

Knows much about important trends in movies

Spends a lot of time watching movies

Is very passionate about movies

Has an extensive formal education on conditions in Afghanistan

Knows detailed facts about conditions in Afghanistan

Knows much about important trends in Afghanistan conditions

Has done research about conditions in Afghanistan

Just wants to help readers of the movie review

Cares about readers of the movie review

Just wants to inform readers about the movie

Just wants to help readers make a good decision about the movie

Will be totally honest with readers about the movie

Will be totally truthful with readers about the movie

Will be totally sincere with readers about the movie

Has reason to misrepresent the truth about the movie

Has reason to deceive readers about the movie

Has reason to mislead readers about the movie

Has reason to hide the truth about the movie from readers

$\begin{array}{lllllll}0 & 1 & 2 & 3 & 4 & 5 & 6 \\ 0 & 1 & 2 & 3 & 4 & 5 & 6 \\ 0 & 1 & 2 & 3 & 4 & 5 & 6 \\ 0 & 1 & 2 & 3 & 4 & 5 & 6 \\ 0 & 1 & 2 & 3 & 4 & 5 & 6 \\ 0 & 1 & 2 & 3 & 4 & 5 & 6 \\ 0 & 1 & 2 & 3 & 4 & 5 & 6 \\ 0 & 1 & 2 & 3 & 4 & 5 & 6 \\ 0 & 1 & 2 & 3 & 4 & 5 & 6 \\ 0 & 1 & 2 & 3 & 4 & 5 & 6 \\ 0 & 1 & 2 & 3 & 4 & 5 & 6 \\ 0 & 1 & 2 & 3 & 4 & 5 & 6 \\ 0 & 1 & 2 & 3 & 4 & 5 & 6 \\ 0 & 1 & 2 & 3 & 4 & 5 & 6 \\ 0 & 1 & 2 & 3 & 4 & 5 & 6 \\ 0 & 1 & 2 & 3 & 4 & 5 & 6 \\ 0 & 1 & 2 & 3 & 4 & 5 & 6 \\ 0 & 1 & 2 & 3 & 4 & 5 & 6 \\ 0 & 1 & 2 & 3 & 4 & 5 & 6 \\ 0 & 1 & 2 & 3 & 4 & 5 & 6 \\ 0 & 1 & 2 & 3 & 4 & 5 & 6 \\ 0 & 1 & 2 & 3 & 4 & 5 & 6 \\ 0 & 1 & 2 & 3 & 4 & 5 & 6 \\ 0 & 1 & 2 & 3 & 4 & 5 & 6 \\ 0 & 1 & 2 & 3 & 4 & 5 & 6 \\ 0 & 1 & 2 & 3 & 4 & 5 & 6\end{array}$

Very much

6

6

6

6

6

6

6 8 8 6 8 8 6 
INSTRUCTIONS: Please indicate from 0 (Not at all) to 6 (Very much) how much you:

\section{Not at}

303

all

Believe the blogger's "About Me" statement

Are convinced about the blogger by the blogger's "About Me"

statement

Are persuaded about the blogger by the blogger's "About Me"

statement

Think the blogger's "About Me" statement is not deceptive

Very

much

$\begin{array}{lllllll}0 & 1 & 2 & 3 & 4 & 5 & 6\end{array}$

0

2

3

456

$\begin{array}{lllllll}0 & 1 & 2 & 3 & 4 & 5 & 6\end{array}$

\section{The personal blog: MOVIE REVIEW}

The actual movie review posted by the blogger is reproduced below. Please read the movie review as you would other movie reviews, being sure to read it thoroughly and completely.

\section{Movie review goes here.}

INSTRUCTIONS: Please indicate from 0 (Not at all) to 6 (Very much) how much you think:

\section{This movie seems good to you This movie seems interesting to you \\ This movie seems likeable to you This movie appeals to you You would enjoy watching this movie You would appreciate watching this movie}

INSTRUCTIONS: Please indicate from 0 (Not at all) to 6 (Very much) how much you think the blogger is:

Knowledgeable on the specific topic it wrote about

An expert on the specific topic it wrote about

Qualified to make statements on the specific topic it wrote about A trustworthy information source on the specific topic it wrote about

A credible information source on the specific topic it wrote about

INSTRUCTIONS: Please indicate from 0 (Not at all) to 6 (Very much) how much you:

Believe what the blogger wrote about the movie Are convinced about the movie by what the blogger wrote Are persuaded about the movie by what the blogger wrote

Think what the blogger wrote about the movie is not deceptive

INSTRUCTIONS: Please indicate from 0 (Not at all) to 6 (Very much) how much you think the blogger's movie review:

Was written to inform consumers Is informative

Is truthful

Is reliable

Is truth well told

Is accurate
Not at

all

$\begin{array}{lllllll}0 & 1 & 2 & 3 & 4 & 5 & 6 \\ 0 & 1 & 2 & 3 & 4 & 5 & 6 \\ 0 & 1 & 2 & 3 & 4 & 5 & 6 \\ 0 & 1 & 2 & 3 & 4 & 5 & 6 \\ 0 & 1 & 2 & 3 & 4 & 5 & 6 \\ 0 & 1 & 2 & 3 & 4 & 5 & 6\end{array}$

Not at

all

$\begin{array}{lllllll}0 & 1 & 2 & 3 & 4 & 5 & 6 \\ 0 & 1 & 2 & 3 & 4 & 5 & 6 \\ 0 & 1 & 2 & 3 & 4 & 5 & 6 \\ 0 & 1 & 2 & 3 & 4 & 5 & 6 \\ 0 & 1 & 2 & 3 & 4 & 5 & 6\end{array}$

Not at

all

(1)

$\begin{array}{llll}0 & 1 & 2 & 3\end{array}$

$\begin{array}{llll}0 & 1 & 2 & 3\end{array}$

$\begin{array}{llll}0 & 1 & 2 & 3\end{array}$

$\begin{array}{llll}0 & 1 & 2 & 3\end{array}$

Not at

all

0

$\begin{array}{llll}0 & 1 & 2 & 3\end{array}$

$\begin{array}{llll}0 & 1 & 2 & 3\end{array}$

$\begin{array}{llll}0 & 1 & 2 & 3\end{array}$

0. 123

$\begin{array}{llll}0 & 1 & 2 & 3\end{array}$

$\begin{array}{llll}0 & 1 & 2 & 3\end{array}$

6

6

6 6

Very

much

Very much

6


INSTRUCTIONS: Please indicate from 0 (Not at all) to 6 (Very much) how much you think the blogger's movie review:
Not at

all
304

Is true

Is dependable

Contains important or essential information
INSTRUCTIONS: Please indicate from 0 (Not at all) to 6 (Very much) how much you think the blogger's movie review:
Is complete

Is consistent Is specific Is objective

Is interesting

Is strongly worded

Contains statements that surprise you

Contains statements that you did not expect

Is easy to follow

Is easy to understand

Is valuable to you

Is helpful to you

Is relevant to you
Not at

all
Very

much

6

6

6

Very

much

6

6

6

6

6

6

6

6

6

6

6

6

6

INSTRUCTIONS: Assuming you have the option in the future, please indicate from 0 (Not likely at all) to 6 (Very likely) the likelihood that you would:

$\begin{array}{lr}\text { Not at } & \text { Very } \\ \text { all } & \text { much }\end{array}$

much

$\begin{array}{lllllllll}\text { Take advice from this blogger } & 0 & 1 & 2 & 3 & 4 & 5 & 6\end{array}$

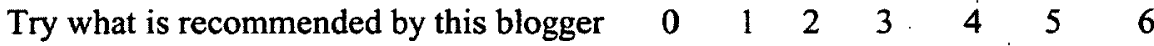

Continue to read this blog $\begin{array}{llllllll}0 & 1 & 2 & 3 & 4 & 5 & 6\end{array}$

$\begin{array}{llllllll}\text { Consult the blog again } & 0 & 1 & 2 & 3 & 4 & 5 & 6\end{array}$

$\begin{array}{llllllll}\text { Pass along information you find on this blog to others } & 0 & 1 & 2 & 3 & 4 & 5 & 6\end{array}$

Recommend this blog to others $\quad 0 \quad \begin{array}{lllllll} & 0 & 2 & 3 & 4 & 5 & 6\end{array}$

INSTRUCTIONS: Please check "Yes" or "No" for each of the following questions about the personal blog.

Did the blogger claim to possess expertise in the ongoing situation in Afghanistan?

Yes No

Did the blogger claim to watch hundreds of movies every year?

Did the blogger admit to receiving compensation for the movie review from the makers of the

movie?

Did the blogger claim that the movie is exciting, energetic, and action packed?

Did the blogger claim that the movie is educational, informative, and factual?

INSTRUCTIONS: Please indicate from 0 (Not at all) to 6 (Very much) how familiar you are with each of the following languages:

Not at

all
Very

much

$\begin{array}{rlllllll}\text { English } & 0 & 1 & 2 & 3 & 4 & 5 & 6 \\ \text { French } & 0 & 1 & 2 & 3 & 4 & 5 & 6 \\ \text { Afghan Persian (or Dari) } & 0 & 1 & 2 & 3 & 4 & 5 & 6 \\ \text { Pashto } & 0 & 1 & 2 & 3 & 4 & 5 & 6 \\ \text { in or around Afghanistan } & 0 & 1 & 2 & 3 & 4 & 5 & 6\end{array}$


INSTRUCTIONS: Please indicate from 0 (Not at all) to 6 (Very much) how familiar you are with each of the following languages:

Not at

all

$\begin{array}{llllll}\text { Your age (please circle): } \quad \text { Less than } 18 & 18-20 & 21-23 & 24-26 & 27-29 & 30\end{array}$ or higher

Gender (please circle): $\quad$ Male Female

\section{YOUR EXPERIENCE WITH THE MOVIE}

Now, imagine that you and your friend are watching the movie at the theatre and that it is apparent that the movie you chose is not what the blogger said it would be. After seeing the movie, you come across other reviews of it by many (blogger error notice goes here).

INSTRUCTIONS: Assuming you have the option in the future, please indicate from 0 (Not likely at all) to 6 (Very likely) the likelihood that you would:

\begin{tabular}{cccc}
$\begin{array}{l}\text { Not } \\
\text { likely } \\
\text { at all }\end{array}$ & & & \\
0 & 1 & 2 & 3 \\
0 & 1 & 2 & 3 \\
0 & 1 & 2 & 3 \\
0 & 1 & 2 & 3 \\
0 & 1 & 2 & 3 \\
0 & 1 & 2 & 3 \\
0 & 1 & 2 & 3 \\
0 & 1 & 2 & 3 \\
0 & 1 & 2 & 3 \\
0 & 1 & 2 & 3 \\
0 & 1 & 2 & 3 \\
0 & 1 & 2 & 3 \\
0 & 1 & 2 & 3 \\
0 & 1 & 2 & 3 \\
0 & 1 & 2 & 3 \\
0 & 1 & 2 & 3 \\
0 & 1 & 2 & 3 \\
0 & 1 & 2 & 3 \\
\hline
\end{tabular}

Take advice from this blogger

Try what is recommended by this blogger

Continue to read this blog

Consult the blog again

Pass along information you find on this blog to others

Recommend this blog to others

Discourage people you know from reading the blog

Speak negatively about the blog to people you know

Criticize the blog to people you know

Leave negative feedback about the movie review on the blog

Post a critical comment about the movie review on the blog

Criticize the movie review on the blog

Discourage people you know from seeing the movie

Speak negatively about the movie to people you know

Criticize the movie to people you know

Post a negative review of the movie on a website

Post a critical comment of the movie on a website

Criticize the movie on a website

INSTRUCTIONS: Please indicate from 0 (Not at all) to 6 (Very much) how much you think:

Not at

all

The blogger knowingly misrepresented the truth about the movie

The blogger knowingly attempted to deceive readers about the movie

The blogger knowingly attempted to mislead readers about the movie

The blogger knowingly hid the truth about the movie from readers

The makers of the movie are totally responsible for the blogger's actions

The makers of the movie are totally at fault for the blogger's actions

The makers of the movie are totally blameworthy for the blogger's actions

The makers of the movie had total control over the blogger's actions

Very

likely

6 6 6 6 6 6 6 6 6 6 6 6

$$
6
$$

$$
6
$$$$
6
$$$$
6
$$$$
6
$$
6 


\section{6}

INSTRUCTIONS: Please indicate from 0 (Not at all) to 6 (Very much) how much you think:

Not at

all

You are outraged by what happened

You are angry because of what happened

You are mad because of what happened

You are disappointed by what happened

You are dissatisfied by what happened

You feel discontented by what happened

You are displeased by what happened

The movie review was truthful

The movie review was accurate

The movie review was true

$\begin{array}{llllll}0 & 1 & 2 & 3 & 4 & 5\end{array}$

6

$\begin{array}{lllllll}0 & 1 & 2 & 3 & 4 & 5 & 6\end{array}$

$\begin{array}{lllllll}0 & 1 & 2 & 3 & 4 & 5 & 6\end{array}$

$\begin{array}{lllllll}0 & 1 & 2 & 3 & 4 & 5 & 6\end{array}$

$\begin{array}{lllllll}0 & 1 & 2 & 3 & 4 & 5 & 6\end{array}$

$\begin{array}{lllllll}0 & 1 & 2 & 3 & 4 & 5 & 6\end{array}$

$\begin{array}{lllllll}0 & 1 & 2 & 3 & 4 & 5 & 6\end{array}$

$\begin{array}{lllllll}0 & 1 & 2 & 3 & 4 & 5 & 6\end{array}$

$\begin{array}{lllllll}0 & 1 & 2 & 3 & 4 & 5 & 6 \\ 0 & 1 & 2 & 3 & 4 & 5 & 6\end{array}$


Appendix 5.4: Measures Used in Study 3

\begin{tabular}{|c|c|c|c|}
\hline Measure Area & Topic & Items & Source \\
\hline \multirow[t]{25}{*}{$\begin{array}{l}\text { Category-level } \\
\text { beliefs }\end{array}$} & \multirow{5}{*}{$\begin{array}{l}\text { 1. Credibility of the } \\
\text { typical blogger } \\
\text { who posts a } \\
\text { movie review on } \\
\text { a personal blog or } \\
\text { similar website }\end{array}$} & $\begin{array}{l}\text { a. Knowledgeable source } \\
\text { of information on the } \\
\text { topic }\end{array}$ & \multirow{5}{*}{$\begin{array}{l}\text { Jain and } \\
\text { Posavac, } \\
\text { 2001; Wang } \\
\text { and Doong, } \\
2010\end{array}$} \\
\hline & & $\begin{array}{l}\text { b. Expert source of } \\
\text { information on the topic }\end{array}$ & \\
\hline & & $\begin{array}{l}\text { Qualified source of } \\
\text { information on the topic }\end{array}$ & \\
\hline & & $\begin{array}{ll}\text { d. } & \text { Trustworthy source of } \\
\text { information on the topic }\end{array}$ & \\
\hline & & $\begin{array}{l}\text { e. Credible source of } \\
\text { information on the topic }\end{array}$ & \\
\hline & \multirow{11}{*}{$\begin{array}{l}\text { 2. Qualities of the } \\
\text { typical movie } \\
\text { review posted on } \\
\text { a personal blog }\end{array}$} & a. Complete & \multirow{11}{*}{$\begin{array}{l}\text { Sussman and } \\
\text { Siegal, 2003; } \\
\text { Wang and } \\
\text { Doong, 2010; } \\
\text { Wang and } \\
\text { Sun, 2010 }\end{array}$} \\
\hline & & b. Consistent & \\
\hline & & c. Specific & \\
\hline & & d. Objective & \\
\hline & & e. Interesting & \\
\hline & & $\begin{array}{ll}\text { f. } & \text { Strongly worded }\end{array}$ & \\
\hline & & g. Easy to follow & \\
\hline & & h. Easy to understand & \\
\hline & & i. Valuable to you & \\
\hline & & j. Helpful to you & \\
\hline & & k. Relevant to you & \\
\hline & \multirow[t]{9}{*}{ 3. Scepticism } & $\begin{array}{l}\text { a. Written to inform } \\
\text { consumers }\end{array}$ & \multirow{9}{*}{$\begin{array}{l}\text { Obermiller } \\
\text { and } \\
\text { Spangenberg, } \\
\text { 1998; van } \\
\text { Heerden et al., } \\
\text { 2009; Wang, } \\
2005\end{array}$} \\
\hline & & b. Informative & \\
\hline & & c. Truthful & \\
\hline & & d. Reliable & \\
\hline & & e. Truth well told & \\
\hline & & f. Accurate & \\
\hline & & g. True & \\
\hline & & h. Dependable & \\
\hline & & $\begin{array}{l}\text { i. } \begin{array}{l}\text { Based on important or } \\
\text { essential information }\end{array} \\
\end{array}$ & \\
\hline \multirow{4}{*}{$\begin{array}{l}\text { Experience with } \\
\text { blogs and } \\
\text { similar websites }\end{array}$} & \multirow{4}{*}{$\begin{array}{l}\text { 1. Number of years } \\
\text { you have been } \\
\text { reading movie } \\
\text { reviews posted } \\
\text { on blogs or } \\
\text { similar websites }\end{array}$} & a. 0 (Never) & \\
\hline & & b. Less than 1 year & \\
\hline & & c. 1-2 years & \\
\hline & & d. More than 2 years & \\
\hline
\end{tabular}




\begin{tabular}{|c|c|c|c|}
\hline Measure Area & Topic & Items & Source \\
\hline & \multirow{6}{*}{$\begin{array}{l}\text { 2. Number of } \\
\text { movie reviews } \\
\text { you read in an } \\
\text { average week in } \\
\text { a blog or a } \\
\text { similar website }\end{array}$} & a. 0 (None) & \\
\hline & & $\begin{array}{l}\text { b. 1-2 movie review(s)/ } \\
\text { week }\end{array}$ & \\
\hline & & $\begin{array}{l}\text { c. 3-4 movie reviews / } \\
\text { week }\end{array}$ & \\
\hline & & $\begin{array}{l}\text { d. } \begin{array}{l}5-6 \text { movie reviews / } \\
\text { week }\end{array} \\
\end{array}$ & \\
\hline & & $\begin{array}{l}\text { e. } 7-8 \text { movie reviews / } \\
\text { week }\end{array}$ & \\
\hline & & f. +8 movie reviews / week & \\
\hline \multirow[t]{12}{*}{$\begin{array}{l}\text { Beliefs about } \\
\text { blogger }\end{array}$} & \multirow[t]{8}{*}{ 1. Ability } & $\begin{array}{l}\text { a. Watches a large number } \\
\text { of movies }\end{array}$ & \multirow{8}{*}{$\begin{array}{l}\text { Ridings, } \\
\text { Gefen, and } \\
\text { Arinze, } 2002\end{array}$} \\
\hline & & $\begin{array}{l}\text { b. Knows much about } \\
\text { important trends in } \\
\text { movies }\end{array}$ & \\
\hline & & $\begin{array}{l}\text { c. Spends a lot of time } \\
\text { watching movies }\end{array}$ & \\
\hline & & $\begin{array}{l}\text { d. Is very passionate about } \\
\text { movies }\end{array}$ & \\
\hline & & $\begin{array}{l}\text { e. Has an extensive formal } \\
\text { education on conditions } \\
\text { in Afghanistan }\end{array}$ & \\
\hline & & $\begin{array}{l}\text { f. Knows detailed facts } \\
\text { about conditions in } \\
\text { Afghanistan }\end{array}$ & \\
\hline & & $\begin{array}{l}\text { g. Knows much about } \\
\text { important trends in } \\
\text { Afghanistan }\end{array}$ & \\
\hline & & $\begin{array}{l}\text { h. Has done research about } \\
\text { conditions in } \\
\text { Afghanistan }\end{array}$ & \\
\hline & \multirow[t]{4}{*}{ 2. Character } & $\begin{array}{l}\text { a. Just wants to help } \\
\text { readers of the movie } \\
\text { review }\end{array}$ & \multirow{4}{*}{$\begin{array}{l}\text { Campbell and } \\
\text { Kirmani, } \\
2000 ; \\
\text { Karmarkar } \\
\text { and Tormala, } \\
\text { 2010; Lankton } \\
\text { and } \\
\text { McKnight, } \\
\text { 2011; Ridings, } \\
\text { Gefen, and } \\
\text { Arinze, 2002; }\end{array}$} \\
\hline & & $\begin{array}{l}\text { b. Cares about readers of } \\
\text { the movie review }\end{array}$ & \\
\hline & & $\begin{array}{l}\text { c. Just wants to inform } \\
\text { readers about the movie }\end{array}$ & \\
\hline & & $\begin{array}{l}\text { d. Just wants to help } \\
\text { readers make a good } \\
\text { decision about the } \\
\text { movie }\end{array}$ & \\
\hline
\end{tabular}




\begin{tabular}{|c|c|c|c|}
\hline Measure Area & Topic & Items & Source \\
\hline \multirow{11}{*}{$c_{1}$} & & $\begin{array}{l}\text { e. Will be totally honest } \\
\text { with readers about the } \\
\text { movie }\end{array}$ & \multirow[t]{7}{*}{$\begin{array}{l}\text { Schlosser, } \\
\text { White, and } \\
\text { Lloyd, } 2006\end{array}$} \\
\hline & & $\begin{array}{l}\text { f. Will be totally truthful } \\
\text { with readers about the } \\
\text { movie }\end{array}$ & \\
\hline & & $\begin{array}{l}\text { g. Will be totally sincere } \\
\text { with readers about the } \\
\text { movie }\end{array}$ & \\
\hline & & $\begin{array}{l}\text { h. Has reason to } \\
\text { misrepresent the truth } \\
\text { about the movie }\end{array}$ & \\
\hline & & $\begin{array}{ll}\text { i. } & \text { Has reason to deceive } \\
\text { readers about the movie }\end{array}$ & \\
\hline & & $\begin{array}{ll}\text { j. } & \text { Has reason to mislead } \\
\text { readers about the movie }\end{array}$ & \\
\hline & & $\begin{array}{l}\text { k. Has reason to hide the } \\
\text { truth about the movie } \\
\text { from readers }\end{array}$ & \\
\hline & \multirow[t]{3}{*}{ 3. Likeability } & $\begin{array}{l}\text { a. Is someone you could } \\
\text { like as a person }\end{array}$ & \multirow{3}{*}{$\begin{array}{l}\text { Karmarkar } \\
\text { and Tormala, } \\
\text { 2010; Smith, } \\
\text { Menon, and } \\
\text { Sivakumar, } \\
\text { 2005). }\end{array}$} \\
\hline & & $\begin{array}{l}\text { b. Made a favourable } \\
\text { impression on you }\end{array}$ & \\
\hline & & $\begin{array}{l}\text { c. Is someone you would } \\
\text { like to socialize with }\end{array}$ & \\
\hline & $\begin{array}{l}\text { 4. Blogger- } \\
\text { participant } \\
\text { similarity }\end{array}$ & $\begin{array}{l}\text { a. Is similar to you } \\
\text { b. Has beliefs and values } \\
\text { that are similar to yours } \\
\text { c. Has tastes and } \\
\text { preferences that are } \\
\text { similar to yours } \\
\text { d. Has things in common } \\
\text { with you }\end{array}$ & $\begin{array}{l}\text { Karmarkar } \\
\text { and Tormala, } \\
\text { 2010; Price, } \\
\text { Feick, and } \\
\text { Higie, 1989; } \\
\text { Riordan and } \\
\text { Wayne, 2008 }\end{array}$ \\
\hline $\begin{array}{l}\text { Acceptance of } \\
\text { "About Me" } \\
\text { statement }\end{array}$ & & $\begin{array}{l}\text { a. Believe the blogger's } \\
\text { "About Me" statement } \\
\text { b. Are convinced about the } \\
\text { blogger by the blogger's } \\
\text { "About Me" statement } \\
\text { c. Are persuaded about the } \\
\text { blogger by the blogger's } \\
\text { "About Me" statement } \\
\text { d. Think the blogger's } \\
\text { "About Me" statement is } \\
\text { not deceptive }\end{array}$ & Wang, 2005 \\
\hline General movie- & & a. Good & Darke and \\
\hline
\end{tabular}




\begin{tabular}{|c|c|c|c|}
\hline Measure Area & Topic & Items & Source \\
\hline related attitudes & & $\begin{array}{ll}\text { b. Interesting } \\
\text { c. Likeable } \\
\text { d. Appealing } \\
\text { e. Would enjoy watching } \\
\text { this movie } \\
\text { f. Would appreciate } \\
\text { watching this movie } \\
\end{array}$ & $\begin{array}{l}\text { Ritchie, 2007; } \\
\text { Jo, 2004; } \\
\text { Oliver and } \\
\text { Bartsch, } 2010\end{array}$ \\
\hline $\begin{array}{l}\text { Blogger-directed } \\
\text { trust intentions }\end{array}$ & & $\begin{array}{l}\text { a. Take advice from this } \\
\text { blogger } \\
\text { b. Try what is } \\
\text { recommended by this } \\
\text { blogger } \\
\text { c. Continue to read this } \\
\text { blog } \\
\text { d. Consult the blog again } \\
\text { e. Pass along information } \\
\text { you find on this blog } \\
\text { f. Recommend this blog to } \\
\text { others }\end{array}$ & Study 2 \\
\hline $\begin{array}{l}\text { Negative word- } \\
\text { of-mouth } \\
\text { communication }\end{array}$ & & $\begin{array}{l}\text { a. Discourage people you } \\
\text { know from reading the } \\
\text { blog } \\
\text { b. Speak negatively about } \\
\text { the blog to people you } \\
\text { know } \\
\text { c. Criticize the blog to } \\
\text { people you know } \\
\text { d. Leave negative feedback } \\
\text { about the movie review } \\
\text { on the blog } \\
\text { e. Post a critical comment } \\
\text { about the movie review } \\
\text { on the blog } \\
\text { f. Criticize the movie } \\
\text { review on the blog } \\
\text { g. Discourage people you } \\
\text { know from seeing the } \\
\text { movie } \\
\text { h. Speak negatively about } \\
\text { the movie to people you } \\
\text { know } \\
\text { i. Criticize the movie to } \\
\text { jeople you know } \\
\text { j. Post a negative review of } \\
\text { the movie on a website }\end{array}$ & $\begin{array}{l}\text { Bonifield and } \\
\text { Cole, 2007; } \\
\text { Grégoire, } \\
\text { Laufer, and } \\
\text { Tripp, 2010; } \\
\text { Hess, } \\
\text { Ganesan, and } \\
\text { Klein, 2003; } \\
\text { Wang and } \\
\text { Huff, 2007 } \\
\text { Bougie, } \\
\text { Pieters, and } \\
\text { Zeelenberg, } \\
\text { 2003 }\end{array}$ \\
\hline
\end{tabular}




\begin{tabular}{|c|c|c|c|}
\hline Measure Area & Topic & Items & Source \\
\hline & & $\begin{array}{l}\text { k. Post a critical comment } \\
\text { of the movie on a } \\
\text { website } \\
\text { 1. Criticize the movie on a } \\
\text { website }\end{array}$ & 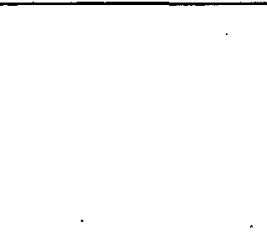 \\
\hline $\begin{array}{l}\text { Blogger and } \\
\text { movie company } \\
\text { blameworthiness }\end{array}$ & . & $\begin{array}{l}\text { a. The blogger knowingly } \\
\text { misrepresented the truth } \\
\text { about the movie } \\
\text { b. The blogger knowingly } \\
\text { attempted to deceive } \\
\text { readers about the movie } \\
\text { c. The blogger knowingly } \\
\text { attempted to mislead } \\
\text { readers about the movie } \\
\text { d. The blogger knowingly } \\
\text { hid the truth about the } \\
\text { movie from readers } \\
\text { e. The makers of the movie } \\
\text { are totally responsible for } \\
\text { the blogger's actions } \\
\text { f. The makers of the movie } \\
\text { are totally at fault for the } \\
\text { blogger's actions } \\
\text { g. The makers of the movie } \\
\text { are totally blameworthy } \\
\text { for the blogger's actions } \\
\text { h. The makers of the movie } \\
\text { had total control over the } \\
\text { blogger's actions }\end{array}$ & $\begin{array}{l}\text { Argo, White, } \\
\text { and Dahl, } \\
2006 ; \\
\text { Grégoire, } \\
\text { Laufer, and } \\
\text { Tripp, 2010; } \\
\text { Hess, } \\
\text { Ganesan, and } \\
\text { Klein, 2003; } \\
\text { Román, 2010; } \\
\text { Varela-Neira, } \\
\text { Vázquez- } \\
\text { Casielles, and } \\
\text { Iglesias, 2010 }\end{array}$ \\
\hline $\begin{array}{l}\text { Affective } \\
\text { responses to } \\
\text { blogger error }\end{array}$ & & $\begin{array}{l}\text { a. You are outraged by } \\
\text { what happened } \\
\text { b. You are angry because of } \\
\text { what happened } \\
\text { c. You are mad because of } \\
\text { what happened } \\
\text { d. You are disappointed by } \\
\text { what happened } \\
\text { e. You are dissatisfied by } \\
\text { what happened } \\
\text { f. You feel discontented by } \\
\text { what happened } \\
\text { g. You are displeased by } \\
\text { what happened }\end{array}$ & $\begin{array}{l}\text { Bonifield and } \\
\text { Cole, 2007; } \\
\text { Bougie, } \\
\text { Pieters, and } \\
\text { Zeelenberg, } \\
\text { 2003; } \\
\text { Grégoire, } \\
\text { Laufer, and } \\
\text { Tripp, 2010; } \\
\text { Kalamas, } \\
\text { Laroche, } \\
\text { Makdessian, } \\
\text { 2008; Varela- } \\
\text { Neira, } \\
\text { Vázquez- } \\
\text { Casielles, and }\end{array}$ \\
\hline
\end{tabular}




\begin{tabular}{|c|c|c|c|}
\hline Measure Area & Topic & Items & Source \\
\hline & & & $\begin{array}{l}\text { Iglesias, 2010; } \\
\text { Wang and } \\
\text { Huff, } 2007 \\
\text { Bougie, } \\
\text { Pieters, and } \\
\text { Zeelenberg, } \\
2003\end{array}$ \\
\hline $\begin{array}{l}\text { Discovered } \\
\text { accuracy of } \\
\text { movie review }\end{array}$ & . & $\begin{array}{l}\text { a. The movie review was } \\
\text { truthful } \\
\text { b. The movie review was } \\
\text { accurate } \\
\text { c. The movie review was } \\
\text { true }\end{array}$ & $\begin{array}{l}\text { Obermiller } \\
\text { and } \\
\text { Spangenberg, } \\
\text { 1998; van } \\
\text { Heerden } \text { et al., } \\
2009\end{array}$ \\
\hline
\end{tabular}


Appendix 5.5: Item-Level Descriptive Statistics

\begin{tabular}{|c|c|c|c|c|}
\hline $\begin{array}{c}\text { Constructs } \\
\text { Items }\end{array}$ & Mean $^{a}$ & S.D. & Skewness & Kurtosis \\
\hline \multicolumn{5}{|l|}{ Credibility of typical blogger } \\
\hline a. Knowledgeable & 3.15 & 1.27 & -.12 & -.13 \\
\hline b. Expert & 2.15 & 1.33 & $.28^{*}$ & -.36 \\
\hline c. Qualified & 2.35 & 1.45 & .23 & -.51 \\
\hline d. Trustworthy & 2.55 & 1.32 & .02 & -.24 \\
\hline e. Credible & 2.39 & 1.39 & .23 & -.10 \\
\hline \multicolumn{5}{|l|}{$\begin{array}{l}\text { Qualities of the typical movie review posted on } \\
\text { a personal blog }\end{array}$} \\
\hline a. Complete & 2.50 & 1.47 & .12 & $-.56^{*}$ \\
\hline b. Consistent & 2.83 & 1.26 & .04 & $-.55^{*}$ \\
\hline c. Specific & 3.41 & 1.27 & -.22 & -.34 \\
\hline d. Objective & 3.08 & 1.63 & -.14 & $-.73 * *$ \\
\hline e. Interesting & 4.01 & 1.29 & $-.61 * * *$ & .44 \\
\hline f. Strongly worded & 3.81 & 1.38 & $-.40 * *$ & -.27 \\
\hline g. Easy to follow & 4.06 & 1.17 & $-.30^{*}$ & -.27 \\
\hline h. Easy to understand & 4.19 & 1.11 & $-.43 * *$ & .04 \\
\hline i. Valuable to you & 3.12 & 1.39 & -.09 & -.39 \\
\hline j. $\quad$ Helpful to you & 3.30 & 1.35 & -.23 & -.41 \\
\hline k. Relevant to you & 3.06 & 1.46 & -.18 & -.33 \\
\hline \multicolumn{5}{|l|}{ Scepticism } \\
\hline a. Written to inform consumers & 4.01 & 1.32 & $-.47^{* *}$ & -.14 \\
\hline b. Informative & 3.82 & 1.08 & $-.43 * *$ & .41 \\
\hline c. Truthful & 3.42 & 1.24 & .17 & -.42 \\
\hline d. Reliable & 2.81 & 1.13 & $.28^{*}$ & .45 \\
\hline e. Truth well told & 2.98 & 1.12 & .20 & .49 \\
\hline f. Accurate & 2.98 & 1.01 & .03 & $.54^{*}$ \\
\hline g. True & 3.05 & 1.05 & .02 & .39 \\
\hline h. Dependable & 2.93 & 1.19 & $.34^{*}$ & .04 \\
\hline i. Based on important / essential info. & 2.97 & 1.28 & .12 & -.33 \\
\hline \multicolumn{5}{|l|}{ Blogger ability } \\
\hline a. Watches a large number of movies & 3.96 & 1.85 & $-0.54^{* *}$ & $-0.83 * *$ \\
\hline $\begin{array}{l}\text { b. Knows much about important trends in } \\
\text { movies }\end{array}$ & 3.55 & 1.75 & $-0.34^{*}$ & $-0.86 * *$ \\
\hline c. Spends a lot of time watching movies & 3.85 & 1.96 & $-0.54 * *$ & $-1.01 * *$ \\
\hline
\end{tabular}


314

\begin{tabular}{|c|c|c|c|c|}
\hline $\begin{array}{c}\text { Constructs } \\
\text { Items }\end{array}$ & Mean $^{a}$ & S.D. & Skewness & Kurtosis \\
\hline d. Is very passionate about movies & 3.97 & 1.92 & $-0.62 * *$ & $-0.90 * *$ \\
\hline $\begin{array}{l}\text { e. Has an extensive formal education on } \\
\text { conditions in Afghanistan }\end{array}$ & 3.09 & 2.05 & -0.06 & $-1.23 * *$ \\
\hline $\begin{array}{l}\text { f. Knows detailed facts about conditions } \\
\text { in Afghanistan }\end{array}$ & 3.19 & 1.99 & -0.12 & $-1.22 * *$ \\
\hline $\begin{array}{l}\text { g. Knows much about important trends in } \\
\text { Afghanistan }\end{array}$ & 3.13 & 1.99 & -0.11 & $-1.24 * *$ \\
\hline $\begin{array}{l}\text { h. Has done research about conditions in } \\
\text { Afghanistan }\end{array}$ & 3.16 & 2.03 & -0.13 & $-1.25 * *$ \\
\hline \multicolumn{5}{|l|}{ Blogger character } \\
\hline $\begin{array}{l}\text { a. Just wants to help readers of the } \\
\text { movie review }\end{array}$ & 3.20 & 1.49 & -0.22 & -0.43 \\
\hline $\begin{array}{l}\text { b. Cares about readers of the movie } \\
\text { review }\end{array}$ & 2.86 & 1.56 & -0.04 & $-0.73 * *$ \\
\hline $\begin{array}{l}\text { c. Just wants to inform readers about the } \\
\text { movie }\end{array}$ & 3.21 & 1.50 & -0.15 & -0.52 \\
\hline $\begin{array}{l}\text { d. Just wants to help readers make a } \\
\text { good decision about the movie }\end{array}$ & 3.14 & 1.46 & -0.18 & -0.50 \\
\hline $\begin{array}{l}\text { e. Will be totally honest with readers } \\
\text { about the movie }\end{array}$ & 3.09 & 1.63 & -0.17 & $-0.75 * *$ \\
\hline $\begin{array}{l}\text { f. Will be totally truthful with readers } \\
\text { about the movie }\end{array}$ & 3.03 & 1.56 & -0.10 & $-0.65^{*}$ \\
\hline $\begin{array}{l}\text { g. Will be totally sincere with readers } \\
\text { about the movie }\end{array}$ & 3.05 & 1.57 & -0.15 & $-0.66^{*}$ \\
\hline $\begin{array}{l}\text { h. Has reason to misrepresent the truth } \\
\text { about the movie }\end{array}$ & 3.21 & 1.73 & -0.02 & $-0.88 * *$ \\
\hline $\begin{array}{l}\text { i. Has reason to deceive readers about } \\
\text { the movie }\end{array}$ & 2.99 & 1.77 & 0.07 & $-0.97^{* *}$ \\
\hline $\begin{array}{ll}\mathrm{j} . & \begin{array}{l}\text { Has reason to mislead readers about } \\
\text { the movie }\end{array}\end{array}$ & 2.96 & 1.79 & 0.13 & $-1.05^{* *}$ \\
\hline $\begin{array}{l}\text { k. Has reason to hide the truth about the } \\
\text { movie from readers }\end{array}$ & 2.97 & 1.78 & 0.01 & $-0.97 * *$ \\
\hline \multicolumn{5}{|l|}{ Blogger-rater rapport } \\
\hline \multicolumn{5}{|l|}{ Likeability } \\
\hline a. Is someone you could like as a person & 3.13 & 1.13 & -0.16 & 0.27 \\
\hline b. Made a favourable impression on you & 3.09 & 1.24 & -0.17 & -0.09 \\
\hline $\begin{array}{l}\text { c. Is someone you would like to } \\
\text { socialize with }\end{array}$ & 2.83 & 1.21 & -0.05 & -0.13 \\
\hline \multicolumn{5}{|l|}{ Similarity to participant } \\
\hline a. Is similar to you & 1.86 & 1.30 & $0.34^{*}$ & -0.16 \\
\hline
\end{tabular}




\begin{tabular}{|c|c|c|c|c|}
\hline $\begin{array}{c}\text { Constructs } \\
\text { Items }\end{array}$ & Mean $^{a}$ & S.D. & Skewness & Kurtosis \\
\hline $\begin{array}{l}\text { b. Has beliefs and values that are similar } \\
\text { to yours }\end{array}$ & 2.26 & 1.31 & 0.12 & -0.28 \\
\hline $\begin{array}{l}\text { c. Has tastes and preferences that are } \\
\text { similar to yours }\end{array}$ & 2.23 & 1.34 & 0.09 & -0.37 \\
\hline d. Has things in common with you & 2.38 & 1.33 & 0.12 & -0.44 \\
\hline \multicolumn{5}{|l|}{ Acceptance of About Me statement } \\
\hline $\begin{array}{l}\text { a. Believe the blogger's "About Me" } \\
\text { statement }\end{array}$ & 3.24 & 1.45 & $-0.38^{*}$ & -0.34 \\
\hline $\begin{array}{l}\text { b. Are convinced about the blogger by } \\
\text { the blogger's "About Me" statement }\end{array}$ & 2.96 & 1.37 & -0.13 & -0.43 \\
\hline $\begin{array}{l}\text { c. Are persuaded about the blogger by } \\
\text { the blogger's "About Me" statement }\end{array}$ & 2.68 & 1.39 & -0.02 & -0.40 \\
\hline $\begin{array}{l}\text { d. Think the blogger's "About Me" } \\
\text { statement is not deceptive }\end{array}$ & 2.93 & 1.39 & -0.15 & -0.17 \\
\hline \multicolumn{5}{|l|}{ General movie-related attitudes } \\
\hline a. Good & 3.35 & 1.48 & $-0.33 *$ & -0.40 \\
\hline b. Interesting & 3.37 & 1.53 & $-0.31^{*}$ & $-0.61 *$ \\
\hline c. Likeable & 3.19 & 1.49 & -0.20 & $-0.60^{*}$ \\
\hline d. Appealing & 3.07 & 1.56 & -0.03 & $-0.80 * *$ \\
\hline e. Would enjoy watching this movie & 3.18 & 1.53 & -0.18 & $-0.63 *$ \\
\hline f. Would appreciate watching this movie & 3.37 & 1.57 & $-0.30^{*}$ & $-0.58 *$ \\
\hline . & & & & \\
\hline \multicolumn{5}{|l|}{ Credibility of the specific blogger } \\
\hline a. Knowledgeable & 3.11 & 1.43 & -0.23 & -0.47 \\
\hline b. Expert & 2.49 & 1.42 & $0.29 *$ & -0.31 \\
\hline c. Qualified & 2.71 & 1.47 & 0.13 & -0.49 \\
\hline d. Trustworthy & 2.74 & 1.46 & -0.04 & -0.51 \\
\hline e. Credible & 2.66 & 1.51 & 0.05 & $-0.54^{*}$ \\
\hline \multicolumn{5}{|l|}{ Acceptance of movie review } \\
\hline a. Believe the movie review & 3.42 & 1.33 & $-0.39 * *$ & -0.15 \\
\hline b. Are convinced by the movie review & 3.17 & 1.43 & -0.14 & -0.48 \\
\hline c. Are persuaded by the movie review & 3.05 & 1.42 & -0.17 & -0.48 \\
\hline $\begin{array}{l}\text { d. Think the movie review is not } \\
\text { deceptive }\end{array}$ & 3.06 & 1.34 & -0.09 & -0.47 \\
\hline \multicolumn{5}{|l|}{ Scepticism toward the movie review } \\
\hline a. Written to inform consumers & 3.67 & 1.43 & $-0.41 * *$ & -0.23 \\
\hline
\end{tabular}


316

\begin{tabular}{|c|c|c|c|c|}
\hline $\begin{array}{c}\text { Constructs } \\
\text { Items }\end{array}$ & Mean ${ }^{a}$ & S.D. & Skewness & Kurtosis \\
\hline b. Informative & 3.56 & 1.41 & $-0.31^{*}$ & -0.41 \\
\hline c. Truthful & 3.34 & 1.30 & -0.12 & -0.19 \\
\hline d. Reliable & 3.13 & 1.34 & -0.14 & -0.20 \\
\hline e. Truth well told & 3.13 & 1.34 & -0.14 & -0.17 \\
\hline f. Accurate & 3.08 & 1.29 & -0.15 & -0.18 \\
\hline g. True & 3.22 & 1.29 & $-0.22:$ & -0.01 \\
\hline h. Dependable & 2.99 & 1.35 & -0.11 & -0.28 \\
\hline i. Based on important / essential info. & 3.23 & 1.55 & -0.17 & $-0.65^{*}$ \\
\hline \multicolumn{5}{|l|}{ Qualities of the movie review } \\
\hline a. Complete & 2.96 & 1.54 & -0.17 & $-0.69 *$ \\
\hline b. Consistent & 3.55 & 1.32 & $-0.36 * *$ & -0.12 \\
\hline c. Specific & 3.31 & 1.45 & -0.24 & $-0.54^{*}$ \\
\hline d. Objective & 3.08 & 1.48 & -0.15 & -0.43 \\
\hline e. Interesting & 3.19 & 1.52 & $-0.30^{*}$ & -0.44 \\
\hline f. $\quad$ Strongly worded & 3.09 & 1.56 & -0.07 & $-0.58 *$ \\
\hline g. $\quad$ Surprising & 2.32 & 1.68 & 0.25 & $-0.83^{* *}$ \\
\hline h. Unexpected & 2.31 & 1.71 & 0.26 & $-0.88^{* *}$ \\
\hline i. Easy to follow & 4.44 & 1.21 & $-0.68 * *$ & 0.32 \\
\hline j. Easy to understand & 4.47 & 1.25 & $-0.69 * *$ & 0.39 \\
\hline k. Valuable to you & 2.68 & 1.51 & 0.09 & -0.42 \\
\hline 1. Helpful to you & 2.89 & 1.48 & -0.12 & -0.52 \\
\hline m. Relevant to you & 2.55 & 1.45 & 0.10 & -0.37 \\
\hline \multicolumn{5}{|l|}{$\begin{array}{l}\text { Blogger-directed trust intentions (Before } \\
\text { error) }\end{array}$} \\
\hline a. Take advice from this blogger & 2.67 & 1.43 & -0.08 & $-0.55^{*}$ \\
\hline $\begin{array}{l}\text { b. Try what is recommended by this } \\
\text { blogger }\end{array}$ & 2.70 & 1.52 & 0.01 & $-0.69 *$ \\
\hline c. Continue to read this blog & 2.29 & 1.68 & 0.21 & $-0.98^{* *}$ \\
\hline d. Consult the blog again & 2.33 & 1.67 & 0.14 & $-0.94 * *$ \\
\hline $\begin{array}{l}\text { e. Pass along information you find on this } \\
\text { blog }\end{array}$ & 2.27 & 1.69 & 0.26 & $-0.93 * *$ \\
\hline f. Recommend this blog to others & 2.01 & 1.66 & $0.40^{* *}$ & $-0.85^{* *}$ \\
\hline \multicolumn{5}{|l|}{ Blogger-directed trust intentions (After error) } \\
\hline a. Take advice from this blogger & 1.34 & 1.66 & $1.09 * *$ & .15 \\
\hline $\begin{array}{l}\text { b. Try what is recommended by this } \\
\text { blogger }\end{array}$ & 1.28 & 1.58 & $1.13 * *$ & .37 \\
\hline
\end{tabular}


317

\begin{tabular}{|c|c|c|c|c|}
\hline $\begin{array}{c}\text { Constructs } \\
\text { Items }\end{array}$ & Mean $^{a}$ & S.D. & Skewness & Kurtosis \\
\hline c. Continue to read this blog & 1.30 & 1.60 & $1.08^{* *}$ & .15 \\
\hline d. Consult the blog again & 1.28 & 1.59 & $1.10^{* *}$ & .25 \\
\hline $\begin{array}{l}\text { e. Pass along information you find on this } \\
\text { blog }\end{array}$ & 1.23 & 1.64 & $1.16^{* *}$ & .26 \\
\hline f. Recommend this blog to others & 1.17 & 1.60 & $1.25^{* *}$ & $.57^{*}$ \\
\hline \multicolumn{5}{|l|}{ Word-of-mouth behaviours } \\
\hline $\begin{array}{l}\text { a. Discourage people you know from } \\
\text { reading the blog }\end{array}$ & 3.27 & 1.95 & -0.17 & $-1.14 * *$ \\
\hline $\begin{array}{l}\text { b. Speak negatively about the blog to } \\
\text { people you know }\end{array}$ & 3.03 & 1.87 & 0.07 & $-1.11 * *$ \\
\hline c. Criticize the blog to people you know & 2.95 & 1.87 & 0.08 & $-1.04 * *$ \\
\hline $\begin{array}{l}\text { d. Leave negative feedback about the } \\
\text { movie review on the blog }\end{array}$ & 2.24 & 1.89 & $0.43 * *$ & $-0.91 * *$ \\
\hline $\begin{array}{l}\text { e. Post a critical comment about the } \\
\text { movie review on the blog }\end{array}$ & 2.28 & 1.93 & $0.34^{*}$ & $-1.00 * *$ \\
\hline f. Criticize the movie review on the blog & 2.26 & 1.93 & $0.39^{* *}$ & $-0.96 * *$ \\
\hline $\begin{array}{l}\text { g. Discourage people you know from } \\
\text { seeing the movie }\end{array}$ & 3.34 & 1.92 & -0.26 & $-1.10 * *$ \\
\hline $\begin{array}{l}\text { h. Speak negatively about the movie to } \\
\text { people you know }\end{array}$ & 3.15 & 1.91 & -0.08 & $-1.11^{* *}$ \\
\hline $\begin{array}{l}\text { i. Criticize the movie to people you } \\
\text { know }\end{array}$ & 3.23 & 1.87 & -0.11 & $-1.06^{* *}$ \\
\hline $\begin{array}{l}\text { j. Post a negative review of the movie on } \\
\text { a website }\end{array}$ & 1.68 & 1.71 & $0.91 * *$ & 0.004 \\
\hline $\begin{array}{l}\text { k. Post a critical comment of the movie } \\
\text { on a website }\end{array}$ & 1.77 & 1.76 & $0.81^{* *}$ & -0.25 \\
\hline 1. Criticize the movie on a website & 1.73 & 1.76 & $0.85^{* *}$ & -0.18 \\
\hline \multicolumn{5}{|l|}{ Error attribution } \\
\hline $\begin{array}{l}\text { a. The blogger knowingly misrepresented } \\
\text { the truth about the movie }\end{array}$ & 3.40 & 1.66 & -0.23 & $-0.70^{* *}$ \\
\hline $\begin{array}{l}\text { b. The blogger knowingly attempted to } \\
\text { deceive readers about the movie }\end{array}$ & 3.28 & 1.67 & -0.11 & $-0.72 * *$ \\
\hline $\begin{array}{l}\text { c. The blogger knowingly attempted to } \\
\text { mislead readers about the movie }\end{array}$ & 3.29 & 1.66 & -0.19 & $-0.71 * *$ \\
\hline $\begin{array}{l}\text { d. The blogger knowingly hid the truth } \\
\text { about the movie from readers }\end{array}$ & 3.30 & 1.67 & -0.26 & $-0.78 * *$ \\
\hline $\begin{array}{l}\text { e. The makers of the movie are totally } \\
\text { responsible for the blogger's actions }\end{array}$ & 1.97 & 1.66 & $0.28^{*}$ & $-1.03 * *$ \\
\hline $\begin{array}{l}\text { f. The makers of the movie are totally at } \\
\text { fault for the blogger's actions }\end{array}$ & 1.83 & 1.66 & $0.41^{* *}$ & $-0.99 * *$ \\
\hline $\begin{array}{l}\text { g. The makers of the movie are totally } \\
\text { blameworthy for the blogger's actions }\end{array}$ & 1.81 & 1.66 & $0.41^{* *}$ & $-1.00 * *$ \\
\hline
\end{tabular}




\begin{tabular}{|c|c|c|c|c|}
\hline $\begin{array}{l}\text { Constructs } \\
\text { Items }\end{array}$ & Mean $^{a}$ & S.D. & Skewness & Kurtosis \\
\hline $\begin{array}{l}\text { h. The makers of the movie had total } \\
\text { control over the blogger's actions }\end{array}$ & 1.71 & 1.71 & $0.58^{* *}$ & $-0.79^{* *}$ \\
\hline & & & & \\
\hline Affective responses to blogger error & & & & \\
\hline a. You are outraged by what happened & 1.99 & 1.59 & $0.39^{* *}$ & $-0.66^{* *}$ \\
\hline $\begin{array}{l}\text { b. You are angry because of what } \\
\text { happened }\end{array}$ & 2.19 & 1.67 & 0.26 & $-0.91^{* *}$ \\
\hline $\begin{array}{l}\text { c. You are mad because of what } \\
\text { happened }\end{array}$ & 2.25 & 1.71 & $0.30^{*}$ & $-0.80^{* *}$ \\
\hline $\begin{array}{l}\text { d. You are disappointed by what } \\
\text { happened }\end{array}$ & 3.05 & 1.75 & -0.23 & $-0.89^{* *}$ \\
\hline e. You are dissatisfied by what happened & 3.02 & 1.75 & -0.19 & $-0.91^{* *}$ \\
\hline f. You feel discontented by what \\
\hline happened & 2.85 & 1.78 & -0.02 & $-0.92^{* *}$ \\
\hline$\quad$ You are displeased by what happened & 2.96 & 1.78 & -0.13 & $-0.96^{* *}$ \\
\hline Measures of error size & & & & \\
\hline a. The movie review was truthful & 1.44 & 1.56 & $0.91^{* *}$ & 0.01 \\
\hline b. The movie review was accurate & 1.29 & 1.50 & $0.95^{* *}$ & 0.07 \\
\hline c. The movie review was true & 1.35 & 1.54 & $0.95^{* *}$ & 0.02 \\
\hline
\end{tabular}

${ }^{a}$ All items measured from 0 to 6 .

${ }^{*} p<.05{ }^{* *} p<.01$. Two-tailed test. 
Appendix 6.1: Co-Author Releases 


\section{Co-Author Release}

\section{Article}

James D. Doyle, Louise A. Heslop, Alex Ramirez, David Cray, Anahit Armenakyan, (2012) "Trust building in wine blogs: a content analysis", International Joumal of Wine Business Research, Vol. 24 Iss: 3, pp. $196-218$.

I give my permission for the inclusion of materials from the above journal article, of which I am a co-author, in this dissertation by James Doyle, entitled "Building it Up and Tearing it Down: A Three-Study Examination of Trust, Trust Building, and the Effects of Erroneous Messaging in the Blogosphere," in all forms in which it is published and archived.

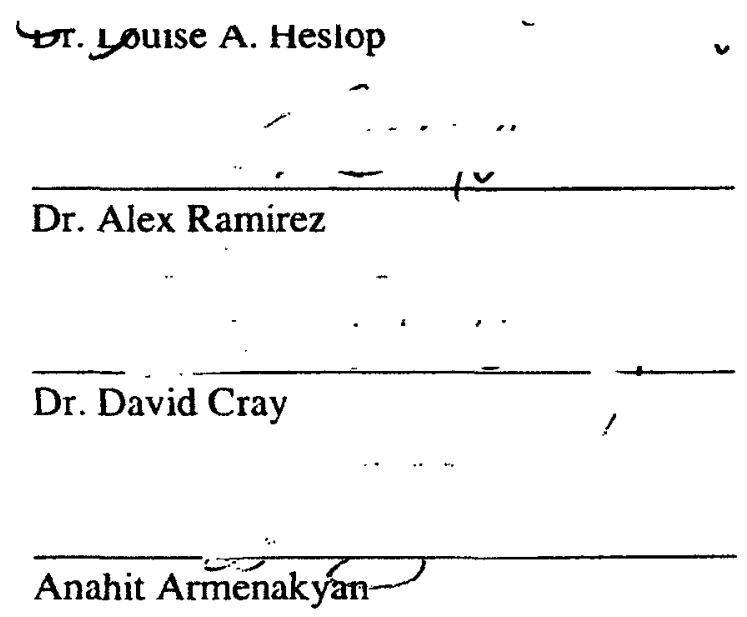




\section{Co-Author Release}

\section{Article}

James D. Doyle, Louise A. Heslop, Alex Ramirez, David Cray, (2012) "Trust intentions in readers of blogs", Management Research Review, Vol. 35 Iss: 9, pp. 837 - 856.

I give my permission for the inclusion of materials from the above journal article, of which I am a co-author, in this dissertation by James Doyle, entitled "Building it Up and Tearing it Down: A Three-Study Examination of Trust, Trust Building, and the Effects of Erroneous Messaging in the Blogosphere," in all forms in which it is published and archived.

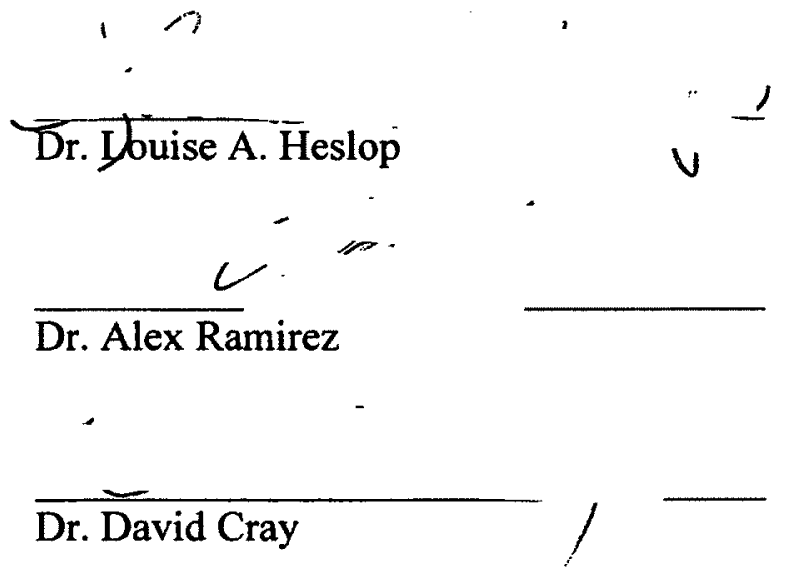

